\title{
THE INFLUENCE OF FAULTING ON HYDROCARBON MIGRATION IN THE KUPE AREA, SOUTH TARANAKI BASIN, NEW ZEALAND
}

By

Sam Hemmings-Sykes

A thesis submitted for the partial fulfilment for the degree of Masters of Science in Petroleum Geoscience

School of Geography, Environment and Earth Sciences

Victoria University of Wellington

2012 


\section{Abstract}

Faults play an important role in petroleum systems as both barriers and conduits to the flow of hydrocarbons. An understanding of the relationship between fluid and gas migration and accumulation, and faulting is often required during hydrocarbon exploration and production, and $\mathrm{CO}_{2}$ storage. While methods for predicting across-fault flow are well advanced (e.g. Yielding et al., 1997; Manzocchi et al., 1999), current geomechanical and geometrical methods for predicting the locations of up-fault (up-dip) hydrocarbon migration (and leakage) are relatively untested.

This thesis investigates the relationships between up-sequence gas migration in the form of gas chimneys and Pliocene to Recent normal faults in the Kupe Area, South Taranaki Basin. It undertakes studies of the Kupe Area's structural development, examines spatial relationships between faults and gas chimneys, tests current geomechanical and geometrical models to predict up-dip gas flow in faults, and investigates the outcrop expression of fault structure below seismic reflection data resolution and gas flux rates at an onshore site of fault-related gas leakage. Data for this study are provided by highquality 2D and 3D seismic reflection lines (tied to stratigraphy in fifteen wells), and outcrop of Miocene and Oligocene strata in coastal cliff sections, together with methane concentration and flux measurements.

Structural development in the Kupe Area was complex and provides a near complete record of deformation since the Late Cretaceous ( $\sim 5 \mathrm{Ma}$ ). Basin strata up to $9 \mathrm{~km}$ thick record four main periods of deformation that reflect changing plate boundary configurations. Fault reactivation was common in the Kupe Area, with the locations and orientations of pre-existing faults strongly influencing the locations and geometries of younger faults and folds. Pliocene to Recent normal faults are highly segmented with low strain, consistent with an immature fault system in which fault lengths were established rapidly and subsequent fault growth was mainly achieved by accumulation of displacement.

Plio-Pleistocene to Recent reactivation of Cretaceous rift faults provides conduits for gas migration from below the regional top seal in the Kupe Area into shallow strata and results in up-dip gas migration within the Plio-Pleistocene to Recent fault zones. These late-stage normal faults (younger than $4 \mathrm{Ma}$ ) are shown to have a strong spatial relationship with gas chimneys suggesting that fault zones are capable of producing channelised pathways for up-dip hydrocarbon migration. Fifteen of seventeen gas 
chimneys within the study area are rooted within fault zones. All of these fifteen faultrelated gas chimneys occur at geometrical complexities in fault structure (i.e. relay zones, lateral fault tips or fault intersections). Geometrical complexities are associated with locally high throw gradients which are inferred to be accompanied by off-fault strain in the form of fractures and/or bedding rotation.

Three geomechanical modelling techniques (Slip Tendency, Dilation Tendency and Fracture Stability) for predicting the locations of up-fault hydrocarbon flow (leakage) are tested using the spatial distribution of gas chimneys and Pliocene to Recent normal faults in the Kupe Area. Slip Tendency, Dilation Tendency and Fracture Stability data for all of the faults analysed predict comparable likelihoods of gas migration on chimney and non-chimney sections of the fault surfaces and therefore do not provide a robust basis for predicting where on fault surfaces channelised up-dip gas flow will occur.

Field-based observations of faults show that fractures observed in outcrop and below seismic reflection data resolution are localised around bends, steps and intersections of faults and show evidence of fluid flow post fault activity. In north Taranaki these fault complexities are present in a lateral equivalent to the Otaraoa top seal and, if present in the Kupe Area, are also likely to induce up-sequence gas migration through fracture networks.

Methane concentrations measured at one site (Bristol Road Quarry) along the Inglewood Fault suggest that gas flux rates up faults may not be uniform over time. Based on the measured gas flux rates gas chimneys in the Kupe Area may form in association with gas migration in a series of discrete events lasting from days to years, with possible gas flows at the seabed of $\sim 930 \mathrm{ft}^{3}$ per chimney per day or 0.34 million $\mathrm{ft}^{3}$ per year. 


\section{Acknowledgments}

This thesis has benefited greatly from the combined input of many generous people who gave their time, support, knowledge and friendship. First, I would like to say the most important thank you to my fiancée Madeleine and her family, Mr and Mrs French and Hugh French for all of your support and encouragement over the past two years. A very special thanks to Andy for all of the effort and time you have put into this project and for always having the time to discuss faults, look at faults and pass on knowledge. Brad Ilg thank you for the drive and energy you put into this research and for giving me the opportunity to finish what you started. Thanks to Tim Stern for helping supervise this thesis and for always providing guidance and another view point. A huge thanks to Hilco for helping with the fieldwork, providing the 'Hilco Hilton' and for the numerous discussions on faults and geological modelling. Thanks to John Collen for inspiring me to look at this area of research and for your enthusiasm for all things petroleum geology. Thank you to everyone at GNS Science, especially the Hydrocarbons Group, who provided me with their time, data, support, friendship and indoor footy. Thanks to Jan and Malcolm for answering my endless questions, Dom for all your sage advice, El Blandito for your endless knowledge of outcrops and real rocks, Peter, Rob and Richard for many discussions and supporting this project, Miko, Karsten and Eva for all the Kupe knowledge, Matt for modelling discussions, Paul ‘Viscorias’ Viskovich, G. Quagmire and all of the indoor footy team. Thanks also to all the Victoria University team, especially my brief but brilliant office mates Ben and Megan, and also to all those on the structure field trips I attended. A big thank you to all my former colleagues at ARANZ Geo for keeping me gainfully employed during my studies and providing some of the more interesting and colourful discussions on life and geological modelling. Hopefully the Christchurch earthquakes will not slow the geological modelling down! Special thanks to Victoria University, GNS Science, AusIMM New Zealand, OMV New Zealand and AAPG for financially supporting this research and giving me the opportunity to undertake fieldwork. 


\section{Table of Contents}

Abstract .............................................................................................................................. II

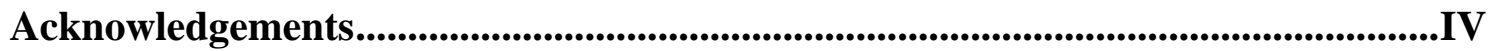

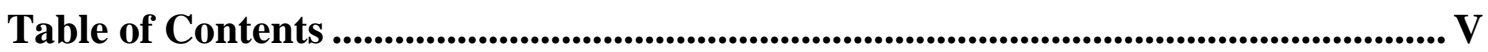

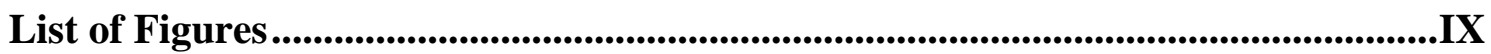

List of Tables ............................................................................................................... XIII

1.0 Introduction ....................................................................................................................... 1

1.1 Study Background and Aims ..................................................................................................... 1

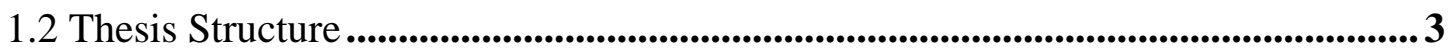

1.3 Geological Background ......................................................................................4

1.4 Data and Methods ..................................................................................................................9

2.0 Structural History of the Kupe Area............................................................ 14

2.1 Introduction ....................................................................................................................................... 14

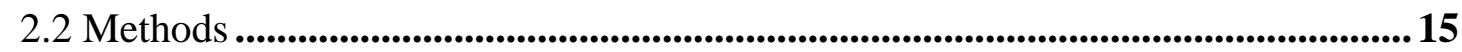

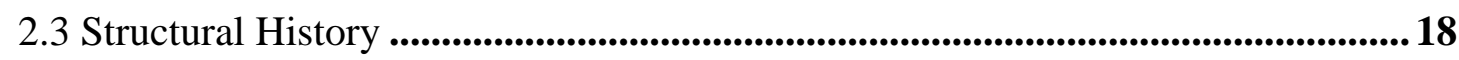

2.3.1 Pre-Late Cretaceous (> $85 \mathrm{Ma})$.............................................................................. 20

2.3.2 Late Cretaceous to Paleocene Extension ( 85-55 Ma)...................................... 21

2.3.3 Late Eocene to Miocene Contraction ( 35-5 Ma)............................................... 27

2.3.4 Plio-Pleistocene to Recent Extension ( 5-0 Ma)............................................36

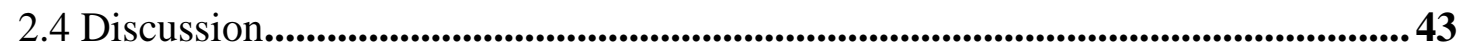

2.4.1 Deformation History and Implications for Plate Boundary Formation .......... 43

2.4.2 Fault Reactivation..................................................................................................45

2.5 Conclusions ........................................................................................................................ 47 


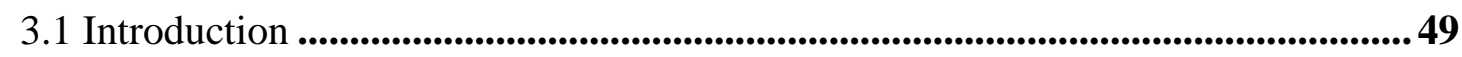

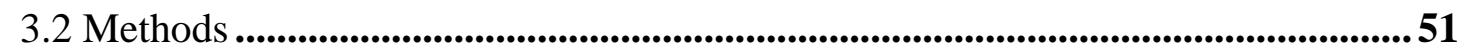

3.2.1 Chimney Identification ....................................................................5 51

3.2.2 Chimney Mapping ........................................................................................5 54

3.2.2.1 Manual Seismic Mapping ............................................................................ 54

3.2.2.2 Multi-Attribute Chimney Definition ......................................................... 54

3.3 Gas Chimney Geometries and Seismic Character.....................................................5 56

3.4 Spatial Relations Between Gas Chimneys and Faulting ........................................66

3.5 Faults and Petroleum Migration Model........................................................................6 68

3.5.1 Fault Reactivation and Top Seal Breach .....................................................68 68

3.5.2 Up-Sequence Channelised Gas Flow........................................................................ 70

3.5.3 Sub-Seal Lateral Gas Flow ............................................................................. 72

3.5.4 Stratigraphic Gas Chimney Migration..................................................................... 76

3.5.5 Estimates of Fault Permeability................................................................................ 77

3.6 Ages of Gas Chimneys ...................................................................................... 77

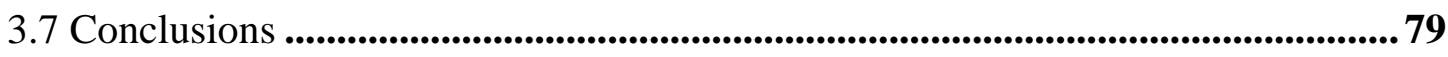

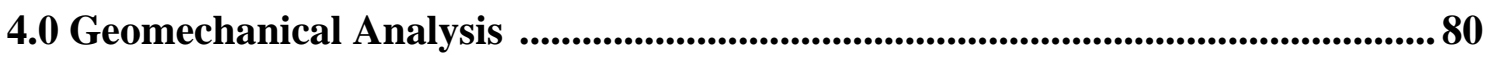

4.1 Introduction ..........................................................................................................................8 80

4.2 Geomechanical Models for Predicting Fluid and Gas Flow .....................................8 82

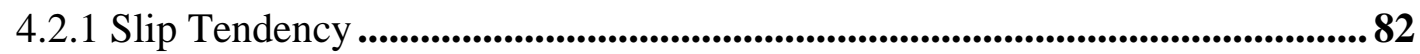

4.2.2 Dilation Tendency ......................................................................................................... 83

4.2.3 Fracture Stability ...........................................................................................................85 85

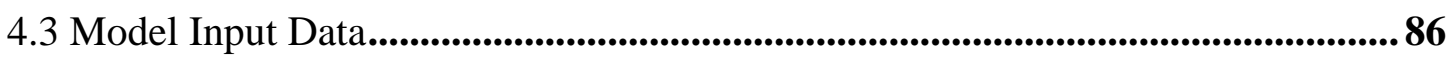

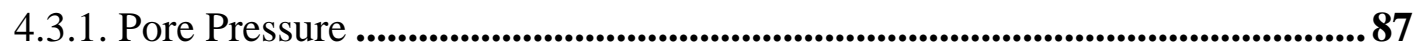

4.3.2 $\mathrm{S}_{\mathrm{Hmax}}$ and $\mathrm{S}_{\mathrm{hmin}}$ Directions ......................................................................................8 89

4.3.3 Stress Magnitudes...........................................................................................90

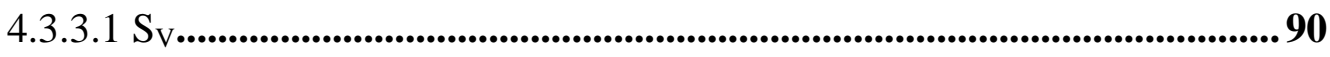

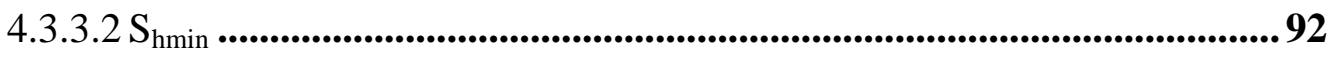

4.3.3.3 $\mathrm{S}_{\mathrm{Hmax}}$..........................................................................................................99

4.3.3.4 Fault-rock Properties .......................................................................... 100

4.3.4 Parameter Testing ................................................................................................... 102

4.4 Spatial Relations Between Fault Geomechanics and Gas Chimneys................... 103 
4.4.1 Slip Tendency ................................................................................................................ 103

4.4.2 Dilation Tendency ......................................................................................... 107

4.4.3 Fracture Stability ............................................................................109

4.5 Predicting Gas Chimney Locations on Individual Faults.....................................112

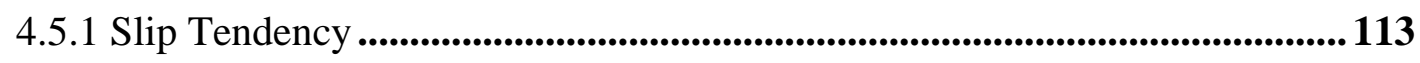

4.5.2 Dilation Tendency ............................................................................116

4.5.3 Fracture Stability ..................................................................................119

4.6 Ability of Geomechanical Techniques for Predicting Gas Flow........................... 122

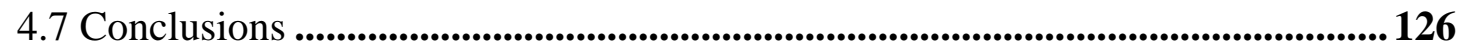

5.0 Fault Structure and Gas Flux Rates................................................................ 127

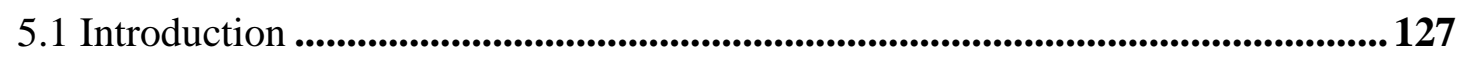

5.2 Fault Zone Structure ............................................................................................ 128

5.2.1 Late Miocene Reservoir - Tongaporutu............................................................... 131

5.2.1.1 Fault Heterogeneity ......................................................................... 145

5.2.2 Oligocene Seal - Waikawau Beach.................................................................. 145

5.2.2.1 Fractures as Migration Pathways ........................................................... 154

5.3 Rates of Gas Flux ..................................................................................... 154

5.3.1 Introduction ........................................................................................... 154

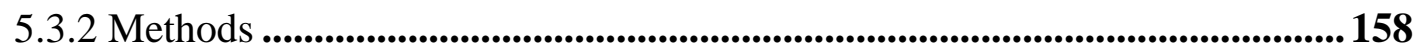

5.3.3 Gas Concentration Measurements ............................................................. 159

5.3.4 Estimated Flux Rates ........................................................................................ 160

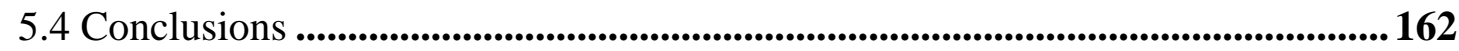

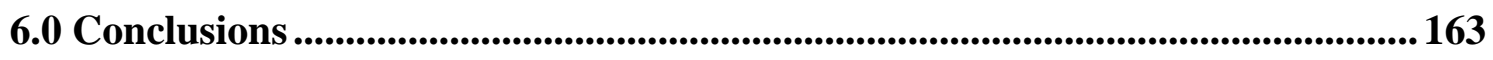

6.1 Introduction ........................................................................................................................ 163

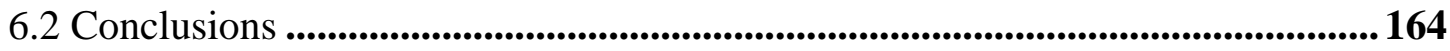

6.3 Further Research Areas ...................................................................................166

6.3.1 Inversion of Cretaceous Rift Faults ............................................................... 166

6.3.2 Implications of Structural Style in the Kupe Area on Plate Boundary Settings

6.3.3 Plio-Pleistocene Fault Kinematics and Growth History ................................... 168

6.3.4 Further Measurements of Gas Flux Rates at the Bristol Road Quarry .......... 168

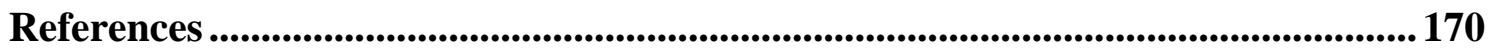


Appendix I - Global Fault Statistics References ........................................................ 192

Appendix II - Seismic Reflection Surveys ......................................................... 194

Appendix III - Well Data ................................................................................................ 196

Appendix IV - Petroleum Reports used in Study ..............................................197 


\section{List of Figures}

\section{Chapter I}

Figure 1.1 Taranaki Basin - Location and Tectonic Setting 5

Figure 1.2 Chronostratigraphic Panel for South Taranaki 8

$\begin{array}{lll}\text { Figure } 1.3 & \text { Study Area Data Map } & 11\end{array}$

$\begin{array}{lll}\text { Figure } 1.4 & \text { Field Work Localities } & 13\end{array}$

\section{Chapter II}

Figure 2.1 Displacement Back-Stripping Technique 16

Figure 2.2 Study Area Data Map with Seismic Cross Section Locations 17

$\begin{array}{lll}\text { Figure 2.3 East-West Seismic Reflection Transect of Study Area } & 19\end{array}$

Figure 2.4 Seismic Reflection Section of Pre-Cretaceous Strata 20

Figure 2.5 Late Cretaceous Isopach Map 22

Figure 2.6 Northeast-Southwest Cross Section through the Kerry 3D Seismic Reflection Volume 23

Figure 2.7 Late Cretaceous-Paleocene Fault Growth Curves $(>500 \mathrm{~m}) \quad 24$

Figure 2.8 Late Cretaceous-Paleocene Fault Growth Curves $(<500 \mathrm{~m}) \quad 26$

Figure 2.9 East-West Cross Section through the Kerry 3D Seismic Reflection Volume $\quad 27$

Figure 2.10 Structure Contour Map of P60 (25 Ma) Horizon 29

Figure 2.11 North-South Cross Section through the Kerry 3D Seismic Reflection Volume $\quad 31$

Figure 2.12 Oligocene Isopach Map 32

Figure 2.13 Oligocene-Miocene Fault Growth Curves 33

Figure 2.14 Miocene Isopach Map 35

Figure 2.15 Structure Contour Map of N74 ( 3 Ma) Horizon 37

Figure 2.16 Seismic Reflection Section showing Reactivation of the Kupe and Kupe South-4 Faults $\mathbf{3 8}$

Figure 2.17 Plio-Pleistocene to Recent Fault Growth Curves 39

Figure 2.18 500 ms TWTT Coherency Slice through Kerry 3D Seismic Reflection Volume $\quad \mathbf{4 0}$

Figure 2.19 Fault Displacement versus Length Plot $4 \mathbf{4 1}$ 
Figure 2.20 Fault Tip Line Profiles 42

Figure 2.21 Kupe Area Structural Evolution Diagram 46

\section{Chapter III}

Figure 3.1 Fault Zone Architecture Diagram 51

Figure 3.2 Chimney Probability Cube Section 56

Figure 3.3 Chimney and Fault Location Maps $\quad$ 57-58

Figure 3.4 Seismic Sections through Chimneys B \& C 60

Figure 3.5 Seismic Sections through Chimneys D \& E 61

Figure 3.6 Seismic Sections through Chimneys F, G \& H 62

Figure 3.7 Geobody Extraction of Gas Charged Channel 63

Figure $3.8 \quad 150 \mathrm{~ms}$ TWTT Slice through Kerry 3D Seismic Volume $\quad 63$

Figure 3.9 High Resolution Seismic Sections through Chimney H $\quad 65$

$\begin{array}{lll}\text { Figure } 3.10 & \text { Fault Strike Length Throw Profiles } & 67\end{array}$

$\begin{array}{lll}\text { Figure 3.11 Rose Diagram of Late Cretaceous-Paleocene Faults } & \mathbf{7 0}\end{array}$

$\begin{array}{lll}\text { Figure } 3.12 & \text { Fault Reactivation Relationship }\end{array}$

$\begin{array}{lll}\text { Figure 3.13 Gas Migration Model for Kupe Area } & \text { 74-75 }\end{array}$

\section{Chapter IV}

$\begin{array}{lll}\text { Figure } 4.1 & \text { Slip Tendency } & \mathbf{8 3}\end{array}$

$\begin{array}{lll}\text { Figure } 4.2 & \mathbf{8 4}\end{array}$

$\begin{array}{lll}\text { Figure } 4.3 & \text { Fracture Stability } & \mathbf{8 6}\end{array}$

Figure 4.4 Components of Stress Tensor acting on a Plane $\quad \mathbf{8 7}$

Figure 4.5 Pore Pressure Gradient for Kupe Area 88

Figure 4.6 Vertical Stress $\left(\mathrm{S}_{\mathrm{V}}\right)$ Profile for Kupe Area 91

Figure 4.7 Minimum Horizontal Stress $\left(\mathrm{S}_{\mathrm{hmin}}\right)$ Profile for Kupe Area 93

Figure 4.8 Stress Tensor using Circumferential Stress for Kupe Area 96

$\begin{array}{lll}\text { Figure } 4.9 & \text { Rose Diagram of Plio-Pleistocene Faults } & 97\end{array}$

Figure 4.10 Allowable Region Diagram for Kupe Area 98

Figure 4.11 Final Stress Tensor for Geomechanical Modelling 99

Figure 4.12 Normal and Shear Stress Acting on an Arbitrarily Orientated $\begin{array}{ll}\text { Plane } & \mathbf{1 0 0}\end{array}$ 
Figure 4.13 Equal Area Stereonet Plots of Slip Tendency at $\sim 2000 \mathrm{~m}$ (TVDSS)

$\begin{array}{lll}\text { Figure 4.14 Slip Tendency mapped onto Reservoir Faults } & \mathbf{1 0 5}\end{array}$

$\begin{array}{lll}\text { Figure 4.15 Mohr Plot of Slip Tendency } & 106\end{array}$

Figure 4.16 Equal Area Stereonet Plots of Dilation Tendency at $\sim 2000 \mathrm{~m}$ (TVDSS)

Figure 4.17 Map View of Dilation Tendency Mapped onto Reservoir Faults

Figure 4.18 Equal Area Stereonet Plots of Dilation Tendency at 3300m (TVDSS)

Figure 4.19 Equal Area Stereonet Plots of Fracture Stability at $2000 \mathrm{~m}$ (TVDSS)

Figure 4.20 Fracture Stability mapped onto Reservoir Faults

Figure 4.21 Slip Tendency Values and Chimney Locations on Faults

Figure 4.22 Histograms of Slip Tendency

Figure 4.23 Dilation Tendency Values and Chimney Locations on Faults

Figure 4.24 Histograms of Dilation Tendency

117-118

Figure 4.25 Fracture Stability Values and Chimney Locations on Faults

Figure 4.26 Histograms of Fracture Stability

120-121

Figure 4.27 Kupe Central Field Area with Dilation Tendency on Faults

\section{Chapter V}

Figure 5.1 Model of Fault Zone Structure

Figure 5.2 Field Work Locations North Island, New Zealand

Figure 5.3 Tongaporutu Aerial View of Outcrop Locations

Figure 5.4 Fault Zone 1, Outcrop A, Tongaporutu

Figure 5.5 Deformation Bands in Fault-Rock

Figure 5.6 Sandstone Smear in Fault Zone

$\begin{array}{lll}\text { Figure 5.7 } & \text { Fault Zone 1, Outcrop B, Tongaporutu } & 137\end{array}$

Figure 5.8 Close up of Main Fault Zone 1, Outcrop B, Tongaporutu 138

Figure 5.9 Fault Zone 1, Outcrop C, Tongaporutu

Figure 5.10 Close-up of the Bottom of Fault 4, in Outcrop C, 
$\begin{array}{lll}\text { Figure 5.11 } & \text { Fault Zone 2, Tongaporutu } & 141\end{array}$

$\begin{array}{lll}\text { Figure 5.12 Close-up of Fault Zone } 2 & 142\end{array}$

$\begin{array}{lll}\text { Figure 5.13 Sandstone Lenses in Fault-rock } & 142\end{array}$

Figure 5.14 Deformation Bands Enclosing Slip-surface of Minor Fault 143

$\begin{array}{lll}\text { Figure 5.15 } & \text { Fault Zone 3, Tongaporutu } & 144\end{array}$

$\begin{array}{lll}\text { Figure 5.16 Waikawau Beach Outcrop Locations } & 146\end{array}$

$\begin{array}{lll}\text { Figure 5.17 } & \text { Outcrop 1, Waikawau Beach } & 147\end{array}$

$\begin{array}{lll}\text { Figure 5.18 Higher Density of Fractures at Bend in Fault Zone } & 148\end{array}$

$\begin{array}{lll}\text { Figure 5.19 Calcite Veining in Fault Zone } & 148\end{array}$

$\begin{array}{lll}\text { Figure 5.20 Increased Vein Thickness at Fault Intersection } & 149\end{array}$

$\begin{array}{lll}\text { Figure 5.21 Outcrop 2, Waikawau Beach } & 150\end{array}$

$\begin{array}{lll}\text { Figure 5.22 Outcrop 2, Waikawau Beach } & 151\end{array}$

Figure 5.23 Calcite Veining in Fault Zone exposed on Wave-cut

Platform 152

$\begin{array}{lll}\text { Figure 5.24 Striations on exposed Fault Surface } & 152\end{array}$

$\begin{array}{lll}\text { Figure 5.25 Fault Trace across Wave-Cut Platform } & 153\end{array}$

$\begin{array}{lll}\text { Figure 5.26 Bristol Road Quarry and Inglewood Fault } & 155\end{array}$

Figure 5.27 Oil and Gas emanating through Quarry Floor 156

$\begin{array}{lll}\text { Figure 5.28 Pockmarks in Quarry Floor } & 157\end{array}$

$\begin{array}{lll}\text { Figure 5.29 Operating the Gas Sniffer } & 158\end{array}$

$\begin{array}{lll}\text { Figure 5.30 Gas Concentration Measurements } & 159\end{array}$

\section{Chapter VI}

Figure 6.1 Inversion Related Fold Structure in Kupe Area 


\section{List of Tables}

Table 2.1 Spatial and Geometric Statistics of Structures in the Kupe $\begin{array}{ll}\text { Area } & \mathbf{2 8}\end{array}$

Table 4.1 $\quad$ Borehole Break-out Values from Horan (1997) 89

Table 4.2 $\quad \mathrm{S}_{\text {Hmax }}$ Calculations from Circumferential Stress 95

$\begin{array}{lll}\text { Table } 4.3 & \text { Fault-rock Properties Data from TrapTester 6.0 } & 101\end{array}$

$\begin{array}{lll}\text { Table } 4.4 & \text { Final Geomechanical Modelling Inputs }\end{array}$

$\begin{array}{lll}\text { Table 4.5 Statistical Analysis of Geomechanical Attributes } & \mathbf{1 1 2}\end{array}$

Table 6.1 Gas Flux Calculations for Single Point Source 160 


\section{Chapter I}

\subsection{Introduction}

\subsection{Study Background and Aims}

The relationship between faulting and hydrocarbon migration and accumulation is important for hydrocarbon exploration and production. Faults can act as conduits and/or barriers to fluid and gas flow. The potential for flow in and across faults can vary between basins, and spatially and temporally along individual fault zones (e.g., Knipe et al., 1998 and references therein,). Faults acting as barriers to subsurface flow may trap migrating hydrocarbons on geological time scales and compartmentalise reservoirs on production time scales, impacting on hydrocarbon extraction (e.g., Jolly et al., 2007 and references therein,). Conversely, faults can act as conduits to up-sequence fluid and gas flow, providing pathways for hydrocarbon migration from source rocks to reservoirs (e.g., Losh et al., 2002). These conduits may also produce breaches in top seal units and influence the ability of fault bound traps to retain hydrocarbon columns (e.g., Cartwright et al., 2007). Faults can therefore have a profound influence on when and where hydrocarbon reservoirs form. Costs for drilling exploration and production wells are increasing, particularly in deep water environments, and thus an understanding of the role faults play in subsurface hydrocarbon accumulation is becoming more crucial to exploration success. Underground storage of $\mathrm{CO}_{2}$ can also require an understanding of the flow properties of faults (i.e. permeability) which have the potential to result in leakage of $\mathrm{CO}_{2}$ flow through top seals and towards the ground surface (e.g., Streit and Hillis, 2004; Dockrill and Shipton, 2010)

While studies into horizontal flow of fluids and gas across fault zones are well advanced and have been rigorously tested against hydrocarbon production and reservoir simulations (e.g., Yielding, et al., 1997; Manzocchi et al., 1999; James et al., 2004; Meyers et al., 2007; Manzocchi et al., 2008; Corona et al., 2010) there has been limited development in the understanding of up-fault (e.g., up-dip) hydrocarbon migration. Hydrocarbon seeps at the ground surface and gas chimneys indicate that fluid and/or gas flow up faults is often channelised (e.g., Halliday et al., 2008), although agreement has not been reached regarding the primary mechanisms that result in up-dip flow of hydrocarbons within fault zones (e.g., Ferrill et al., 1999; Losh et al., 2002; Kachi et al., 2004; Mildren et al., 2005; Cartwright et 
al., 2007). Models developed to predict the locations of up-dip fluid and gas migration on fault surfaces have generally not been rigorously tested against independent evidence of fluid and/or gas flow (e.g., Ferrill et al., 1999; Kachi et al., 2004; Mildren et al., 2005), and these models are often applied in isolation, with limited investigation of the spatial and temporal variations in fault structure that might influence where up-dip migration initiates and where flow rates are greatest within fault zones.

Historically, the most significant impediment to studying the migration of hydrocarbons up-sequence and its relationship to faulting has been the inability to identify fluid and gas migration pathways in the subsurface. Recent improvements in the quality, analysis and interpretation of seismic reflection data now enable fluid and gas, and the structures produced by the passage of fluid and gas to be identified within sedimentary rocks and sediments. Pockmarks, mud volcanoes, carbonate mounds and other physical disturbances within strata, directly or indirectly caused by fluids or gas, are now commonly identified and correlated with faults within seismic reflection data, enabling the locations and geometries of up-sequence hydrocarbon flow to be investigated (e.g., Ligtenberg, 2003; Ligtenberg, 2005; Halliday, et al., 2008; Loseth et al., 2009). Direct seismic reflection imaging of gas within strata in the form of gas chimneys has been linked to faults and thus provides a means of inferring where migration pathways are in relation to fault zones (e.g., O’Brien and Woods, 1995; Cowley and O’Brien 2000; Ligtenberg, 2005; Schroot et al., 2005; Van Rensbergen et al., 2007; Halliday et al., 2008; Medialdea et al., 2008; Ilg et al., in prep). Manual and automated methods for mapping gas chimneys in seismic reflection data have been developed and used for charge prediction and fault trap integrity investigations (e.g., Ligtenberg, 2003; Ligtenberg, 2005). Leakage interpretation of gas chimneys now provides a qualitative means of determining if hydrocarbon migration has occurred in the past or is presently active, and with high quality 3D seismic reflection data has also been used to infer the locations of zones of high permeability in, and proximal to, fault zones.

This thesis makes use of advances in seismic data quality to investigate the relationship between normal faulting and up-sequence hydrocarbon migration taking the form of gas chimneys within the Kupe Area, South Taranaki Basin, New Zealand. The Taranaki Basin is currently New Zealand's only producing petroleum basin and as such is rich in high 
quality data with over 400 petroleum wells (Crown Minerals, 2010) and 3000 km line length of 2D and $\sim 1300 \mathrm{~km}^{2}$ area of 3D seismic reflection profiles (Milner et al., 2009). The Basin is structurally complex, with multiple overprinted phases of deformation. Active faults penetrate through the regional top seal in the southern section of the Basin and multiple fault-bounded targets exist in the northern section of the Basin (Crown Minerals, 2010). These faults have been inferred to be important conduits for hydrocarbon migration by Mildren et al., 2005 and to represent risks to hydrocarbon entrapment on geological time scales by Ilg et al., (in prep). Results of this thesis could have application outside of the Taranaki Basin for the prediction of locations where up-dip fault-related fluid and gas migration is most likely to occur in fault zones and, as a consequence, where hydrocarbon reservoirs could be located.

\subsection{Thesis Structure}

This thesis has four main objectives, each addressed as a separate chapter. Each chapter has a particular focus and is self-contained. Chapter I outlines the purpose and structure of the thesis, provides an introduction to the Taranaki Basin's geological history and petroleum systems, and outlines the data and methods used in the thesis. Chapter II investigates the structural development of the Kupe area, focusing on the development of faults that could influence fluid and/or gas migration. Fault growth histories, fault kinematics and reactivation of pre-existing faults are examined. Chapter III explores the spatial distribution of gas chimneys in the Kupe Area and considers how chimneys relate to Pliocene to Recent normal faults. The relationship between gas chimneys and faults is then applied to develop a model for up-dip fault based gas migration. Chapter IV tests the application of current geomechanical methods in the prediction of up-dip gas leakage in faults that have associated gas chimneys, and the locations on individual faults where gas chimneys occur. Chapter V synthesises field-based observations of fault structure and gas flux rates to explore controls on the initiation of fault based up-sequence fluid and gas migration and possible migration rates. Chapter VI summarises the main conclusions and topics that may prove fruitful in future investigations. Potential areas for future research have been suggested due to the time and resource limitations of Masters of Science thesis research. 


\subsection{Geological Background}

The Kupe Area is located in the South Taranaki Basin, which covers an area of approximately $100,000 \mathrm{~km}^{2}$ predominantly west of the North Island of New Zealand on the Australasian Plate (Fig. 1.1a). The South Taranaki Basin is structurally complex, with multiple phases of deformation that have been influenced by previous structural fabrics (King and Thrasher, 1996). The Basin contains Late Cretaceous ( 84 Ma) and younger sedimentary strata up to $9 \mathrm{~km}$ thick that rest unconformably on a basement consisting of meta-sedimentary and cratonic accretionary terranes formed on the Gondwana Margin (Bradshaw, 1989; King and Thrasher, 1996; Mortimer et al., 2004) (Fig. 1.1d).

Three main phases of deformation since $~ 84$ Ma have been recognised in the Taranaki Basin. These consist of Late Cretaceous to Eocene rifting ( 84-50 Ma), Eocene to Recent shortening ( 40 Ma-0 Ma) and Late Miocene to Recent extension ( 12-0 Ma) (e.g., Stern and Davey, 1989; King and Thrasher, 1992 and 1996, Holt and Stern, 1994; Nicol et al., 2005; Stagpoole and Nicol, 2008; Giba et al., 2010). Late Cretaceous extension and rifting in the Taranaki Basin developed simultaneously with the breakup of Gondwana and associated seafloor spreading in the Tasman Sea and South Pacific Ocean (King and Thrasher, 1996; Sutherland et al., 2001). The rift that developed in the Taranaki Basin, away from the main seafloor spreading centres, was approximately $100 \mathrm{~km}$ wide and 400 $\mathrm{km}$ long and contains a series of north to northeast striking normal faults with throws up to $3 \mathrm{~km}$ (King and Thrasher, 1996). The faults form a series of grabens and half grabens that controlled the deposition of Cretaceous to Paleocene sediments (King and Thrasher, 1996). Shortening and inversion of Late Cretaceous normal faults occurred throughout the South Taranaki Basin from 40- 4 Ma in response to the onset of subduction of the Pacific Plate along the Hikurangi Margin (Holt and Stern, 1994; King and Thrasher, 1996; Nicol et al., 2007). The Taranaki fault, a crustal scale thrust fault bounding the eastern margin of the Basin developed up to $15 \mathrm{~km}$ of reverse displacement which resulted in basement strata being thrust over basin sediments (Stagpoole and Nicol, 2008). Shortening on the Taranaki fault formed an extensive foreland basin that contains up to $3 \mathrm{~km}$ of Miocene sediments (Stern and Davey, 1990; King and Thrasher, 1996). Inversion also occurred across other north striking Cretaceous rift faults including the Manaia, Motumate and Cape Egmont 
Faults and resulted in a number of north trending anticlines forming (e.g. Fig. 1.1c and d) (Thrasher, 1990; Voggenreiter, 1991; King and Thrasher, 1996).
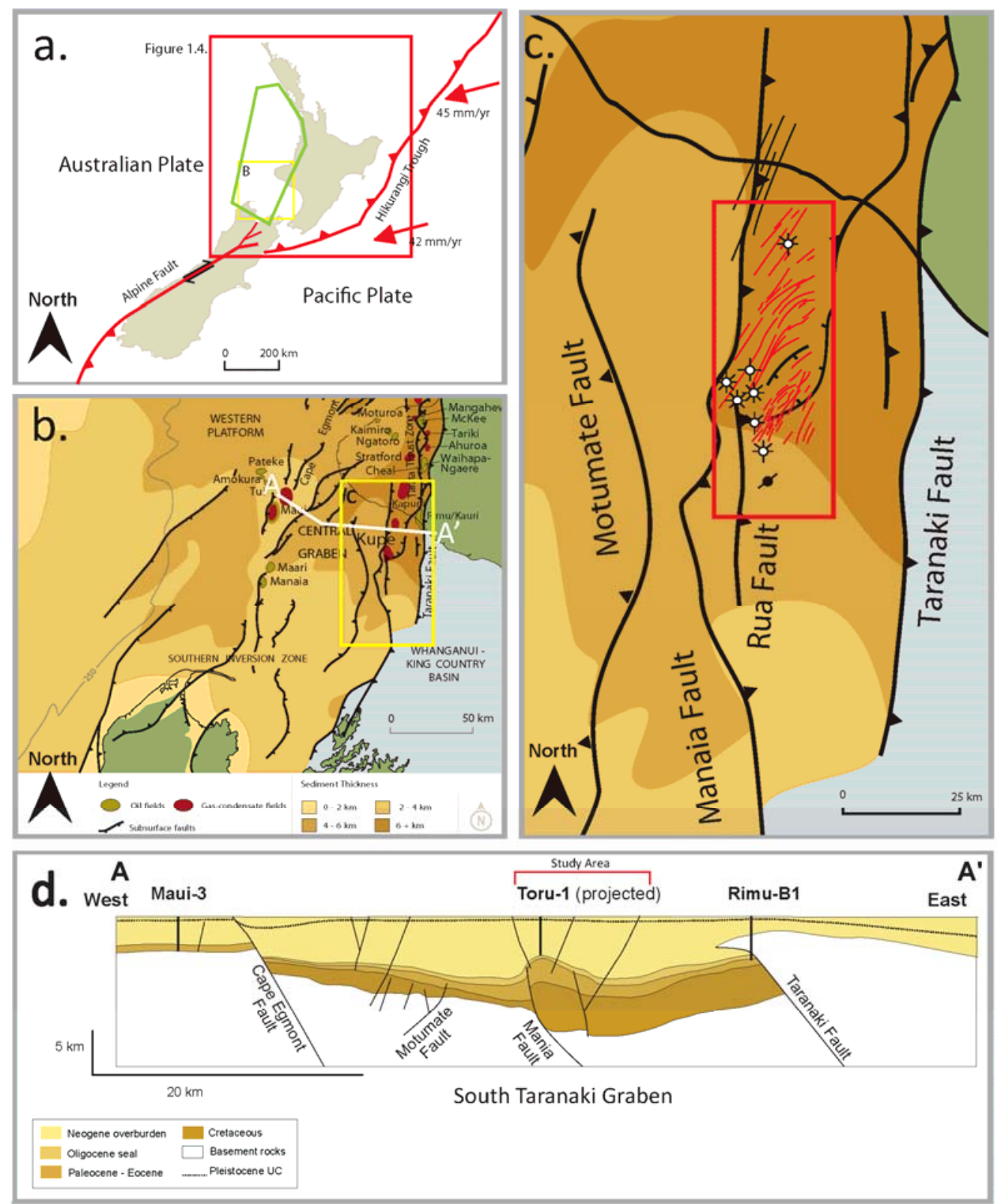

Figure 1.1 (a) Taranaki Basin (green polygon) plate boundary settings. Location of Figure 1.4 shown by the red rectangle (b) South Taranaki Basin with main subsurface structure and sediment thickness shown. The study area is located within yellow box, (c) Study area with the late-stage normal faults which are the main focus of this study highlighted in the red rectangle, (d) East-west cross section through South Taranaki Basin. Figures adapted from Crown Minerals (2010) and Ilg et al. (in prep). 
Northwest to southeast orientated back-arc extension and crustal thinning developed during the Late Miocene to Recent. Extension commenced first in the northern Taranaki Basin at $\sim 12 \mathrm{Ma}$, and at this time was synchronous with contraction in the South Taranaki Basin (King and Thrasher, 1996; Giba et al., 2010). Rollback of the subducting Pacific Plate and/or the collision of the more buoyant Hikurangi Plateau with the Hikurangi Subduction Zone resulted in clockwise rotation of the eastern North Island at rates up to ca $7^{\circ} / \mathrm{Myr}$ east relative to the stable Western Platform (Stern et al., 2006 and references therein,). These rotations resulted in a southward decrease in extension rates and a fan like opening of a back-arc rift in the central and western North Island. The southern limit of extension gave way southwards to contraction across a zone of zero strain (King and Thrasher, 1996; Giba et al., 2010). The location where this change occurs has migrated southward over the last $12 \mathrm{Myr}$ and currently lies 5-10 km south of the Kupe Area (Giba et al., 2010).

The main structure within the Kupe Area of the South Taranaki Basin is the north-south trending Manaia Anticline, which formed as a result of inversion of the Cretaceous riftrelated Manaia Fault (Fig. 1.1d) (King and Thrasher, 1996). The anticline is segmented at depth by a series of minor Late Cretaceous to Paleocene extensional faults (Schmidt and Robinson, 1989). The southern section of the Manaia Anticline contains the Rua Fault, a Miocene age piggy back thrust fault which formed on the eastern limb of the Anticline (Schmidt and Robinson, 1989; this study). The Motumate Fault located on the western side of the Kupe Area is a westward dipping inverted Cretaceous rift fault and comprises several segments that are interconnected (hard-linkage) or form relay zones (soft-linkage) (King and Thrasher, 1996; this study). The Kupe Area is bound to the east by the north-south striking Taranaki Fault, an Eocene-Miocene age crustal scale fault (Stagpoole and Nicol, 2008). Overprinting the Cretaceous-Miocene faults in the study area are north-east striking Pliocene and younger normal faults (King and Thrasher, 1996; Giba, 2010; Ilg et al. in prep). 
The proven petroleum systems within the Taranaki Basin are comprised of the following source, reservoir and seal rocks (Fig. 1.2):

(1) Sources rocks are predominantly Late Cretaceous to Eocene coals and coaly muds (Rakopi, North Cape, Farewell, Kaimiro and Mangahewa Formations; Killops et al., 1994);

(2) Reservoir rocks are predominantly Late Cretaceous fluvial to shore-face sands (Farewell Formation), Eocene lower alluvial plain, coastal plain to marginal marine sands (Mangahewa Formation; King and Thrasher, 1996) and Miocene slope channel and basin floor fan systems (Moki Formation; Grain, 2008 and Mt Messenger Formation; King et al., 2001); and

(3) Top seals are Oligocene to Early Miocene marine siltstones and marls (Otaraoa and Taimana Formations; King and Thrasher, 1996).

One dimensional basin modelling suggests that oil and gas expulsion in the South Taranaki Basin began in the Middle Miocene and continues to the present day (Armstrong et al., 1996). Two dimensional hydrocarbon generation and migration modelling show that from about 11 Ma actively growing structures, such as the Manaia Anticline, focused and captured hydrocarbon charge (Benchilla et al., 2006). Active migration of hydrocarbons in the Kupe Area is likely to have occurred concurrently with Miocene contraction and reactivation of Late Cretaceous normal faults and continued during post-Miocene back-arc extension. The earliest possible entrapment of hydrocarbons currently contained within reservoirs in the Kupe Area is constrained to latest Miocene-earliest Pliocene; prior to this time meteoric water flushed hydrocarbons from the Farewell Formation which was exposed above sea level (Martin et al., 1994). 


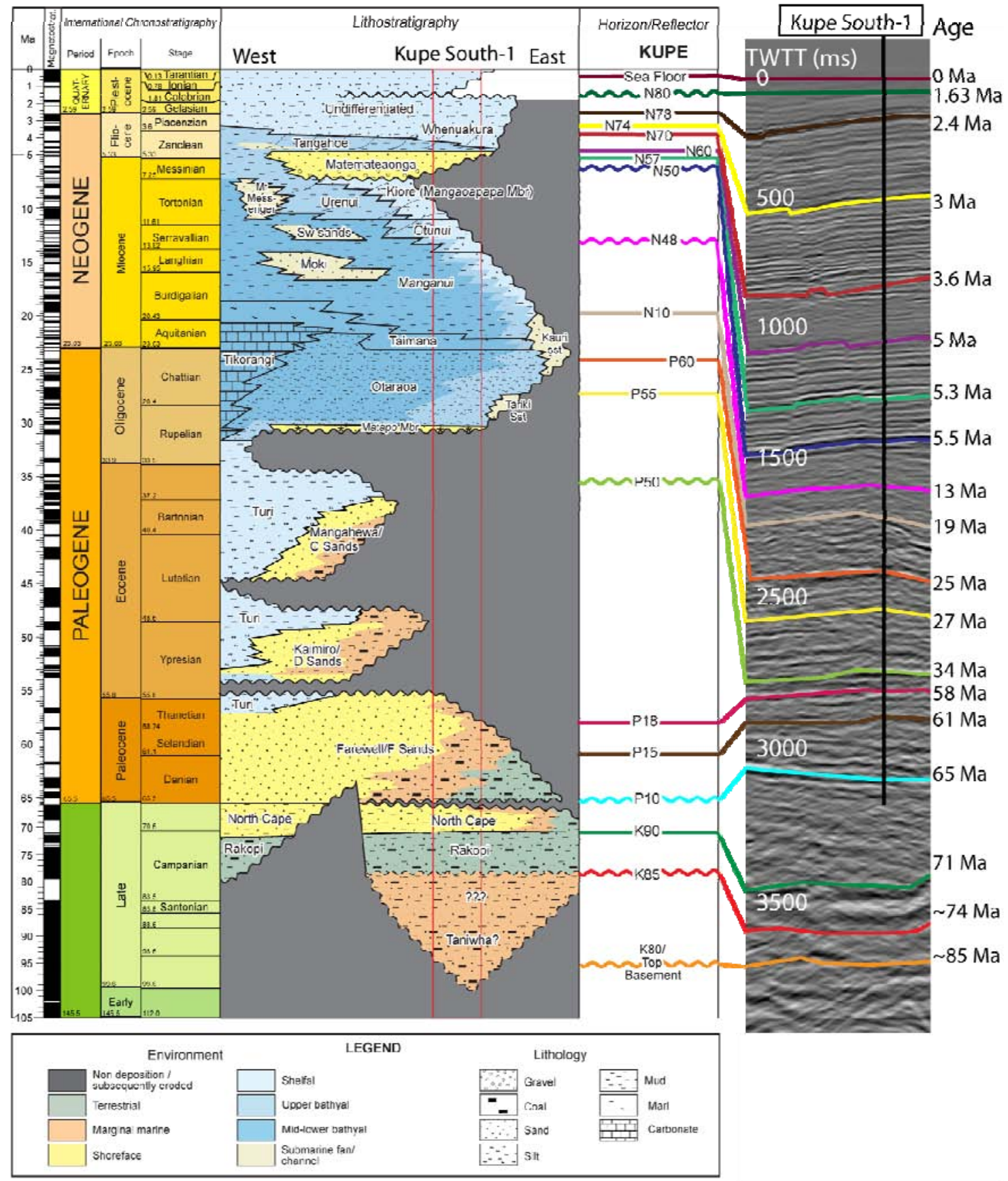

Figure 1.2 Chronostratigraphic panel for the South Taranaki Basin. Horizons interpreted in this thesis are shown in the Horizon/Reflector column and a lithologic column for the Kupe South-1 area is shown within the red box. Interpreted horizons are shown on a seismic reflection crossline where they are tied to the Kupe South-1 petroleum exploration well. Horizon data and stratigraphy are from Roncaglia et al. 2008 and Roncaglia et al. 2010. Figure adapted from Roncaglia et al. 2010. 


\subsection{Data and Methods}

This study primarily uses seismic reflection lines tied to exploration wells in the offshore Kupe Area and greater South Taranaki Basin. The Kupe Area contains a gas condensate field (Kupe Field) operated by Origin Energy, and therefore has a wealth of industry seismic data and high quality petroleum well data. Data used in this study comprises: (1) high quality 2D and 3D industry seismic reflection lines tied to fifteen petroleum exploration wells throughout the South Taranaki Basin; (2) high resolution shallow site survey seismic reflection data at the Kupe gas condensate field; (3) analysis of normal faults in coastal outcrops along the northern margin of the Taranaki Basin; and (4) $\mathrm{CH}_{4}$ gas concentration measurements at the Bristol Road Quarry, located proximally to the Inglewood Fault in the onshore section of the Taranaki Basin. Seismic reflection data and well data used in this study were made available through GNS Science's Hydrocarbons Petroleum Database (Milner et al., 2009, GNS Science 2002-2006) and obtained from Origin Energy Ltd.

The geometries and locations of seismic reflectors, structures and gas chimneys were resolved in three sets of seismic reflection lines of varying depth of penetration and line spacing. Detailed mapping has been undertaken over an area of $384 \mathrm{~km}^{2}$ of the reprocessed Kerry 3D seismic reflection volume obtained from Origin Energy Ltd (Fig. 1.3) (CGG Australia Services Pty Ltd, 2004). These seismic lines are high quality down to 2-3 seconds Two Way Travel Time ('TWTT') and provide information to a maximum 4.5 seconds TWTT. These 3D seismic reflection data have been interpreted on every $10^{\text {th }}$ inline and crossline ( 120 m) and are the primary seismic data used in this study. Horizon interpretation has been undertaken at a coarser resolution (50-100 line spacing) to a depths of 4000 and 5000 seconds TWTT in the Maui (Compagnie Generale de Geophsique, 1992) and Kapuni (SIPM, 1989) 3D seismic volumes respectively. Deep ( 4.5 seconds TWTT) 2D seismic reflection lines from GNS Science (Milner et al., 2009) that cover $~ 3000 \mathrm{~km}$ total line length, with line spacing of 1-20 km, have been used to examine structures outside the 3D volumes. The 2D seismic data are of similar quality to the 3D seismic lines and have been predominantly used to map east and south of the Manaia and Rua Faults, and Manaia Anticline. A second more restricted $32 \mathrm{~km}$ total line length 2D seismic reflection data set comprising eight lines of high resolution shallow data $<1500 \mathrm{~ms}$ TWTT provided 
detailed information on faults and gas chimneys, particularly in the upper 500ms TWTT. This survey $(\mathrm{Og})$ is within the area covered by the Kerry 3D seismic volume, between Kupe South-2 and Kupe South 5 wells. It was obtained from Origin Energy and is not publically available.

Lithological and biostratigraphic data from fourteen offshore petroleum exploration wells and one onshore petroleum exploration well have been used to constrain seven horizons ranging in age from Late Cretaceous ( $\sim 85 \mathrm{Ma}$ ) to Late Miocene ( $\sim \mathrm{Ma})$ on 2D seismic reflection lines and two 3D seismic reflection volumes (Maui 3D and Kapuni 3D), and 19 horizons from Late Cretaceous ( 85 Ma) to Quaternary (10, $000 \mathrm{ka}$ ) in age within the reprocessed Kerry 3D seismic reflection volume (Fig. 1.2 and Fig 1.3). References and reports for all well data can be found in Appendix III. Biostratigraphic intervals from the GNS Seismic Facies Mapping Project (Roncaglia, 2008) and GNS digital well sheets (GNS, 2002-2006) were used to define a series of discrete reflectors that represent time lines throughout the Kupe Area (see Fig. 1.2). The earliest two reflector ages were estimated based on ages of similar stratigraphic intervals outside the study area, and as such are only guidelines. Time based horizon data was converted to depth using a pre-existing velocity model developed internally at GNS Science (see Hill et al, in prep).

Problems encountered during horizon interpretation were predominantly due to poor reflector resolution and continuity at depth, and lack of seismic reflection data coverage in areas of structural complexity. At depths of more than 2000 ms TWTT reflectors were often discontinuous, likely due to laterally discontinuous fluvial depositional systems and the complex overprinted deformation history of the Kupe Area. Lack of reflector continuity was overcome by decreasing the interpretation line spacing (within 3D volumes) and by loop-tying reflectors around areas of poor data. In areas where there was a lack of seismic reflection data coverage (e.g., south of the Kerry 3D seismic reflection volume), faults have been extrapolated based on all seismic data surrounding the data void (i.e. the interpreted faults were consistent with the observations of locations, geometries and displacements of faults in the high quality 3D seismic reflection data). Seismic interpretation and well correlation also had to be undertaken outside the main study area, such as in the Maui 3D seismic reflection volume, to enable accurate correlation of 
reflector horizons across large displacement faults that lacked well control in either their foot-wall or hanging-wall.

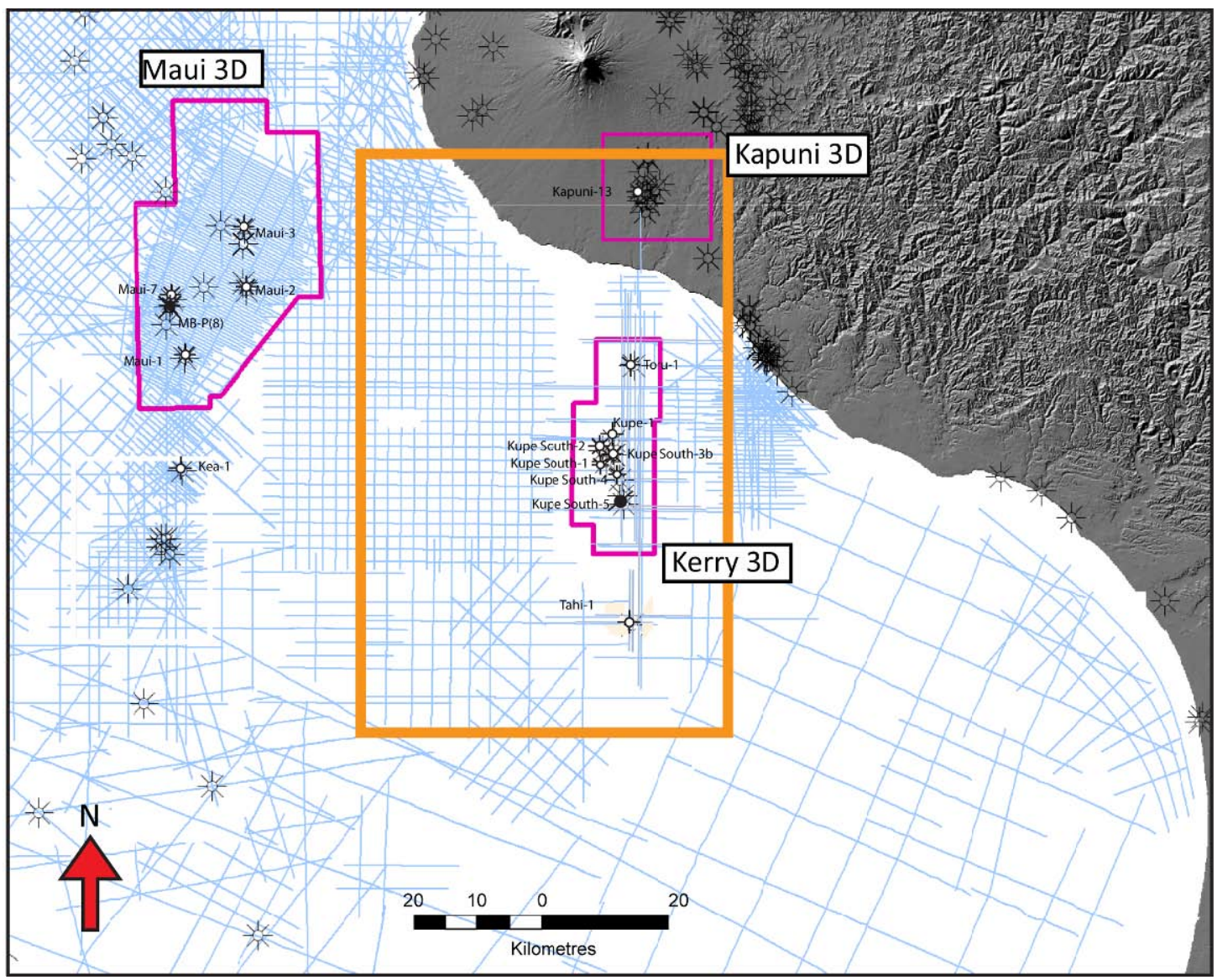

Figure 1.3 Map showing data used in this study. The study area is indicated by the orange rectangle. 3D seismic reflection volumes used in study are outline by pink polygons. 2D seismic reflection data lines are shown in blue. Seismic reflection lines are from Milner et al. (2009). Petroleum exploration wells used in study are labelled. Figure adapted from Roncaglia et al. 2010.

Leak-off test data ('LOT’), fracture integrity test data ('FIT'), repeat formation test data ('RFT'), drill string test data ('DST'), mud weights from drilling and derived density data from well logs have been used to create a stress model for geomechanical modelling in the Kupe Area. LOT, FIT, RFT, DST and mud weight data were used from Kupe-1, Kupe South 1-5, Tahi-1 and Toru-1 wells, and rock density data from the Kupe-1 well (Fig. 1.3) 
(see Appendix IV for complete reference list of well logs used in this study). All geomechanical modelling was undertaken using Badley Geoscience’s Trap Tester software (www.badleysgeoscience.co.uk).

As marine seismic reflection data do not provide direct access to faults and gas chimneys, some fieldwork was undertaken in onshore Taranaki. Faults were investigated in outcrop at Tongaporutu, 60 km north-east of New Plymouth and Waikawau Beach, Port Waikato, 70 km south of Auckland (Fig. 1.4). The faults provided detailed analogues of sub-seismic fault structure for faults at or below seismic data resolution to compliment the seismically imaged structure of faults in the Kupe Area (faults with throws $<10 \mathrm{~m}$ are not routinely resolved in high resolution industry seismic reflection data within the Kupe Area, as evidenced by the $12.5 / 25 \mathrm{~m}$ bin spacing in the Kerry 3D seismic reflection volume (CGG Australia Services Limited, (2004)). The locations where faults were studied were chosen because they represented both reservoir (Mt Messenger Formation at Tongaporutu) and top seal (Te Kuiti Group at Waikawau Beach) facies. These field observations provided information on potential densities of fractures in top seal rocks and of the complexities of fault zones. Field work also comprised of investigating an active hydrocarbon seep in the Bristol Road Quarry, 15 km south-east of New Plymouth, in the onshore Taranaki Basin (Fig. 1.4). Gas flux rates were measured in the floor of the Quarry, located in the immediate hanging-wall of the Inglewood fault $20 \mathrm{~m}$ from the surface fault trace. Gas flux rates measured in the Quarry have been used as an onshore analogue for possible flux rates through chimneys imaged in seismic reflection data in the Kupe Area. 


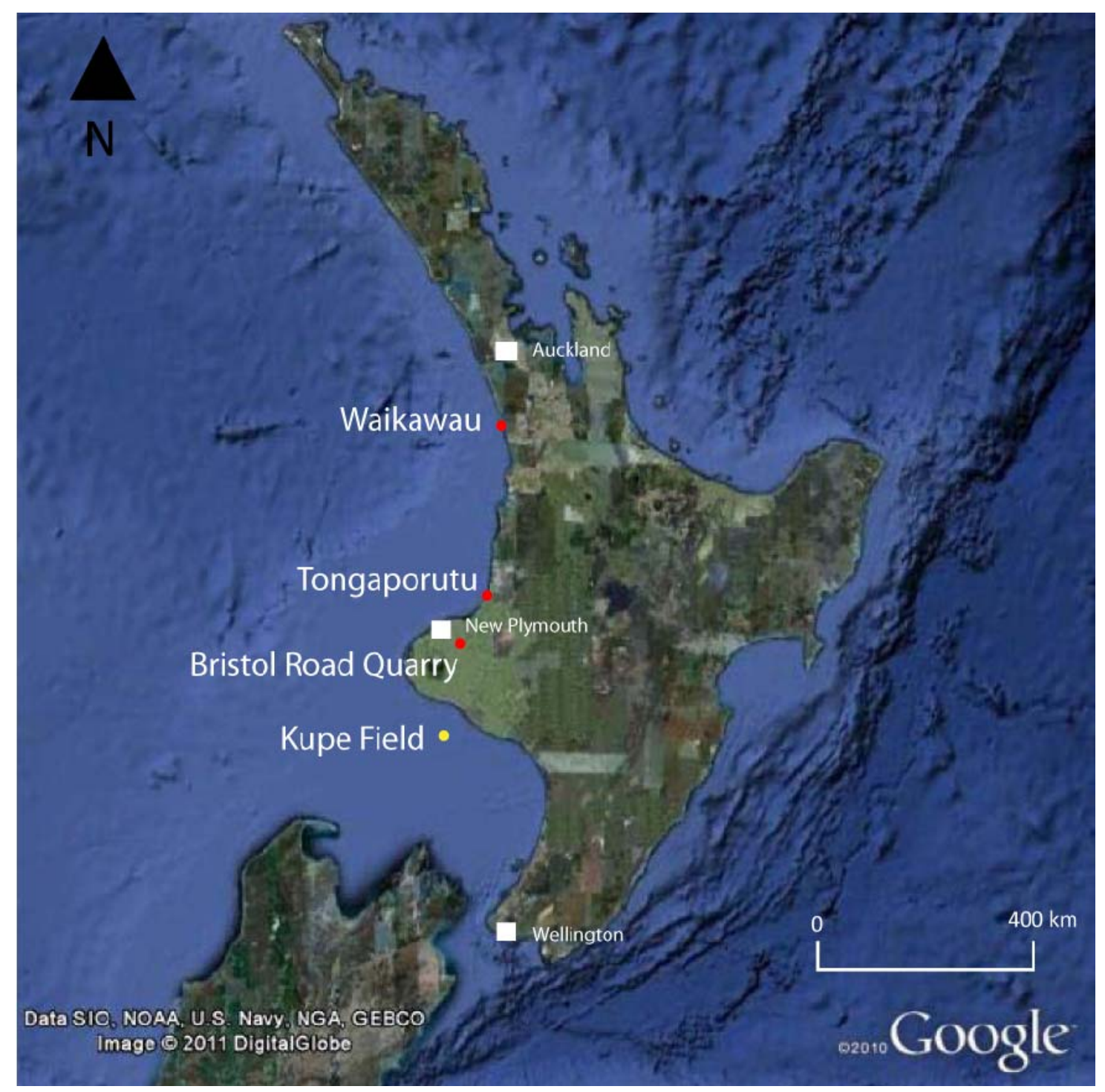

Figure 1.4 Map of North Island, New Zealand showing the locations where field work has been conducted. See Figure 1.1a for figure location. Image adapted from Google Maps (http://maps.google.com). 


\section{Chapter II}

\subsection{Structural History of the Kupe Area}

\subsection{Introduction}

Deformation of the Earth's crust is typically greatest along boundaries between tectonic plates which have different relative motions (e.g. Kremer et al., 2003; Nicol et al., 2007). At many plate boundaries (both active and ancient) strains can be poorly constrained because uplift and erosion has removed strain markers; later deformation overprints and masks previously active structures; and/or insufficient data are available to adequately describe the strain history. In the East Coast of the North Island along the Hikurangi Subduction Margin, for example, all three of the aforementioned explanations apply (Nicol et al., 2007). Along the Hikurangi Margin pre-Late Miocene deformation has been overprinted by Pleistocene deformation and is sporadically observed in the fore-arc region, while strata are not preserved across the Axial Ranges in the central North Island and provide few clues to the Tertiary deformation history in this region (e.g., Nicol et al., 2007). In the absence of such data, the evolution of plate boundaries and the processes that produce them may be difficult to resolve.

Faults and folds developed in the Taranaki Basin provide an excellent record of Late Cretaceous to present deformation along the New Zealand plate boundary (King and Thrasher, 1996). Basin strata up to 9 km thick are deformed by normal faults associated with the breakup of Gondwana, together with later faults and folds that developed in response to subduction. The timing, styles and magnitudes of strain are primarily recorded by offshore seismic reflection lines and petroleum exploration wells. This chapter focuses on three topics relating to the Kupe Area. The first topic considered is the timing, styles and magnitudes of deformation in the Kupe Area. The second topic investigates what implications the structural evolution of the Kupe area has for the evolution of the New Zealand plate boundary. The third topic considers how pre-existing structures in the Kupe Area influence the locations, geometries and growth of subsequent structures.

Though the structural history of the South Taranaki Basin is well understood (e.g., Schmidt and Robinson, 1989; Stern and Davey, 1989; King and Thrasher, 1992 and 1996, Stern et al., 1993; Holt and Stern, 1994; Nicol et al., 2005; Stern et al., 2006; Stagpoole and Nicol, 
2008; Giba et al., 2010), the precise relationships between the Kupe Area's structural development and the evolution of the plate boundary have not been completely resolved. The exact timing of contraction and inversion of structures related to convergence of the Pacific and Australian Plates, and the relationship between pre-existing basement structure and subsequent fault development are still not well defined in the Kupe Area. This study proposes to address these unresolved questions through the interpretation and analysis of high quality 2D and 3D seismic reflection data.

\subsection{Methods}

Horizon interpretation from seismic data has been applied to investigate fault growth histories using the displacement back-stripping technique (Petersen et al., 1992; Childs et al., 1993). In extensional settings where sedimentation rates are greater than displacement rates, sediments blanket fault scarps and the displacement history of faults is preserved in the sedimentary record. Fault growth is recorded by thickness changes in syn-faulting sedimentary sequences across faults and across fault displacement of correlative time horizons (Fig. 2.1). The displacement back-stripping technique is predominantly applied to investigations of normal fault growth (e.g., Childs et al., 1995 and 2003; Nicol et al., 1996 and 1997), due to complexities of folding often associated with the growth of reverse faults. However, it has been applied to reverse faults in this study, with folding associated with fault growth included in horizon displacement measurements (see Fig. 2.1). The across fault throw of each horizon is measured on depth converted seismic data and then backstripped. Back-stripping requires the sequential subtraction of throws on progressively older horizons from throws of underlying horizons. The resultant throws on the horizons are then indicative of the amount of growth that occurred on the fault up until the time the horizon was deposited and can be used to estimate the start and end of fault growth. 


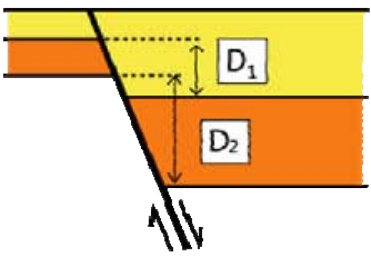

Fault at time $t_{2}$

$\left(\mathrm{i}_{\mathrm{R}}\right)$

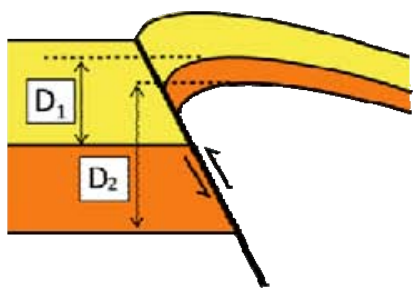

Fault at time $t_{2}$

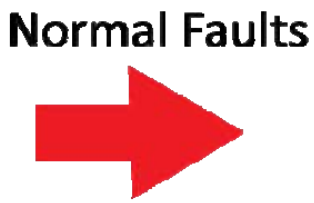

Back-stripping

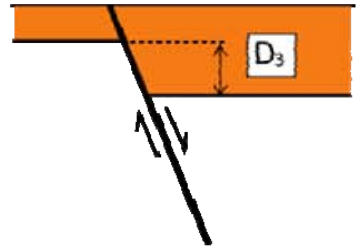

Fault at time $\mathrm{t}_{1}$

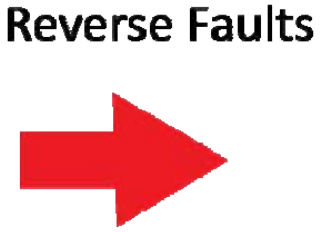

Back-stripping (ii $)$

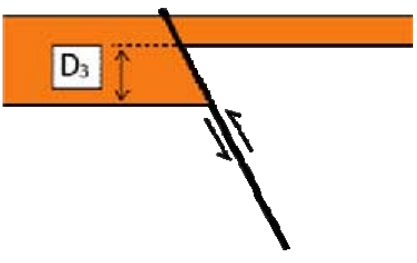

Fault at time $\mathrm{t}_{1}$

(iii)

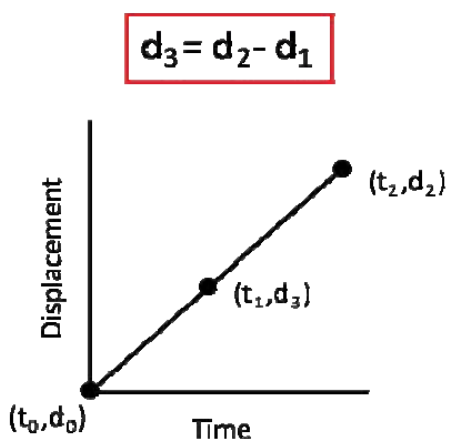

Figure 2.1 Schematic diagrams illustrating the displacement back-stripping technique of Peterson et al. (1992) and Childs et al. (1993) used to record fault (and fold) displacement accumulation and growth histories. (i) At present $\left(t_{2}\right)$ the fault has a total displacement $d_{2}$ on the base of the orange unit. Red arrows indicate the process of back-stripping of displacement across the fault at time $t_{2}$ to displacement across the fault at time $t_{2}$. (ii) Before deposition of the yellow layer at time $t_{1}$, the fault had a total displacement of $d_{3}=d_{2^{-}}$ $\mathrm{d}_{1}$. By subtracting displacements of syn-rift horizons (normal faults) or syn-contraction horizons (reverse faults) from displacements of underlying horizons a fault growth curve can be constructed (see iii). Figure and caption adapted from Giba, 2010. 
Depth structure maps have been created for eight key allostratigraphic horizons and isopach maps have been created for three key allostratigraphic intervals in the Kupe area. Seismic horizons were interpreted on all 2D seismic lines within the orange rectangle in Figure 2.2 and at $~ 120 \mathrm{~m}$ intervals north-south and east-west within the Kerry 3D seismic volume. Depth structure maps were created by depth converting time based seismic interpretation using the velocity model of Hill et al. (in prep) and then gridding the horizons at $500 \mathrm{~m}$ resolution. Isopach maps were created for allostratigraphic intervals of interest by calculating the depth thickness between the upper and lower depth structure maps that bound the interval.

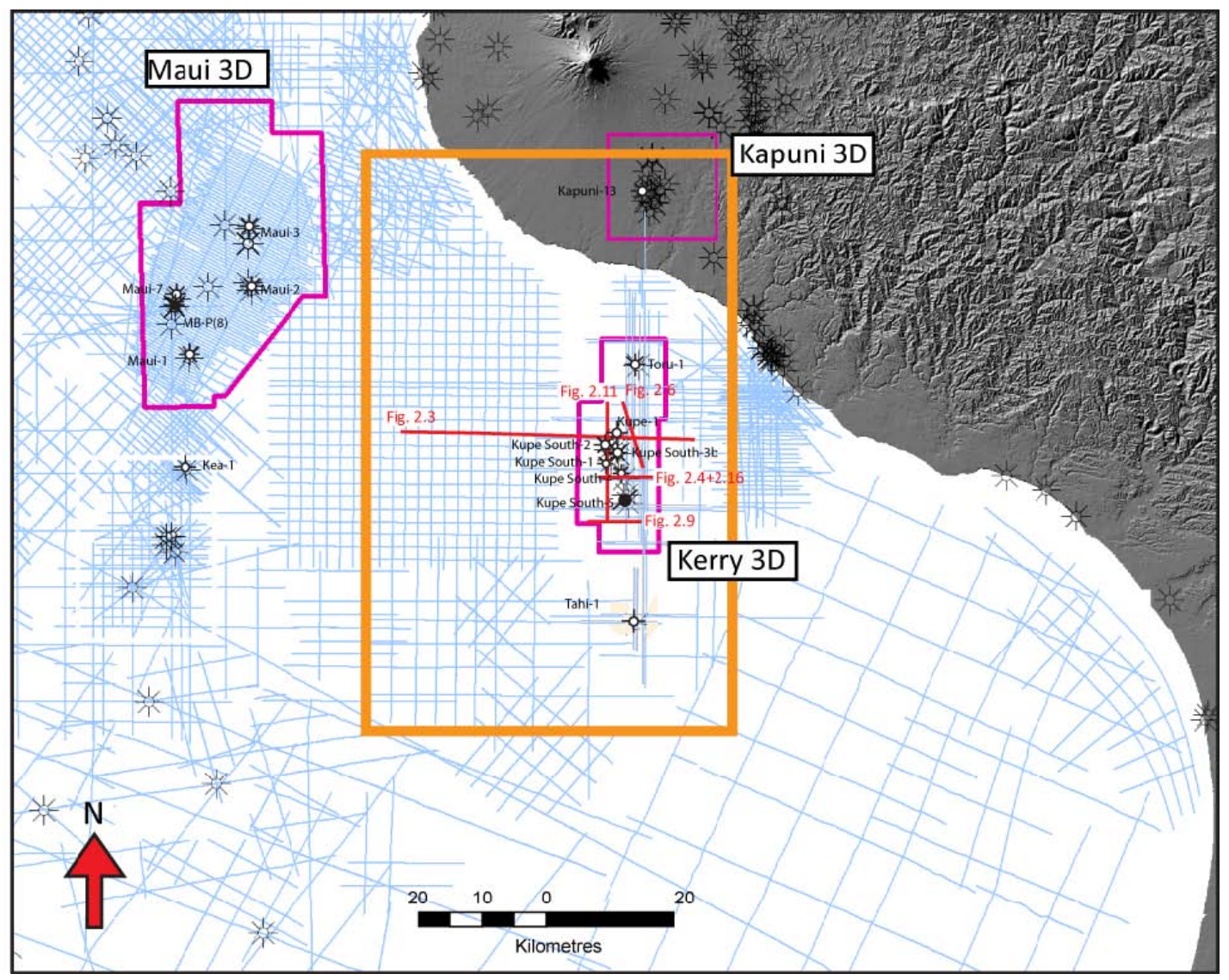

Figure 2.2 Study area (orange rectangle) with data used in this chapter. All 3D seismic reflection volumes used in this chapter are outlined by pink polygons and 2D seismic reflection data lines are shown in blue. Petroleum exploration wells used in study are labelled. Locations of seismic reflection sections in Figures 2.3-2.16 are shown by the red lines. Figure adapted from Roncaglia et al. (2010). 


\subsection{Structural History}

In this study four overprinted phases of structural development have been recognised in the Kupe Area. The youngest three phases were influenced by pre-existing structural fabrics and their development is well recorded in both thickness variations in sedimentary deposits and changes in fault displacement on dated sedimentary horizons. The timing, style and magnitudes of these phases of deformation are outlined in detail in Section 2.3. The main structural elements during these phases of deformation are illustrated by Figure 2.3, which shows an east-west composite seismic reflection line through the study area. The Manaia Fault, Manaia Anticline, Motumate Fault and Kupe Fault which are all significant structures in the study area are all shown on the composite seismic reflection line. Interpreted horizons on the seismic reflection line in Figure 2.3 also illustrate the three youngest phases of structural development in the Kupe Area. East of the Manaia Fault, below the P50 horizon, thicknesses variations across the Manaia and Kupe Faults evidence active growth during extensional faulting. The Manaia Fault is currently inverted postrifting as shown by the reverse offset on the P60, P50 and K85 horizons. Thinning of reflector intervals between the P60 and N50 horizons, over the Manaia Anticline, above the Manaia Fault, provides further evidence of inversion of the Manaia Fault and growth of the Manaia Anticline during the P60-N50 time period. The Kupe Fault shows evidence of a Pliocene to Recent period of normal fault growth where reflectors above the N50 horizon are displaced in a normal sense. 


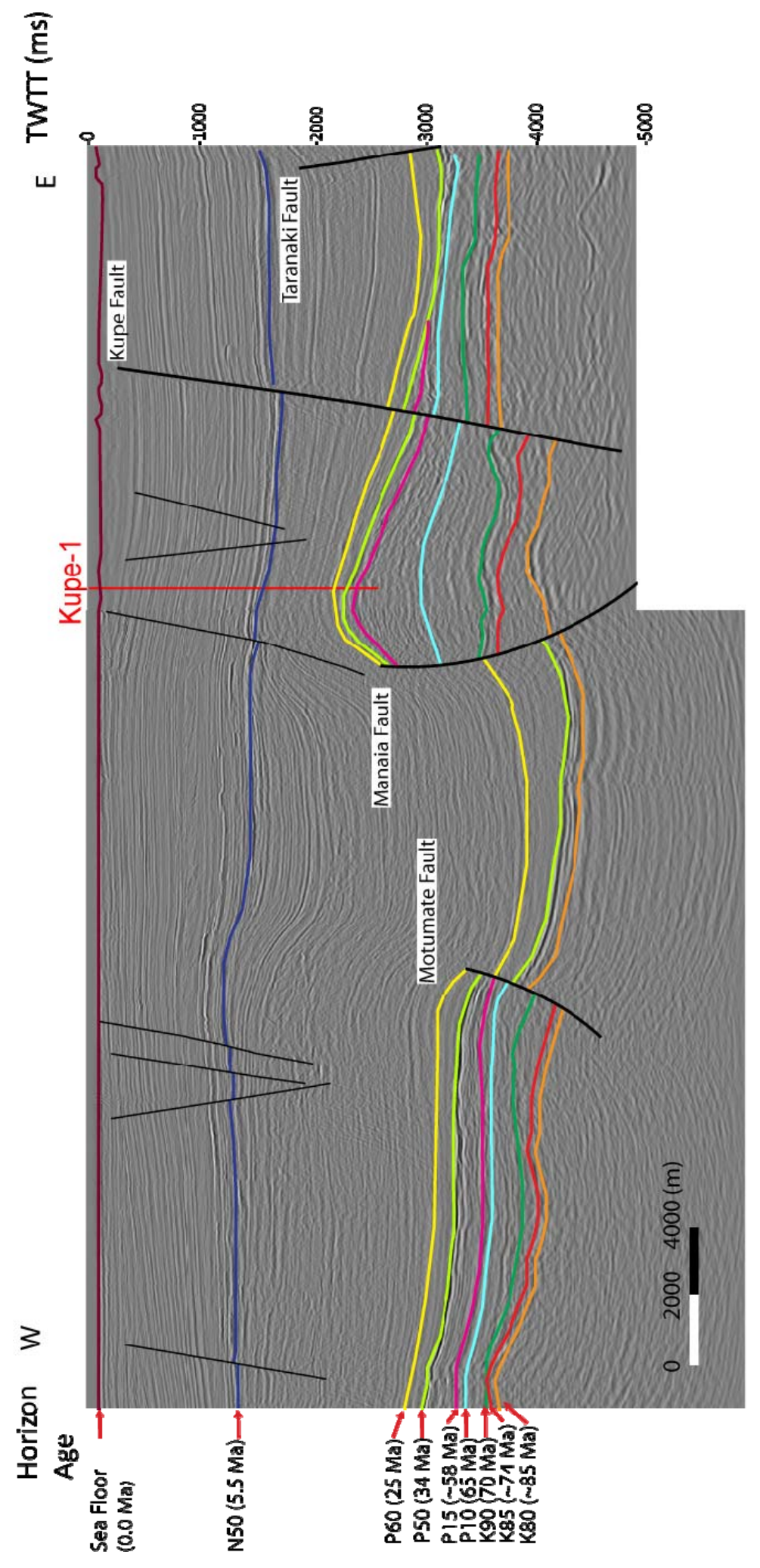

Figure 2.3 East-west composite 2D seismic reflection transect across the study area showing the main structural elements and regional seismic reflector horizons interpreted in this study. See Figure 2.2 for section location. 


\subsubsection{Pre-Late Cretaceous (> 85 Ma)}

Poor data quality precludes a detailed analysis of the geometries and ages of the Pre-Late Cretaceous (>85 Ma) strata within the Kupe Area. However, within the Pre-Late Cretaceous strata there is evidence for contraction that predates the K80 seismic horizon ( $\sim 55 \mathrm{Ma}$ ). Below the K80 horizon, between the current locations of the Manaia and Rua Faults, Pre-Late Cretaceous strata appear to be folded and faulted. These structures do not deform the K80 horizon and are therefore older than 85 Ma. For $13 \mathrm{~km}$ south of the northern lateral tip of the Rua Fault pre-K80 strata are truncated by an unconformity (see reflectors highlighted by red arrows in Fig. 2.4). The angular discordance between the reflectors and the unconformity evidenced in Figure 2.4 increases northwards. Two kilometres north and three kilometres east of northern tip of the Rua Fault pre-Late Cretaceous strata become conformable with the overlying Late Cretaceous strata.

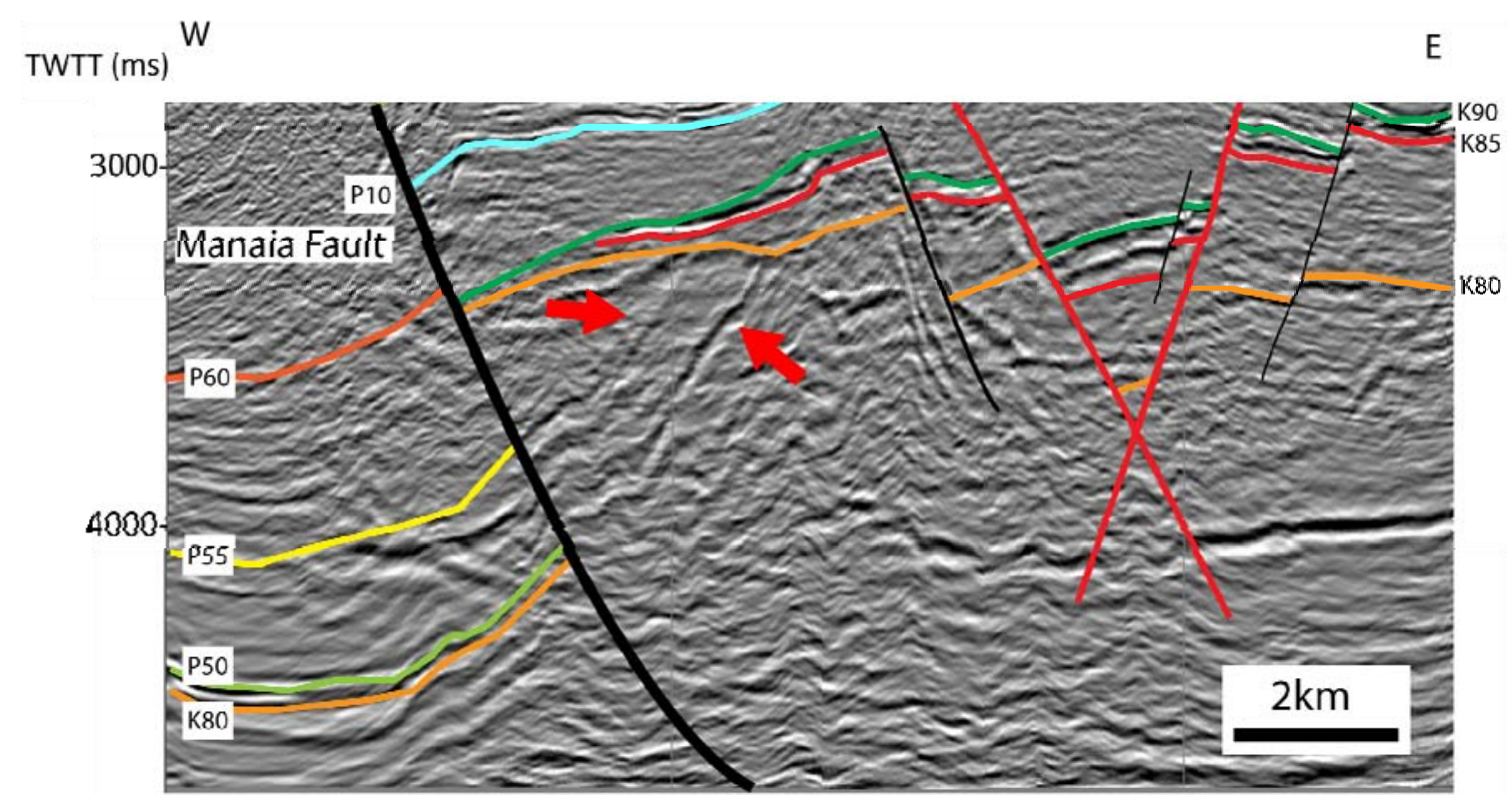

Figure 2.4 Pre-Cretaceous strata. Pre-Cretaceous reflectors highlighted by red arrows truncate against the unconformity surface (pink line) consistent with a component of contraction pre 85 Ma. See Figure 2.2 for section location. 


\subsubsection{Late Cretaceous to Paleocene Extension ( 85-55 Ma)}

During the Late Cretaceous to Paleocene, the Kupe Area underwent $>3 \mathrm{~km}$ east-west extension which was mainly taken up across three large displacement ( 1200-3700 m) north-south to northeast-southwest striking faults (Manaia, Kupe and Motumate Faults) (Fig. 2.5). The Area contained a series of grabens and half grabens into which sediments were preferentially deposited. Minor faults (less than 100m throw) within the grabens and half grabens developed with a variety of orientations and densities (Fig. 2.5 and Fig. 2.6).

The Manaia and Kupe Faults accrued the largest Late Cretaceous to Paleocene displacements in the Kupe Area and developed as north to northeast striking grabenbounding faults (Fig. 2.5, Fig. 2.6 and Fig. 2.7). The strike lengths of the Manaia and Kupe Faults during this period were 60 and $25 \mathrm{~km}$ respectively. Displacement on the major faults was recorded by accumulation of up to $\sim 3500 \mathrm{~m}$ of Cretaceous to Paleocene sediments within graben and half graben structures (Fig. 2.5). The foot-wall of the Manaia Fault was a basement high during the Cretaceous and Paleocene, on which little sediment accumulated during this time interval (Fig 2.5). The Motumate Fault was a north-south striking fault $\sim 40 \mathrm{~km}$ in length that formed antithetic to the Manaia Fault in its foot-wall. Displacement on the Motumate Fault created a local half graben filled with Late Cretaceous to Paleocene sediments (Fig. 2.5).

Sedimentary thickness variations across faults and the associated up-dip displacement decreases indicate that extension probably initiated in the Late Cretaceous after $\sim 85 \mathrm{Ma}$ (Fig. 2.7). As the ages of reflectors below $\sim 70$ Ma are not well constrained in the Kupe Area, it is not possible to precisely date the inception of normal faulting. Projection of average displacement rates on the Manaia and Kupe Faults (see dashed lines on Fig. 2.7) suggest that this phase of extension could have commenced between 75 and 80 Ma. Thickening of latest Cretaceous strata east of the Manaia Fault, in the Kupe Area, indicate movement on the Manaia and Kupe Faults continued during the deposition of the Rakopi Formation, with significant sediment accumulation from K85 ( 74 Ma) to P10 (65 Ma) (Fig. 2.5). The Manaia and Kupe Faults appear to have been the dominant faults during the deposition of sediments below the P10 ( 65 Ma) horizon in the Kupe Area. 

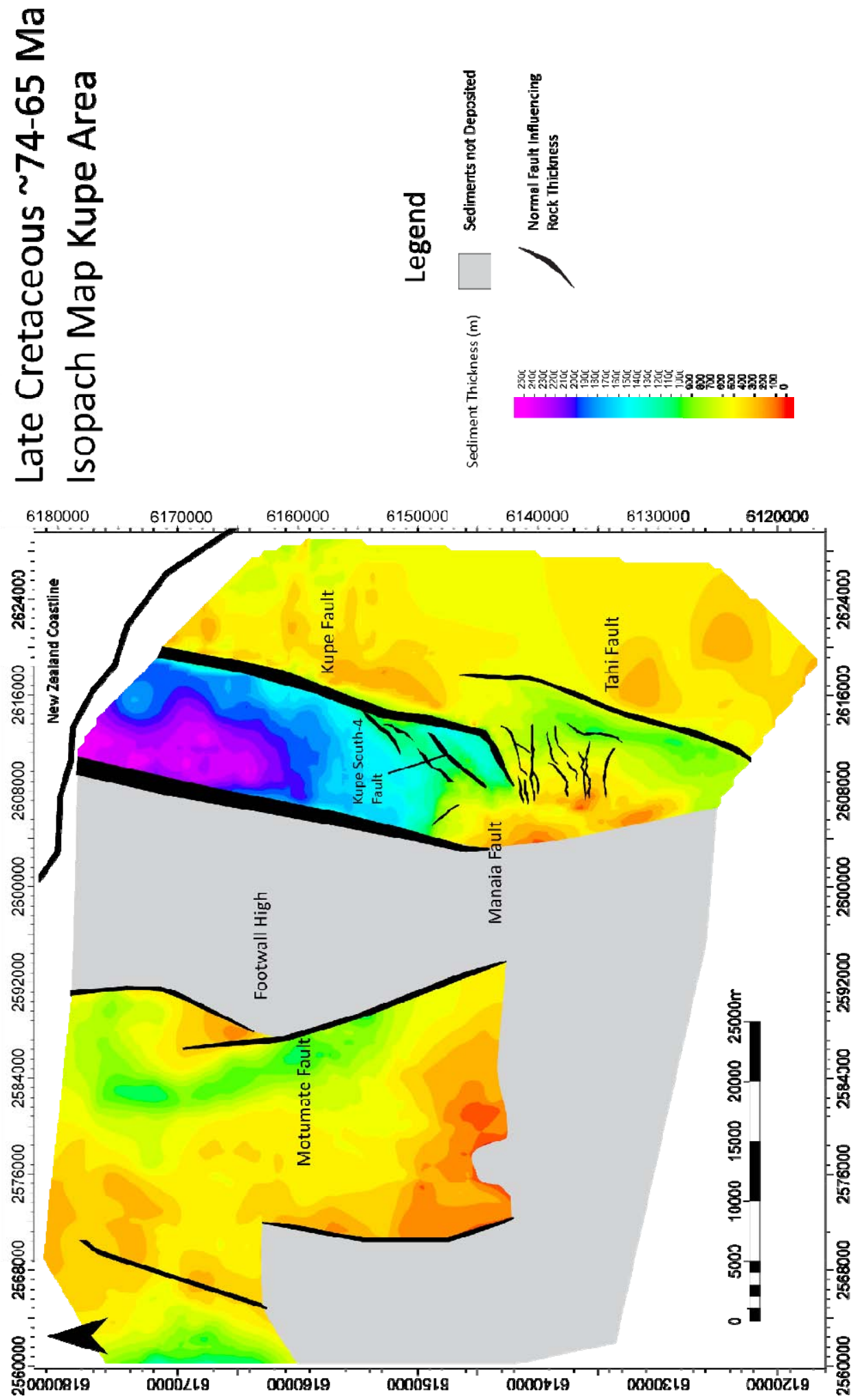

Figure 2.5 Late Cretaceous (K80-P10) isopach map for Kupe Area. Faults show their Late-Cretaceous kinematics. Seismic lines that contributed to the isopach map are shown in Figure 2.2. Within the Kerry 3D seismic reflection volume horizons were interpreted on seismic lines at $\sim 120$ m intervals. 


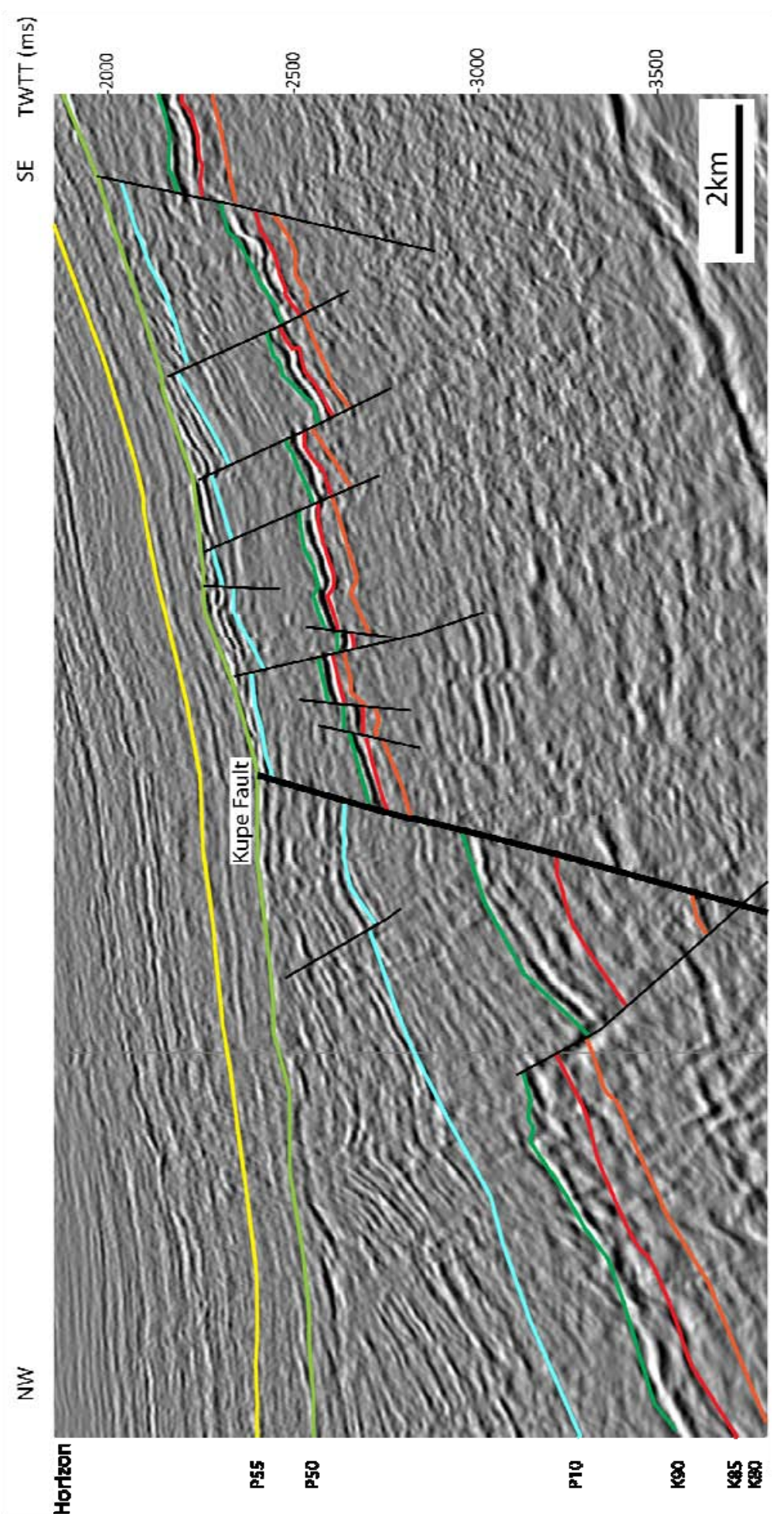

Figure 2.6 Northwest-southeast section through the Kerry 3D seismic reflection volume. Rift faults are present below the light green P50 horizon. See Figure 2.2 for section location. 
Throw profiles for smaller faults (i.e. $<500 \mathrm{~m}$ throw) support the suggestion that some normal faults commenced growth between 75 and $80 \mathrm{Ma}$ (Fig. 2.8). However, it is clear from displacement curves that many of the smaller faults initiated after $75 \mathrm{Ma}$, with the youngest structures commencing activity at about 60 Ma (e.g., Faults 93, 92 and 135 (Fig. 2.8).

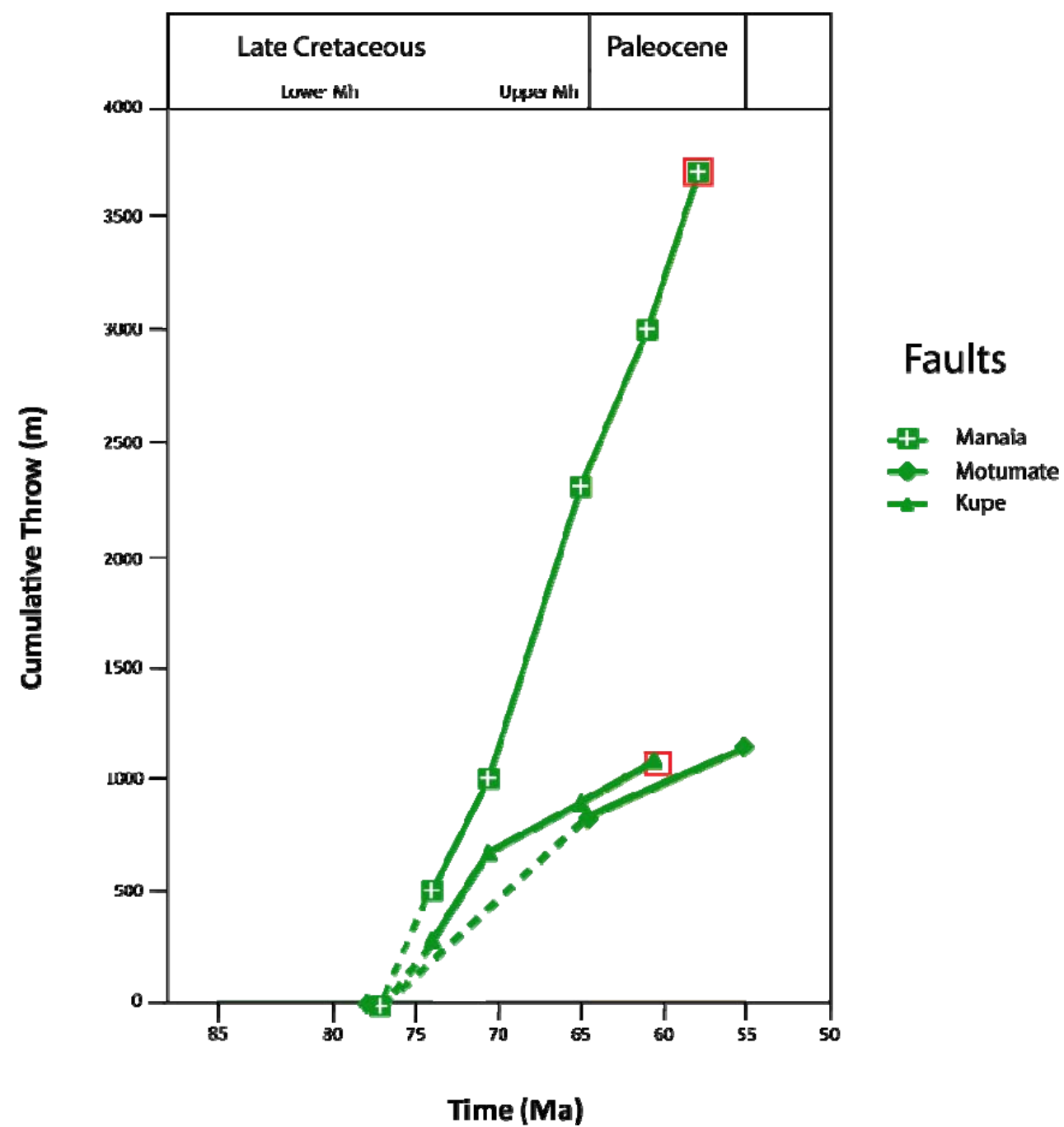

Figure 2.7 Cretaceous-Paleocene fault growth curves showing maximum cumulative throw on large displacement $(>500 \mathrm{~m})$ faults in the study area. Red squares on the last data point of a fault indicate that the top of the fault has been eroded. Maximum cumulative throws were calculated by back-stripping fault throws using the technique of Peterson et al. (1992) and Childs et al. (1993) (See Fig. 2.1). Dashed lines indicate sections of growth curve which have been estimated based on strata ages from wells outside of the study area or extrapolated. 
The death of fault 62 at 72 Ma and the decreased rates of growth on the Kupe and Motumate faults from 70 Ma may in part reflect displacement transfer onto the Manaia Fault and increases its displacement rate at this time (Fig. 2.7). This increase in rate ( 0.06 $\mathrm{mm} / \mathrm{yr}$ ) was lower than the total decrease on the Kupe and Motumate Faults ( $0.16 \mathrm{~mm} / \mathrm{yr}$ ), suggesting the transfer of displacement to other faults within the rift system and/or a slight regional decrease in rates of extension. Some of the difference in these rates may have been taken up by formation of minor faults developed at the southern lateral tips of the Manaia and Kupe Faults. These minor faults appear to have developed at 70 Ma, $65 \mathrm{Ma}$ and $61 \mathrm{Ma}$ (Fig. 2.8), with strikes that varied from east-west to northeast-southwest and northwest. Many of the minor faults and the Manaia, Kupe and Motumate Faults continued to develop into the Paleocene ( 65-55 Ma). Most of the minor faults stopped accruing displacement and died between 60-55 Ma and appear to have has shorter growth histories (5-10 Ma) compared with the larger faults ( $\geq 15 \mathrm{Ma}$ ) (Fig. 2.7 and Fig. 2.8). The precise timing of fault death on the Manaia and Kupe Faults cannot be defined due to subsequent erosion of the Paleocene strata thus preventing further analysis. The Motumate Fault stopped accruing displacement between 60-55 Ma. Therefore, the available data is consistent with the view that Cretaceous extension continued into the Paleocene and, at least in the Kupe Area, ceased between 60 and 55 Ma. This age for the termination of extension is comparable to that observed elsewhere in the Taranaki Basin (e.g., King and Thrasher, 1996; Giba, 2010), and to the 55 Ma cessation of seafloor spreading in the Tasman Sea (Sutherland et al., 2001b and references therein,). 

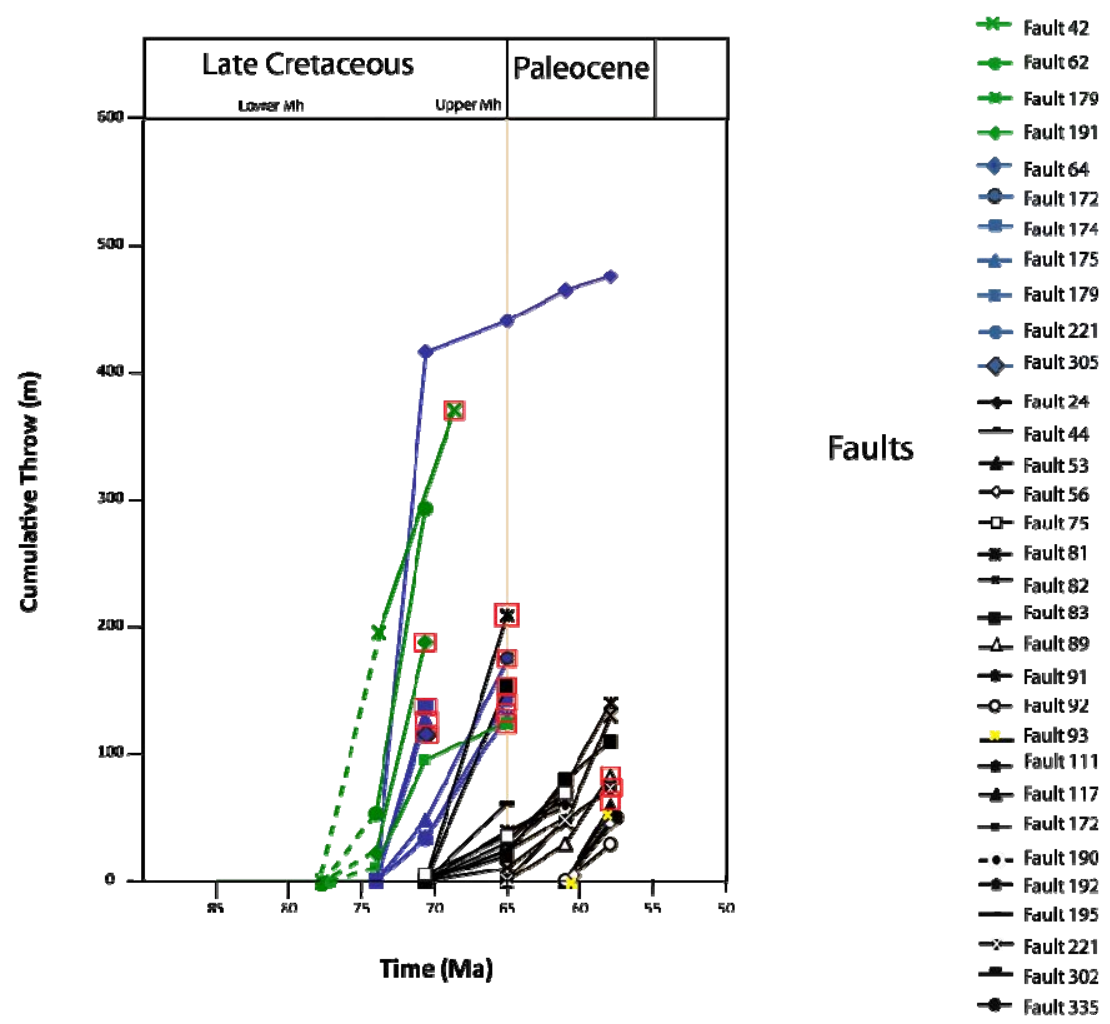

Figure 2.8 Cretaceous-Paleocene fault growth curves showing maximum cumulative throw on small displacement $(<500 \mathrm{~m})$ faults in study area. Red squares on the last data point of a fault indicate that the top of the fault has been eroded. Maximum cumulative throws calculated by back-stripping fault throws using the technique of Peterson et al. (1992) and Childs et al. (1993) (See Fig. 2.1).

Previous interpretations in the Kupe Area have suggested that the Rua Fault, a Miocene age contractional structure on the eastern limb of the Manaia Anticline (Fig. 2.9), was active during the Late Cretaceous as an extensional fault. The westward onlap of the North Cape Formation reflectors (P10) onto Rakopi Formation reflectors (K90-K85) across the Rua Fault suggests that deposition of the North Cape Formation was not controlled by contemporary displacement of the Rua Fault and that the Rua Fault was not active during this time period (see Fig 2.9). Similarly, these onlap relationships suggest that the Manaia and Kupe Faults tipped out southwards in the Late Cretaceous-Paleocene. Southwards, beyond the tips of the Manaia and Kupe Faults Late Cretaceous strata (K80-P10) thicken towards the Tahi Fault (Fig. 2.5), suggesting that the Tahi Fault was accruing displacement at this time. 


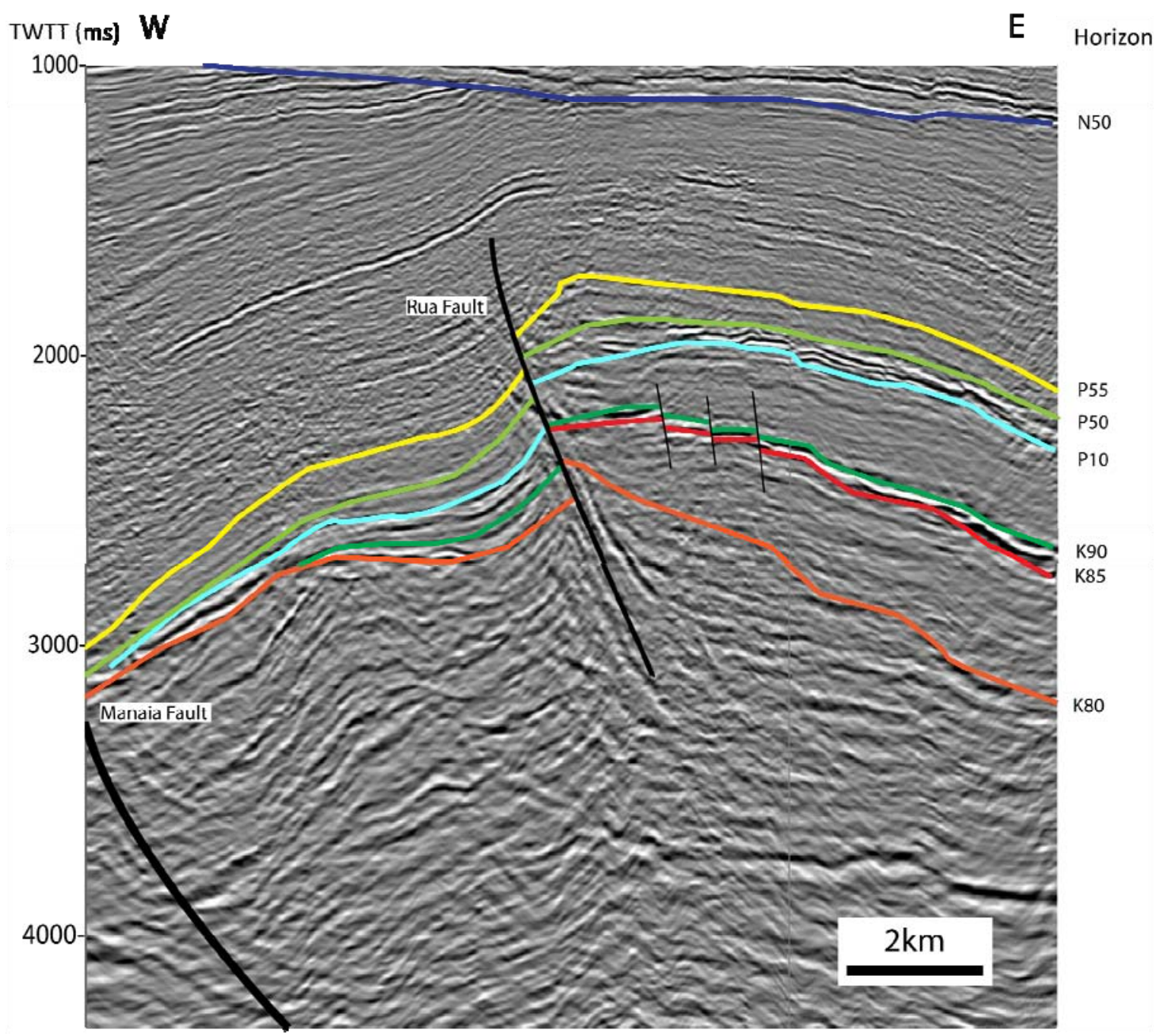

Figure 2.9 East-west cross section through the Kerry 3D seismic reflection volume showing the Rua and Manaia Faults. See Figure 2.2 for section location. Note the onlap of reflectors below P10 onto K90-K85 and lack of growth across the Rua Fault suggesting there was no movement on the Rua Fault during deposition of these packages.

\subsubsection{Late Eocene to Miocene Contraction ( 37-5 Ma)}

During the Late Eocene to Miocene, the Kupe Area underwent contraction with slip primarily accruing on three large displacement north-south striking faults and associated folds. These faults and folds form part of a regional north-south contractional fault and fold system that stretches from Nelson to west of Auckland ( 500 km). Table 2.1 outlines the spatial and geometric attributes of the fault and fold structures within the Kupe Area. 
Late Eocene to Oligocene contraction in the Kupe Area initially resulted in inversion and reverse displacement on the Manaia Fault. Inversion and reverse displacement continued during the Miocene on the Manaia, Motumate and Rua Faults (Fig. 2.10). The strike length of the Manaia Fault extended to $>120 \mathrm{~km}$ during the Late Eocene to Miocene, and it accrued $\sim 3500$ m vertical separation (i.e. fault throw and folding, see Fig. 2.1i. . $_{\mathrm{R}}$ for diagrammatic explanation of vertical separation), accommodating 3000 m east-west shortening. The accumulation of reverse displacement on the Manaia Fault resulted in growth of the northward plunging Manaia Anticline. The anticlinal fold developed as a fault propagation fold. Shortening on the Manaia fault gradually transferring into surrounding strata up-section at the fault tip creating the fold (e.g. Suppe, 1983; Mitra, 1990). The Manaia Anticline stretches from the Kapuni Field in the north to $30 \mathrm{~km}$ south of the Kupe Area (see Figure 1.1b, Chapter 1). The Motumate Fault (Fig. 2.3) accrued 1400 m vertical separation and 700 m east-west shortening during the Miocene, with a strike length of $60 \mathrm{~km}$. The Rua Fault (Fig. 2.9) initiated during the Miocene, accruing $>750 \mathrm{~m}$ vertical separation and $>1900$ m east-west shortening, growing to a strike length of $>45 \mathrm{~km}$. The growth of the Rua Fault formed a north-south striking, northward plunging fold on the western limb of the pre-existing Manaia Anticline (Fig. 2.10). Table 2.1 outlines the spatial and geometrical features of the Late Eocene to Miocene contractional structures.

Table 2.1 Spatial and geometric statistics of structures in the Kupe Area.

\begin{tabular}{|l|l|l|l|l|l|}
\hline Structure & Strike/Trend & $\begin{array}{l}\text { Vertical } \\
\text { Separation } \\
(\mathbf{m})\end{array}$ & Shortening (m) & $\begin{array}{l}\text { Strike Length } \\
\mathbf{( k m )}\end{array}$ & Age \\
\hline $\begin{array}{l}\text { Manaia } \\
\text { Fault/Anticline }\end{array}$ & North-South & 3500 & 3000 & $>120$ & $\begin{array}{l}\text { Oligocene- } \\
\text { Miocene }\end{array}$ \\
\hline $\begin{array}{l}\text { Motumate } \\
\text { Fault }\end{array}$ & North-South & 1400 & 700 & 60 & Miocene \\
\hline Rua Fault & North-South & 750 & 1900 & 45 & Miocene \\
\hline
\end{tabular}



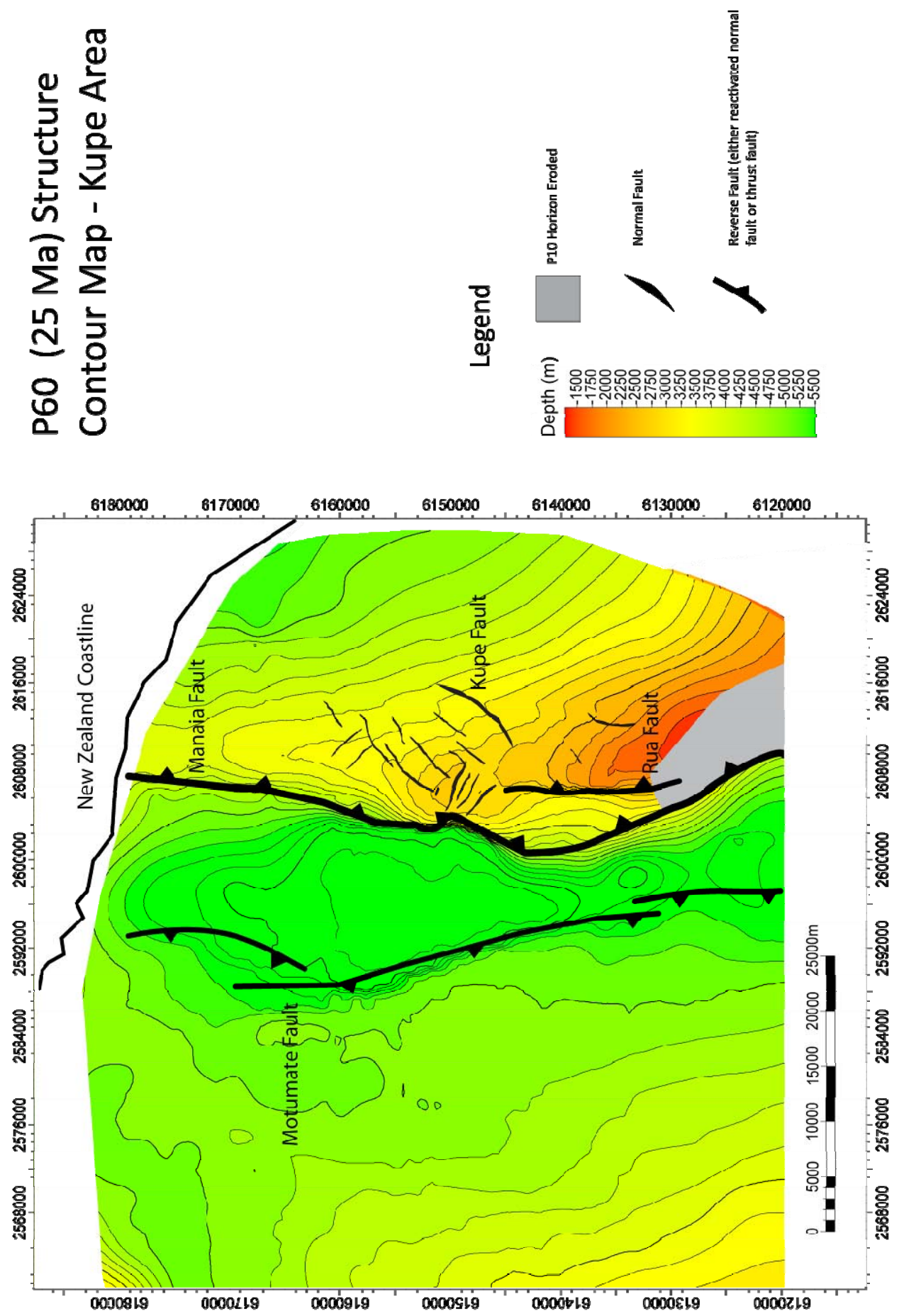

Figure 2.10 Depth structure contour map of P60 (25 Ma) horizon. Faults show their Miocene kinematics. Seismic lines that contributed to the isopach map are shown in Figure 2.2. Within the Kerry 3D seismic reflection volume horizons were interpreted on seismic lines at $\sim 120 \mathrm{~m}$ intervals. 
The timing of the initiation of contraction in the Kupe Area cannot be determined with precision, although it must post date the cessation of Late Cretaceous-Paleocene rifting at 55 Ma. The extent to which contraction occurred in the Kupe Area during the Eocene remains equivocal. Eocene strata in the hanging-wall of the Manaia Fault and across the hinge of the Manaia Anticline are thin, and have only been recorded in Toru-1 ( 200m thick). From Toru-1 Eocene strata thicken northwards to $1500 \mathrm{~m}$ in the Kapuni area. The southward thinning of Eocene strata is associated with an unconformity (Fig. 2.11, P50 horizon), across which Oligocene and Eocene strata become increasingly divergent in dip and age to the south. The dip discordance suggests differential uplift along the hinge of the Manaia Anticline during the formation of the unconformity. Biostratigraphy from the Toru-1 well indicated that the unconformity and associated differential uplift formed between 43-34 Ma. Contraction across the Manaia Fault may have also commenced during this time interval. This timing is consistent with the inferred onset of contraction on the Manaia Anticline north of the study area (Voggenreiter, 1991) and movement on the Taranaki Fault (Palmer and Andrews, 1993; Stagpoole and Nicol, 2008).

The Oligocene age (34-23 Ma) Otaraoa Formation (a marine siltstone) provides a widespread record of variations in available accommodation space created by fault and fold growth throughout the Kupe Area. The isopach for the P50-P60 interval (34-25 Ma) indicates that contraction occurred during this period, with evidence of strata thinning westward across Manaia Anticline in the hanging-wall of the Manaia Fault and thickening in the adjacent syncline within the foot-wall of the Fault (Fig. 2.12). Inversion may not have occurred synchronously along the entire strike length of the Manaia Fault. A general thinning of the Oligocene isopach from the north and south directions towards the southern Cretaceous tip of the Manaia Fault indicates that this area may have been where inversion on the southern section of the Manaia Fault initiated. 


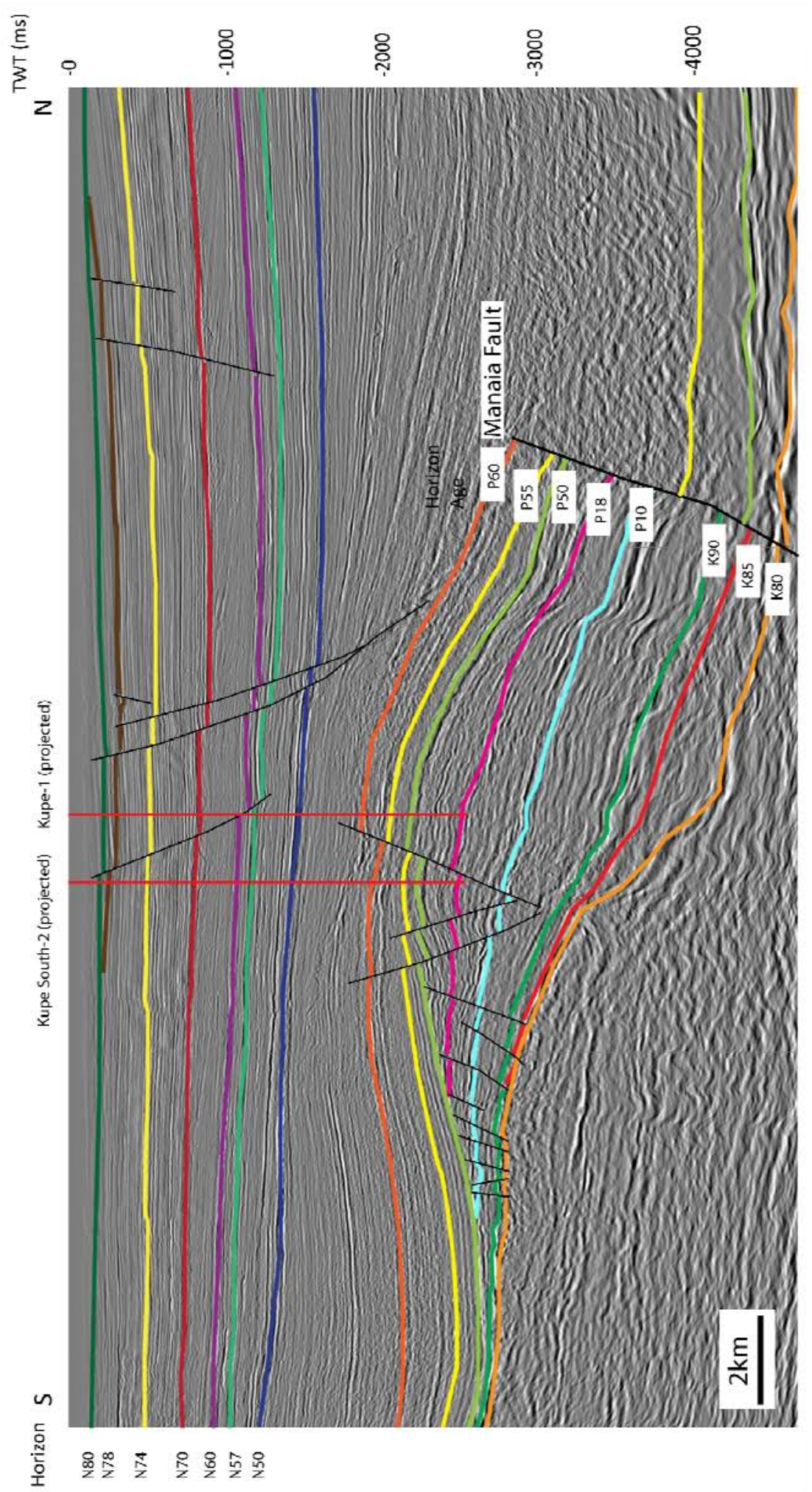

Figure 2.11 North-south section through the Kerry 3D seismic reflection volume. The seismic section follows the trend of the Manaia Anticline and passes obliquely across the Manaia Fault and Anticline. See Figure 2.2 for section location. 

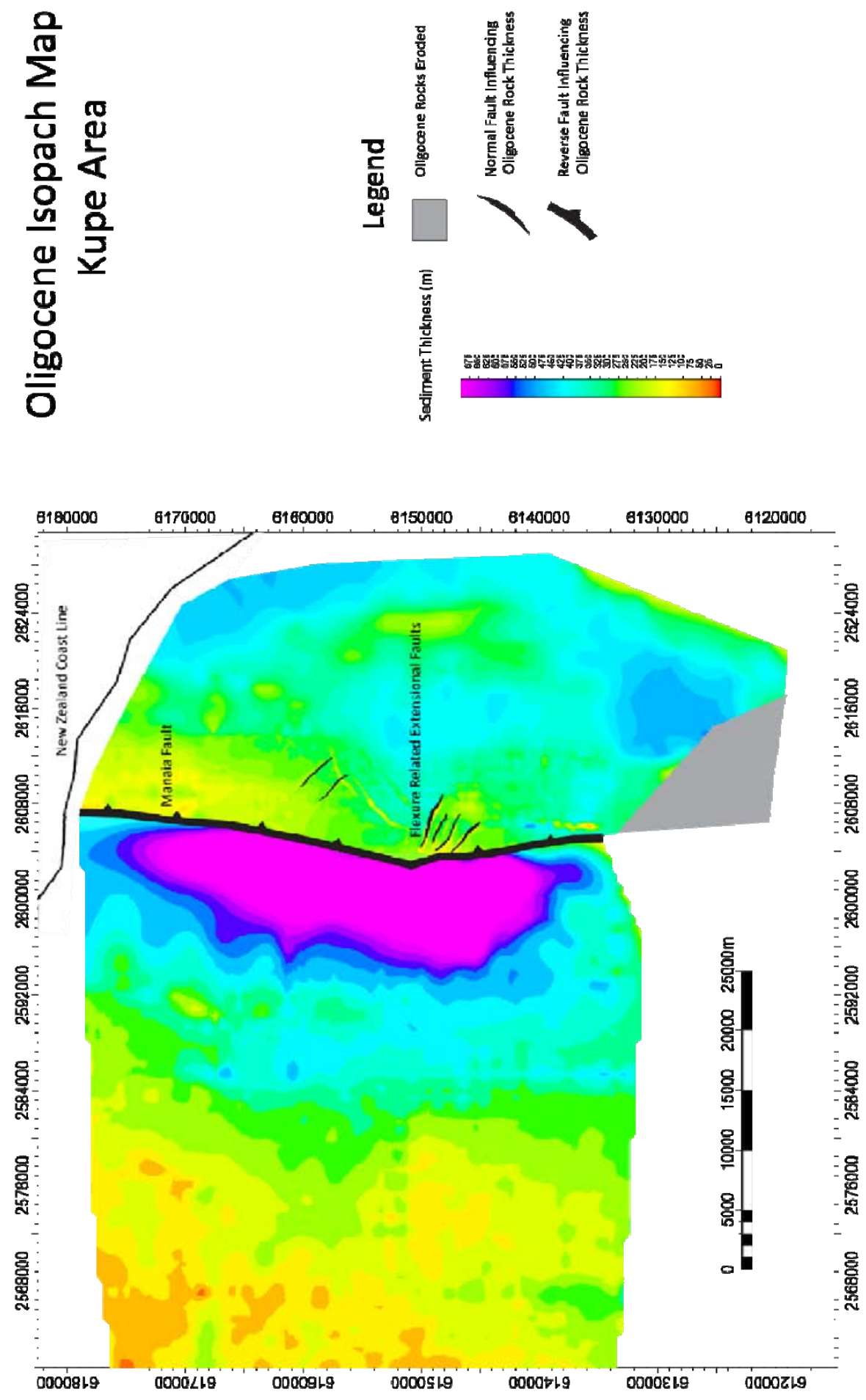

Figure 2.12 Oligocene (P50-P60) ( 34-23 Ma) isopach map for the Kupe Area. Seismic lines that contributed to the isopach map are shown in Figure 2.2. Within the Kerry 3D seismic reflection volume horizons were interpreted on seismic lines at $\sim 120$ m intervals. 
The rate of contraction during the Eocene and Oligocene appears to have been low compared to the rates of Miocene shortening. On the Manaia Fault, for example, the rate of vertical separation was about $0.04 \mathrm{~mm} / \mathrm{yr}$ from 35-20 Ma and about $1 \mathrm{~mm} / \mathrm{yr}$ from 20-17 Ma (Fig. 2.13b). The Oligocene isopach shows no discernable change in sediment thickness across the Rua or Motumate Faults, suggesting they were not active during this time (Fig. 2.12).
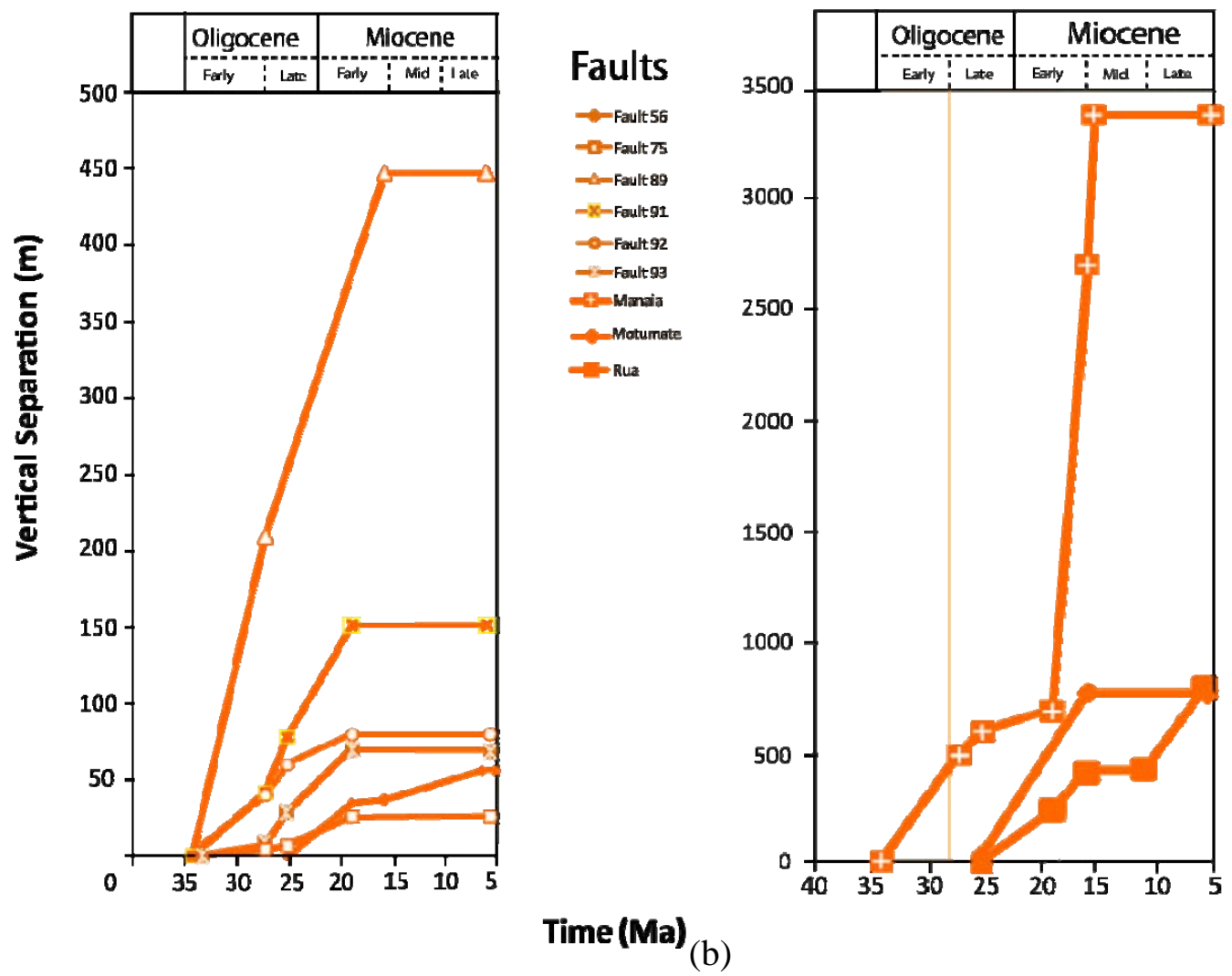

(a)

Time (Ma)

(b)

Figure 2.13 Oligocene-Miocene fault growth curves showing cumulative displacement (i.e. throw or vertical separation) on (a) normal faults with low displacement $(<500 \mathrm{~m})$ formed during flexure across the Manaia Anticline and (b) reverse faults with large displacement (>500 m). Vertical separation has been calculated by back-stripping fault throw and related folding, using the technique of Peterson et al. (1992) and Childs et al. (1993) (See Fig. 2.1). 
Throw profiles suggest the growth of the Rua Fault and reactivation of the Motumate Fault appear to have initiated close to the base of the Miocene and the Miocene ( 23-5 Ma) isopach map indicates variations in sedimentary thickness from east to west across these two faults (Fig 2.14). Throw profiles show that movement on the Rua Fault initiated at $25 \mathrm{Ma}$ and continued until $\sim 16 \mathrm{Ma}$, accumulating $\sim 400 \mathrm{~m}$ vertical separation over this time (Fig. 2.13b). Between 15-10 Ma there appears to have been little to no growth on the Rua Fault. This period of tectonic quiescence was followed by a further $\sim 400 \mathrm{~m}$ displacement on the fault between $~ 10-5$ Ma. These data suggest that deformation on the Rua Fault was episodic, as appears to have been the case elsewhere on some other faults in the plate boundary zone (e.g., Nicol et al., 2007 and references therein). The Rua Fault does not appear to have reactivated a pre-existing Cretaceous normal fault, but may have developed due to upward propagation of a pre-existing basement discontinuity (e.g., bedding plane or fault).

The growth of the Manaia Anticline and later the Rua Fault appears to have caused complex localised folding at the Late Cretaceous lateral tip of the Manaia Fault. This folding formed a dome on the top of the Manaia Anticline that is transected by a series of northwest-southeast striking faults (Fig. 2.10) that reactivated Late Cretaceous to Paleocene extensional faults and accumulated up to 300 metres of normal throw during the Oligocene to Miocene (Fig. 2.12, Fig. 2.13a and Fig. 2.14). These normal faults appear to have formed in association with flexure across the apex of the dome, rather than reflecting a regional extensional event at this time. 

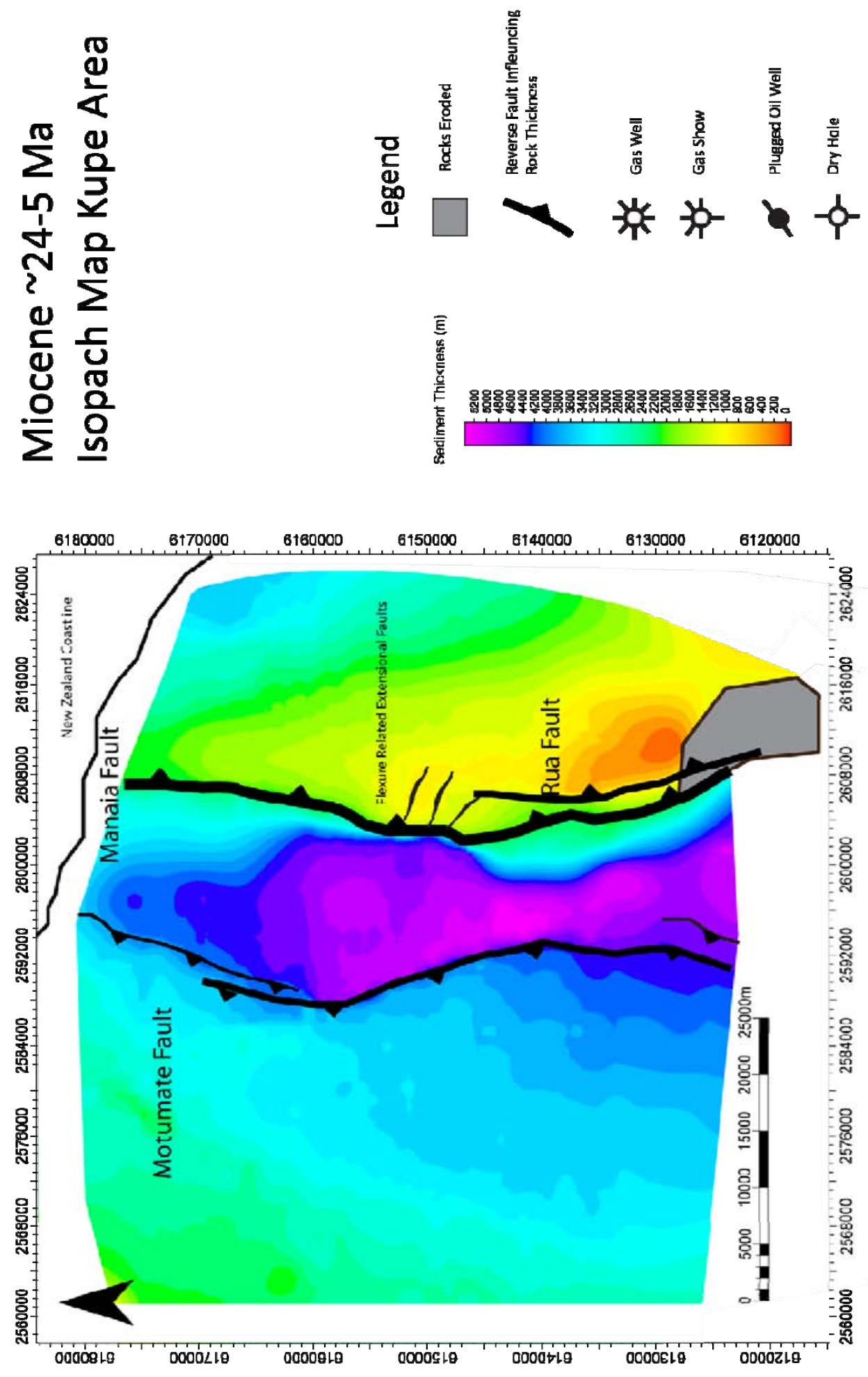

Figure 2.14 Miocene isopach map for the Kupe Area. Faults shown are at Miocene locations and display their Miocene kinematics. Seismic lines that contributed to the isopach map are shown in Figure 2.2. Within the Kerry 3D seismic reflection volume horizons were interpreted on seismic lines at 120 m intervals. 


\subsubsection{Plio-Pleistocene to Recent Extension ( 5-0 Ma)}

Plio-Pleistocene strata in the Kupe Area up to $2.5 \mathrm{~km}$ thick onlap southward onto the Miocene structural high, and fill the structural lows in the foot-walls of the Manaia and Taranaki Faults (Fig. 2.3). These sedimentary rocks provide a high resolution record of the transition within the Kupe Area from Miocene contraction to the current extensional regime. Approximately $1 \mathrm{~km}$ of northwest-southeast Pliocene to Recent ( 3.6-0 Ma) extension has occurred in the Kupe Area and is manifested as a series of low-throw northeast striking (average $041^{\circ}$ strike direction) normal faults (Fig. 2.15). These faults form the southern part of a regional back-arc rift that stretches from the southern extent of the Kupe Area to south of Auckland ( 300 km) (King and Thrasher, 1996). Reactivation of underlying Late Cretaceous-Paleocene faults (in preference to generation of new faults) occurs where these older faults strike between $010-070^{\circ}$. Reactivation of sections of Late Cretaceous-Paleocene faults often occurs along strike lengths of $\sim 5000 \mathrm{~m}$ at which point the newly developing fault steps off the underlying Cretaceous-Paleocene fault, with its Pliocene and younger throw decreasing to zero over $1000 \mathrm{~m}$ lateral distance. Up-dip fault bifurcation from the upper tip lines of Late Cretaceous-Paleocene faults is common, with single fault surfaces in Miocene strata splaying upwards into a number of fault segments separated by relay zones in the Late Miocene to Pleistocene strata (Fig. 2.16). PlioPleistocene fault strike lengths range from 500-20,000 m and fault displacement ranges from $\sim 20-150 \mathrm{~m}$. The largest Plio-Pleistocene fault displacements are generally found on faults that are reactivated. Fault planes generally dip at $\sim 65^{\circ}$, and have down-dip lengths of $\sim 4500$-6800 m when reactivating underlying structure and $\sim 1300$-3000 when not reactivating underlying structure. 


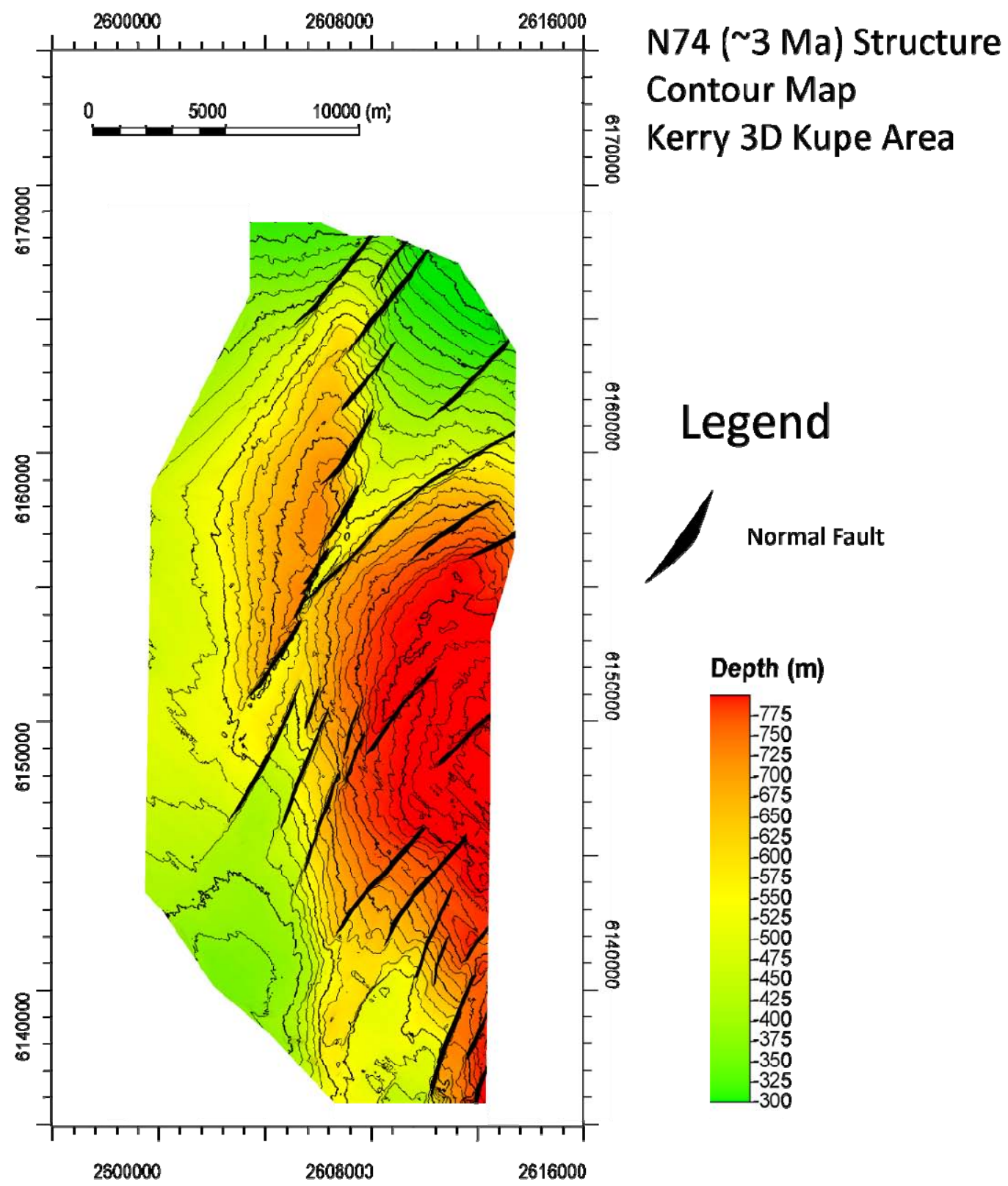

Figure 2.15 Structure contour map of N74 ( $3 \mathrm{Ma})$ horizon within the Kerry 3D seismic volume. PlioPleistocene faults form segmented arrays at the N74 horizon that converge into single structures below in Miocene-Oligocene strata. Within the Kerry 3D seismic volume horizons were interpreted on seismic lines at $~ 120$ m intervals. 


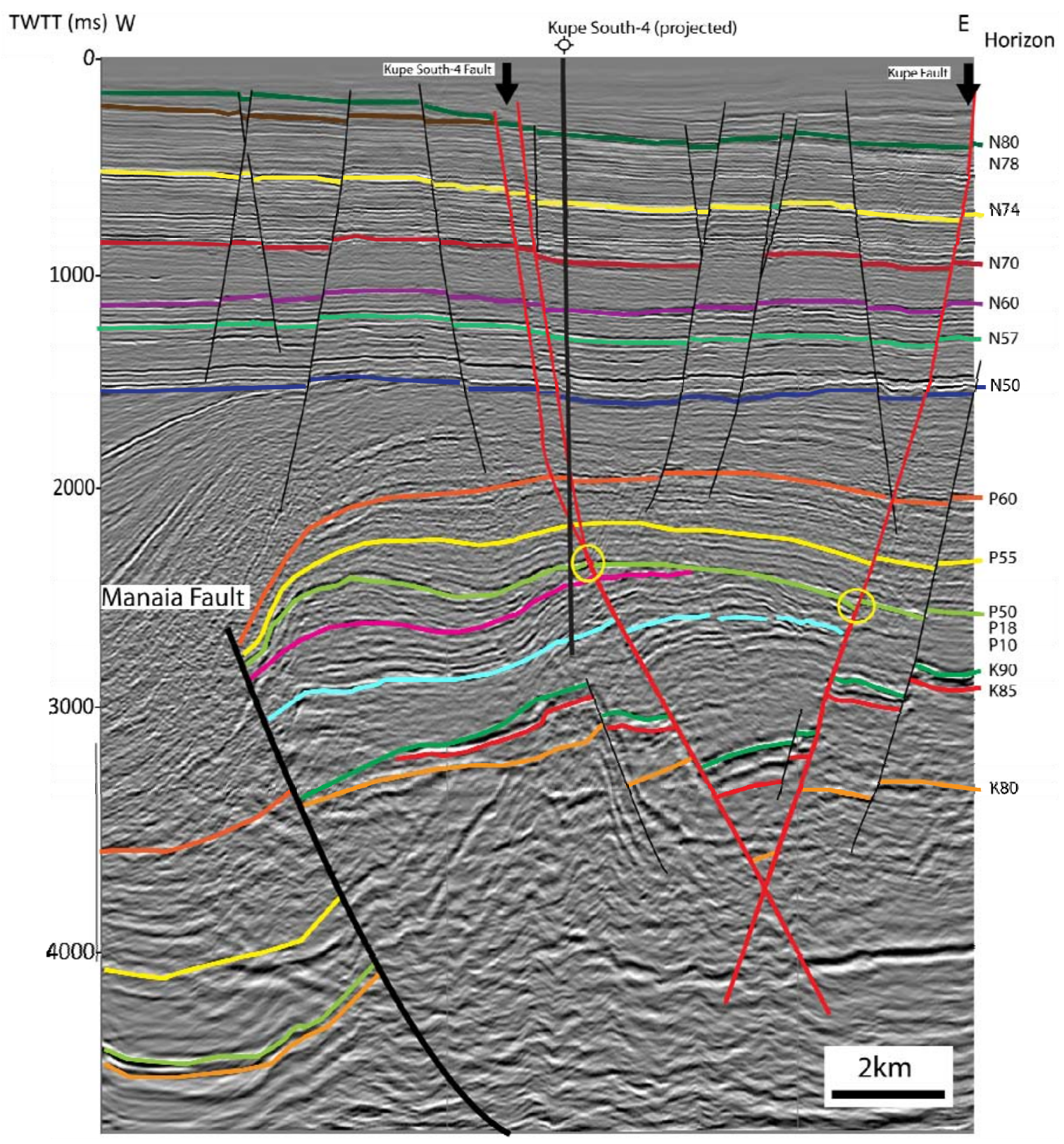

Figure 2.16. East-west cross section through the Kerry 3D seismic reflection volume showing reactivation of the Kupe fault and Kupe South-4 fault (Kupe and Kupe South-4 faults are red and locations are shown with filled arrows) (see Figure 2.5 for locations of the reacted Late Cretaceous-Paleocene faults in study area). Yellow circles indicate the locations at which reactivation of the two faults is occurring (above the $\sim 34 \mathrm{Ma}$ unconformity surface). 
Throw profiles show the initiation of Pliocene fault growth at approximately 3.5 Ma (Fig. 2.17). Fault growth continued on all mapped faults until between $2.3-1.6 \mathrm{Ma}$, when $90 \%$ of faults died. The remaining $10 \%$ of faults are active and continue to grow up to the present day.

When viewed on time slices through the Kerry 3D seismic reflection volume, the PlioPleistocene to Recent faults have the appearance of Riedel shears (Fig. 2.18). Based on these 'Riedel' like geometries, previous workers has suggested that a significant component of strike-slip movement accrued in the system (e.g., Pilar and Wakefield, 1978; Schmidt and Robinson, 1989). This study, however, suggests that the faults are predominantly dipslip. Evidence for this can be found in number of Pliostocene submarine channel complexes that formed synchronously with faulting and show no horizontal offset across faults at seismic resolution (10-20m). Mainly dip-slip faulting has also been observed from striations in outcrops on faults of similar age and strike north of the Kupe Area (Giba, 2010; Townsend et al., 2010).

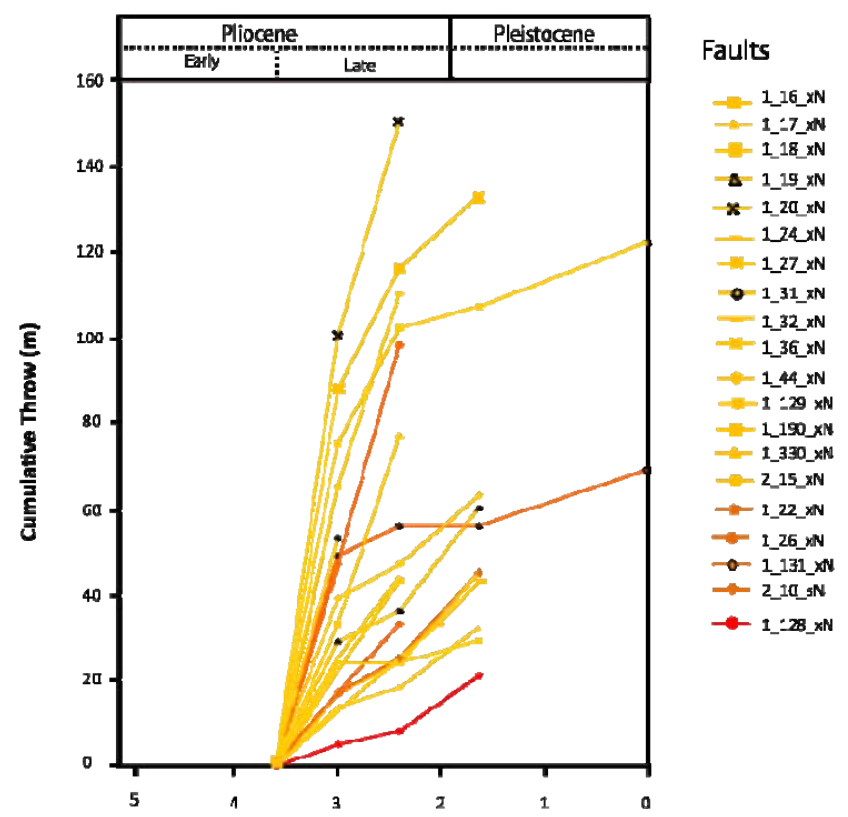

Figure 2.17 Plio-Pleistocene to Recent fault growth curves showing cumulative throw on faults in the study area. Cumulative throws calculated by back-stripping fault throws using the technique of Peterson et al. (1992) and Childs et al. (1993) (See Fig. 2.1). Note the low rates of growth on most faults (average $\sim 0.01$ $0.15 \mathrm{~mm} / \mathrm{yr}$ ). 


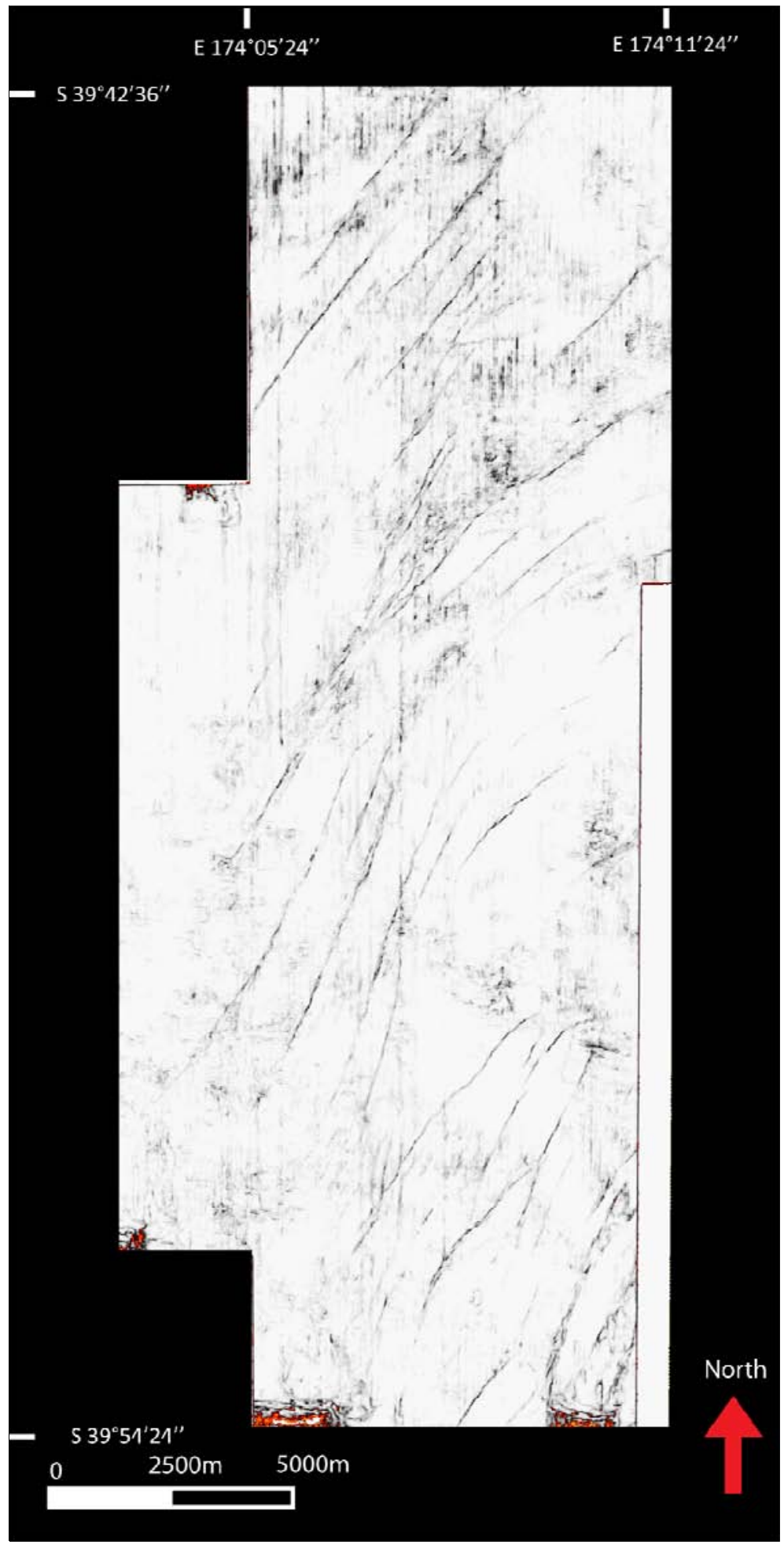

Figure 2.18500 ms TWTT Coherency slice through Kerry 3D seismic reflection volume. Faults are indicated by dark lineaments. The pink outline within the orange box of Figure 2.2 shows the location of the Kerry 3D seismic reflection volume. 
Plio-Pleistocene normal faults are considered to be primarily tectonic in origin, although throw on some faults on the western limb of the Manaia Anticline may have been increased by differential compaction. The impact of differential compaction has been small, and the faults have low throws (most $<100 \mathrm{~m}$ and all $<200 \mathrm{~m}$ ) and low displacement rates (0.01$0.15 \mathrm{~mm} / \mathrm{yr}$ ) (Fig 2.17), while the system as a whole exhibits low strain (0.04 northeastsouthwest across the Kupe Area). These low strains are associated with low displacement to length ratios compared to global data sets (Fig. 2.19). The fault segmentation, low displacements, low displacement to length ratios and low strains are all consistent with the view that Plio-Pleistocene normal faults in the Kupe Area form a relatively immature system (e.g., Meyer et al., 2002; Lamarche et al., 2005).

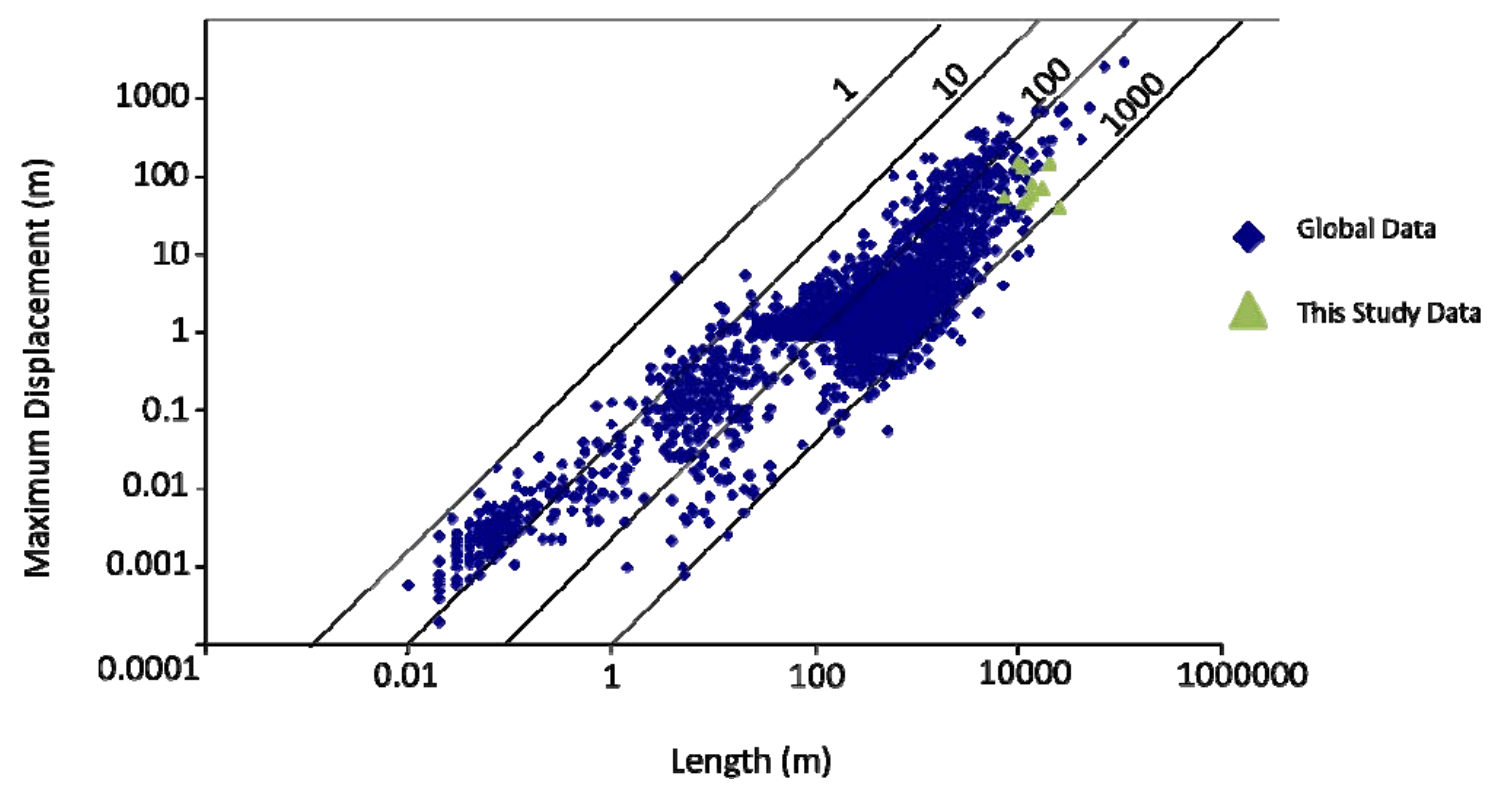

Figure 2.19 Plot of displacement to length ratio of Plio-Pleistocene faults in the study area (green triangles) against global data set (blue diamonds). Study area faults are at the high end of length for their displacement. Global data obtained from GNS Science Internal Faults Archive - for a list of individual data sources in the GNS Science Internal Faults Archive see Appendix I. 
Plio-Pleistocene normal fault segments between the N50 ( 3.6Ma) and P10 ( 65 Ma) seismic reflectors generally appear to have developed both strike length and dip length instantaneously on a geological time scale. Figure 2.20 shows, for example, that the tip locations for two of the fault tips remained approximately fixed for all of the PlioPleistocene horizons profiled. If the faults had gradually propagated it would be expected that the younger profiles would extend to greater lengths than the shorter profiles. In fact the opposite seems to be happening in the only case where tip migration has taken place. The right-hand tip of the fault profiled in Fig. 2.20a appears to have been decreasing in fault length through time. Tip retreat is most often observed on faults that are not active and may be part of the fault death process (e.g., Meyer et al., 2002).

The available data suggest that the faults attained their lengths rapidly (i.e. possibly within several hundred thousand years) as has been suggested for faults in the Timor Sea (Meyer et al., 2002) and analogue models (Schlagenhauf et al., 2008). Rapid fault-length growth is observed for both reactivated and newly formed normal faults in the Kupe Area. Therefore, rapid growth in fault dimensions does not require the existence of pre-existing structure to occur. The Kupe data support a growing body of evidence which suggests that such rapid growth in fault length is the norm rather than the exception (e.g., Meyer et al., 2002; Walsh et al., 2002; Childs et al., 2003; Schlagenhauf et al., 2008).
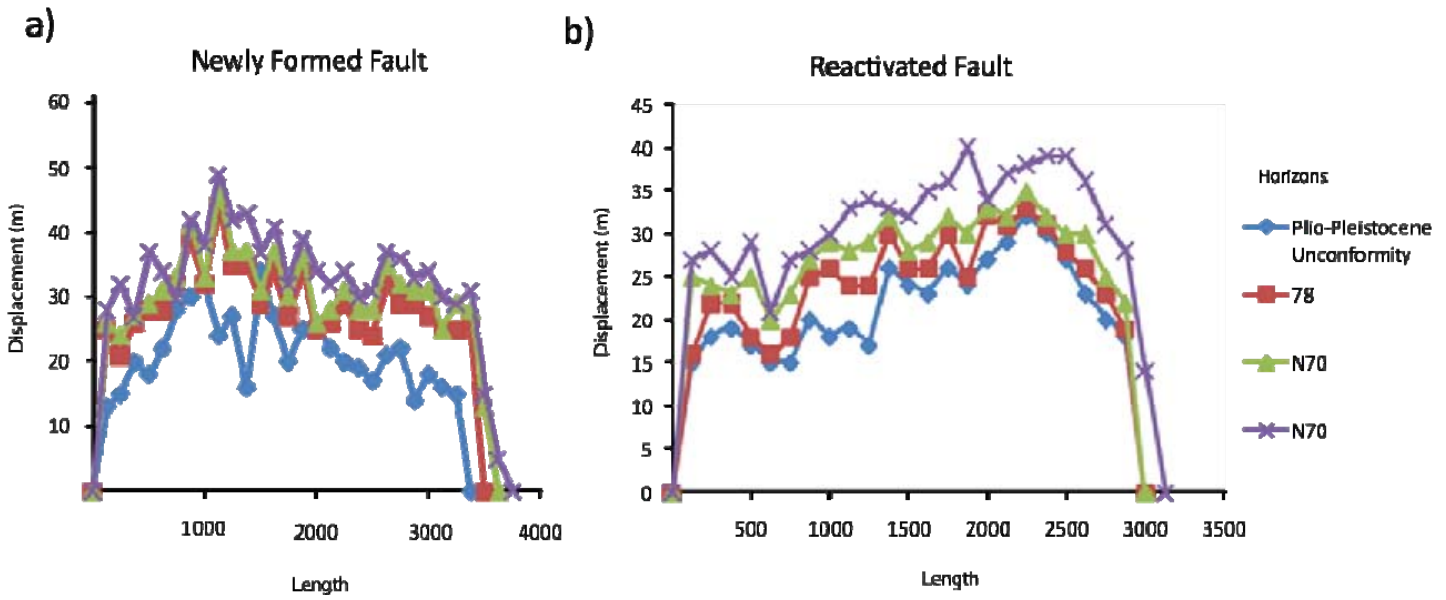

Figure 2.20 Tip-line profiles for newly formed (a) and reactivated (b) faults. Profiles show N70 (3.6 Ma) to N80 (1.6 Ma). 


\subsection{Discussion}

\subsubsection{Deformation History and Implications for Plate Boundary Formation}

Sedimentary strata in the Kupe Area provide a near complete record of deformation from the Late Cretaceous ( $\sim 5 \mathrm{Ma}$ ) through to Recent (Fig. 2.21). This structural development provides important information on the development of the Taranaki Basin and the evolution of the plate boundary through New Zealand. Results from this thesis suggest that pre-K80 ( $\sim 85 \mathrm{Ma}$ ) basement strata may record contraction in the form of folding and thrusts, resulting from subduction along the north-east Gondwana margin (Fig. 2.21). The K80 surface is an angular unconformity which in other studies has been inferred to have been produced by regional uplift and erosion (e.g. King and Thrasher, 1996). This regional uplift may record the final stages of subduction death. Independent of the origin of the unconformity, it is clear that subduction must predate the K80 horizon (i.e., 85 Ma) due to evidence presented in Section 2.3.2 of extensional tectonics after development of the K80 stratigraphic horizon. This thesis suggests that the Late Cretaceous-Paleocene extensional faulting in the Taranaki Basin occurred between 84-55 Ma and thus must have developed coeval with seafloor spreading between Australia, Antarctica and New Zealand (e.g. Sutherland et al., 2001b). Whether the rifting evidenced in this thesis within the Taranaki Basin represents a failed attempt to further break up Gondwana, or it records normal faults marginal to the main zones of crustal extension remains unclear. The interpreted onset of contraction in the Kupe Area presented in Section 2.3.3 (e.g., Fig. 2.13) marked another significant change in plate boundary configuration from Gondwana rifting and sea-floor spreading, to a convergent plate boundary north of the New Zealand and possibly along the Hikurangi Margin (Sutherland et al., 2001b). Other studies have suggested that contraction in the Taranaki Basin, including the Kupe Area, appears to have initiated no later than about 30 Ma (Fig. 2.21) (e.g., Holt and Stern, 1994; King and Thrasher, 1996 ; Nelson et al., 1994), and could have started as early as 40 Ma (Palmer and Andrews, 1993; Voggenrieter, 1991; Stagpoole and Nicol 2008). This thesis has shown in Section 2.3.3 that the rates of shortening in the Taranaki Basin prior to $30 \mathrm{Ma}$ appear to have been relatively low (e.g., Fig. 2.13). These low rates may signify that subduction proper did not commence until after $30 \mathrm{Ma}$, or that subduction rates were low, as would be inferred from 
the proximity of the Pacific-Australasian plate Euler Poles to New Zealand (e.g., Sutherland, 1995).

The main period of contraction in the Kupe Area (and South Taranaki Basin) as evidenced in the sedimentary thickness variations across faults in isopach maps and fault growth in throw profiles of Section 2.3.3 commenced in the early Miocene. Stern and Davey (1990) suggested that during the Miocene the Kupe Area experienced a significant increase in accommodation space and sedimentation rate associated with the development of a foreland Basin in the hanging-wall of the Taranaki fault. This thesis has shown through fault throw profiles that the rate of growth of most shortening structures increased by a factor of 10 or more at about $20 \mathrm{Ma}$. It also suggests that developing contraction related faults reactivated pre-existing structures, with inversion occurring on north-northeast Cretaceous extensional faults in the Kupe Area and possibly along older basement structures further south.

The interpreted onset of significant contraction in Section 2.3.3 approximately coincides in time with the onset of back-arc volcanism in the northern Taranaki, Auckland and Northland regions at 20-25 Ma (Ballance, 1976; King and Thrasher, 1996; Stern et al., 2006; Giba et al., 2010). The onset of back-arc volcanism can be used to place a latest time on the initiation of subduction on the east coast of New Zealand. Back-arc volcanoes in the Taranaki Basin and Auckland region have been dated to 20-25 Ma (Giba, 2010) and therefore the initiation of subduction must predate this time. Based on rates of plate motion, an inferred depth of $\sim 110 \mathrm{~km}$ of the subducting plate at 20-25 Ma (to satisfy the generation of back-arc volcanism) and the present Pacific Plate geometry, subduction must have initiated prior to 27 Ma and possibly before 30-35 Ma (H. Seebeck, pers com 2011). The interpreted increase in shortening during the Early Miocene on the Manaia, Motumate and Rua Faults in section 2.3.3 (e.g. Fig. 2.13) is therefore most likely related to the rapid southward migration of the Pacific-Australian Plates Euler Poles at this time (Cande and Stock, 2004).

The evidence presented in Section 2.3.4 of extensional fault growth in Plio-Pliestocene strata within the Kupe Area likely reflects the southward migration of back-arc rifting from the northern Taranaki Graben as suggested by Giba et al. (2010). The Kupe Area lies at the eastern margin of the South Taranaki Graben and based on the observations within this thesis appears to mark the southern limit of extension in the Taranaki Basin during the Plio- 
Pleistocene. King and Thrasher (1996) suggested that reverse faulting initiated in the Miocene within the Taranaki Basin and continued during the Plio-Pleistocene period in the Southern Inversion Zone (south of the Kupe area) and the across the northern South Island. They suggested the reverse faulting was likely related to vertical axis clockwise rotation of the North Island relative to the stable Western Platform generating contraction across the southern North Island and northern South Island. Further analysis of fault growth histories by Giba et al. (2010) suggested that this vertical axis of rotation has migrated southward from northern Taranaki to its current position south of the Kupe Area over the last 8-12 Ma. The low regional extension on normal faults in the Kupe Area observed in Section 2.3.4 (e.g. Fig 2.17) and the fault's low growth rates may indicate that the Kupe Area has been close to the southern limit of extension for the past $~ 3 \mathrm{Ma}$.

\subsubsection{Fault reactivation}

Structural fabrics developed during accretion of various terranes at the Gondwana Margin appear to have had a significant influence on the location of subsequent deformation configurations. Fault reactivation has influenced the successive locations and geometries of faults within the Kupe Area of the Taranaki Basin. This thesis has shown that pre-existing faults have provided localised zones of weakness which were exploited during subsequent deformation events, resulting in complex fault geometries. The locations and orientations of earlier formed faults influence whether they have been reactivated in later deformational events.

The miss-orientation between the strike of Late Cretaceous-Paleocene rift faults (northsouth) in the study area and concurrent strike of faults at mid-ocean ridges (north-westsoutheast) suggests that the north-south striking basement fabric developed during subduction on the margin of Gondwana may have influenced the orientations of Late Cretaceous-Paleocene faults in the Kupe Area. Bradshaw (1989) suggest that the area that subsequently became the Taranaki Basin was transected by a number of north-south striking dextral strike-slip faults in the early to mid Cretaceous. These faults or the inferred north-south striking Mesozoic terrane boundaries (e.g., Mortimer, 2004) could have provided zones of pre-existing weakness that subsequent Late Cretaceous-Paleocene faults reactivated. 


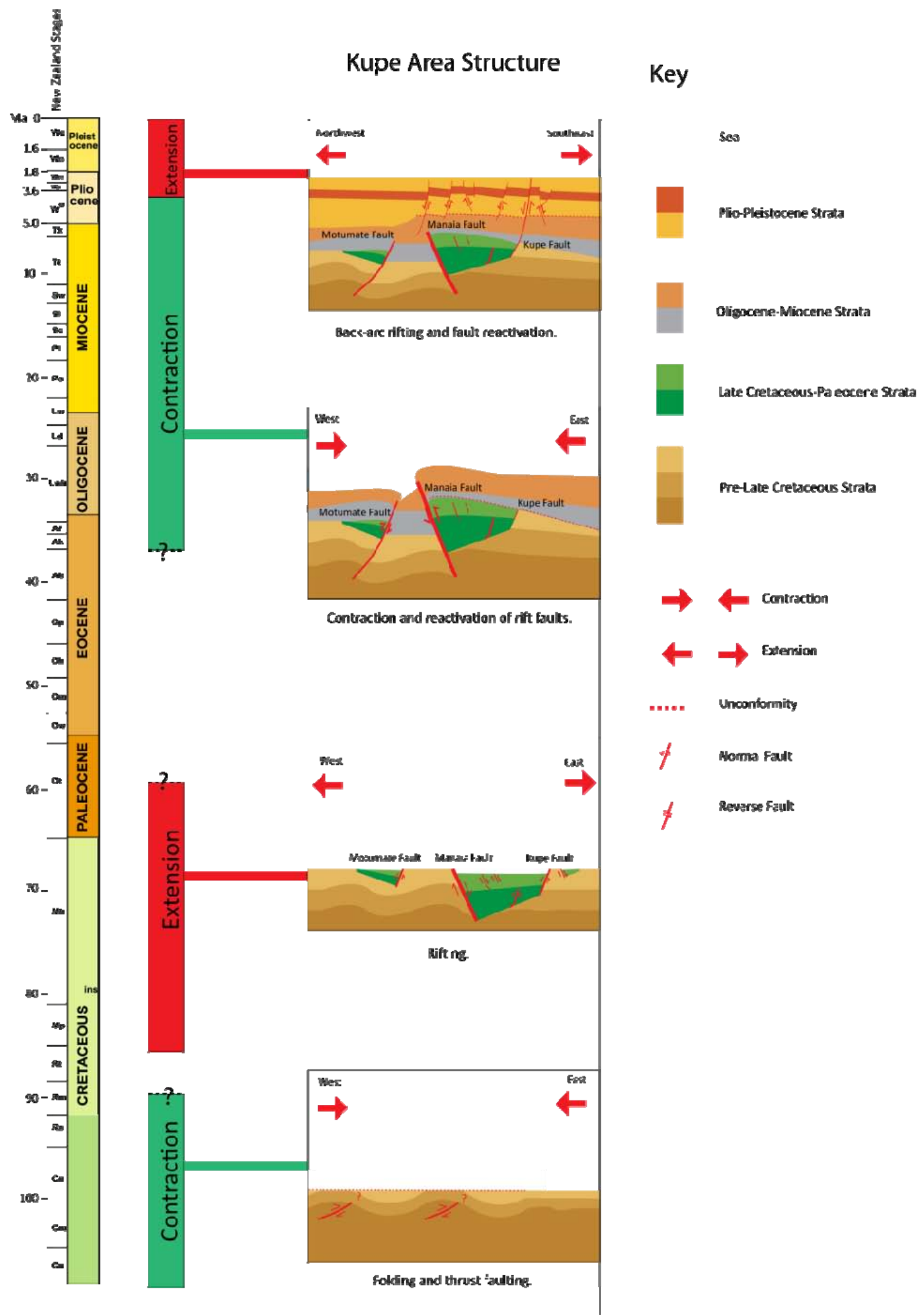

Figure 2.21 Kupe Area structural evolution diagram. Diagramatic cross sections through the Kupe Area show the progression of structural development. Red arrows indicate the direction of principle horizontal shortening or extension in the plane of the cross section. Time scale adapted from Roncaglia et al. (2010) 
Inversion of the Late Cretaceous-Paleocene extensional Manaia and Motumate Faults is shown in this thesis to have occurred during the Late Eocene to Miocene contraction. Shortening was evidenced on the two main north-south striking Late Cretaceous-Paleocene Faults (Manaia and Motumate), however, the Kupe fault which strikes north-east was not reactivated during this time period (e.g., Fig. 2.13). The strike lengths of the Manaia and Motumate Faults were shown in Section 2.3 .3 to have extended $100 \mathrm{~km}$ and $20 \mathrm{~km}$ respectively southward of their pre-existing Late Cretaceous structures towards the top of the South Island. The strike length extension of these faults may have exploited preexisting north-south striking discontinuities (e.g., faults and formation boundaries) in Mesozoic basement. The fact that the largest Late Cretaceous-Paleocene faults were reactivated during contraction suggests that fault size may be an important determinant for reactivation. This relationship may arise because larger displacement faults tend to form wider and weaker fault zones (compared to smaller faults) which are most likely to be reused in subsequent deformation. Fault orientation is also an important control for reactivation (e.g., Sibson, 1985). For example, the non-reactivation of the Kupe Fault during contraction may reflect the fact that its orientation was not favourable for reactivation during regional shortening.

This thesis suggests that locations and strike of Plio-Pleistocene extensional faults in the Taranaki back-arc rift have also been controlled by Late Cretaceous-Paleocene faults. Late Cretaceous-Paleocene faults aligned approximately parallel to the northeast trending principal horizontal shortening direction during the Plio-Pleistocene tend to have been reactivated (Chapter 2.3.4). These faults form single faults that bifucate upwards into segmented arrays containing multiple relay zones and splays within Miocene and PlioPleistocene strata (e.g., Fig. 2.16). Individual segments form parts of kinematically coherent systems where displacement is transferred from segment to segment. Reactivation also controls the down-dip extent of Plio-Pleistocene faults. Faults that reactivate Late Cretaceous-Paleocene faults have down-dip extents from Plio-Pleistocene strata to Late Cretaceous strata; faults that form independent of Late Cretaceous-Paleocene faults predominantly tip out down-dip in Miocene strata (e.g., Fig. 2.16). 


\subsection{Conclusions}

Sedimentary strata with the Kupe Area of the Taranaki Basin record four main periods of deformation that reflect changing plate boundary configurations from pre-Late Cretaceous through to Recent. Pre-Late Cretaceous strata show evidence of contraction and uplift, Late Cretaceous strata record $>3 \mathrm{~km}$ of east-west extension across the Kupe Area that initiated $\sim 85 \mathrm{Ma}$ and likely ceased no later than $\sim 55 \mathrm{Ma}$, east-west contraction and inversion of Cretaceous rift faults initiated at the latest by Early Oligocene ( $\sim 30 \mathrm{Ma})$, possibly by Late Eocene $~ 37-34 \mathrm{Ma}$, and ceased by $\sim 5$ Ma with $>5.5 \mathrm{~km}$ of shortening across the Kupe Area. A change to northwest-southeast extension occurred at 3.6 Ma and continues to present time, with $<1 \mathrm{~km}$ extension across the Kupe Area.

Reactivation of pre-existing faults has influenced the locations and orientations of successive faults over the last $\sim 85$ Ma within the Kupe Area. North-south structural grain inherited from the Gondwana Subduction Margin appears to have influenced the location and orientation of Late Cretaceous-Paleocene rifting in the Kupe Area. These north-south orientated rift faults were reactivated during Eocene to Miocene contraction as reverse faults. From the Pliocene to Recent, north-east orientated Late Cretaceous-Paleocene rift faults have been reactivated and control the orientation of shallow extensional faults. The Pliocene to Recent extensional faults are low strain, and likely reflect an immature fault system. The faults appear to have established their strike lengths rapidly, consistent with the ‘constant length' growth model (e.g., Walsh et al., 2002). 


\section{Chapter III}

\subsection{Relations Between Faults and Hydrocarbon Migration}

\subsection{Introduction}

The impact of faults on the flow of fluids and gas in the subsurface is increasingly recognised as being important for hydrocarbon exploration and production and $\mathrm{CO}_{2}$ storage (e.g., Streit and Hillis, 2004; Jolly et al., 2009). Faults have the ability to act as conduits and/or barriers to the flow of hydrocarbons. The potential for both vertical and lateral flow within fault zones can often vary spatially and temporally along individual faults (Knipe et al., 1998 and references therein,). Faults acting as barriers to subsurface lateral flow may trap migrating fluids and gas and form accumulations on geological time scales; they can also compartmentalise a reservoir impacting on hydrocarbon extraction on production time scales (e.g., Jolly et al., 2007 and references therein,). Conversely, faults can act as conduits for up-sequence fluid and gas flow (Fig. 3.1) providing pathways for hydrocarbon migration from source rocks to reservoir intervals (e.g., Losh et al., 2002). These conduits may also breach top seals and influence the ability of the fault-bound traps to retain hydrocarbon columns (e.g., Cartwright et al., 2007). While studies of the horizontal flow of fluids and gas across fault zones are well advanced (e.g., Yielding, et al., 1997; Manzocchi et al., 1999; James et al., 2004; Meyers et al., 2007; Manzocchi et al., 2008; Corona et al., 2010), there has been limited development in the understanding of up-dip hydrocarbon migration. The mechanisms that result in up-dip flow of hydrocarbons within fault zones have still not been conclusively established and there are a number of relatively untested models for predicting where up-dip hydrocarbon migration (or leakage) is most likely to occur (e.g., Ferrill et al., 1999; Kachi et al., 2004; Mildren et al., 2005).

Historically, the most significant impediment to studying the up-dip migration of hydrocarbons and its relationship to faulting has been the inability to identify fluid and gas migration pathways in the subsurface. Recent improvements in the quality, analysis and interpretation of seismic reflection data now enable fluid and gas, together with the structures produced by their migration, to be identified within sedimentary rocks and sediments. Pockmarks, mud volcanoes, carbonate mounds and physical disturbances within strata directly or indirectly caused by the passage of gas or fluids (e.g., disrupted 
layering, mounding strata, fracture networks and hydrocarbon-related diagenesis zones) are now commonly identified and correlated with faults, enabling the locations and geometries of up-sequence hydrocarbon flow to be investigated (e.g., Ligtenberg, 2003; Ligtenberg, 2005; Halliday et al., 2008; Loseth et al., 2009). In addition, direct seismic reflection imaging of gas within strata, in the form of gas chimneys, provides a means of inferring where migration pathways may be located in relation to fault zones (e.g., O’Brien and Woods, 1995; Cowley and O’Brien 2000; Ligtenberg, 2005; Schroot et al., 2005; Van Rensbergen et al., 2007; Halliday et al., 2008; Medialdea et al., 2008; Ilg et al., in prep). Manual and automated methods for mapping gas chimneys in high quality 3D seismic reflection lines have been developed and used for charge prediction and fault trap integrity investigations (e.g., Ligtenberg, 2003; Ligtenberg, 2005). These data provide a qualitative means of determining if hydrocarbon migration has occurred in the past or is presently active, and have also been used to infer the locations of zones of high structural permeability in, and adjacent to, fault zones.

The advent of high quality 3D seismic reflection data also permits fault geometries and displacements to be mapped in space and time (e.g., Nicol et al., 1995; Meyer et al., 2002; Childs et al., 2003; Nicol et al., 2005; Walsh et al., 2002; Walsh et al., 2003; Gatrell et al., 2006). These seismic reflection data indicate that fault displacement gradients are typically highest at relay zones and fault intersections (Walsh and Watterson, 1989; Childs et al., 1995; Walsh et al., 1999), where high densities of fractures are observed in outcrop (e.g., Childs et al., 1996; Davatzes and Aydin, 2003; Fossen, et al., 2005; Eichhubl et al., 2009). Such zones of fracturing are expected to locally promote fluid and gas flows (e.g., Eichhubl and Boles, 2000) (Fig. 3.1), however, this inference is rarely tested.

In this chapter, high quality 3D seismic reflection data from the Kupe Area of the South Taranaki Basin are used to test relations between fault-zone structure and gas chimney locations, with three primary topics examined. The first topic considers whether the spatial distribution of gas chimneys and migration is related to, or influenced by the locations of Pliocene to Recent normal faults. The second topic investigates the important features of the spatial relationship between gas chimneys and faults. The third topic explores whether gas chimneys are preferentially located at sites on faults where high densities of fractures are predicted to occur (e.g., fault tips, relay zones, fault intersections and fault bends). 
Addressing these topics may provide a basis for determining whether fault zone structure and associated changes in displacement can be used to predict sites on faults of up-dip fluid and/or gas flow. These predictions may have application for both hydrocarbon exploration and for locating $\mathrm{CO}_{2}$ storage sites.

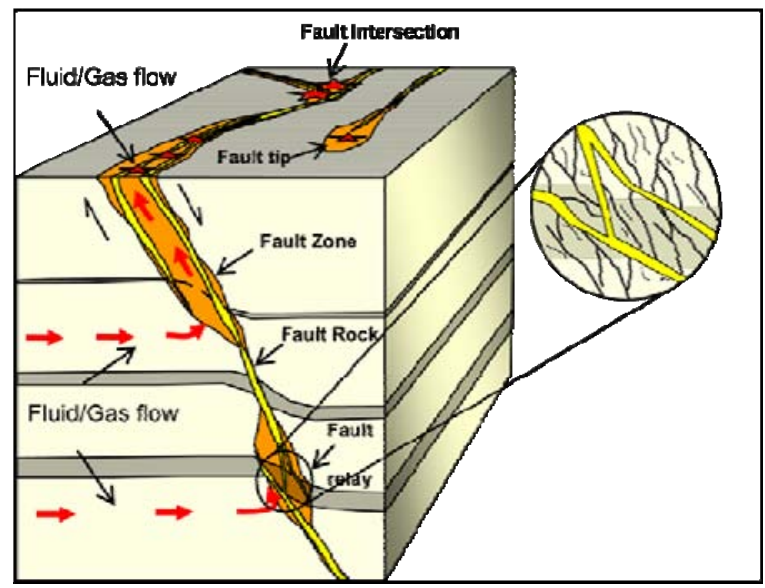

Figure 3.1 Schematic block diagram showing fault zone architecture and potential fluid and gas flow paths through open fractures within fault zones. Densities of conductive fractures are highest at a number of sites within fault zones including fault relay zones, fault intersections and fault tips. Insert shows high densities of fractures (black lines) proximal to fault-rock (yellow polygons) in a breached relay zone. Figure adapter from Nicol (pers. comm., 2011).

\subsection{Methods}

\subsubsection{Chimney Identification}

Fluid and gas migration pathways in marine sedimentary basins are typically identified using three types of data:

i) Variations and anomalies within subsurface seismic reflection signatures such as local loss of reflector coherency, bright spots and phase reversals (Brown, 1999);

ii) seabed morphological features such as pockmarks and mud volcanoes (Gay et al., 2006); and

iii) acoustic or chemical evidence from the water column (Judd and Hovland 1992).

This study focuses on the types of data set out in points (i) and (ii), derived from seismic reflection lines. 
Variations in the seismic response of strata arise due to changes in bulk rock properties, and these changes may reflect modifications in strata's gas or fluid content, diagenesis, biologic activity within sediments and/or mechanical alterations. The presence of gas in pores of water wet strata can cause marked contrasts in acoustic impedance across subsurface interfaces, and may result in increased reflector amplitude (Brown, 2004). Although there are a variety of sedimentological and fluid scenarios that can cause a similar response, a large increase in acoustic impedance is commonly attributed to gas or oil saturated low impedance sands sitting in a higher impedance unit such as shale, (Brown, 2004). The presence of gas in water wet systems can also result in compressional wave attenuation, decreased reflector strength and frequency and a reduction in compressional wave velocity (White, 1975; Anderson and Hampton, 1980). Localised variations in seismic velocity through gas chimneys are often manifested as reflector pulldowns (i.e. increased travel time) within gas filled sediments or strata (Schroot and Schuttenhelm, 2003), or reflector pull-ups (i.e. decreased travel time) in areas where diagenic alteration or carbonate formation has occurred (O’Brien and Woods, 1995; Halliday et al., 2008). Variations in interval velocity can also be diagnostic of gas, gas hydrate or carbonate accumulations (Sultan et al., 2007). Low reflector continuity in shallow sediments is often attributed to disturbance or alteration of sediments by mobile pressurised gas and fluids. Sediments with a lack of horizontal layering can cause refraction of seismic energy and therefore, a degradation of the seismic signal (e.g., O’Brien and Woods, 1995; Van Rensbergen et al., 2007).

Sea-bed morphological features (e.g., mud volcanoes or pockmarks) can be diagnostic of gas and fluid migration to the sea bed from deeper (e.g., > $2 \mathrm{~km}$ ) thermogenic sources (Judd and Hovland, 1992; Heggland, 1998). Mud volcanoes can occur over areas where high gas flux from biogenic and thermogenic free gas or from gas hydrates mobilises unconsolidated sediments (Rad et al., 2000; Loseth et al., 2009 and references therein). Pockmarks are often found over sea-floor vent sites indicating subsurface flux of fluids and gas (Judd and Hovland, 1992; Berndt, 2005 and references therein; Chand and Munshall, 2009). These morphological features can often be visually correlated with deeper gas chimneys and provide an independent means of testing the gas chimney model (Loseth et al., 2009 and references therein). Sea-floor mud volcanoes and pockmarks are also important as they suggest active fluid and gas migration. 
To identify potential chimneys manual seismic mapping, together with single and multiseismic attributes, were applied to the recently reprocessed Kerry 3D seismic reflection volume to 4.5 seconds TWTT, to 2D seismic reflection surveys to $\sim 4.5$ seconds TWTT and to high frequency shallow seismic data to 1.8 seconds TWTT. Coherency, RMS amplitude, instantaneous frequency and neural network based multi-attributes were used to further identify chimney zones missed during manual interpretation. Attributes were also applied to extract volumetric representations of shallow gas charged sediments (geobody extraction).

As robust chimney identification is critical to establishing the relationship between hydrocarbon migration and faulting, care has been taken in the detailed interpretation of each individual seismic anomaly inferred to represent the presence of gas. Chimneys can have a similar seismic reflection appearance to processing artefacts or sub-seismic deformation and therefore a set of criteria based on published literature and previous work by Ilg et al. 2010 have been used to identify chimneys. These criteria are listed below.

Seismic anomalies had to meet all of the following seismic reflection criteria to be considered a chimney structure (as opposed to noise or deformation):

- Must be visible across a minimum of 5 lines in the 3D seismic reflection data (12.5m line spacing);

- No surrounding zones of similar reflector character that form a linear pattern i.e. acquisition footprints or processing artefacts;

- If the anomaly is spatially related to a fault zone there must be further evidence in the seismic reflection data of the anomaly away from the main fault zone;

- Seismic anomaly correlates with sea floor morphological features, including; (a) pockmarks, (b) mounding, (c) convex or concave seabed reflector; and

- Anomalous seismic reflectors over at least 100ms TWTT including; (a) chaotic, (b) bright spots, (c) flat spots, (d) low amplitude zones, (e) low frequency, (f) disturbed /incoherent, (g) phase reversal, (h) tubular or conical shaped disturbance in reflectors, (i) enlarged misshaped reflectors, (j) velocity pull up or push down, (k) must have vertical presence of $100 \mathrm{~ms}$ or more. 


\subsubsection{Chimney Mapping}

\subsubsection{Manual Seismic Mapping}

Manual seismic mapping of chimneys was undertaken using a workflow similar to that of Loseth et al. (2009). Individual anomalies were identified, mapped in three dimensions and then described. Each anomaly was divided into a root zone (the lowest visible section of the chimney), leakage zone (the main chimney body) and top zone (the highest visible occurrence of the chimney). These subdivisions assisted in identifying how, where and when migration was occurring.

Potential chimneys were first identified based on shallow time slices from the Kerry 3D seismic data volume (<1000 ms TWTT), with amplitude, coherency and instantaneous frequency attribute volumes used. Areas of likely gas expulsion appeared as high amplitude or incoherent zones on time slices (e.g., Fig. 3.3 and Fig. 3.8). Once locations of potential chimneys had been picked on time slices, they were further investigated on inline and cross lines throughout the 3D volume. Chimney body outlines were interpreted on every second inline and crossline (i.e. $25 \mathrm{~m}$ spacing) and where clearly visible on time slices. Care was taken to map the root zones of the chimneys and to establish their spatial relationships with faults. It is suggested that the chimneys within the Kupe Area are due to either current migration of gas or previous episodes of gas flow, with causal mechanisms of reflector disturbance within the mapped chimneys likely to be as varied as their recorded characteristics (see Loseth et al., 2009).

\subsubsection{Multi-Attribute Chimney Definition}

Manual interpretation of gas chimneys was augmented by a semi-automated seismic attribute analysis. This semi-automated approach has been used to test the manual interpretation and as a means of defining the 3D geometries of chimney bodies. The method makes use of supervised artificial neural networks. A neural network is trained to differentiate attributes that identify chimneys and non-chimneys within seismic reflection volumes (OpendTect 4.0 Manual, 2009). Chimneys identified during the manual mapping process were selected at a number of locations, and a pick-set was generated that represented the spectrum of reflector characteristics seen across all the identified chimneys. 
Approximately 1130 picks were selected to represent chimneys and 770 picks were selected to represent non-chimneys. Pre-determined attributes that differentiate chimneys from nonchimneys (see Chimney Cube ${ }^{\mathrm{TM}}$ attribute set, OpendTect Manual V4, 2010) were extracted at each pick location and the network trained to identify the important seismic reflection characteristics of each set. A test set of $30 \%$ of picks was excluded from the neural network training, and used to test the network's ability to pick chimney or non-chimney locations. The network was allowed to train until the number of miss-picked locations and the miss-pick RMS reached a plateau at 5.7\%.

The chimney probability attribute analysis within the Kerry 3D seismic reflection volume located most manually picked chimneys (approximately 80\%). However, the method does not permit the precise shape of chimneys, with numerous locations within chimneys were assigned a low chimney probability (e.g., Fig. 3.2). In addition, entire stratigraphic sections in the Miocene and Pliocene sequences contained no observed gas chimneys or gas yet they displayed high chimney probabilities. Similarly, across the Otararoa Formation areas of deformation that have a comparable seismic reflection signature to chimneys in shallower sections ( $<2$ seconds TWTT) and were assigned a high chimney probability. In some cases, entire fault zones were picked as high chimney probability locations even in locations where there was no evidence of gas chimneys. Collectively fault zones and the two stratigraphic intervals account for all the miss-picks using probability seismic attribute analysis. Incorrect gas chimney picks (i.e. locations where gas chimneys were determined not to be present during manual seismic mapping but with high chimney probability) identified using seismic attribute analyses have been removed from the data set. 


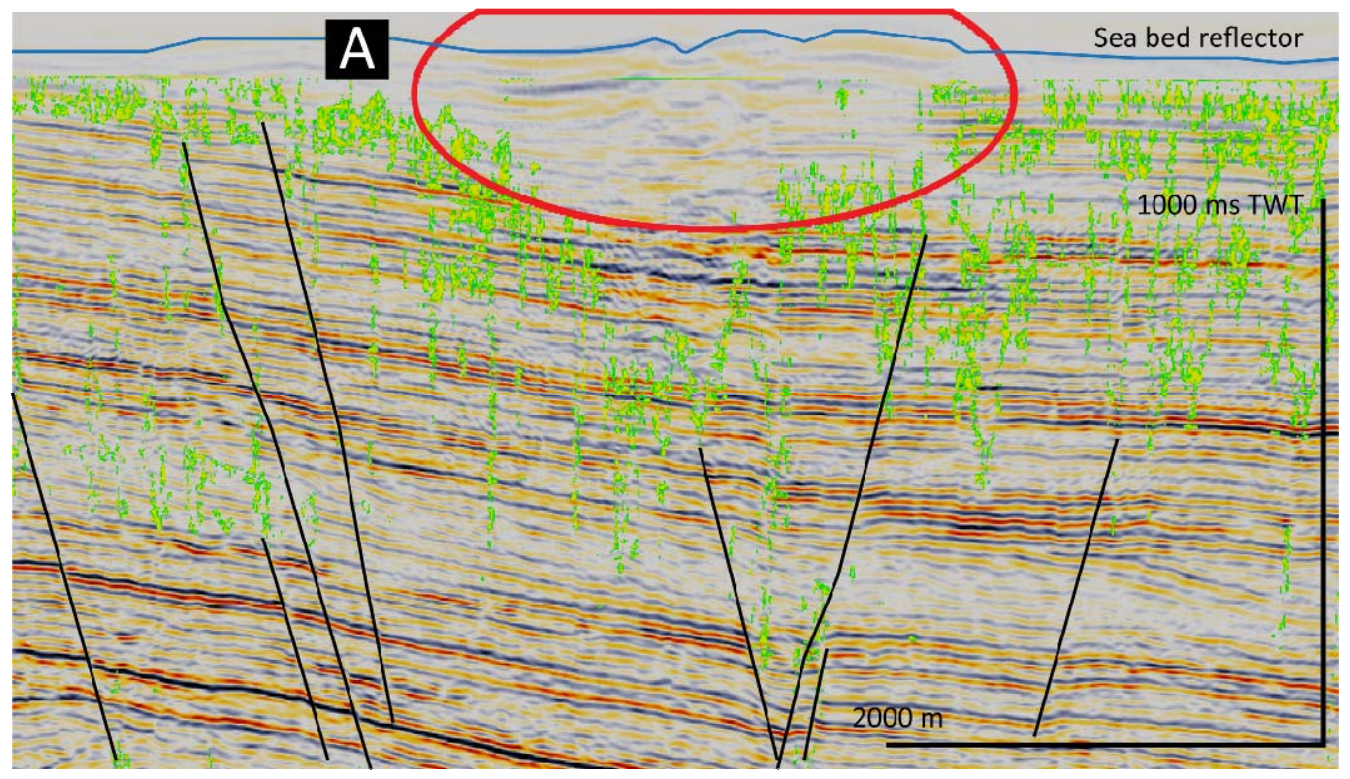

Figure 3.2 Chimney A showing Chimney Cube probability displayed over seismic data from Kerry 3D (green-yellow is high probability with lower probability values transparent). Location of section is shown in Figure 3.3b. General outline of the chimney inside the red oval has been picked using the criteria outlined on Page 53 and shows low chimney probability.

\subsection{Gas Chimney Geometries and Seismic Character}

Manual seismic mapping resulted in the identification of 17 anomalies interpreted to be chimneys formed through hydrocarbon migration (Fig. 3.3a). Significant variation was found in the size, shape, and up-sequence seismic reflector patterns of the chimney population, and can be used to categorise individual chimneys. Figure 3.3a shows the maximum outlines of chimneys and each chimney has a yellow circle that shows the precise location of the chimney's root zone. The root zone's are necessarily located at the 1200 ms TWTT depth of the time slice and are only projected onto the time slice for easier viewing. Figure 3.3b provides a base-map showing the locations and orientations of chimneys and faults in Figures 3.2 - 3.9. 


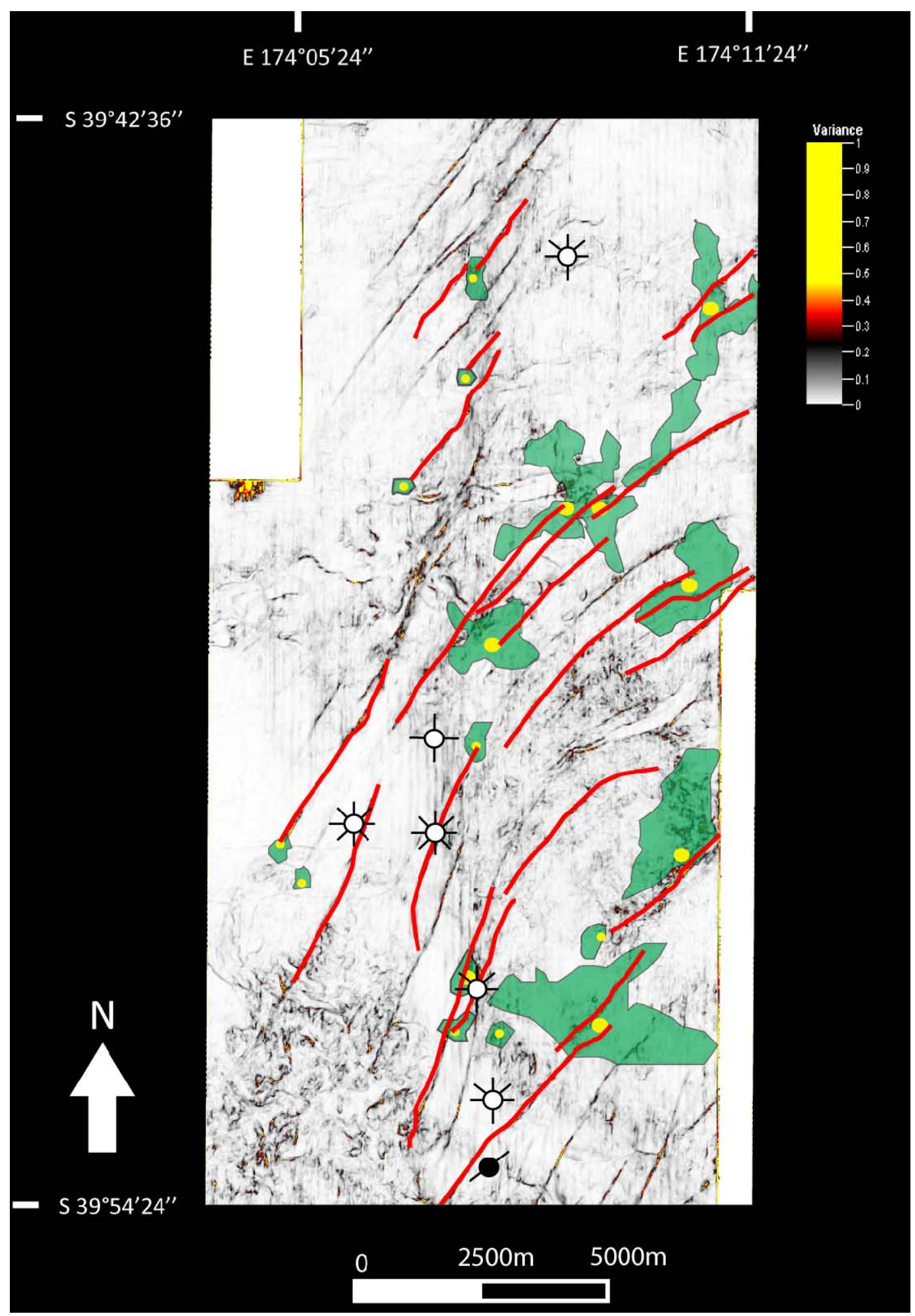

Figure 3.3(a) Kerry 3D 1200 ms variance slice. North-east striking normal faults are highlighted by high variance. The green outlines are maximum chimney widths and yellow circles are the horizontal locations of the chimney root zones; red highlighted faults have spatially associated chimneys. Locations of wells are shown in Fig. 1.3, Chapter 1. Location of seismic volume is shown in pink in Figure 1.3, Chapter 1. 


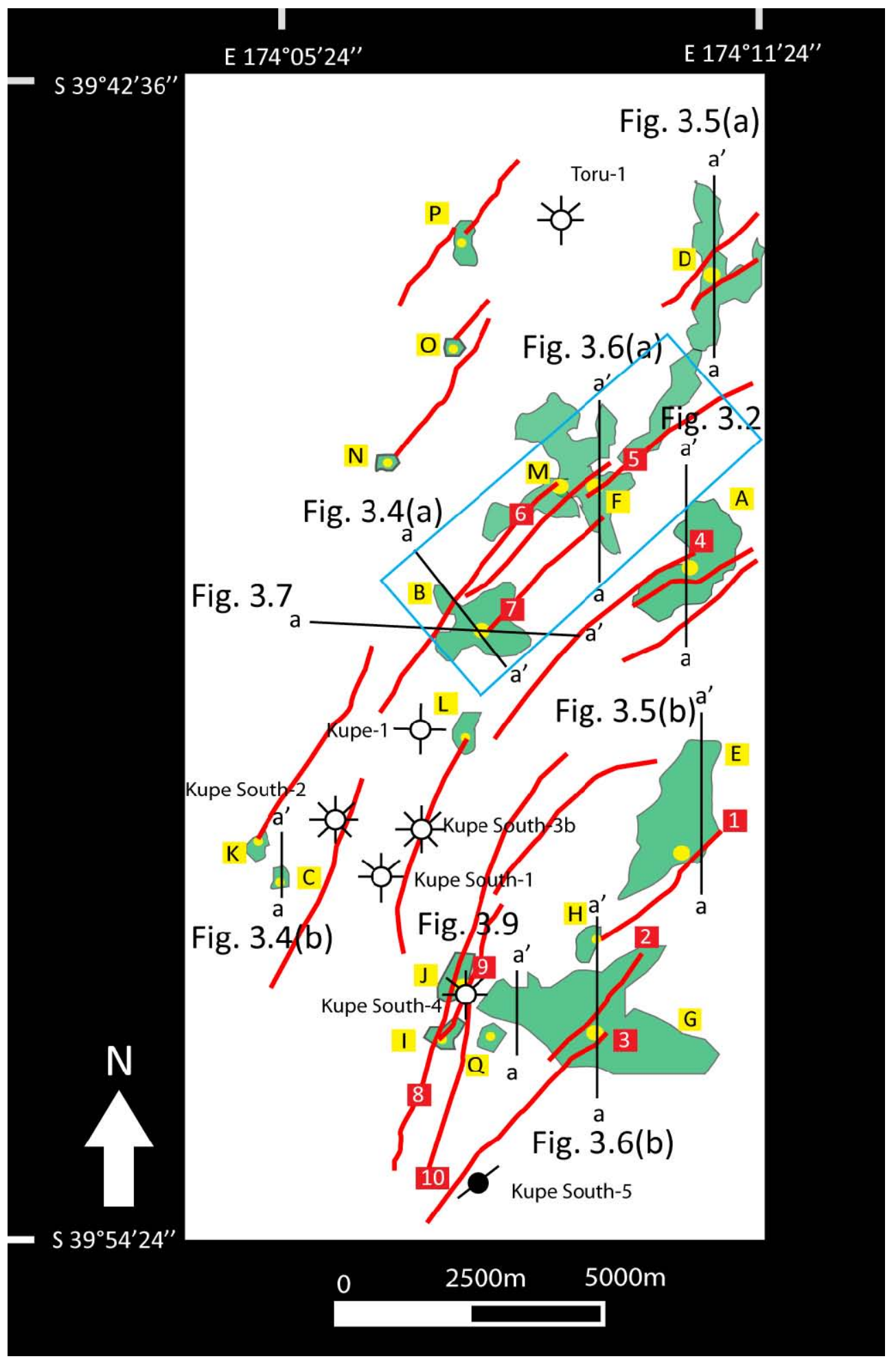

Figure 3.3(b) Chimneys and faults from Figure 6a labelled. Chimneys are labelled A to Q inside yellow boxes with the same letters used on all following figures showing chimneys. Faults 1-10 with throw profiles in Figure 3.10 are labelled inside red boxes. Seismic reflection sections in Figures 3.4-3.9 are shown. The blue rectangle shows the location of Figure 3.12. Locations of wells are shown in Fig. 1.3, Chapter 1. Location of seismic volume is shown in pink in Figure 1.3, Chapter 1. 
Chimneys vary significantly in map-view geometry and dimensions throughout the 3D seismic reflection volume and vertically along individual chimneys. They are typically vertically elongated and have root zones from several hundred milliseconds TWTT (300$400 \mathrm{~m}$ ) down to $2000 \mathrm{~ms}$ TWTT (approximately $3000 \mathrm{~m}$ ). In map-view, chimney widths range from $3000 \mathrm{~m}$ down to $100-200 \mathrm{~m}$ (Fig. 3.3). Two distinct chimney populations are evident based on the depth to root zone and map-view width. Chimneys with deep root zones (2000 ms TWTT) tend to have larger widths (> 1 km) (e.g., Fig. 3.4a), while chimneys with shallow root zones (200-300 ms TWTT) exhibit limited map-view widths (< $1 \mathrm{~km}$ ) (e.g., Fig 3.4b). Generally, chimneys conform to an approximately conical structure with upward increasing diameter. In detail, however, the 3D shape of chimneys can be highly irregular, varying from single bodies that bifurcate upwards into a series of smaller chimneys (e.g., Fig. 3.5a), to individual root zones and pipes that merge upwards into a single large body within 500 ms of the sea-floor (e.g., Fig. 3.5b). A number of chimneys contain zones of strata-bound disturbances that spread out up to $5000 \mathrm{~m}$ from the main chimney body (e.g., Fig. 3.6a). Lateral migration of gas within strata-bound units can also be observed in shallow ( $<200$ ms TWTT) Plio-Pleistocene sections, where gas charges submarine paleo-channel complexes (e.g., Fig. 3.7 and Fig. 3.8). These gas charged channels spread out from the numerous chimney intersections and form extensive sinuous high amplitude zones. 


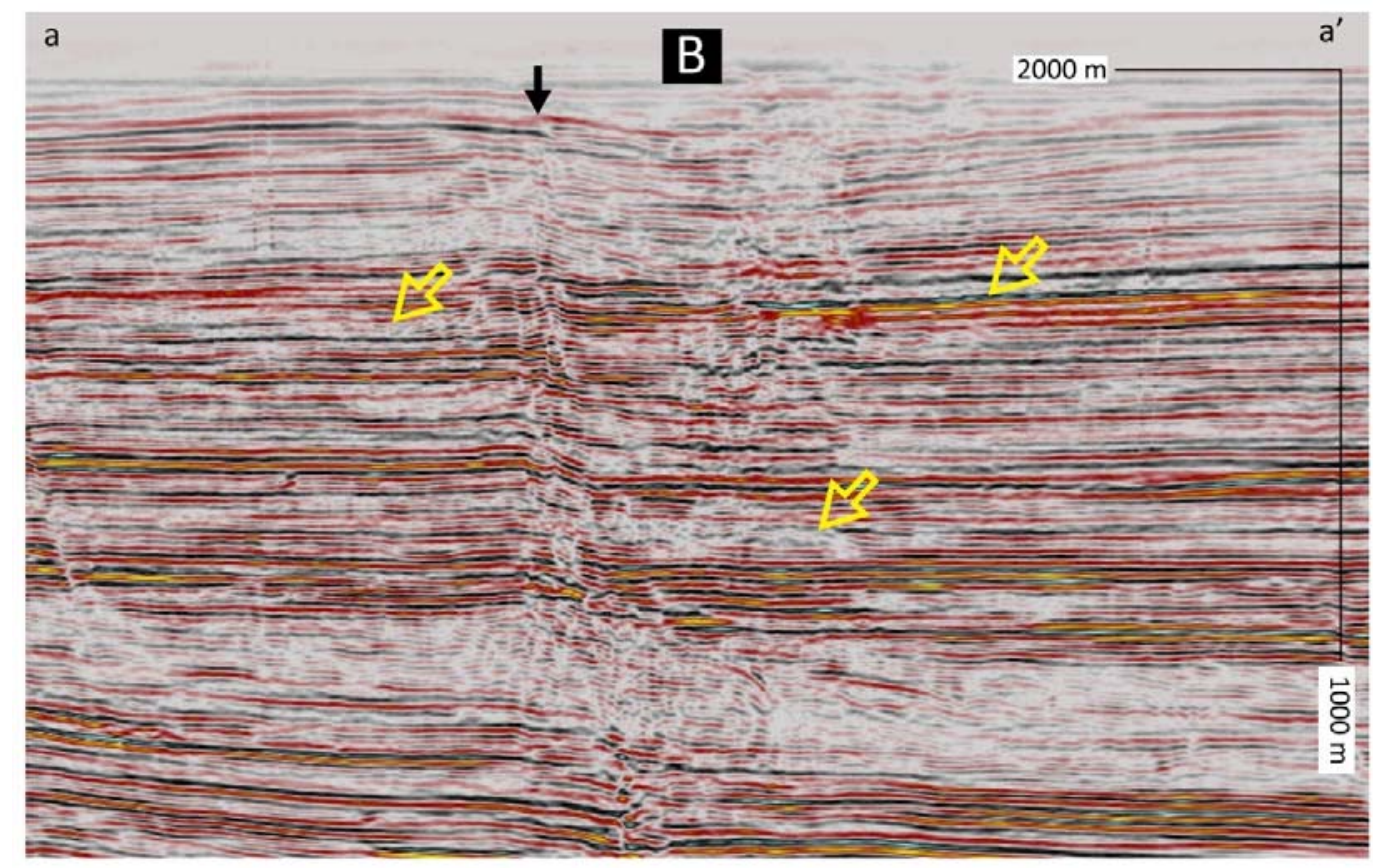

Figure 3.4(a) Larger fault-related chimney (fault indicated by black filled arrow). Note high amplitude packages and disrupted packages (highlighted by yellow unfilled arrows) in the lower chimney that move into surrounding strata. The location of seismic reflection section is shown in Figure 3.3(b).

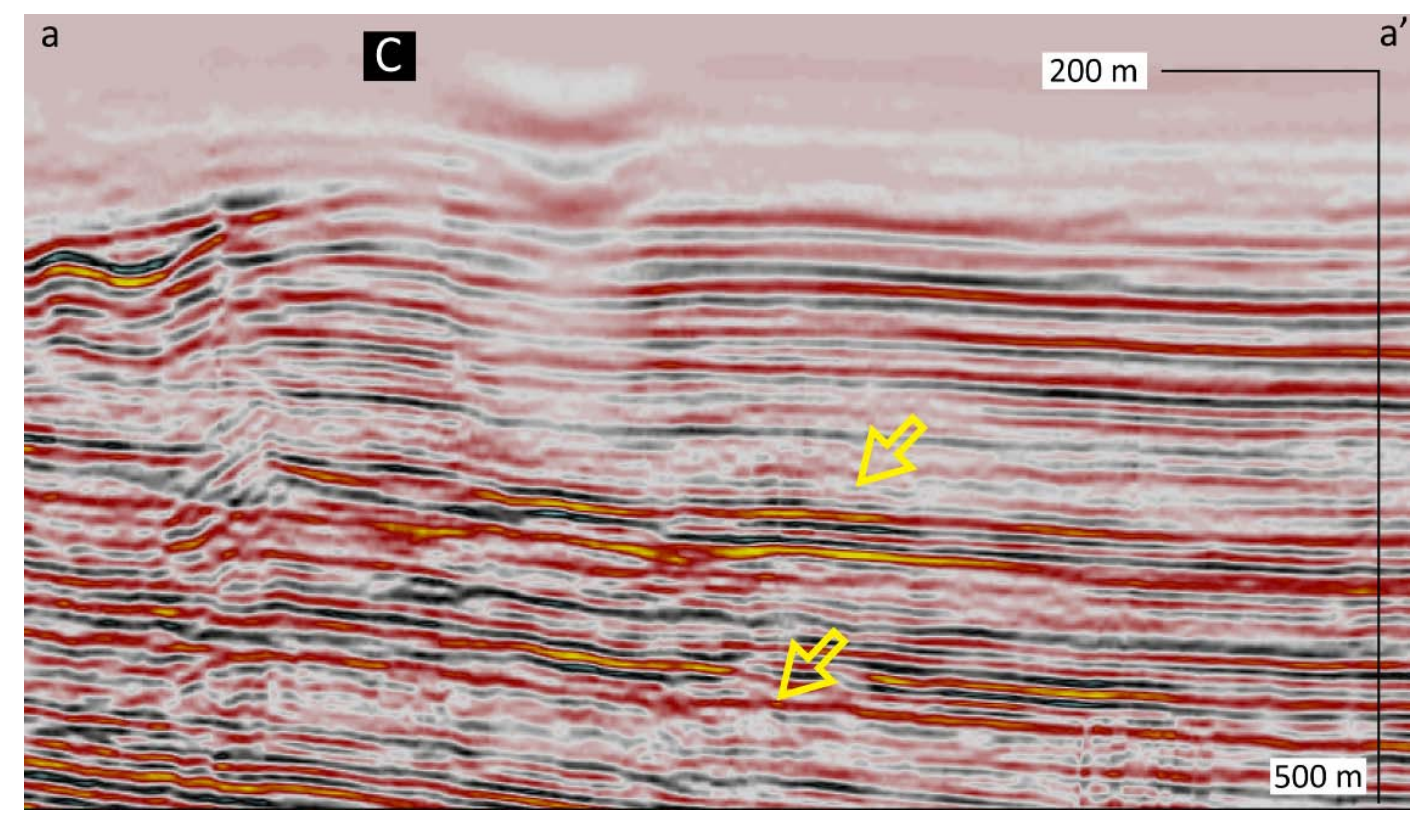

Figure 3.4(b) Small shallow chimney. Note disrupted reflectors indicated by yellow unfilled arrows in strata below chimney. The location of seismic reflection section is shown in Figure 3.3(b). 


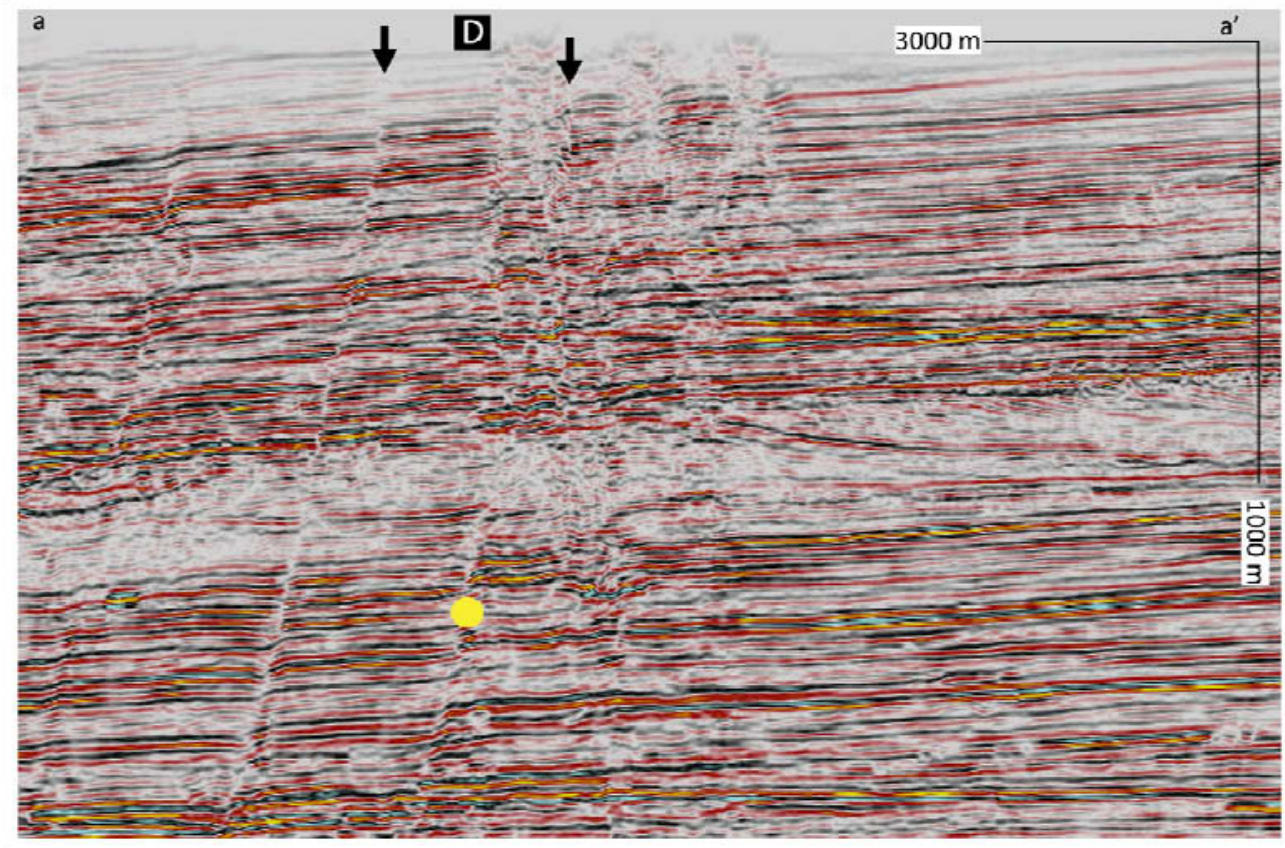

Chimney 3.5(a) Three shallow pipe-like chimneys bifurcate from one root zone located out of the plane of the section (the depth of root zone is shown by yellow circle). The root zone is related to the faults highlighted by black filled arrows. The location of seismic reflection section is shown in Figure 3.3(b).

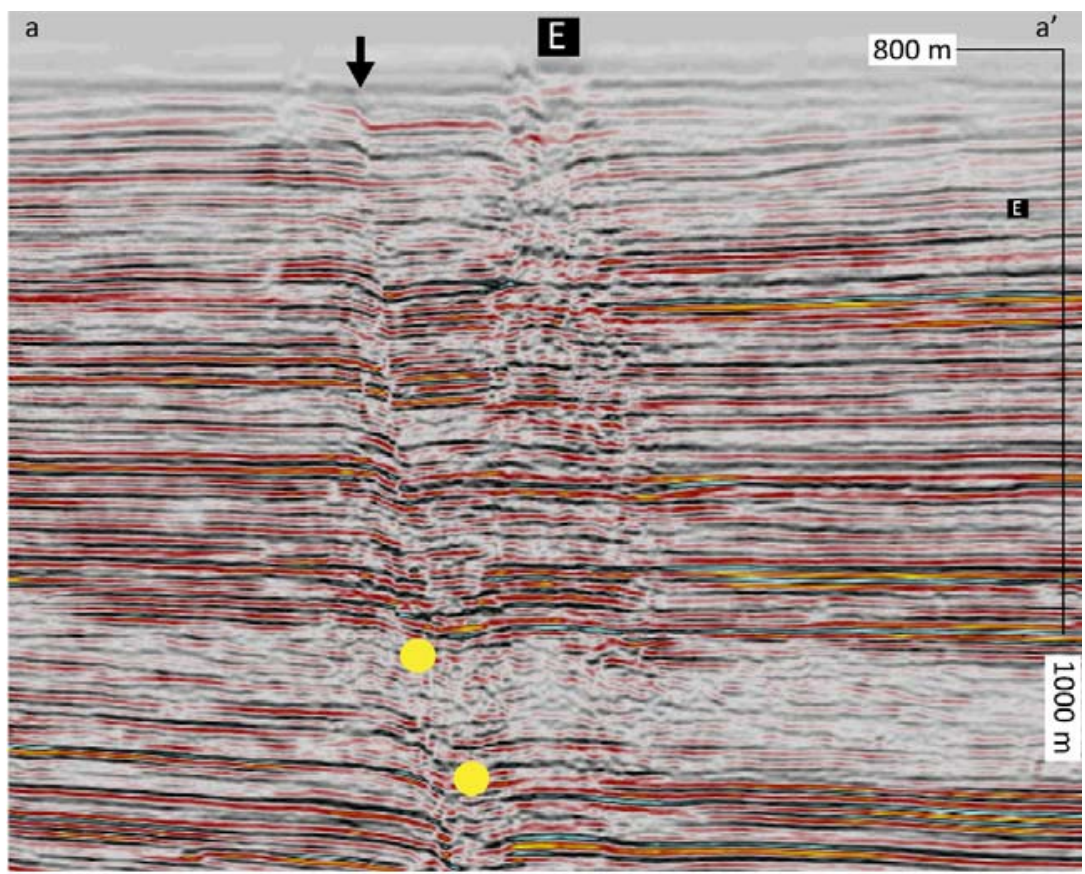

Figure 3.5(b) Chimney with chaotic internal structure. Two root zones located out of plane (depths indicated by yellow filled circles) join into one chimney in the shallow strata. The chimney is related to the fault highlighted by the black filled arrow. The location of seismic reflection section is shown in Figure 3.3(b). 


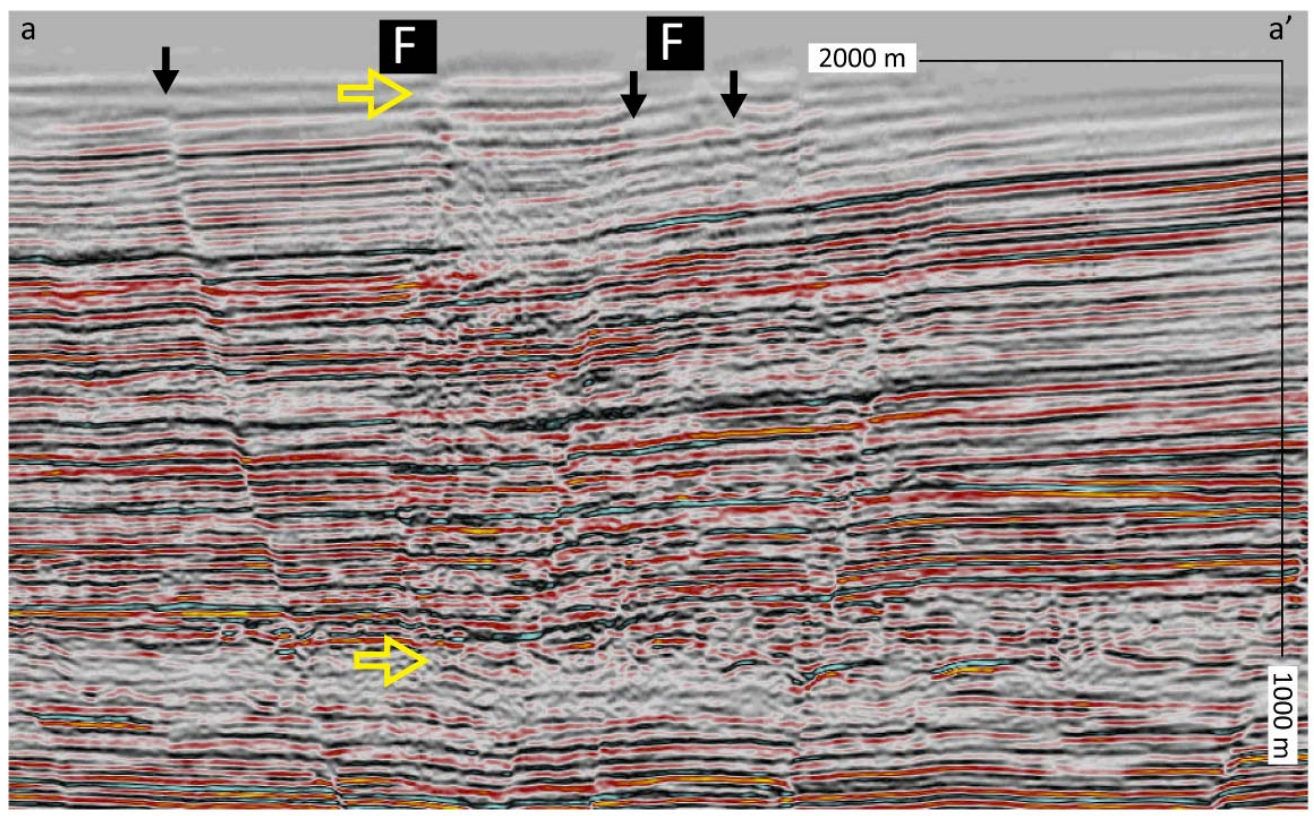

Figure 3.6(a) Main body of Chimney F on left and smaller section of Chimney F on right. Chimney $\mathrm{F}$ reflectors vary from incoherent zones in the base of the chimney (bottom unfilled yellow arrow) to lower frequency coherent reflectors towards the top of the chimney (top unfilled yellow arrow). The location of seismic reflection section is shown in Figure 3.3(b).

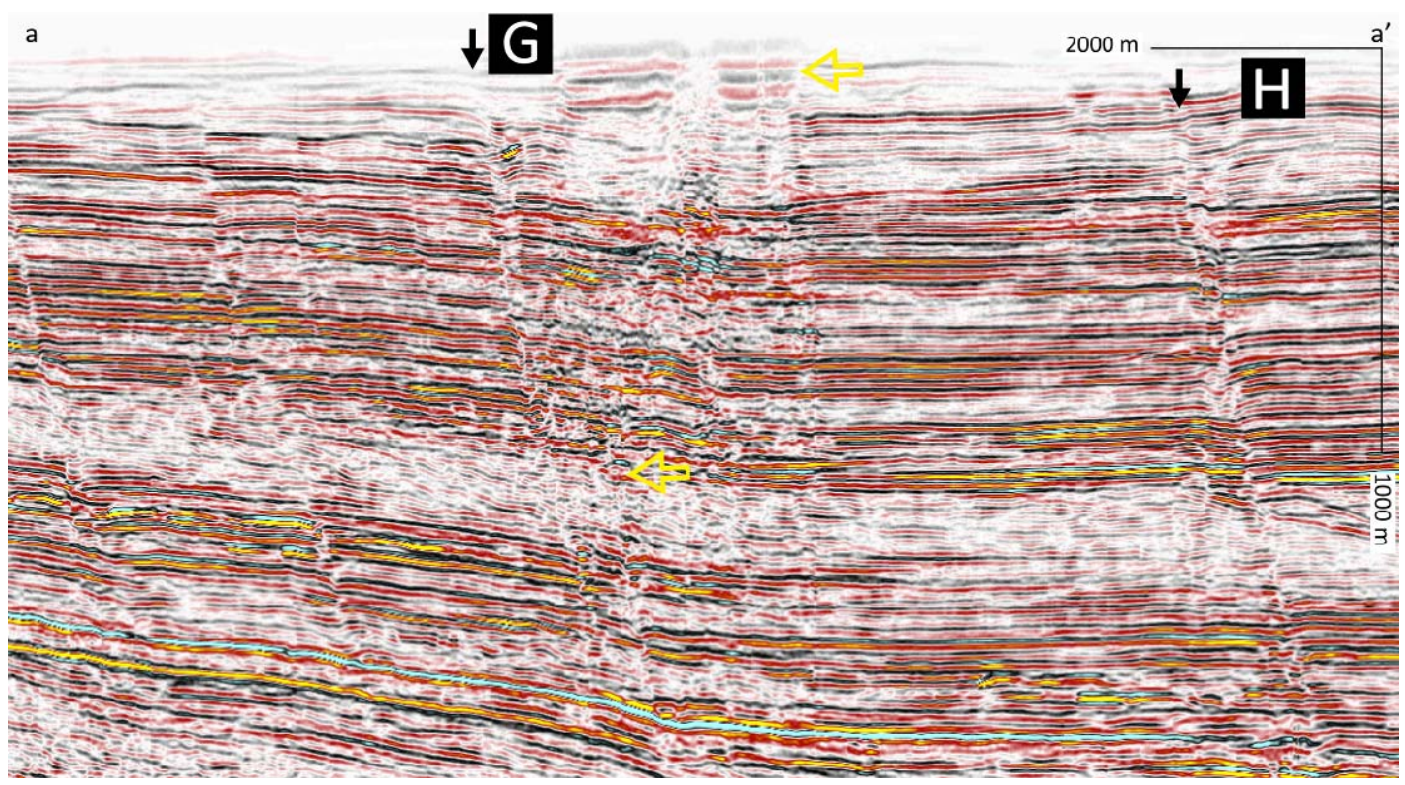

Figure 3.6(b) Chimney $G$ that bifurcates into two shallow conical chimneys with low frequency coherent reflectors in shallow sections (top yellow arrow). Chimney $\mathrm{G}$ emanates from incoherent high amplitude zone (bottom yellow arrow) coming out of fault (black filled arrow). Note the variations in reflector character with increasing depth (yellow arrows) on Chimney G. Chimney H, a smaller fault-related chimney, is shown on the right of the section. The location of seismic reflection section is shown in Figure 3.3(b). 


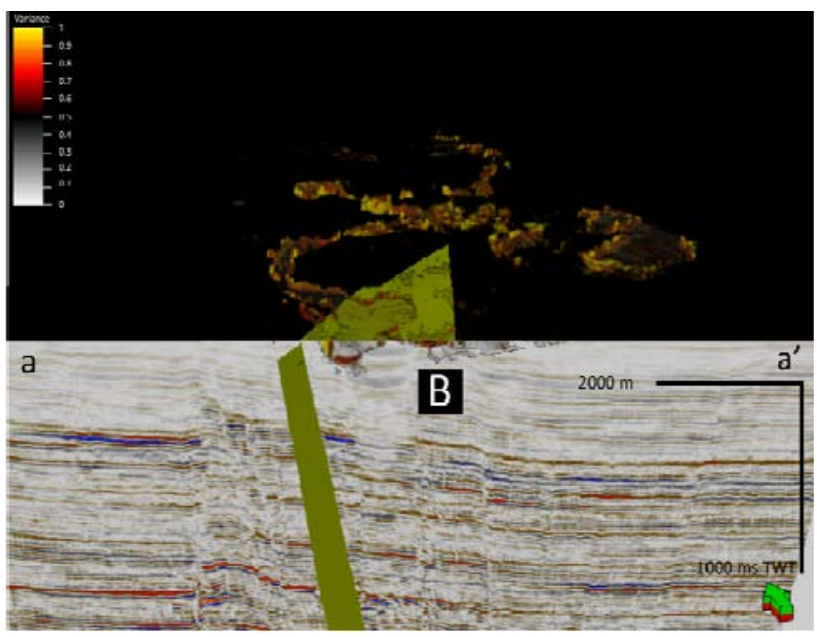

Figure 3.7 Geobody imaging of gas-filled channel charged from fault-related Chimney B. Location of the seismic reflection section is shown in Figure 3.3(b).

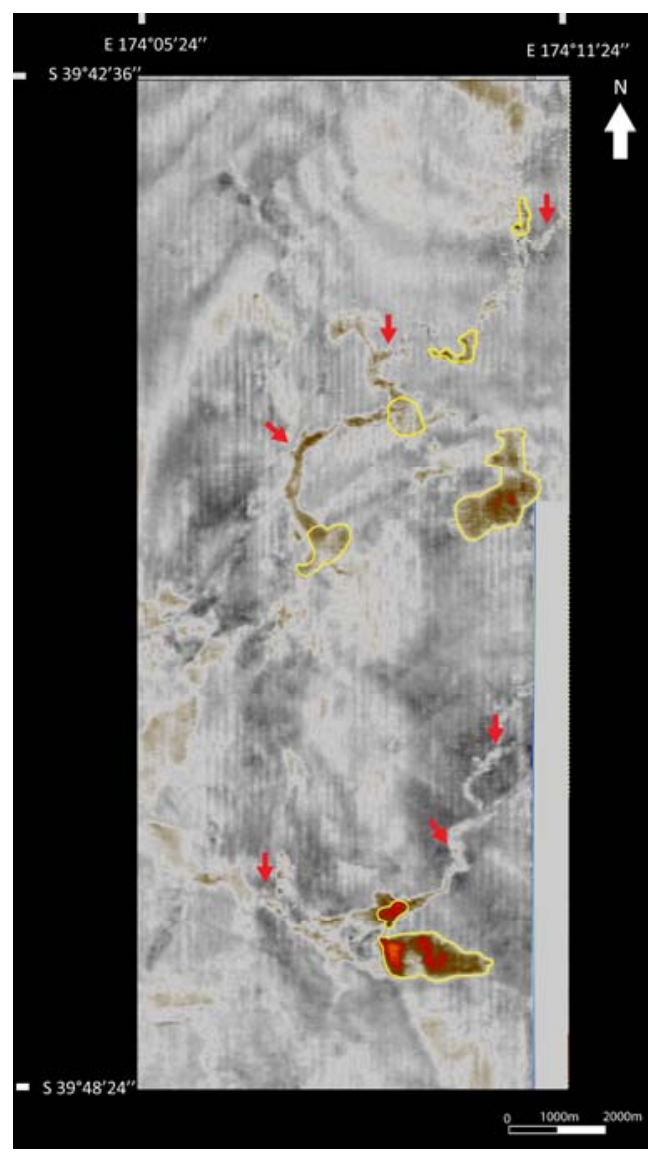

Figure 3.8 150 ms TWTT slice through Kerry 3D seismic reflection volume. Shallow gas-charged channels with elevated amplitudes have been imaged in the slice (indicated by red arrows). The channels are charged by several chimney structures which are outlined in yellow. The location of the Kerry 3D seismic reflection volume is shown by the pink outline in Figure 1.3, Chapter 1. 
Individual chimneys exhibit a range of seismic characteristics over a range of stratigraphic levels. The root zone of chimneys tend to exhibit chaotic, low amplitude reflectors, however at the edges of these deeper root zones discrete individual packages of high amplitude reflectors are often present (e.g., Figs. 3.4a and 3.6b). These high amplitude reflectors spread out laterally from the main root zone and are generally vertically confined to several reflector loops. The main bodies of chimneys are defined by large ( $\leq 3000 \mathrm{~m}$ diameter), vertically elongated, diffuse low amplitude reflector zones (e.g., Fig 4a). Larger chimney bodies typically contain discrete packages of high amplitude reflectors which often appear to be independent of stratigraphic layering. Evidence for velocity pull-down, consistent with a decrease in seismic velocity within gas plumes, is observed on reflectors crossing five chimneys (e.g., Fig. 3.5a and Fig. 3.5b). The top section of chimneys often comprise of several low frequency, high amplitude reflectors and apparent phase reversals re common across the width of chimneys (e.g., Fig. 3.6a and Fig. 3.6b). On closer inspection of high resolution seismic data these phase reversals are revealed to be the bowing up reflectors one phase length or seismic loop (e.g., Fig 3.6a and Fig. 3.6b). The sea-floor reflector is commonly displaced either upward (convex) or downward (concave) over an area approximately equal to that of the underlying chimney body.

High resolution shallow seismic data (Fig. 3.9) reveals a more detailed view of the internal structure of Chimney G than is possible with the Kerry 3D seismic reflection volume. In places, reflectors can be traced across the width of the chimney but exhibit less coherency, lower frequency and larger variations in amplitude than the surrounding reflectors (Fig. 3.9). Reflector coherency varies vertically down the chimney, with no visible layering in some sections and coherent well layered reflectors in others. Chaotic, low amplitude reflector packages spread horizontally out from the main chimney body to confined stratal reflector packages. The shallower sections of the chimney generally exhibit the most incoherent reflectors and also some of the highest amplitudes. The sea-floor reflector across the top of the chimney is domed upward with no evidence of pockmarks or mud volcanoes above the chimney.

Based on spatial extent and seismic character, chimneys can be divided into two distinct groups. Chimneys with the zones of greatest incoherency are those with the deepest root zones, the largest bodies and greatest spatial extent. Conversely, those with more coherent 
reflectors have shallow root zones, smaller chimney body circumference and generally limited spatial extent. This relationship could be a function of gas flux rates through chimneys, and is further explored in Chapter V.

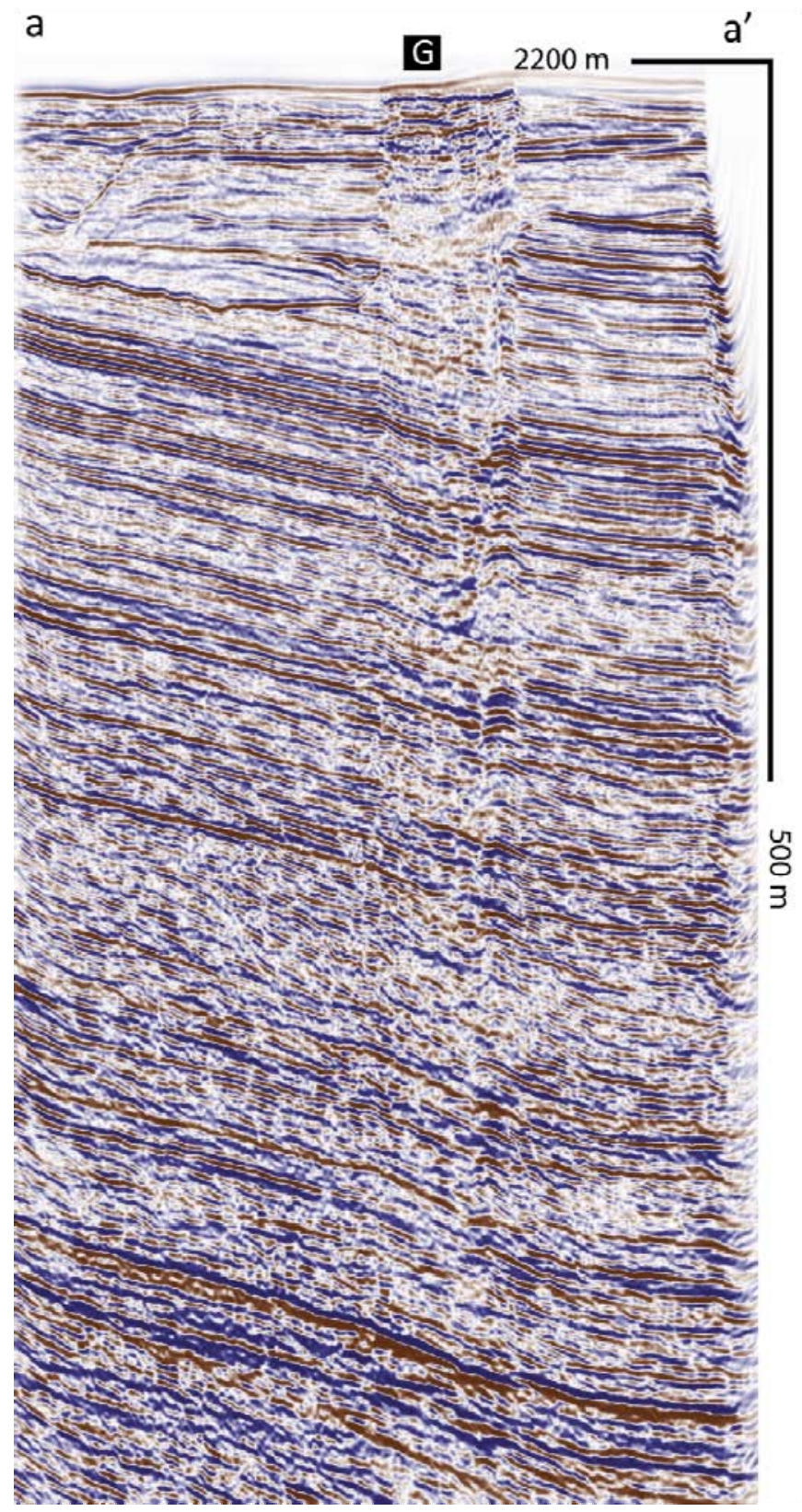

Figure 3.9 High resolution seismic section through Chimney H. The location of seismic reflection section is shown in Figure 3.3(b). 


\subsection{Spatial Relationships between Gas Chimneys and Faulting}

A strong spatial relationship exists between faulting and gas chimneys in the Kupe Area. Fifteen of seventeen chimneys initiate from point sources within Plio-Pleistocene normal fault zones (Fig. 3.3), while the remaining two non-fault related chimneys initiate from within paleo-channels that transect other chimneys that originated from within faults. Therefore, the available data suggest that hydrocarbon migration above the Otaraoa top seal in the Kupe Area is structurally controlled and that Plio-Pleistocene normal faults act as steeply inclined conduits to gas flow. In map-view, gas chimneys occur discontinuously along faults suggesting that migration is channelised. It is suggested in the remainder of this chapter that gas flow may be channelised along irregularities in fault surfaces (e.g., relays, bends and fault intersections) where high densities of fractures might be expected to occur.

Within Plio-Pleistocene strata, normal faults often formed segmented arrays separated by relays, breached relays and intersections that joined into single through-going faults within Miocene-Oligocene strata. These fault segment boundaries appear to be sites of focused gas flow. About 30\% of recorded gas chimneys (6 of 17) are located within relay zones (including one in a vertically segmented fault zone) while another $20 \%$ occur at fault intersections ( 3 of 17) and a further 30\% of chimneys are located at fault tips (6 of 17). Fault relay zones, intersections and lateral tips are typically sites of high displacement gradients and/or displacement lows. Strike-parallel displacement profiles of the PlioPleistocene normal faults indicate that chimneys are typically rooted in faults where their displacement gradients are highest (Fig. 3.10). These gradients are highest at lateral fault tips, within relay zones and where faults intersect (Fig. 3.10). An example of this can be seen in Figure 3.10, where a rapid change in throw occurs on Fault 9 across the intersection with a minor fault segments. 

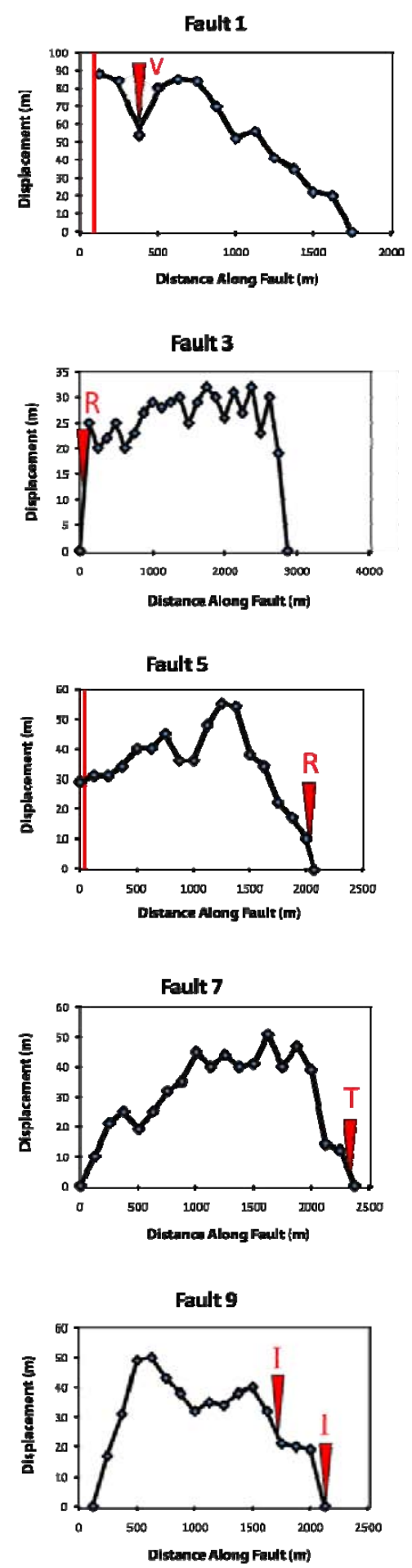

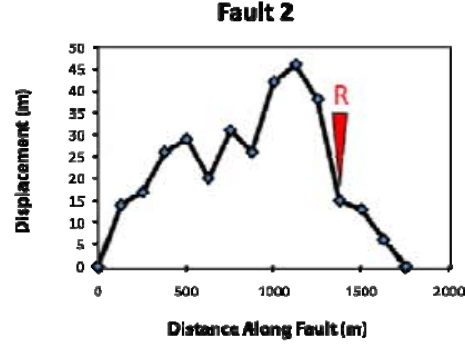

Fault 4
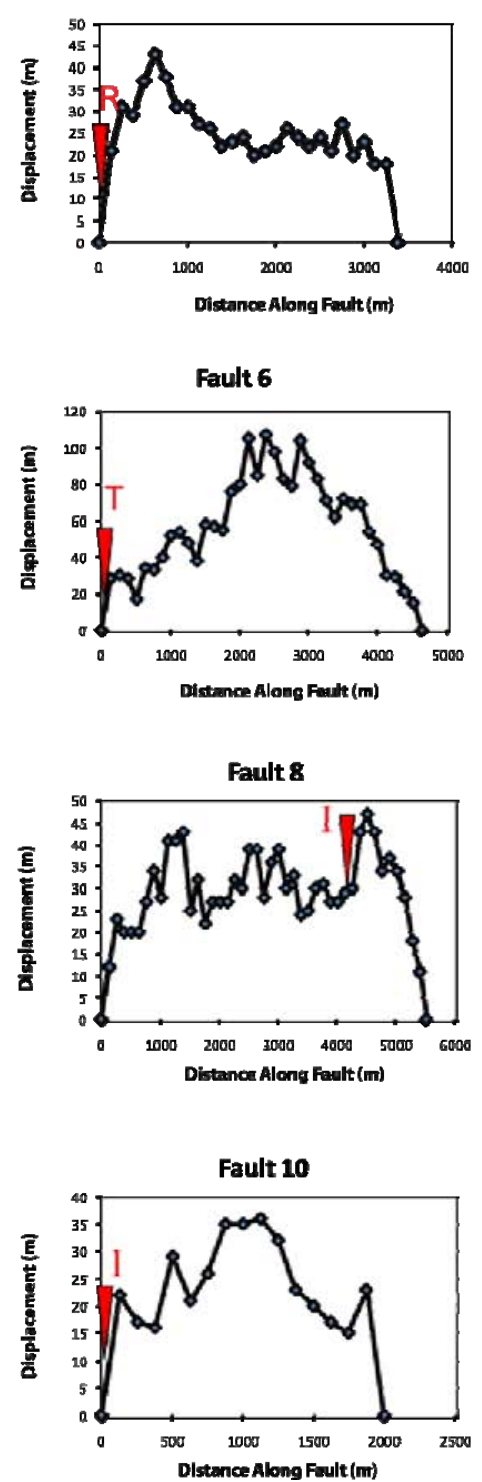

Figure 3.10 Throw profiles measured along strike at N60 (5 Ma) horizon for faults that have related gas chimneys. Locations of faults are shown on Figure 3.3b. Red triangles indicate approximate location of chimneys in relation to fault strike, with letters indicating type of geometric complexity R=Relay zone, $\mathrm{T}=$ Fault tip and I=Fault intersection. Vertical red line indicates edge of Kerry 3D seismic reflection volume. 
Within the study area, however, many faults, fault relays, fault intersections and fault tips are not associated with seismically resolvable gas chimneys raising the question of why some faults leak and promote up-dip gas migration and others do not. The Otaraoa top seal holds hydrocarbon columns of $\sim 40-100 \mathrm{~m}$ in the Kupe gas condensate Field within the study area (Steed et al., 1998) and when combined with no evidence for non-fault related gas chimneys across the top seal, it is unlikely that capillary leakage through the top seal contributes significantly to the charging of the Plio-Pleistocene fault zones. Further, no hydrocarbon reservoirs have been discovered at stratigraphic levels above the base of the Otaraoa seal in any of the eight exploration wells drilled in the area suggesting shallow reservoirs are not the source of gas for chimneys. An important controlling factor on gas chimney formation within the Kupe Area is therefore postulated to be whether the Otaraoa top seal is breached by the Plio-Pleistocene normal faults.

\subsection{Faults and Petroleum Migration Model}

\subsubsection{Fault Reactivation and Top Seal Breach}

Reactivation of underlying Cretaceous-Paleocene extensional faults and subsequent fault displacement of the Otaraoa top seal occurs along two major zones in the Kupe Area. Above these two zones, two separate segmented arrays of Plio-Pleistocene faults have developed and host 15 of 17 gas chimneys. The two zones extend from the north-east margin of the Kupe Area in a southwest direction up to the structural culmination of the Manaia Anticline. The northern most zone ceases at the margin of the main Kupe Field Area (Kupe South-1,2,3 wells, see Fig 3.3b), while the second more southern zone continues into the Kupe South -4 and Kupe South-5 Area (see Figure 3.3b). Both locations contain hydrocarbon pools suggesting that lateral hydrocarbon flux into the anticline exceeds vertical leakage through faults on the anticline's limbs allowing hydrocarbon columns to form at the crest of the structure where faults are not leaking.

Analysis of faults that have associated gas chimneys show Plio-Pleistocene faults that breach the top seal are critical for gas migration into the post Oligocene sequence in the Kupe Area. All of the faults that carry gas breach the Otaraoa top seal or intersect faults that breach the top seal. Larger gas chimneys (e.g., widths $>2 \mathrm{~km}$ ) are rooted in Plio- 
Pleistocene faults that directly displace the Otaraoa Seal and reactivate or intersect reactivated Late Cretaceous-Paleocene faults. Smaller fault-related chimneys (e.g., widths $<2 \mathrm{~km}$ ) are rooted in faults that do not directly displace the top seal or intersect reactivated faults that displace the top seal. However, these faults with associated smaller chimneys form connected arrays with Plio-Pleistocene faults that do cut and displace the top seal, thus providing the likely conduits for gas migration through the seal.

The Otaraoa top seal is only completely breached by Plio-Pleistocene faults that reactivate Late Cretaceous-Paleocene faults. Whether Plio-Pleistocene reactivation of CretaceousPaleocene faults occurs appears to be dependent on fault strike. Reactivation of Late Cretaceous-Paleocene faults occurs at locations where they strike between 030-070 parallel to the $400^{\circ}$ trend of the contemporary maximum horizontal stress (Fig. 3.11). Reactivation occurs along the entire length of Late Cretaceous-Paleocene faults where they strike within $30^{\circ}$ of the trend of maximum horizontal stress (e.g., Fig 3.12). In areas where Late Cretaceous-Paleocene faults vary in strike by 20 - $30^{\circ}$ from the trend of maximum horizontal stress $\left(\mathrm{S}_{\mathrm{Hmax}}\right.$ ), reactivation occurs for a maximum strike length of $5000 \mathrm{~m}$, at which point the Plio-Pleistocene section of the fault deviates from the strike of the underlying Late Cretaceous-Paleocene fault and continues sub-parallel with $\mathrm{S}_{\mathrm{Hmax}}$. Reactivation of the Late Cretaceous fault ceases at this point. In areas where the Cretaceous-Paleocene faults do not strike between $10-70^{\circ}$, there is typically no evidence of reactivation and Plio-Pleistocene faults generally do not displace the Otaraoa top seal. Lastly, it is noted that three of the largest gas chimneys occur above relay zones between reactivated Late Cretaceous-Paleocene faults. At such sites migration of gas through the Otaraoa Formation seal may be facilitated by fracturing within the relay zones and/or associated with upward merging of Cretaceous-Paleocene fault segments into PlioPleistocene fault segments. 


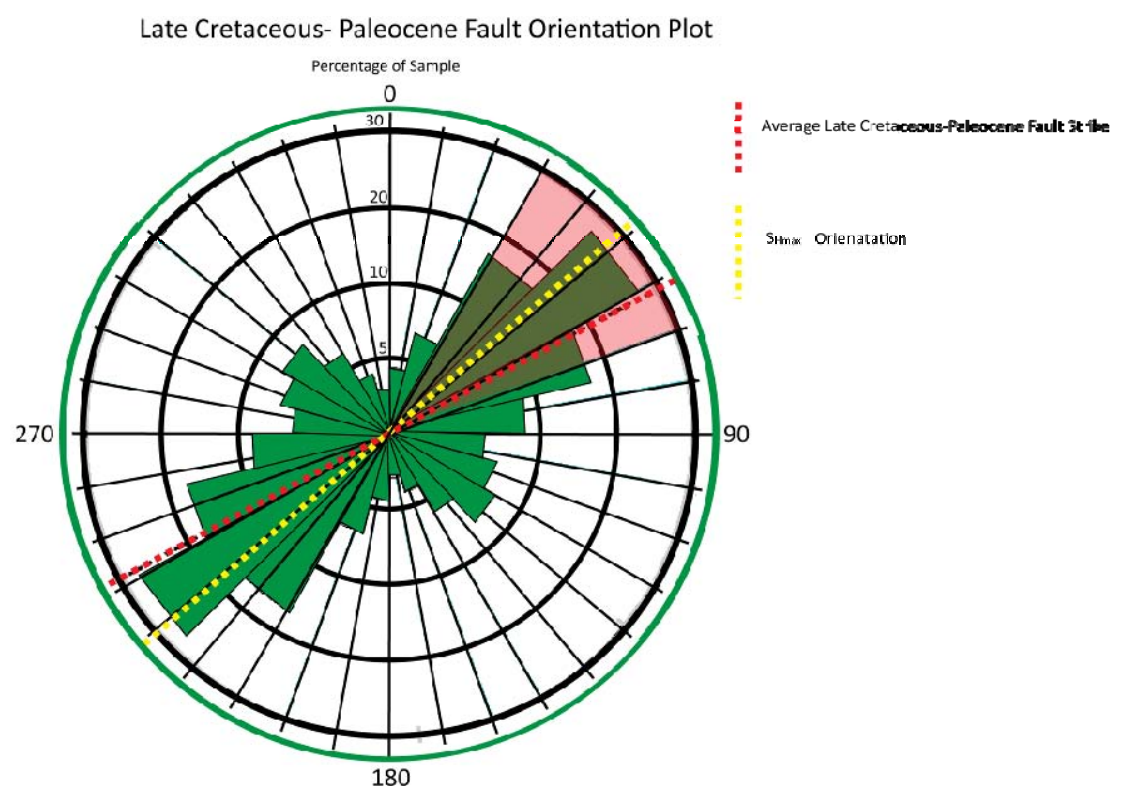

Figure 3.11 Rose diagram of Late Cretaceous-Paleocene faults in the Kupe Area showing average fault strike and $\mathrm{S}_{\mathrm{Hmax}}$. The orientations of faults being reactivated in the current stress field are shown in red.

\subsubsection{Up-Sequence Channelised Gas Flow}

Hydrocarbons generated in lower-most Basin strata of Late Cretaceous-Eocene age are present in Miocene- Pleistocene strata in the Kupe Area, and form economic reservoirs in Miocene sequences elsewhere in the Taranaki Basin. These observations are consistent with significant vertical migration of hydrocarbons. Hydrocarbons found in Miocene-Pleistocene sequences of the Taranaki Basin must have migrated through the thick ( $\leq 600 \mathrm{~m}$ ) regional top seal (Otaraoa siltstone) and up to $3 \mathrm{~km}$ thick of mudstone dominated Miocene strata. Normal faults that displace the regional Otaraoa top seal and the overlying sequence appear to provide a vertical conduit for gas migration in the Kupe Area and may do so in other parts of the Basin.

Gas migration above and through the regional seal is strongly influenced by the locations and geometries of Pliocene-Pleistocene faults. Isolated chimney locations along faults indicate that gas migration is not taking place over entire fault surfaces and that channelised flow occurs via pathways within fault zones. Channelised or enhanced upsequence gas flow is most likely to occur where rock volumes contain interconnected open fracture networks. Such networks are typically observed in rock volumes with high fracture densities. 


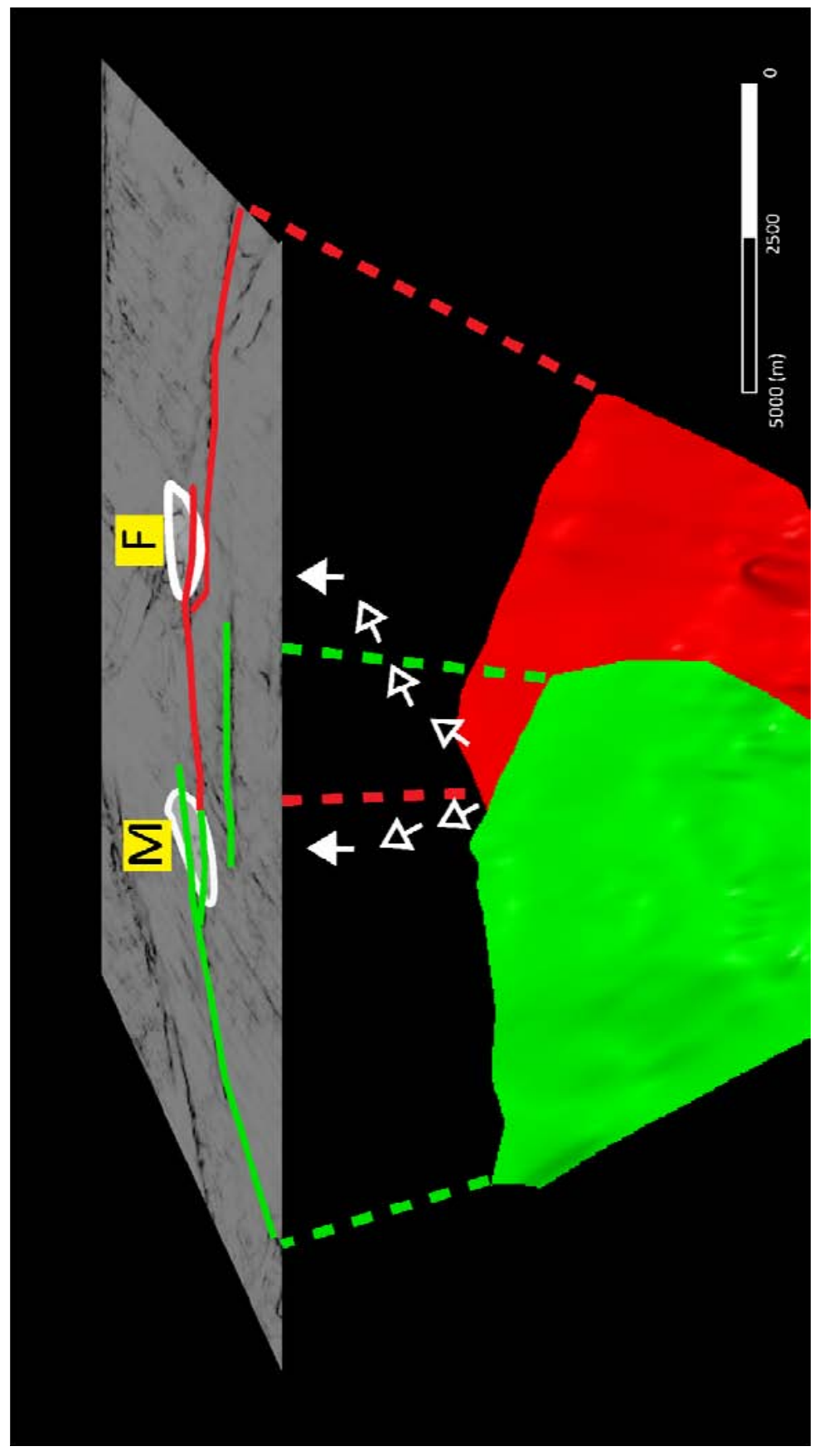

Figure 3.12 Fault reactivation relationship. Red and green fault surfaces are Late Cretaceous rift faults (tops of faults are at $\sim 4000 \mathrm{~m}$ depth). Coherency seismic time slice shows Plio-Pleistocene fault structure at $\sim 2000$ $\mathrm{m}$ depth. Dashed coloured lines show the links between shallow and deep fault structure. Dasher green line outlines Fault 6 and dashed red line outlines Fault 5. White polygons on coherency slice show locations of gas chimneys. White arrows show gas chimney migration paths, with filled arrows at locations of visible gas and unfilled arrows inferred locations of gas migration. The location of the coherency seismic time slice is shown in Figure 3.3b. 
Open interconnected fracture networks and associated channelised gas flow may occur at relay zones, fault intersections and lateral fault tips. Figure 3.3a shows the close spatial relationship between faults and chimneys. Of the chimneys shown in Figure 3.3a, the majority are located in fault relay zones (6 of 17) or proximal to fault tips (6 of 17). Similarly, Figure 3.12 shows diagrammatically a gas chimney that records gas migrating through the seal at a relay zone formed between Late Cretaceous faults reactivated during Plio-Pleistocene extension. Above the seal the chimney bifurcates into two chimneys ( $\mathrm{M}$ and F), with each of the main branches coinciding with relay zones at the top Miocene age reflector. These locations on the faults exhibit high displacement gradients and/or displacement lows (Fig. 3.10, Faults 5 and 6) that in many other studies are generally associated with local increases in off-fault strain manifested as bed rotation and high densities of fractures (e.g., Childs et al., 1996; Davatzes and Aydin, 2003; Foldin and Aydin, 2004; Fossen, et al., 2005; Eichhubl et al., 2009). Fault-related fractures generally form sub-parallel to main faults (e.g., Davatzes and Aydin, 2003; Dockrill and Shipton, 2010), which in the Kupe Area would result in fault-related fractures sub-parallel to $S_{H \max }$. Where fractures and minor faults differ in orientation from major faults there is often a corresponding rotation in the stress tensor (e.g., Homberg et al., 1997; Maerten et al., 2002; Yale, 2003) and thus the minor faults and fractures are likely to still parallel $S_{\text {Hmax. }}$

Fractures that parallel $S_{\mathrm{Hmax}}$ are most likely to be dilated and open and are therefore capable of acting as conduits to gas flow (Jolly and Sanderson, 1997). High displacement gradients are also found at all other locations on faults where gas chimneys were visible. In the Kupe Area fracturing developed between fault initiation and the present. However, faults that form the fracture networks do not need to be active for the fractures to act as conduits for hydrocarbon migration, as suggested by evidence of fault-related oil seeps from faults that have been inactive for $>40$ million years in the Irish Sea (C. Childs pers. com, 2011).

\subsubsection{Sub-Seal Lateral Gas Flow}

The spatial distribution of chimneys within the Kupe Area may provide evidence for horizontal, as well as vertical, migration of hydrocarbons and afford a more complete understanding of the hydrocarbon pathways from source rock to reservoir. Basin modelling indicates that potential source rocks (Rakopi coals) below the Kupe Area are immature and 
unlikely to have generated the gas and condensate found within the Kupe field (Benchilla et al., 2006). Analysis of oil families suggests that oils from Kupe have a common source with oils in Kapuni, an onshore gas field $\sim 50 \mathrm{~km}$ north of Kupe on the same anticlinal structure (Crown Minerals, 2010). Therefore, significant southward lateral migration of hydrocarbons from kitchen areas to the Kupe Field can be inferred to be occurring below the Otaraoa seal (Fig. 3.13a). Ilg et al., (in prep) suggest that significant horizontal migration of hydrocarbons below the Otaraoa top seal was achieved within a series of high net to gross sand dominated carrier beds, with an average permeability (in, or close to, the region of study) of $\sim 130 \mathrm{mD}$ and values locally ranging up to $6 \mathrm{mD}$ (M.Arnot, pers com. 2010).

A lack of visible gas chimneys along the crest of the Manaia Anticline suggests that migration of gas may not be occurring up-sequence from the Kapuni Area to the Kupe Area (Fig 3.13a). A continuous lineation of gas chimneys within the syncline, east of Kupe, northwards towards the kitchen area has been mapped by Ilg et al., (in prep). Gas chimneys mapped within the Kupe Area during this study form a zone that extends approximately eastwards from the crest of the Manaia Anticline to link with those gas chimneys mapped by Ilg et al., (in prep) (Fig. 3.13a) and this study suggests that this line of chimneys delineates a lateral gas migration pathway below the Otaraoa top seal. Based on the observations of Ilg et al. (in prep) and this study, it is suggested that lateral migration of gas from the north-eastern kitchen area into the Kupe Area occurs dominantly within the carrier beds in the syncline to the east (Fig 3.13b). North-east striking Late CretaceousPaleocene faults that offset these carrier beds within the syncline area are inferred to provide some lateral seal to horizontal hydrocarbon flow (based on the likelihood of low permeability fault-rock developing from lower net to gross sections between carrier beds and significant throw accumulation or through juxtaposition relationships). These faults could, therefore, act as barriers guiding hydrocarbons within the carrier beds southwestward up the flank of the Manaia Anticline into closures within the Kupe Field Area and the more southern Kupe South-4 and Kupe South-5 wells (Fig. 3.13b). Along this migration fairway, reactivation of the same Late Cretaceous-Paleocene faults breaches the top seal and results in migration of hydrocarbons vertically through fault-related fracture networks forming seismically visible gas chimneys. 


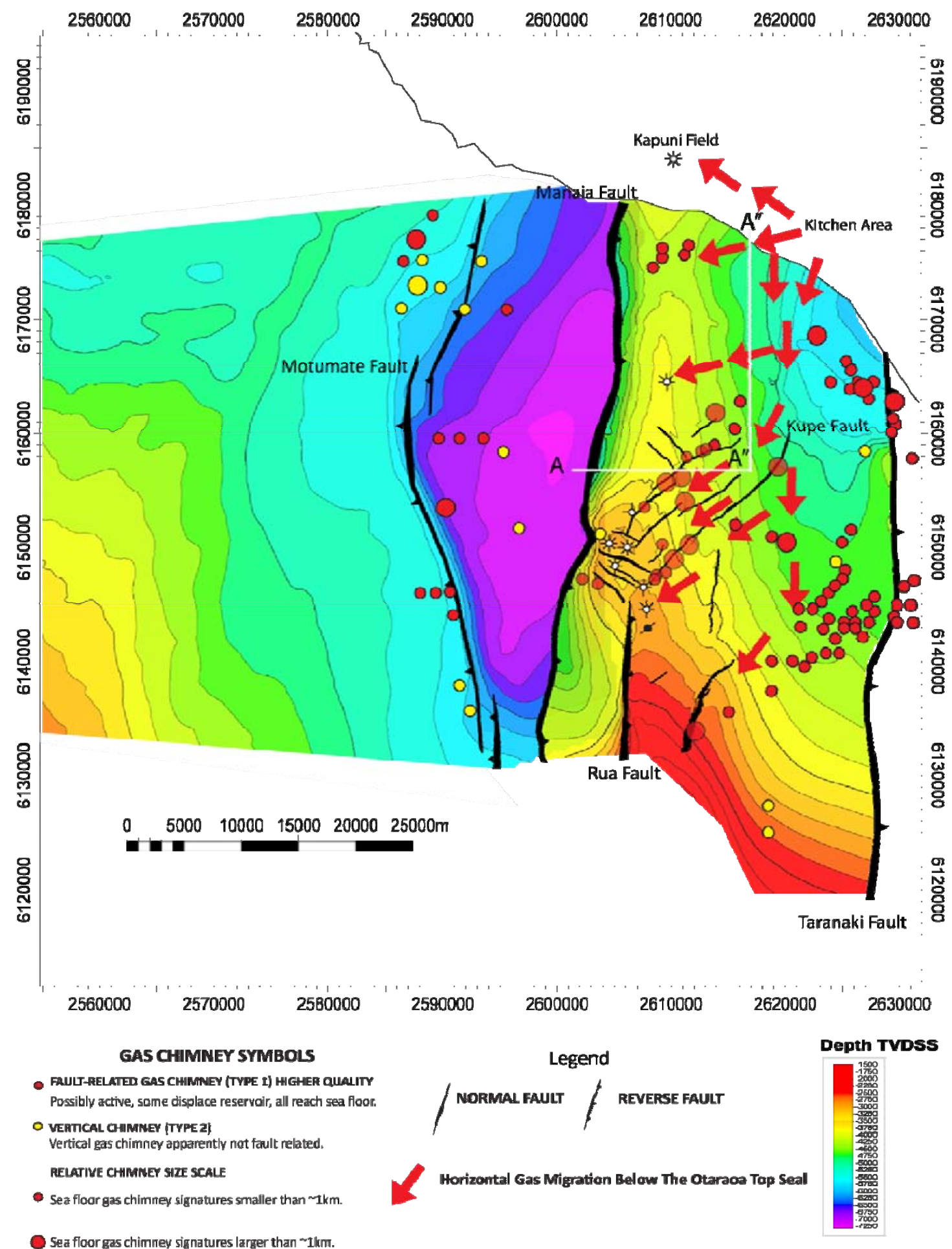

Figure 3.13(a) Migration pathways in the Kupe Area (red arrows) mapped onto the structure contour surface for the base of the Otaraoa seal. Red circles are interpreted gas chimneys. Chimneys have been projected down the fault they have initiated within onto the Otaraoa seal surface. Migration fairways are located along north-east striking faults up into the Manaia Anticline. Chimneys east of the Kupe Fault and west of the Manaia Fault are from Ilg et al., (in prep). 


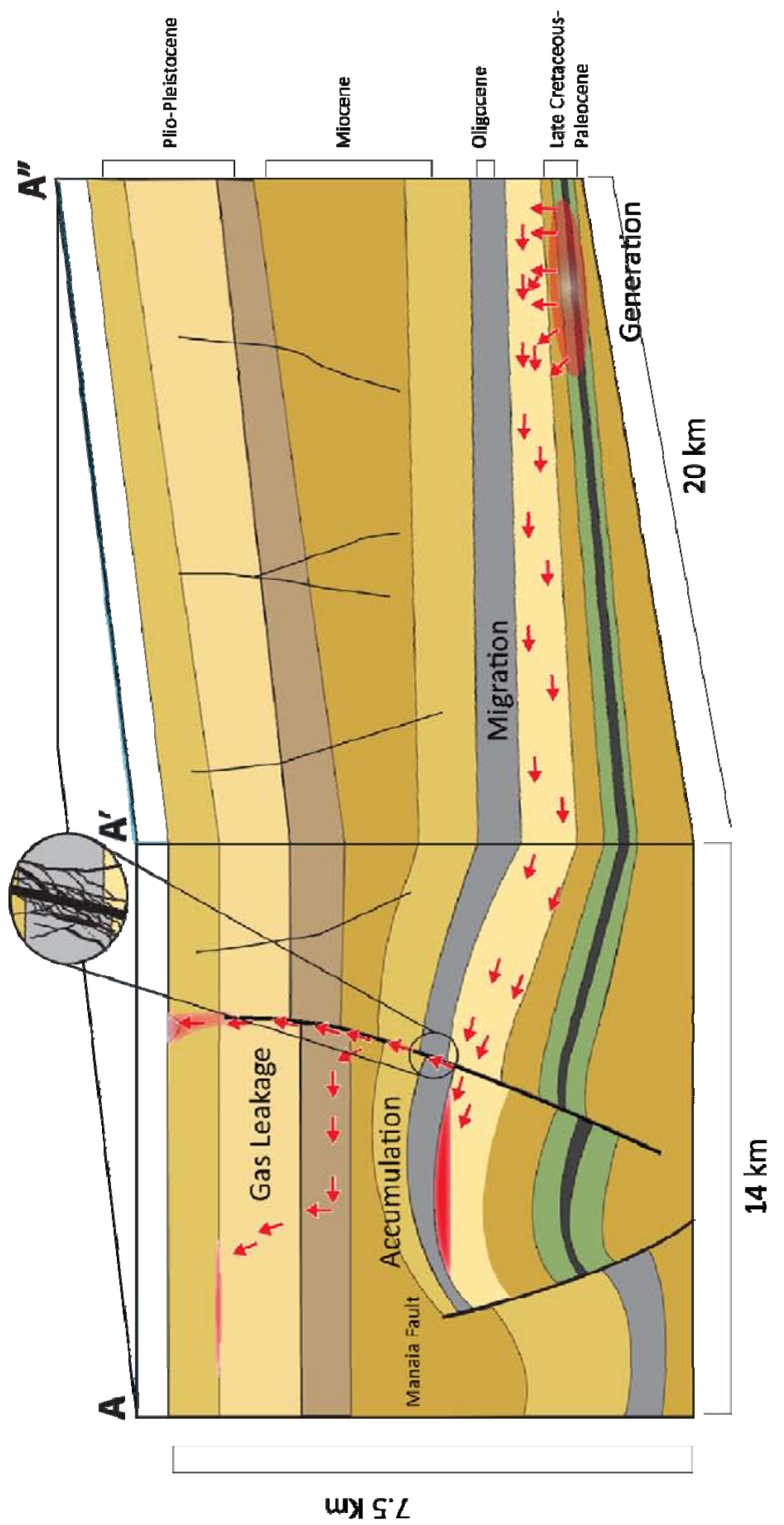

Figure 3.13 (b) Block model of interpreted hydrocarbon migration pathway within the Kupe Area. Red arrows denote migrating hydrocarbons. 


\subsubsection{Stratigraphic Gas Chimney Migration}

The vertical and horizontal migration of gas chimneys away from fault zones in shallower strata $(<1.5 \mathrm{~s}$ TWTT) may be a function of host rock versus fault zone permeability, with the former being strongly influenced by the level of consolidation in Plio-Pleistocene sedimentary rocks that harbour gas. There is little evidence to suggest that gas moves preferentially into fault hanging-walls or fault foot-walls, consistent with the view that host rock permeability does not change significantly across faults. It is clear, however, that gas preferentially migrates into some stratigraphic intervals. Sedimentological controls on chimney migration away from faults is found, for example, in the series of shallow paleochannels that post date the $\sim 1.5$ Ma unconformity surface in the Kupe Area. The elevated seismic reflection amplitude in these channels (see Fig. 3.8) is interpreted to indicate the presence of gas which is charging the channel sand bodies via four vertical gas chimneys. Similar interactions between chimneys and channels were found in the offshore Congo region, where chimney locations were controlled by a paleo-channel acting as a conduit for gas migration (Gay et al., 2006).

The shallow paleo-channels provide an interesting analogue for potential charge mechanisms in deeper sand rich turbidite plays within the Taranaki Basin. Plio-Pleistocene faults could provide migration pathways from deeper reservoirs through the Otaraoa top seal, with the associated chimneys charging shallower Miocene turbidite complexes, such as the Moki Formation or the Mount Messenger Formation. This mechanism may account for charging of shallow Moki Formation reservoirs observed in the Manaia Field, South Taranaki Basin. Faults extend from the Eocene age Mangahewa Formation reservoirs through the Oligocene age Otaroa top seal into the Miocene age Moki Formation in the Manaia Field Area (Engbers et al., 2002), and could be initiating up-sequence migration into the shallower sand rich Moki Formation turbidite sequences. Up-sequence hydrocarbon migration is also evident in the Field Area at Maari-1, where a large gas cloud can be observed in seismic data over the main structural culmination. However, limited quality of the seismic data caused by the gas cloud prevents correlations being made to faults. 


\subsubsection{Estimates of Fault Permeability}

The consistent depth at which chimneys appear to migrate away from faults in the Kupe Area provides a means to estimate upper and lower bounds on fault permeability. At depths where chimneys appear to be confined to fault zones it is likely that fault permeability exceeds that of the surrounding host rock. Locations where chimneys depart from the fault zones into surrounding strata could be a function of higher permeability host rock. Extensive permeability data sets exist for the sedimentary column in the Kupe Area allowing estimates of the permeability of fault hosting sediments from the Otaraoa top seal to the shallow Plio-Pleistocene where chimneys propagate out from faults.

Chimneys appear to be predominantly confined to fault zones through the Oligocene and Miocene strata. These stratigraphic sections dominated by calcareous mudstones and siltstones and have an average permeability of $\sim 12 \mathrm{mD}$ (M. Arnot, pers com. 2010). The low permeability of the Oligocene top seal rocks and the Miocene sequence will tend to inhibit vertical and lateral migration of gas and fluids. Evidence of up-sequence migration through fault zones suggests that their permeability could generally exceed the $\sim 12 \mathrm{mD}$ averages of host strata in the Kupe Area.

Similarly chimneys depart from faults in the sand rich post Miocene strata with an average permeability of $\sim 380 \mathrm{mD}$ (typical values $<1000 \mathrm{mD}$ ) (M. Arnot, pers com. 2010). Though a number of factors could influence the depth of chimney departure from fault zones, a possible explanation is that the sand rich surrounding strata has higher permeability than the faults. If this is correct then fault zones in the Kupe Area may generally have permeability of $<380 \mathrm{mD}$.

\subsection{Ages of Gas Chimneys}

Dating sediments disrupted by gas chimneys provides a maximum age for gas migration within the Kupe Area. Chimneys throughout the Kupe Area using Pliocene-Pleistocene faults must post date the $~ 4$ Ma initiation of fault growth (Nicol et al., 2005; Giba et al., 2010; this study). It is suggested that all chimneys formed after 4 Ma, with direct evidence 
of some chimney activity ceasing prior to $\sim 1.5 \mathrm{Ma}$, and many chimneys remaining active up to $10 \mathrm{ka}$ and possibly to the present day.

Seismic reflection data east and west of the study area indicates that a regional Pleistocene unconformity that occurs at $200-500$ ms TWTT in the Kupe Area and is disrupted by all but one of the chimneys is $1.5 \mathrm{Ma}$ in age (Proust et al., 2005; Nicol et al., 2005).

Correlation of shallow reflectors to well log data and horizons from in the Maui and Wanganui Basin Areas (Nodder, 1993, 1994; Nicol et al., 2005) suggests that seismic reflectors at 50-100 ms TWTT in the Kupe Area may date from 15-30 ka. As most of the gas chimneys observed in the Kupe Area disrupt reflectors between 50-100 ms TWTT, they must have accommodated gas migration after 15-30 ka. Of these chimneys, 14 appear to disrupt the sea-floor (e.g., Fig. 3.5b and Fig. 3.6a respectively) and are likely to be caused by recent (6-10 ka; Nodder, 1993, 1994) gas or fluid flux disturbing shallow sediments before venting into the water column. For example, concave seafloor reflectors (e.g., Fig. 3.5b) appear to be shallow pockmarks that vary from small craters with diameters of $\sim 15$ $\mathrm{m}$, to larger depressions over $1500 \mathrm{~m}$ in diameter. Mounding around the margins of several of these depressions may indicate lateral displacement of sediments during gas saturated mud flow. The presence of these seafloor features suggests that in many cases gas migration has continued into the Holocene.

Background gas readings during drilling of the Kupe-4 well that intersected a gas chimney also suggest that there is still gas residing within at least one chimney. However, it is possible that disruption of the seismic reflectivity in other chimneys results from the past passage of gas through sediments (e.g., Loesth et al., 2009), and that these chimneys are not actively expelling or harbouring gas. There is presently insufficient stratigraphic or geomorphological evidence to determine whether gas flow in chimneys was continuous or episodic. It remains possible, for example, that chimney gas flow rates increase due to a transient rise in strata permeability due to fault dilation during individual large magnitude earthquakes within the Kupe Area. However, for two chimneys that have caused disruption to the sea-floor and are sourced from faults that ceased being active between 0.5-1.5 Ma, it is clear that active faulting is not a prerequisite for chimney activity. For example, Chimney G (Fig. 3.6b) displaces and disturbs reflectors up to the sea-floor, while reflectors are only displaced by the fault (along which the chimney migrates) up to, and just above, 
the unconformity surface ( 200ms TWTT). This suggests that locally chimney formation post dates fault movement. The termination of some gas chimneys below the seafloor reflector also indicates that not all chimneys have been active over the same time interval. However, whether gas flow was typically of shorter duration (e.g., $<0.5 \mathrm{Myr}$ ) or occurred for much of the past 4 Myr is unresolved. Chapter V examines further the potential time scales and frequency of chimney activity.

\subsection{Conclusions}

Gas chimneys within the Kupe Area are spatially related to faulting. Fifteen of 17 chimneys initiate directly within Plio-Pleistocene fault zones and the remaining two are related to shallow paleo-channels charged by other fault-related chimneys. Chimneys predominantly occur at zones of geometrical complexity within faults such as fault relays, lateral fault tips and fault intersections. These zones are likely to host dilated connected fracture networks that enhance up-dip gas migration. Gas chimneys provide a mechanism for exploring horizontal gas migration pathways within the South Taranaki Basin and provide evidence for lateral migration from north-east of the Kupe Area, below the Otaraoa top seal. Based on seismic reflection data evidence of chimney depths and average strata permeabilities, the permeabilities of Pliocene to Recent normal faults in the Kupe Area may range from $12 \mathrm{mD}$. Gas migration is not necessarily synchronous with earthquakes on faults and is unlikely to be continuous for extended periods of time (i.e. > $1 \mathrm{Ma}$ ). 


\section{Chapter IV}

\subsection{Geomechanical Analysis of Up-Dip Gas Migration}

\subsection{Introduction}

The contribution of tectonic and local stresses to the development of structural permeability within sedimentary rocks is recognised as being critical for fault seal and top seal integrity studies and the migration of hydrocarbons (e.g., Aydin, 2000; Cartwright et al., 2007). The interactions between stress cycling, deformation and fluid or gas migration have been widely studied in the context of earthquakes (e.g., Byerlee, 1993; Muir-Wood, 1993; Sibson, 1994) and at crustal scale (e.g.,Townend and Zoback, 2008). These processes may be important for hydrocarbon migration and therefore could have implications for petroleum exploration.

Faults and fractures in the brittle crust play an important role in the subsurface movement of hydrocarbons (e.g., Knipe et al., 1996 and references therein; Childs et al., 1997; Hippler, 1997; Aydin, 2000; Gatrell et al., 2006; Cartwright et al., 2007; Halliday et al., 2008; Corona et al., 2010 ). These structures can both enhance up-fault flow and retard across-fault flow. How faults impact on flow depends on a range of factors including, the rock types enclosing the fault, the fault dimensions, and amount of displacement and the magnitudes and orientations of the principle stresses over the fault surface (e.g., Knipe et al., 1996 and references therein; Childs et al., 1997; Wiprut and Zoback, 2002). During individual slip events (i.e., earthquakes) fractures and faults are thought to dilate, resulting in transient increases of permeability within fault zones and the surrounding fractured strata (Main et al., 2000; Grueschow et al., 2003; Wilkins and Naruk, 2007). The magnitude, orientation and type of fault failure or fracture propagation influence the spatial distribution and magnitude of the transient structural permeability (Wilkins and Naruk, 2007). Between slip events, faults and fracture sets striking normal to the minimum horizontal stress are most likely to experience dilation and to enhance structural permeability (Jolley and Sanderson, 1997).

Geomechanical modelling has grown out of the need to understand and explain observations in complex stress regimes and to predict stresses acting on rocks away from points of measurement (Hunt and Bolt, 2005). Geomechanical modelling methods are 
applied to predict the probability that structural permeability has developed and is maintained in response to the contemporary stress field (e.g., Ferrill et al., 1999; Wiprut and Zoback, 2002). Geomechanical methods used to predict relative up-dip fault permeabilities are of three main types based on the geological processes that are inferred to increase permeability. These are:

1. Slip Tendency - Faults that are close to failure or reactivation in the current stress field are considered most likely to be permeable due to the development of open (permeable) fracture networks and dilation of existing fractures (Morriss et al., 1996; Ferrill et al., 1999; Wiprut and Zoback, 2002).

2. Dilation Tendency - Faults (and other fractures) structurally dilate under certain stress orientations and magnitudes within active stress regimes leading to enhanced up-dip permeability (Morris et al., 1996; Ferrill et al., 1999).

3. Fracture Stability - The critical pore pressure perturbation required to induce failure of a fault or fracture in shear, extensional shear or extension controls the ability of the fault or fracture to act as a conduit to fluid and/or gas (Mildren et al., 2005).

The three methods, though widely applied, have not been widely tested with independent fluid and/or gas flow data. To gain confidence in the techniques it is important that this testing is undertaken in a locality that provides evidence of fluid and/or gas flow that is independent of geomechanical models. In this chapter, the usefulness of the models to predict locations of up-dip gas leakage is tested using gas chimneys to locate areas of high gas flow along faults. The locations of those chimneys are compared to locations of high leakage potential predicted by the geomechanical models. The main outcome of this chapter is to determine under what circumstances geomechanical methods provide useful predictions of where up-fault hydrocarbon migration will occur. For petroleum exploration and $\mathrm{CO}_{2}$ purposes this information could be used for determining where top seal and fault 
seal integrity is likely to have been compromised, reducing the potential for a hydrocarbon column or for $\mathrm{CO}_{2}$ storage.

\subsection{Geomechanical Models for Predicting Fluid and Gas Flow}

The following section outline the mathematical and mechanical theory behind each of the three geomechanical modelling methods investigated in this chapter. It also describes the methodology used to generate stress tensor and pore pressure models for input into geomechanical models of faults in the Kupe Area.

\subsubsection{Slip Tendency}

Faults with high Slip Tendency (or Critically Stressed faults) are faults that are optimally orientated for reactivation ${ }^{1}$ and capable of accruing slip in a given stress field (Wiprut and Zoback, 2002). Barton et al. (1995) recognised that faults and fractures in crystalline rock optimally oriented for shear failure exhibited higher permeability. Their work led to the recognition that critically stressed faults can form important pathways for the movement of subsurface fluids and gas. Faults that are close to slipping or have high Slip Tendency are considered to have the highest permeability because they are associated with development of open fracture networks which can enhance migration of hydrocarbons (Barton et al., 1995). The application of the theory as a predictor of structural permeability was undertaken by Morris et al., (1996), who defined a method to calculate Slip Tendency based on the ratio of shear stress to effective normal stress acting on a cohesionless fault. They suggested higher shear stresses or lower effective normal stresses acting on faults and fractures increase the chance of slip and the potential for the development of structural permeability.

Slip Tendency is calculated using the orientation of a fault in an applied stress field and is a ratio that varies between zero and one. Zero represents the lowest Slip Tendency and is assumed to record a low likelihood of structural permeability (Fig. 4.1), while one

\footnotetext{
${ }^{1}$ Reactivation in the context of geomechanical modelling is defined as the proximity of a fault to shear failure based on a geomechanical failure envelope. This definition differs from the geological definition of reactivation where a fault developed in an initial stress regime is reactivated and accrues displacement in a new stress regime.
} 
represents the highest Slip Tendency and is assumed to indicate a high likelihood of structural permeability (Ferrill et al., 1999). Faults with a Slip Tendency $\geq 0.6$ are ideally orientated for slip (Byerlee, 1978), and thus are assumed most likely to have zones of increased fracture density and enhanced structural permeability (Zoback et al., 1996; Morris et al., 1996; Ferrill et al., 1999; Chanchani et al., 2003; Rogers, 2003; Takatoshi and Kazuo, 2003)

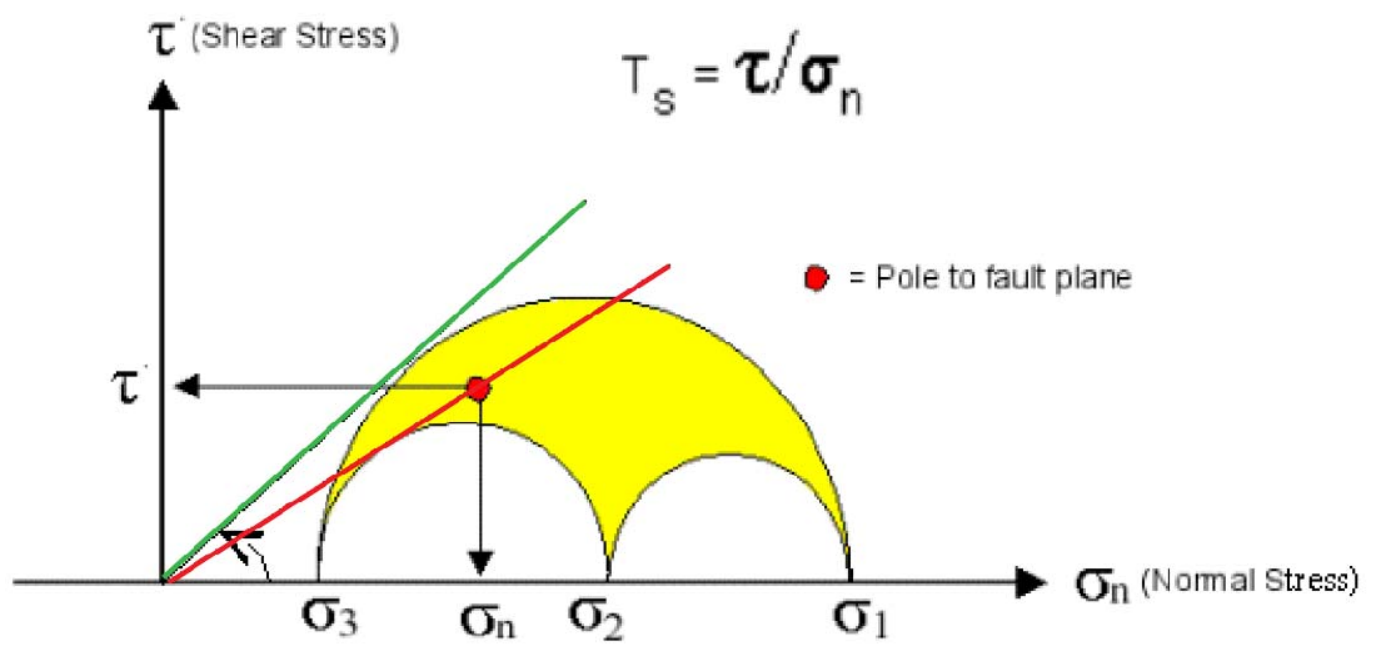

Figure 4.1 Slip Tendency $\left(\mathrm{T}_{\mathrm{s}}\right)$ displayed on a Mohr diagram. Figure from Trap Tester 6.0 Manual (2009). The two lines through the origin of the graph show different stress regimes. The yellow zone shows shear and normal stress magnitudes on all possible orientations of arbitrary fault planes. The red and green lines show different failure envelopes generated using different rock property data.

\subsubsection{Dilation Tendency}

Dilation tendency is a measure of the extent to which dilated or open fault zones, and dilated fractures within a fault zone locally enhance the flow of gas and fluids. Dilation can also occur in strata surrounding fault zones (Scholz, 1990) and in fault-rock (Morone et al., 1990; Morgan, 1999). Only structurally induced dilation of a fault zone and fractures is considered in this study as it has direct application to petroleum exploration and the prediction of subsurface fluid flow. 
Fracture dilation in fault zones is well established in field-based studies demonstrating that zones of dilation are typically the location of mineral deposition or enhanced fluid flow (Sibson, 1989; Nguyen et al., 1998; Branquet et al., 1999; Ferrill and Morris, 2003). Further evidence that dilation influences both fluid flow and earthquake propagation is provided by numerical modelling (Matthai and Fisher, 1996; Zhang and Sanderson, 1996; Zhang and Sanderson, 2006; Zhang et al., 2008). Dilation tendency is commonly calculated via the relationship of fault geometry to a regional stress field and is a dimensionless parameter representing the probability that a fault or fracture is open or dilated (Ferrill and Morris, 1999). The ability of a fault or other type of fracture to dilate or open is a direct function of the normal stress acting on its surface (Fig. 4.2). By resolving the principle stresses and fluid pressure acting on a fault surface or fracture a calculation of the normal stress can be obtained. The resulting dilation tendency is then defined as (Eq. 1):

$T_{\mathrm{d}}=\left(\sigma_{1}-\sigma_{\mathrm{n}}\right) /\left(\sigma_{1}-\sigma_{3}\right)$

where $\sigma_{1}$ is the maximum stress, $\sigma_{\mathrm{n}}$ the normal stress and $\sigma_{3}$ minimum stress. The tendency of a fault or joint to dilate will increase as normal stress acting on it decreases.

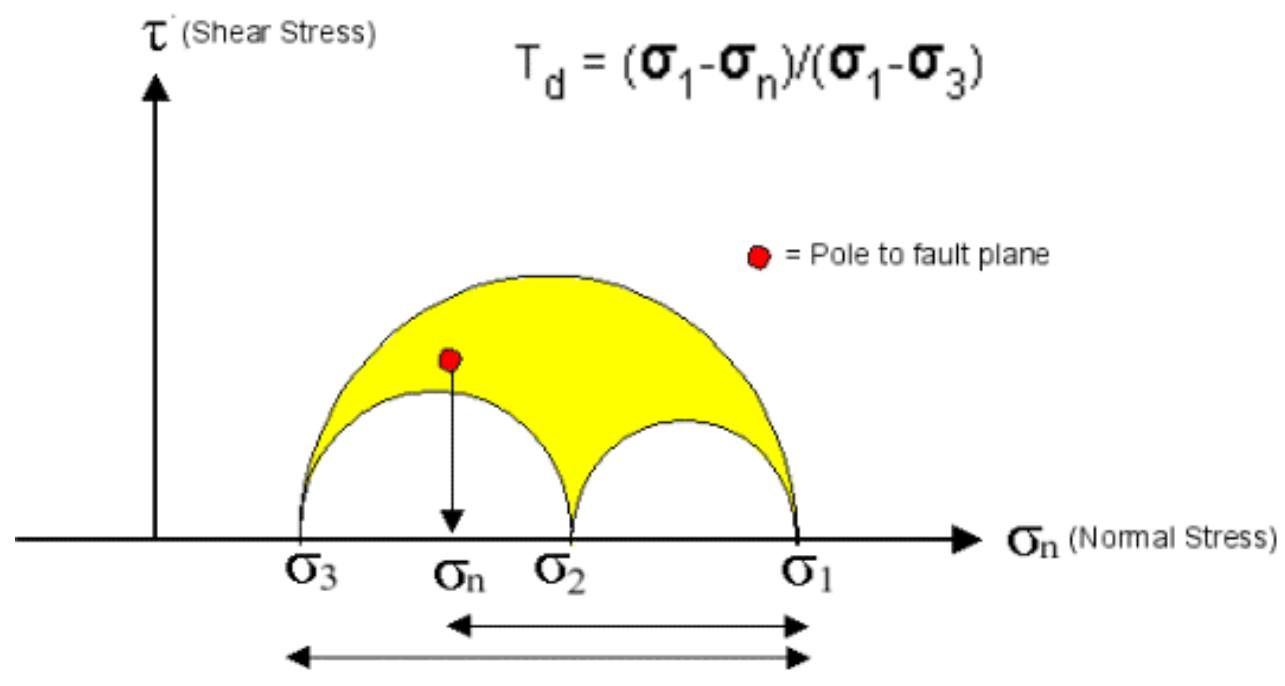

Figure 4.2 Dilation Tendency $\left(\mathrm{T}_{\mathrm{d}}\right)$ displayed on a Mohr diagram. The yellow area shows all possible fault orientations and the magnitudes of shear and normal stress acting on the fault plan. Image from Trap Tester 6.0 Manual (2009). 


\subsubsection{Fracture Stability}

Wiprut and Zoback (2002) further developed the critically stressed fault model by including pore pressure in geomechanical modelling. They defined the risk of reactivation based upon the pore pressure perturbation needed to induce failure on individual faults. It was postulated that increases in hydrocarbon column height or high water phase pressure in a hydrocarbon reservoir could eventually induce slip on a reservoir bounding-fault and thus increase permeability and leakage from the trap. However, areas of high leakage likelihood do not necessarily indicate that leakage is currently occurring and other factors such as the presence of a hydrocarbon accumulation, a reservoir unit abutting the fault and high enough pore pressures must all be met to generate leakage up faults.

Fracture Stability was developed by Mildren et al., (2005) and added to the theory of the pore pressure perturbation needed to induce failure by including cemented fault-rock strength data in the modelled rock failure envelope used in Slip Tendency. The Slip Tendency method of Wiprut and Zoback, (2002) applied a failure envelope for fault-rocks based on the cohesionless frictional law of Byerlee (1979). It was postulated by Mildren et al. (2005) that the frictional experiments conducted by Byerlee (1979) do not correctly represent the likely mechanical properties of some faults, where the development of cements results in fault-rocks with significant cohesive strength. Fracture Stability allows the inclusion of a cohesive strength for fault-rock during geomechanical calculations of leakage risk. A composite Griffith-Coulomb failure envelope, based on Sibson, (1996), is applied to calculate likely reactivation due to its ability to predict, shear, tensile and hybrid tensile fracture (Mildren et al., 2005) (Fig. 4.3). Whether failure occurs as shear, extensional shear or extension depends on the deviatoric stress (maximum compressive stress minus the minimum compressive stress), the orientation of the fault in the stress field, and the values of tensile strength, cohesive strength and coefficient of internal friction for fault-rocks being examined. The lower the fracture stability is, the smaller the increase in pore pressure needed to induce failure on the fault (Mildren et al., 2005). 


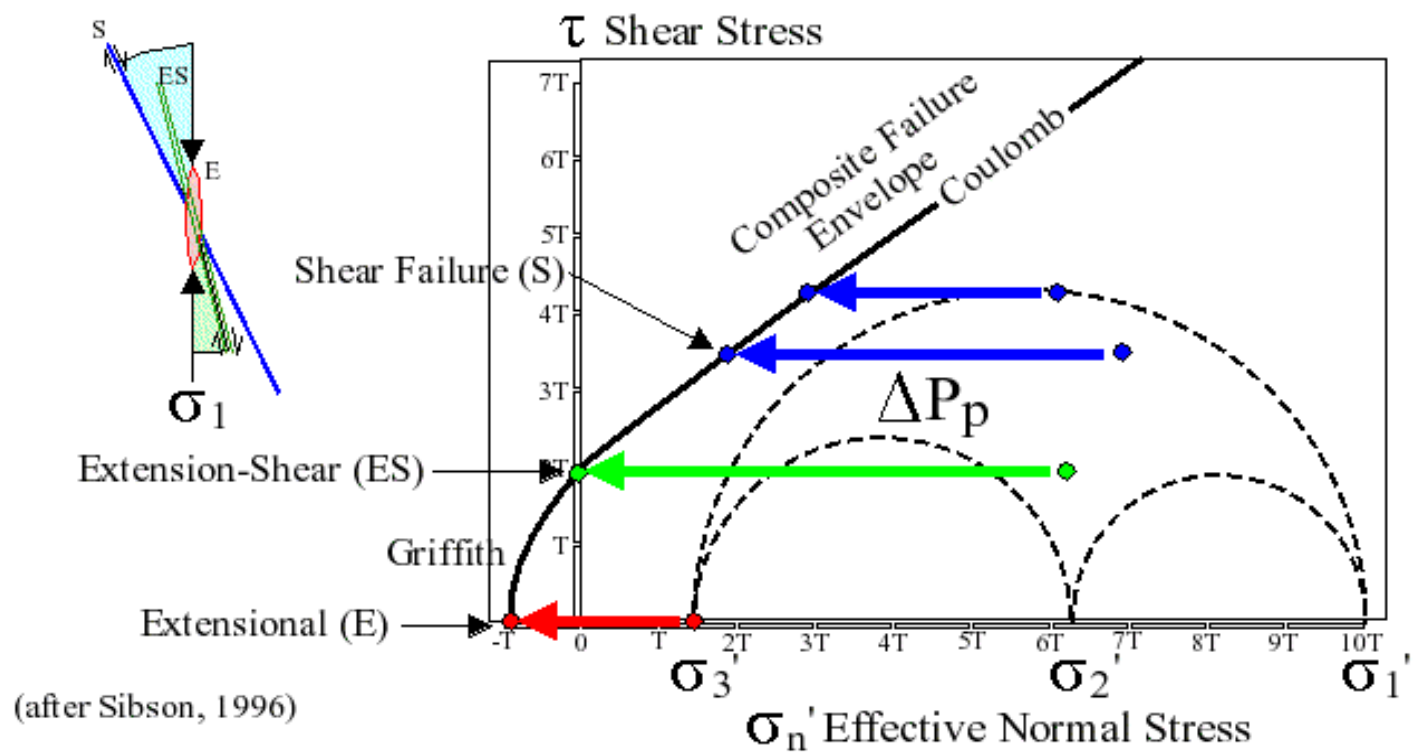

Figure 4.3 Fracture Stability (Mildren et al., 2005), based on Sibson (1996). Failure is predicted using a composite Griffith-Coulomb failure envelope. The different coloured arrows indicate the different modes of failure on various orientations of fault planes. The blue arrows show fault orientations where shear failure is most likely to occur, the green arrow shows a fault orientation where hybrid, or extensional-shear, is most likely to occur and the red arrow shows a fault orientation where extensional failure is most likely to occur. The smaller diagram in the left of the figure shows visually the different types of failure on various fault plane orientations. Image from TrapTester 6.0 Manual (2009)

\subsection{Model Input Data}

Accurate knowledge of the in-situ stress tensor and pore pressure gradient within the Kupe Area was required for input into the three geomechanical models being tested. In sedimentary basins the stress tensor is commonly reduced to three components; the magnitude of vertical stress; the maximum horizontal stress magnitude and direction; and the minimum horizontal stress magnitude and direction (Fig. 4.4) (Zoback, 2007). These data are commonly gathered during petroleum well drilling and are typically used to define the regional stress field. 


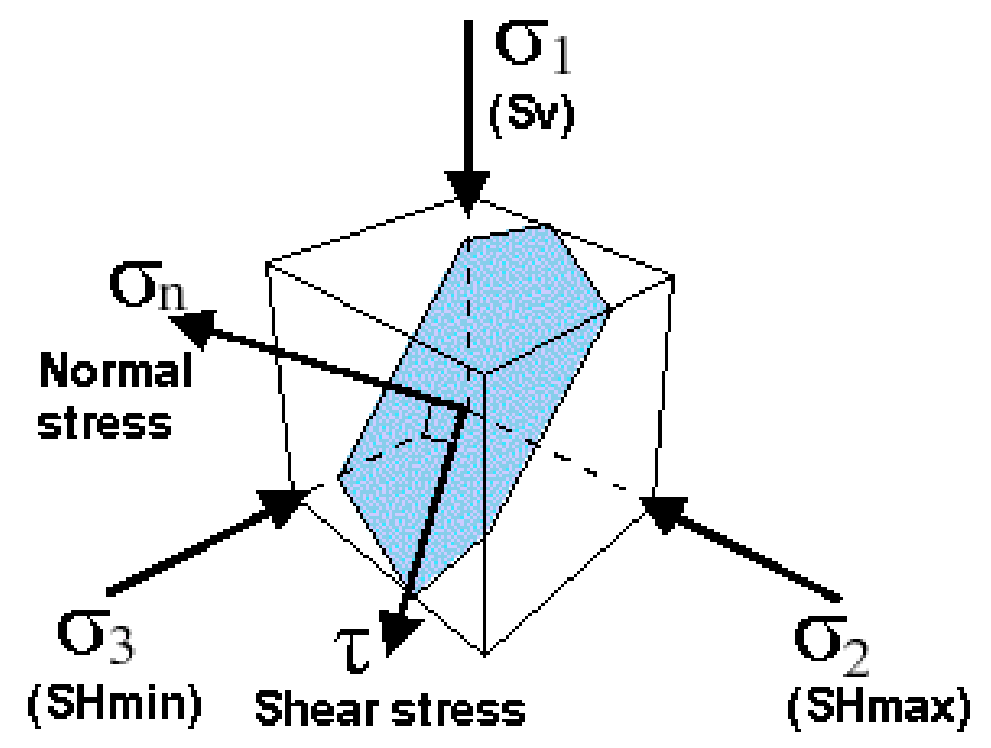

Figure 4.4 Components of stress tensor and the resulting shear and normal stress acting on an arbitrarily orientated surface coloured blue. Stress notations used throughout this chapter are indicated. Image from TrapTester 6.0 Manual (2009)

\subsubsection{Pore Pressure}

Pore pressure was estimated using available DST, RFT and mud weight data, from Petroleum Reports for the Kupe Area (see Appendix III for a list of wells with pressure data and IV for a list of Petroleum reports used). These measurements indicate a vertical pressure gradient of $10.1 \mathrm{MPa} / \mathrm{km}$, with hydrostatic pressures observed down to the Otaraoa top seal ( 3300m depth) in all wells (Fig. 4.5). This gradient is comparable to that derived for the Kupe Area by Jefferies (1996). Below 3000m (i.e. below the top seal) there is evidence of overpressure of approximately 5-6 MPa (i.e. compared to hydrostatic pressure). The coincidence of the top of the overpressured zone with the regional seal is consistent with the view that fluids above and below the seal are not in strong hydraulic communication. This observation supports the suggestion that the seal is capable of holding a hydrocarbon column beneath it. The amount of overpressure is comparable to estimates of 7.2 MPa by Best and Parvar (1989) and, as pore pressure influences effective stress and inputs into geomechanical models two pore pressure models were applied during this study: a hydrostatic model down to approximately 3300m and an overpressure model below 3300m. 


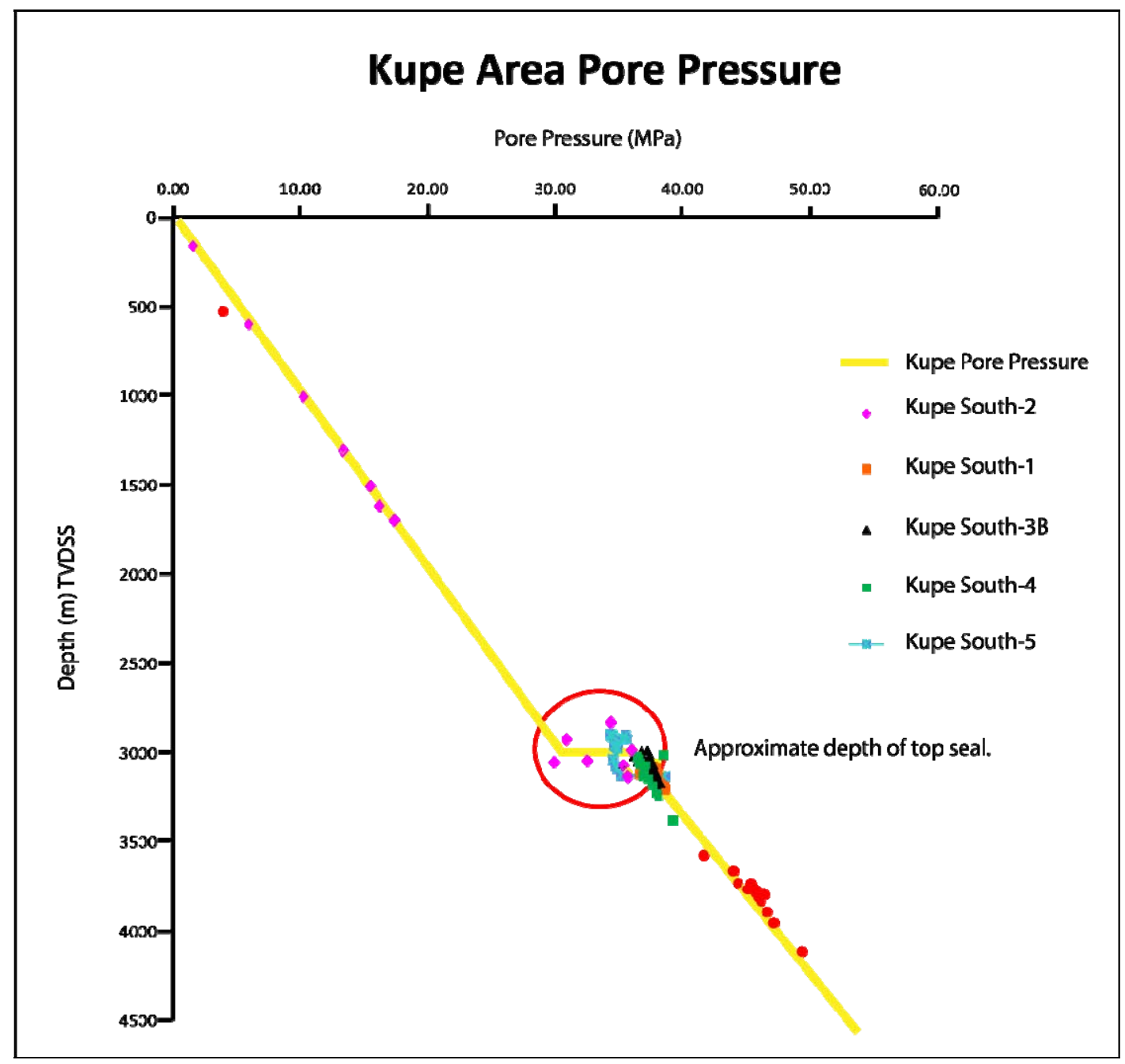

Figure 4.5 Pore pressure gradient verses depth. Pressure values obtained from RFT and DST measurements in Kupe Area exploration wells. Red circle shows the depth of overpressure development. Yellow line shows the line of best fit for the data. The best fit line was created for sections above and below the depth where overpressure develops (3000 m ) using a linear regression and the two sections then horizontally linked at $3000 \mathrm{~m}$. 


\subsection{2 $S_{H \max }$ and $S_{\text {hmin }}$ Directions}

Maximum and minimum horizontal stress directions are commonly constrained in petroleum wells using the orientations of borehole breakouts and tensile induced drilling fractures respectively (e.g., Wiprut et al., 1997; Nelson et al., 2005; Yaghoubi and Zeinali, 2009; Zoback, 2009). Borehole breakout and drilling-induced tensile fractures form due to an increase in stress concentration around the borehole during drilling. The change in stress concentration occurs because the wellbore wall must support the stresses that were previously borne by the removed material. Borehole breakouts occur when the maximum circumferential stress exceeds the compressive strength of wall rock resulting in compressive failure in parts of the well bore wall (Zoback, 2007). The strike of breakout fractures indicates the direction of $S_{\mathrm{hmin}}$ (Vernik and Zoback, 1992 and references therein; Zoback, 2007). Drilling induced tensile fractures occur when the minimum circumferential stress is less than the tensile strength of rock. The strike of tensile fractures is parallel to the direction of $\mathrm{S}_{\mathrm{Hmax}}$ (Zoback, 2007).

As borehole FMI image data for the Kupe Area was unavailable for this study, borehole breakout and tensile fracture strike data from a previous FMI image log and dip meter study by Horan (1997) was used. Breakout and tensile fracture orientations were collated and an average trend for $S_{H \max }$ established (see Table 1.). Average $S_{H \max }$ and $S_{h \min }$ trends of $49^{\circ}$ and $139^{\circ}$, respectively were derived as input into the Kupe stress tensor model. These values correlate well with the horizontal stress orientations derived by Camac et al., (2006), who undertook numerical stress modelling in the Kupe Area.

Table 4.1 Borehole break out values from Horan (1997).

\begin{tabular}{|l|l|l|l|}
\hline Well & BOL Break Out Strike & FMS Image Break Out Strike & Shmin Trend \\
\hline Kupe South-2 & $140^{\circ}$ & $145^{\circ}$ & $140^{\circ}$ \\
\hline Kupe South-4 & $133^{\circ}$ & $132^{\circ}$ & $133^{\circ}$ \\
\hline Kupe South-5 & $140^{\circ}$ & $139^{\circ}$ & $140^{\circ}$ \\
\hline Toru-1 & $142^{\circ}$ & $151^{\circ}$ & $142^{\circ}$ \\
\hline Average & & & $139^{\circ}$ \\
\hline
\end{tabular}




\subsubsection{Stress Magnitudes}

\subsubsection{1 $S_{v}$ Magnitude}

The magnitude of vertical stress $\left(\mathrm{S}_{\mathrm{V}}\right)$ acting at a point in a sedimentary basin can be defined as the pressure exerted by the weight of the overlying sedimentary column. This can be calculated using Equation (2):

$\mathrm{S}_{\mathrm{V}}=\int \rho(\mathrm{z}) \mathrm{gdz}$

Equation (2)

where $\rho$ is the density of the overlying rocks at depth $\mathrm{z}$ and $\mathrm{g}$ is the acceleration due to gravity (Zoback, 2007). A vertical stress profile based on data from the Kupe-1 well has been generated by Lawrence (unpublished data, 2010). The Kupe-1 well profile was chosen as it was considered to contain the best quality density data evident in the good agreement between density and porosity measurements. The $\mathrm{S}_{\mathrm{V}}$ profile was generated from the Kupe-1 sonic density log by integrating calculated density values from well total depth (TD) to the shallowest measurement $(96 \mathrm{~m})$, and then extrapolating these values to the seafloor. The sonic density log was checked for spurious values and cleaned prior to calculating the $S_{\mathrm{V}}$ gradient (M. Lawrence pers. com, 2010). The Kupe-1 well $\mathrm{S}_{\mathrm{V}}$ gradient of $21.7 \mathrm{MPa} / \mathrm{km}$ (see Fig. 4.6) has been adopted for the entire study area; this approach is considered reasonable given the well's central location and the relatively uniform stratigraphy across the study area. The vertical stress gradient $\left(\mathrm{S}_{\mathrm{V}}\right)$ calculated in this study is also similar to that derived by Camac et al., (2005) for the Kupe Area, with only a 0.2 $\mathrm{MPa} / \mathrm{km}$ difference between the two models. 


\section{Kupe $S_{\mathbf{v}}$}

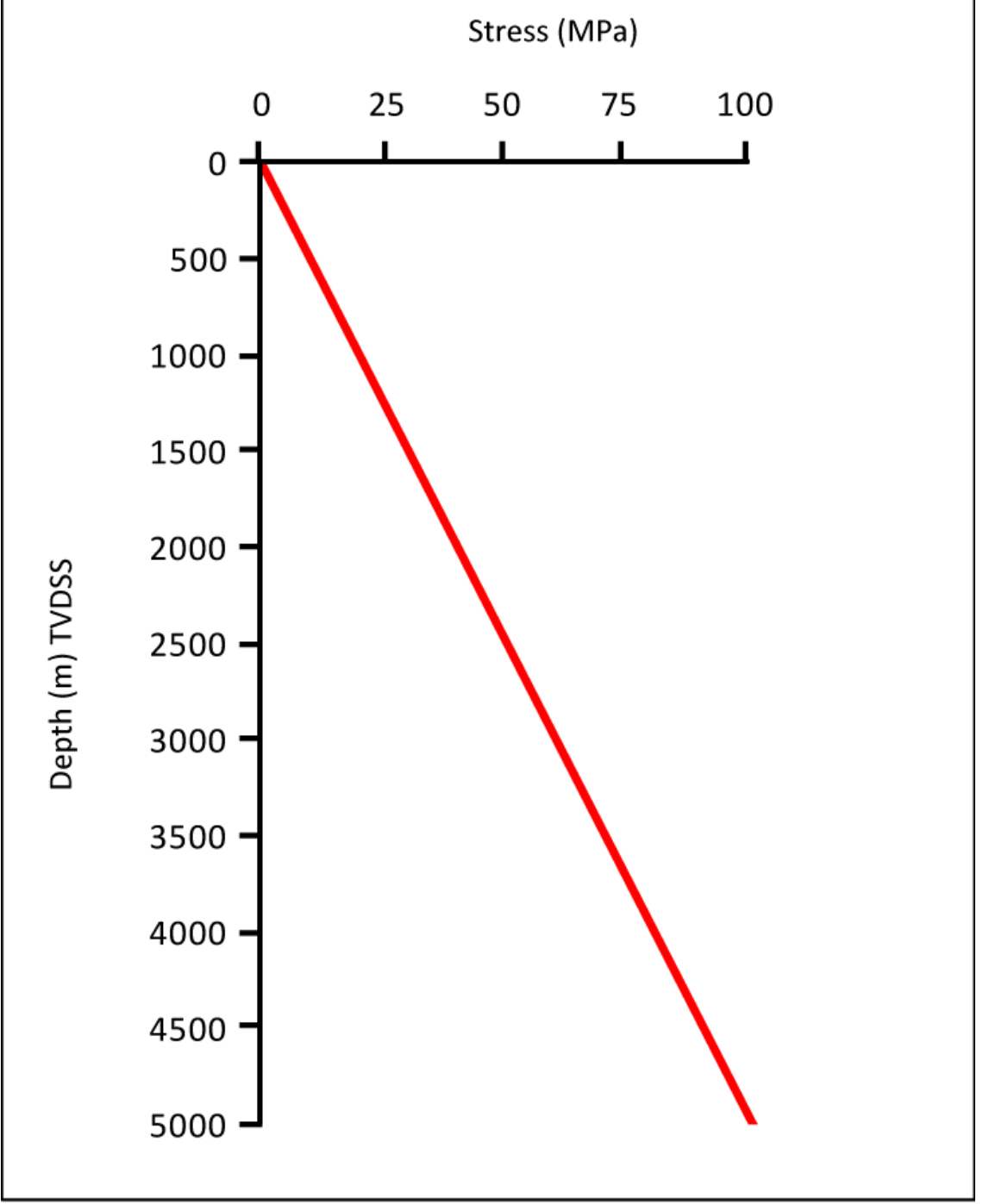

Figure 4.6 Vertical stress $\left(\mathrm{S}_{\mathrm{V}}\right)$ profile generated from Kupe-1 density log (Lawrence, unpublished data 2010). Refer to text for discussion of curve generation. The line of best fit was created using a linear regression. Individual data points are not shown as they have been generated every two metres and are too dense to display. 
To constrain the minimum horizontal stress $\left(\mathrm{S}_{\mathrm{hmin}}\right)$ magnitude within the Kupe Area LOT and FIT data were gathered from unpublished Petroleum Reports (see Appendix IV for Petroleum Reports reports used). These data are plotted on Figure 4.7. LOTs involve pumping drilling mud into the bottom of the well to induce fracturing in the wellbore wall (Zoback, 2009). Leak-off occurs when there is a distinct decrease in down-hole pressure due to loss of drilling fluid into the well bore. The weight of the drilling mud required to induce leak-off is considered an approximate estimate of the magnitude of $S_{\text {hmin }}$. FITs test the ability of a formation to resist drilling fluid pressure by increasing the mud weight. The mud weight is increased to a predefined value to test if tensile fractures in the formation will form at the planned mud weight for drilling the next section of the well. As leak-off is not commonly achieved the mud weight in a FIT is considered a minimum bound to $\mathrm{S}_{\mathrm{hmin}}$ (Zoback, 2009).

The majority of data gathered from reports on the Kupe wells were from FIT and the few LOT values did not have time series measurements to establish if leak-off had occurred. It is therefore assumed that the calculated $S_{\text {hmin }}$ gradient of $15.7 \mathrm{MPa} / \mathrm{km}$ in the Kupe Area is a lower bound (Fig. 4.7). This study's $S_{\text {hmin }}$ estimate of $15.7 \mathrm{MPa} / \mathrm{km}$ is close to that of Camac et al. (2005) who estimated $S_{\mathrm{hmin}}$ for the Kupe Area of $15.5 \mathrm{MPa} / \mathrm{km}$. 


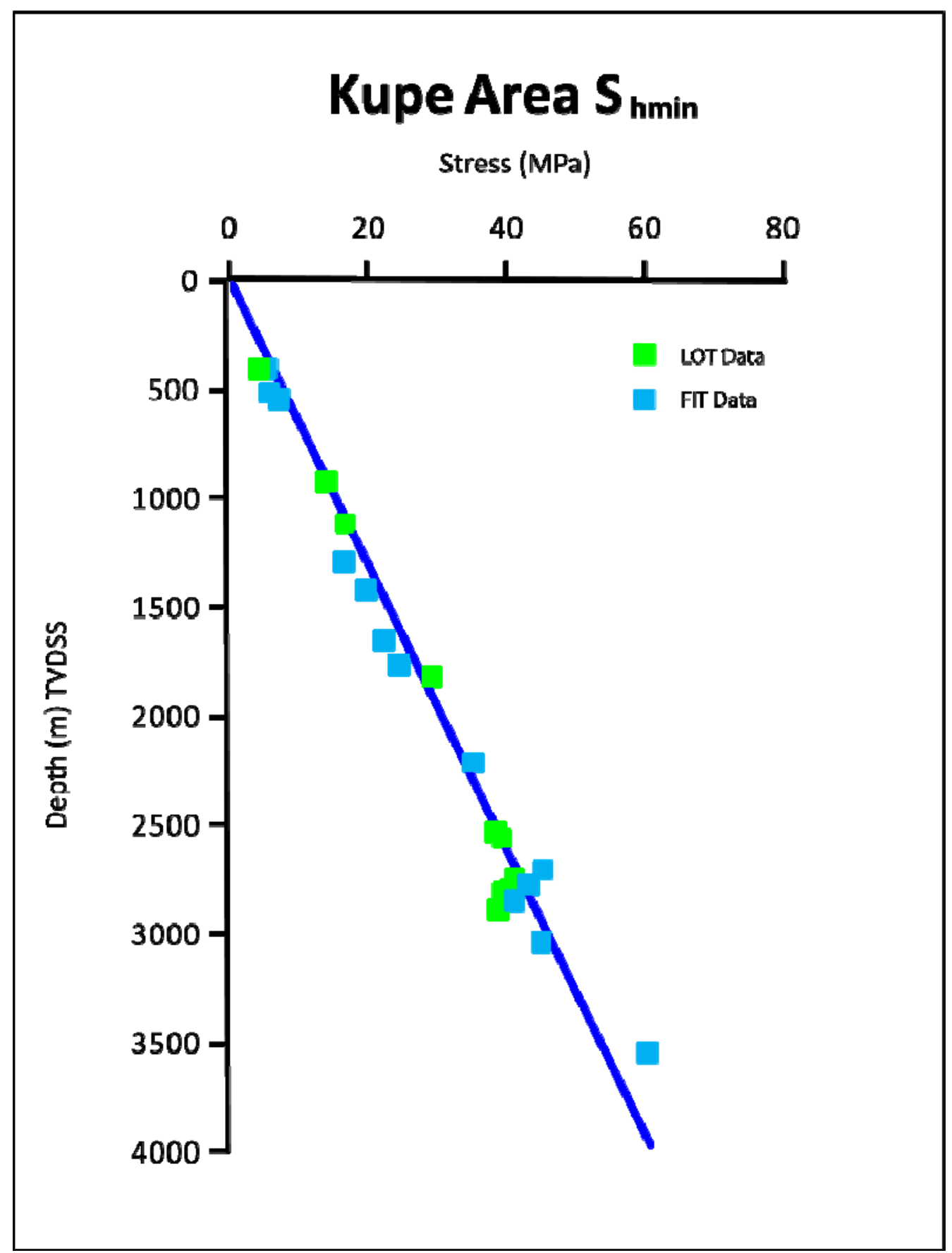

Figure 4.7 Change in $\mathrm{S}_{\mathrm{hmin}}$ with depth estimated from FIT and LOT data. Line of best fit created using a linear regression. 


\subsubsection{3 $S_{\text {Hmax }}$ Magnitude}

The maximum horizontal stress magnitude is the hardest of the three stress magnitudes to constrain. Several different methods can be applied to estimate the magnitude including hydraulic fracturing (e.g., Ito et al., 1999), stress states required to induce tensile fractures or borehole breakout (e.g., Wiprut et al., 1997; Zoback, 2009) and frictional limits of the crust (e.g., Moos and Zoback, 1990). Estimates of $S_{H \max }$ are here based on the later two techniques. $\mathrm{S}_{\mathrm{Hmax}}$ was calculated using depths of drilling-induced fractures as data required on the width of borehole breakout was unavailable.

Maximum horizontal stress can be calculated for the depths of drilling-induced tensile fractures based on the equation for circumferential stress at a wellbore. As tensile failure occurs when the minimum circumferential stress is less than the tensile strength of rock an estimate of $\mathrm{S}_{\mathrm{Hmax}}$ can be made based on Equation (3),

$\sigma \theta \theta_{\min }=3 \mathrm{~S}_{\mathrm{hmin}}-\mathrm{S}_{\mathrm{Hmax}}-\mathrm{P}_{\mathrm{w}}-\mathrm{P}_{\mathrm{p}}<\mathrm{T}$

Equation (3)

where $\sigma \theta \theta_{\min }$ is the minimum circumferential stress, $\mathrm{P}_{\mathrm{w}}$ is the mud weight and $\mathrm{P}_{\mathrm{p}}$ pore pressure, and $\mathrm{T}$ tensile rock strength at the depth of the tensile fracture (Moos and Zoback, 1990). As there are no publicly available measurements of rock strength within the Taranaki Basin, values for tensile rock strength were used from Chen et al., (1998) as they represented measurements from the same lithologies as those in the Kupe wells where tensile failure occurred. Tensile strength values used were low (ranging from 0.7-1.59 psi) and a zero tensile strength for reservoir rocks was also used, as is it is often assumed reservoir rocks have zero tensile strength when calculating $\mathrm{S}_{\mathrm{Hmax}}$ (e.g., (Wiprut et al., 1997a; Wiprut et al., 1997b; Barton et al., 1998; Brudy \& Kjorholt, 2001; Nelson and Hillis, 2005). Results showed little variation ( 0.5 MPa) in $\mathrm{S}_{\mathrm{Hmax}}$ calculated from the tensile strengths of Chen et al., (1998) and a zero tensile strength. Estimates of $\mathrm{S}_{\mathrm{Hmax}}$ at depths of drilling-induced tensile fractures using the circumferential stress technique are shown in Table 2. Due to uncertainties with a number of parameters, the average gradient of $\sim 46 \mathrm{MPa} / \mathrm{km}$ for $\mathrm{S}_{\mathrm{Hmax}}$ should be considered a lower bound. This gradient is twice that of Camac et al. (2005), who suggested a gradient of $23 \mathrm{MPa} / \mathrm{km}$ for $\mathrm{S}_{\mathrm{Hmax}}$ within the Kupe Area. 
Table 4.2 $\mathrm{S}_{\mathrm{Hmax}}$ calculations from circumferential stress associated with formation of tensile fractures. Columns show depth of drilling-induced tensile fracture and the calculated $S_{\text {hmin }}$ at that fracture depth. See Figure 1.3, Chapter 1 for well locations.

\begin{tabular}{|c|c|c|}
\hline Well & $\begin{array}{l}\text { Depth of Drilling Induced Tensile Fracture (m } \\
\text { KB) }\end{array}$ & $\begin{array}{l}\text { Calculated SHmax at } \\
\text { Fracture Depth (Mpa) }\end{array}$ \\
\hline Kupe South-5 & 3014 & 136.8419721 \\
\hline Toru-1 & 3769 & 174.8231713 \\
\hline Toru-1 & 3770 & 174.811291 \\
\hline Toru-1 & 3823 & 177.001633 \\
\hline Toru-1 & 3828 & 175.9726936 \\
\hline Toru-1 & 3840 & 176.7158949 \\
\hline Toru-1 & 4148.5 & 193.4835222 \\
\hline
\end{tabular}

The complete initial stress tensor for the Kupe Area with $\mathrm{S}_{\mathrm{Hmax}}$ estimated based on circumferential stress is shown in Figure 4.8. As the magnitude of $\mathrm{S}_{\mathrm{Hmax}}$ significantly exceeds $S_{V}$ values, a predominantly strike-slip faulting regime is suggested in the Kupe Area based on Andersonian faulting theory Anderson, (1972).The inferred strike-slip faulting regime differs from the normal fault kinematics observed in outcrop and seismic reflection data within the South Taranaki Basin, suggesting that there are either errors in the stress input data or that the circumferential stress technique is not applicable in the study area. Extensive shallow channels within the Kerry 3D seismic reflection volume that predate faulting indicate no evidence of any lateral movement across fault zones. Onshore field-studies of fault striations indicate predominantly dip-slip movement on normal faults throughout the Taranaki Basin, further corroborating the seismic reflection observations (Giba, 2010; Townsend et al. 2010). These observations coupled with the strong correlation of $S_{H \max }$ orientation with average fault strike in the Kupe Area (Fig. 4.9) suggest that faults accommodate predominantly dip-slip extensional movement within the Kupe Area.

Errors in calculated $\mathrm{S}_{\mathrm{Hmax}}$ could have arisen for two possible reasons. First, the circumferential stress technique applied to $S_{H \max }$ calculations was initially applied to crystalline rocks by Vernik and Zoback (1992), who questioned the applicability of the technique to sedimentary cataclastic rocks. Further to this, studies by Santarellie et al. 
(1986) indicate that a level of strain hardening could occur in sedimentary rocks prior to tensile failure, invalidating the circumferential stress technique's assumption of an elastic medium. Secondly, incorrect interpretation of drilling-induced tensile fractures by Horan (1997) could have invalidated the use of the methodology.

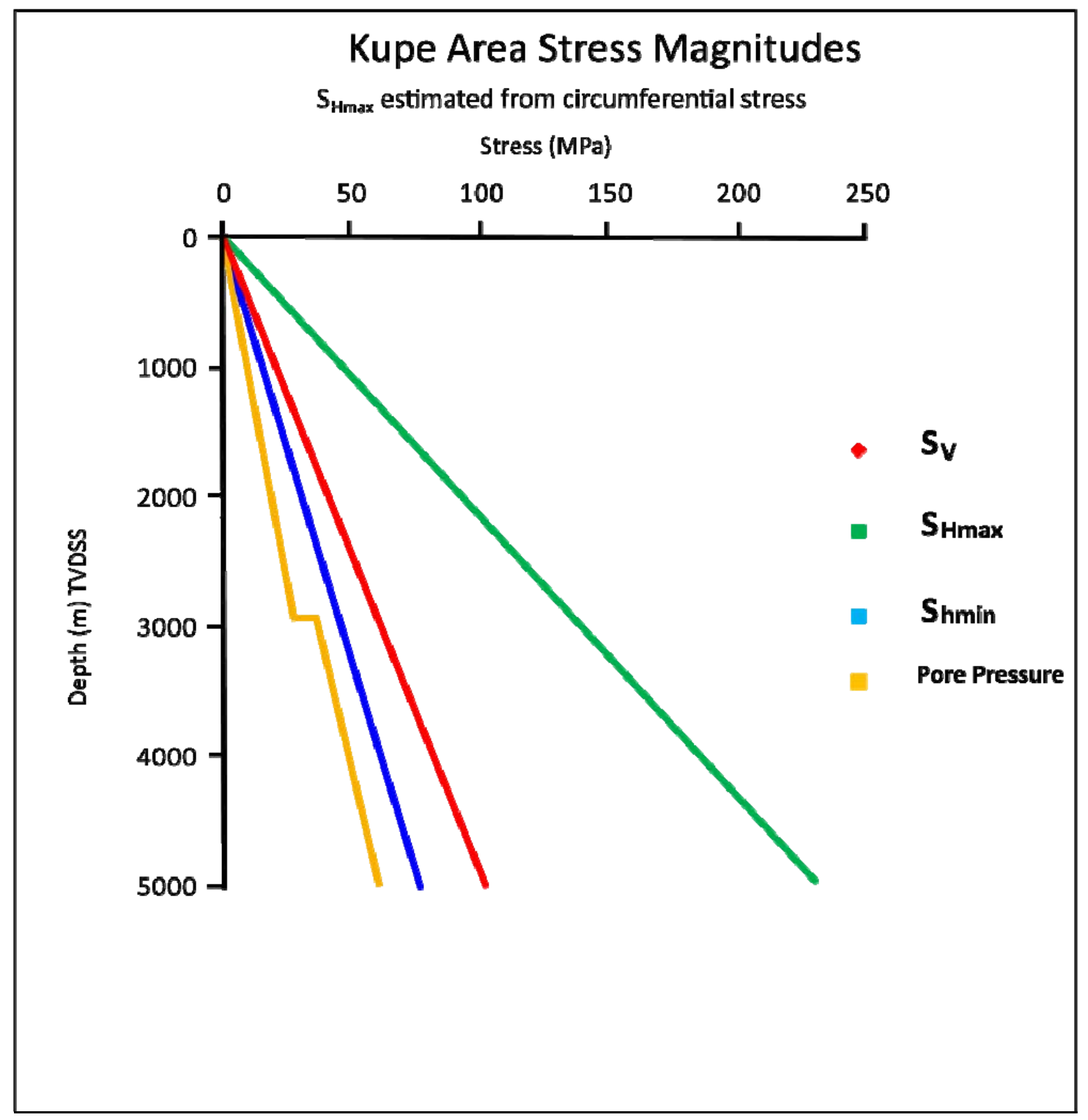

Figure 4.8 Kupe stress tensor with a predominantly strike-slip stress regime. Estimate of $\mathrm{S}_{\mathrm{Hmax}}$ based on equation for circumferential stress. 


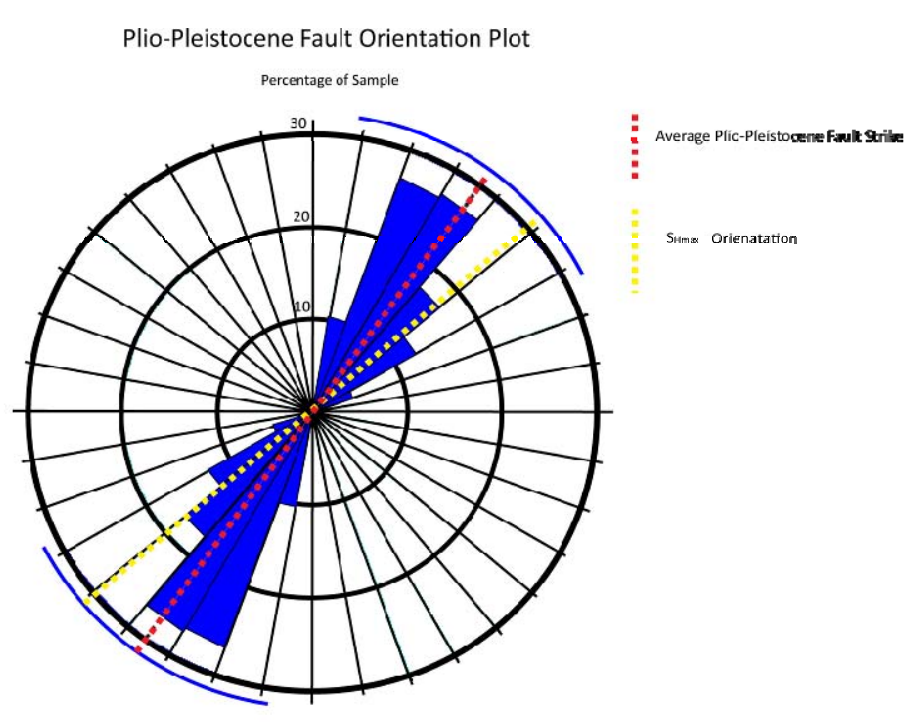

Figure 4.9 Rose diagram of Plio-Pleistocene faults showing correlation between fault orientation and $\mathrm{S}_{\text {Hmax }}$.

As the results of the circumferential stress technique for estimating $\mathrm{S}_{\mathrm{Hmax}}$ were considered erroneous, $\mathrm{S}_{\mathrm{Hmax}}$ magnitude has been constrained using an allowable region diagram (Moos and Zoback, 1990). The diagram defines the frictional limits of the allowable ratio of maximum to minimum effective stress. Frictional limit theory, first suggested by Sibson, (1974), states that the ratio of the maximum to minimum effective stress cannot exceed the magnitude required to cause failure on a cohesionless fault optimally orientated to the principle stress field. The frictional limit of stress is calculated using Equation (4) (Jaeger and Cook, 1979),

$\left(S_{1}-P_{0}\right) /\left(S_{3}-P_{0}\right)=\left[\left(1+\mu^{2}\right)^{0.5}+\mu\right]^{2}$ Equation (4)

where $S_{1}$ is vertical stress, $S_{3}$ is minimum horizontal stress, $P_{0}$ is pore pressure, and $\mu$ the rock's coefficient of friction. Using an $\mathrm{S}_{\mathrm{V}}$ gradient of $21.7 \mathrm{MPa} / \mathrm{km}$ and a $\mu$ of 0.6 (based on Byerlee, 1978), the allowable range of the $S_{H \max }$ gradient was calculated (Fig. 4.10). The lower bound of $\mathrm{S}_{\mathrm{Hmax}}$ is $13.6 \mathrm{MPa} / \mathrm{km}$ and the upper bound is $21.7 \mathrm{MPa} / \mathrm{km}$. 


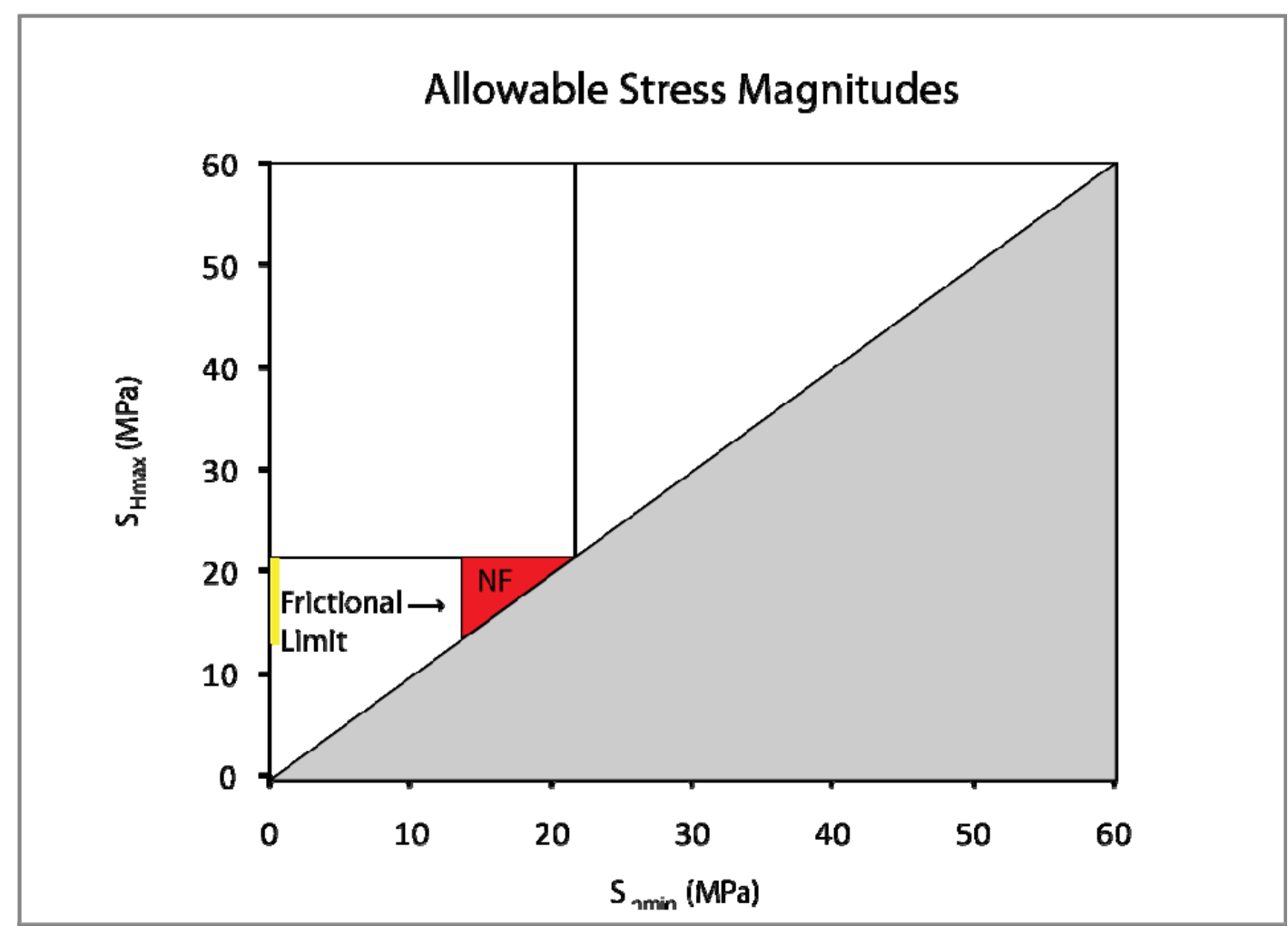

Figure 4.10 Allowable region diagram for the Kupe Area. The red triangle indicates allowable stress magnitudes for normal faulting in the Kupe Area. The yellow bar shows the range of allowable $S_{\mathrm{Hmax}}$ magnitudes. $\mathrm{NF}=$ normal faulting.

As faulting in the Kupe Area is predominantly dip-slip it can be assumed based on MohrCoulomb failure theory that the magnitude of $\mathrm{S}_{\mathrm{Hmax}}$ is approximately halfway between $\mathrm{S}_{\mathrm{hmin}}$ and $\mathrm{S}_{\mathrm{V}}$ (J. Townend pers. com, 2010). This would place a value of $18.7 \mathrm{MPa}$ on $\mathrm{S}_{\mathrm{Hmax}}$, which is within the frictional limits calculated using the allowable region diagram. The final value of the $S_{H \operatorname{Hax}}$ gradient applied was slightly greater than halfway between $S_{\text {hmin }}$ and $\mathrm{S}_{\mathrm{V}}$ to reflect a possibility that a minor component of strike-slip movement on faults in the Kupe Area might exist. Figure 4.11 shows the final stress gradients for the Kupe Area used in geomechanical modelling. 


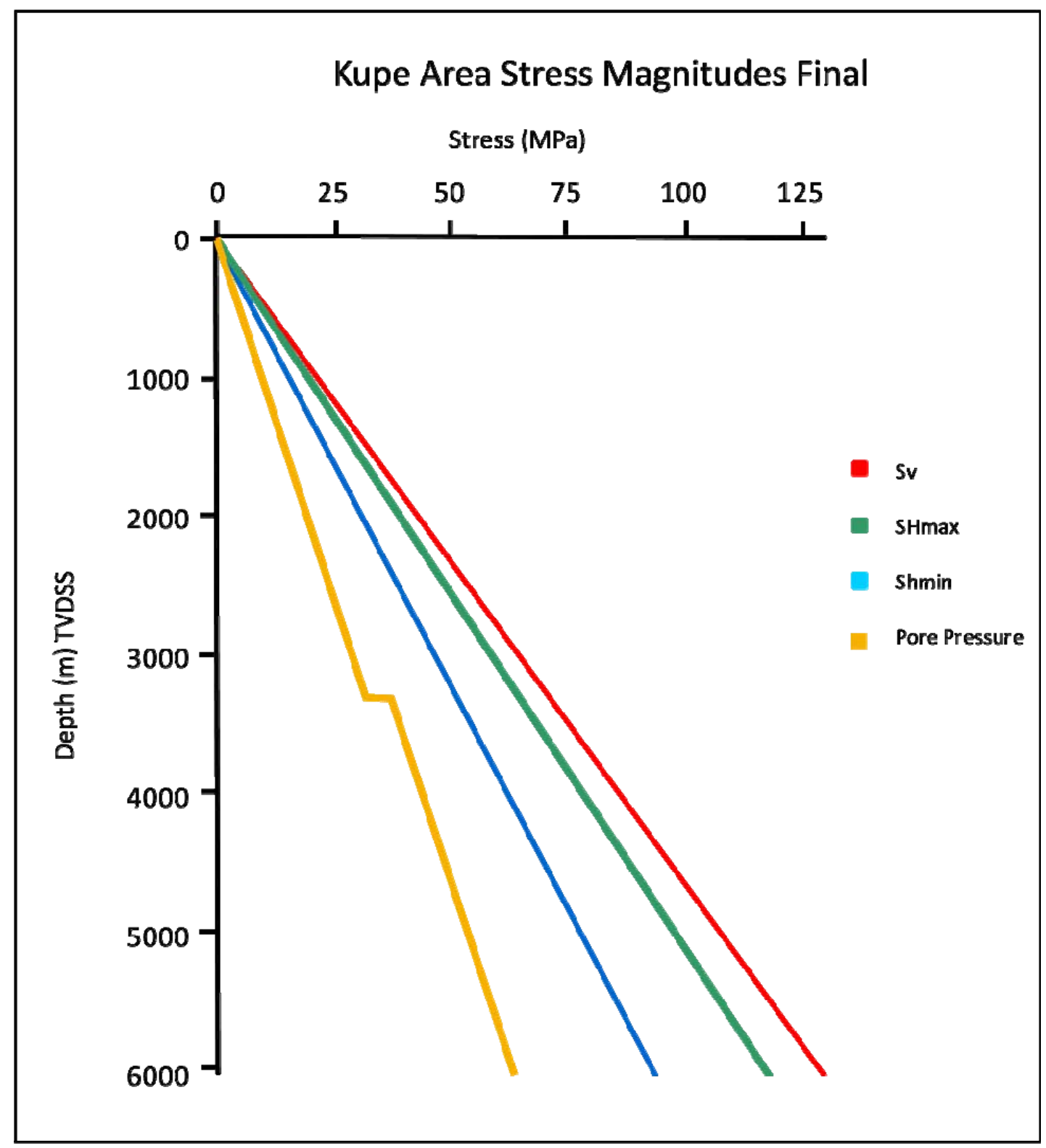

Figure 4.11 Final Kupe stress tensor for geomechanical modelling. Data for these curves are presented in Figures 4.5, 4.6, 4.7 and 4.10. $\mathrm{S}_{\mathrm{Hmax}}$ estimated using Allowable Region Diagram (Moos and Zoback, 1990). 
For application in the geomechanical models the stress tensor for the Kupe Area has been used to calculate the shear and normal stresses acting on all parts of fault surfaces within the stress field. Shear stress and normal stress were calculated for all possible fault orientations within the Kupe stress field based on Equations 5 and 6 respectively.

$\lambda=\left(\frac{\sigma 1-\sigma 3}{2}\right) \sin 2 \theta$

Equation (5)

$\sigma n=\left(\frac{\sigma 1+\sigma 3}{2}\right)+\left(\frac{\sigma 1-\sigma 3}{2}\right) \cos 2 \theta$

Equation (6)

where $\sigma 1$ is maximum principle stress, $\sigma 3$ is minimum principle stress and $\theta$ is the angle between the fault plane and vertical (Zoback, 2009) (see Fig. 4.12).

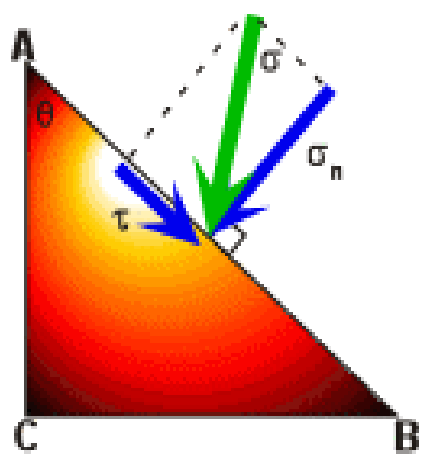

Figure 4.12 Normal $\left(\sigma_{\mathrm{n}}\right)$ and shear $(\tau)$ stress acting on an arbitrarily orientated plane. Image from www.geology.sdsu.edu/visualstructure/vss/htm_hlp/ns_ste.htm

\subsubsection{Fault-Rock Properties}

Strength property data for fault-rocks were not available within the Taranaki Basin. Faults are seldom cored intentionally giving rise to a limited availability in fault-rock failure data. A literature review was conducted for the purpose of establishing bounds on fault-rock properties used in the geomechanical modelling. Data gathered was supplemented with input parameters for various fault-rock types available within TrapTester software (Table 4.3). As faults cutting the Otaraoa top seal are postulated to cause leakage in the Kupe 
Area establishing correct fault strengths at this stratigraphic depth was considered important. Field observations of faults within Te Kuiti Group siltstones (a laterally equivalent facies to the Otaraoa Formation top seal found in the Kupe Area) indicated that fault material, when present, was predominantly cataclasite (in faults of $\sim 5 \mathrm{~m}$ throw and smaller), with limited evidence of clay smears (see Chapter V). All faults examined were filled with calcite veining that post dated fault activity (see Chapter 5 for detailed review of fault material). Field-based observations of the Te Akatea Formation calcareous siltstones $100 \mathrm{~km}$ north of Waikawau Beach by Giba, (2010) found clay gouges and breccias, ranging in thickness from 1-10 cm, in faults with throw between $100-1000 \mathrm{~cm}$. As cataclasites, breccias and clay smears were the commonly observed fault-rocks properties representing these fault-rock types from literature and the Trap Tester software data-set were included in geomechanical model testing.

Table 4.3 Fault-rock properties data table from TrapTester 6.0

\begin{tabular}{|l|l|l|}
\hline Rock Type & $\begin{array}{l}\text { Coefficient of Internal } \\
\text { Friction }\end{array}$ & $\begin{array}{l}\text { Intrinsic Material } \\
\text { Strength (MPa) }\end{array}$ \\
\hline Disaggregation Zone & 0.75 & 0.00 \\
\hline Cataclasite & 0.75 & 4.00 \\
\hline Cemented Cataclasite & 0.75 & 10.00 \\
\hline Phyllosilicate fault-rock & 0.6 & 0.5 \\
\hline $\begin{array}{l}\text { Cemented Phyllosilicate } \\
\text { fault-rock }\end{array}$ & 0.85 & 10.00 \\
\hline Clay smear & 0.45 & 0.5 \\
\hline Smectite-rich clay smear & 0.33 & 2.00 \\
\hline
\end{tabular}




\subsubsection{Parameter Testing}

Due to uncertainty in input parameters for the Kupe Area stress model and the fault-rock properties, extensive sensitivity testing of all three modelling methods has been undertaken. All input parameters were varied to find the upper and lower bounds of the model results and to establish which parameters exerted the greatest influence on modelling results. The final parameters used in modelling are listed in Table 4.4 and were determined from the sensitivity testing.

For a given fault geometry test results indicate that Dilation Tendency was most sensitive to changes in stress magnitudes and stress orientations, Slip Tendency was most sensitive to changes in stress magnitudes, stress orientations and pore pressure, and Fracture Stability was most sensitive to changes in pore pressure gradient and the depth that over-pressure developed.

Variations in fault-rock properties only have a minor influence on modelling results compared to variations in the stress tensor and thus their effects on leakage risk results are considered to be secondary. However, the coefficient of friction does influence the proximity of faults to being critically stressed faults. Uncertainty in this parameter is discussed in Section 4.5.

Table 4.4 Final geomechanical modelling inputs

\begin{tabular}{|l|l|}
\hline Parameter & Value \\
\hline $\mathrm{S}_{\mathrm{hmin}}$ Gradient $\mathrm{MPa} / \mathrm{km}$ & 0.0157 \\
\hline $\mathrm{S}_{\mathrm{Hmax}}$ Gradient MPa/km & 0.0197 \\
\hline $\mathrm{S}_{\mathrm{V}}$ Gradient MPa/km & 0.0217 \\
\hline $\mathrm{S}_{\mathrm{hmin}}$ Orientation & $139^{\circ}$ \\
\hline $\mathrm{S}_{\mathrm{Hmax}}$ Orientation & $49^{\circ}$ \\
\hline Pore Pressure Gradient Hydrostatic MPa/Km & 0.0981 \\
\hline Coefficient of Friction & 0.6 \\
\hline Coefficient of Internal Friction & 0.75 \\
\hline Intrinsic Material Strength MPa & 0.5 \\
\hline
\end{tabular}




\subsection{Spatial Relations between Fault Geomechanics and Gas Chimneys}

This section outlines the results of the three geomechanical modelling methods and the predictions from each modelling method provides for the likelihood of structural permeability existing on modelled fault surfaces in the present day stress field. Results are then compared to gas chimney locations on fault surfaces and a statistical analysis is made of geomechanical modelling results at chimney versus non-chimney locations on fault surfaces. The ability of geomechanical models to differentiate locations of gas leakage and enhanced structural permeability is then assessed.

\subsubsection{Slip Tendency}

Slip Tendency for faults above the Otaraoa top seal (>3300 m) at hydrostatic pressure is low across the entire Kupe Area. Values range from 0-0.37 ( 0 being low Slip Tendency and 1 being high Slip Tendency), with fault orientation within the stress field only exerting a minor influence on Slip Tendency values (Fig. 4.13). Minor local variations in Slip Tendency result from changes in fault surface topography and orientation. Slip Tendency at $2000 \mathrm{~m}$ (where gas chimneys were first unequivocally observed within seismic reflection data), on fault surfaces that have related gas chimneys is between 0.2-0.37. Little variation in values is seen between chimney and non-chimney faults. Modelling indicates that there is a low tendency for faults to slip at this depth and thus a low probability of structural permeability within the fault zones which transect the top seal. All faults plot below the Mohr-Coulomb failure envelope based on a coefficient of internal friction of 0.5. Many faults with associated gas chimneys are still below the failure envelope when the coefficient of friction is decreased to the lower most bound (0.3). 

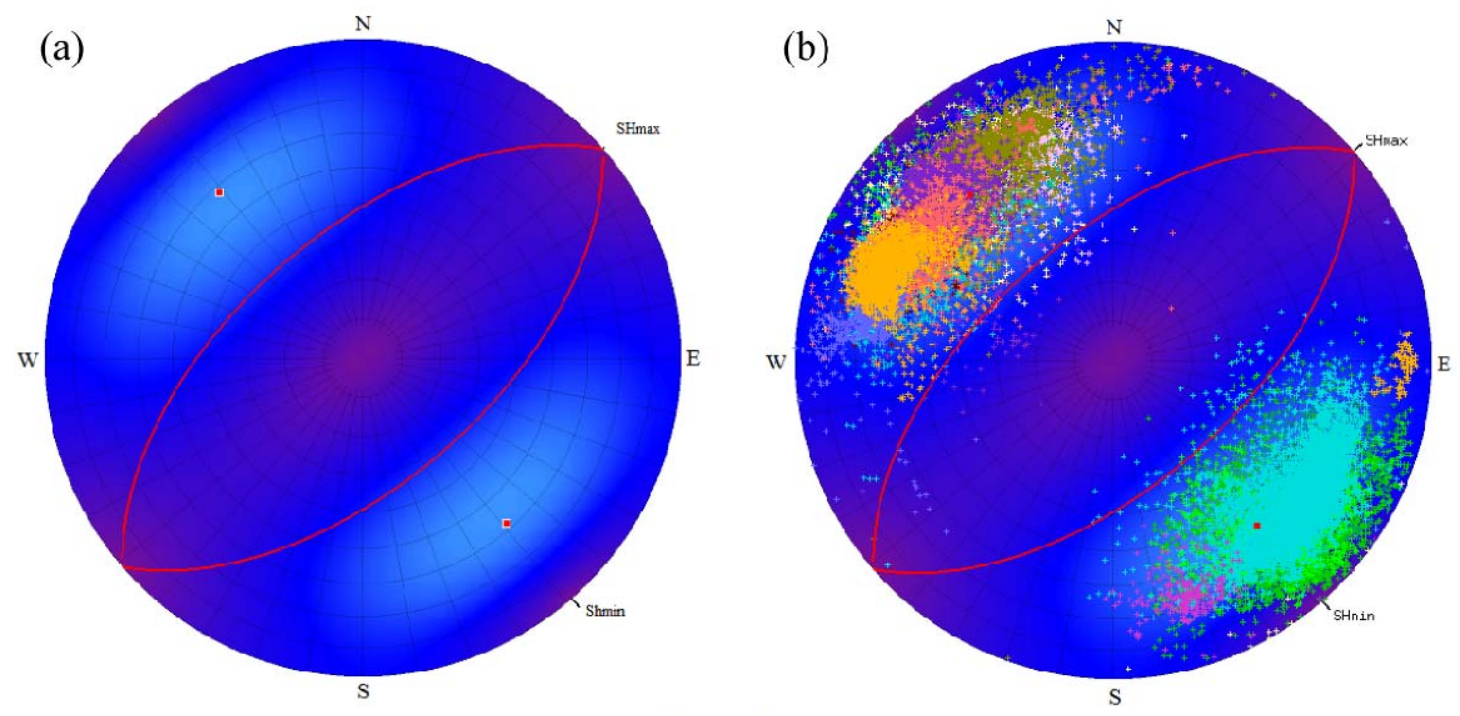

Slip Tendency

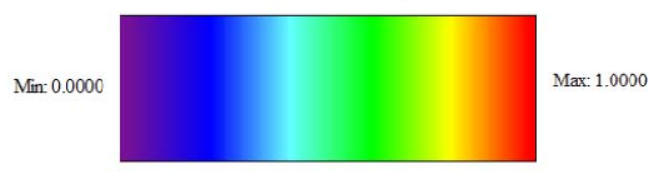

Figure 4.13 Equal area stereonet plots of Slip Tendency at 2000m (TVDSS). (a) Shows Slip Tendency across the Kupe Area. Slip Tendencies are indicated by colours which correspond to values ranging from 0-1 (see colour bar). (b) Slip Tendency with poles to all faults with visible gas chimneys. Each fault has a set of poles that represent locations on individual fault surfaces. All poles to an individual fault surface are the same colour and the pole colours do not represent the Slip Tendency. In both stereonets the red lines and filled squares show the planes and poles respectively to faults with greatest mechanical instability.

Slip Tendency for faults in the region of overpressure through and below the Otaraoa top seal (below $3300 \mathrm{~m}$ ) is again low across the fault population in the Kupe Area. Slip Tendencies of faults within and below the top seal (i.e. in the overpressure zone) ranges from 0 to 0.495 , and is slightly higher than on faults above the top seal, in the hydrostatically pressured zone. This suggests that the faults within and below the top seal are more likely to act as vertical conduits to the flow of fluids and/or gas, based on the assumption of higher Slip Tendency resulting in greater structural permeability. Fault orientation exerts an observable influence on Slip Tendency below $\sim 3300 \mathrm{~m}$ (Fig. 4.14). Faults striking $180-270^{\circ}$ and $0-90^{\circ}$ have the highest Slip Tendency. Faults striking $90-180^{\circ}$ and $270-360^{\circ}$ have the lowest Slip Tendency. Modelling again indicates a relatively low Slip Tendency and an associated low risk of enhanced structural permeability for faults below $\sim 3300 \mathrm{~m}$. The slight increase in Slip Tendency seen below the top seal can be 
attributed to the increase in pore pressure. The increase in pore pressure is not large enough for faults to plot above the Mohr-Coulomb failure envelope based on a coefficient of internal friction of 0.5 (Fig. 4.15). Most of the faults still plot below the failure envelope when the coefficient of internal friction is reduced to the lower most bound of 0.3 , suggesting faults are not Critically Stressed.

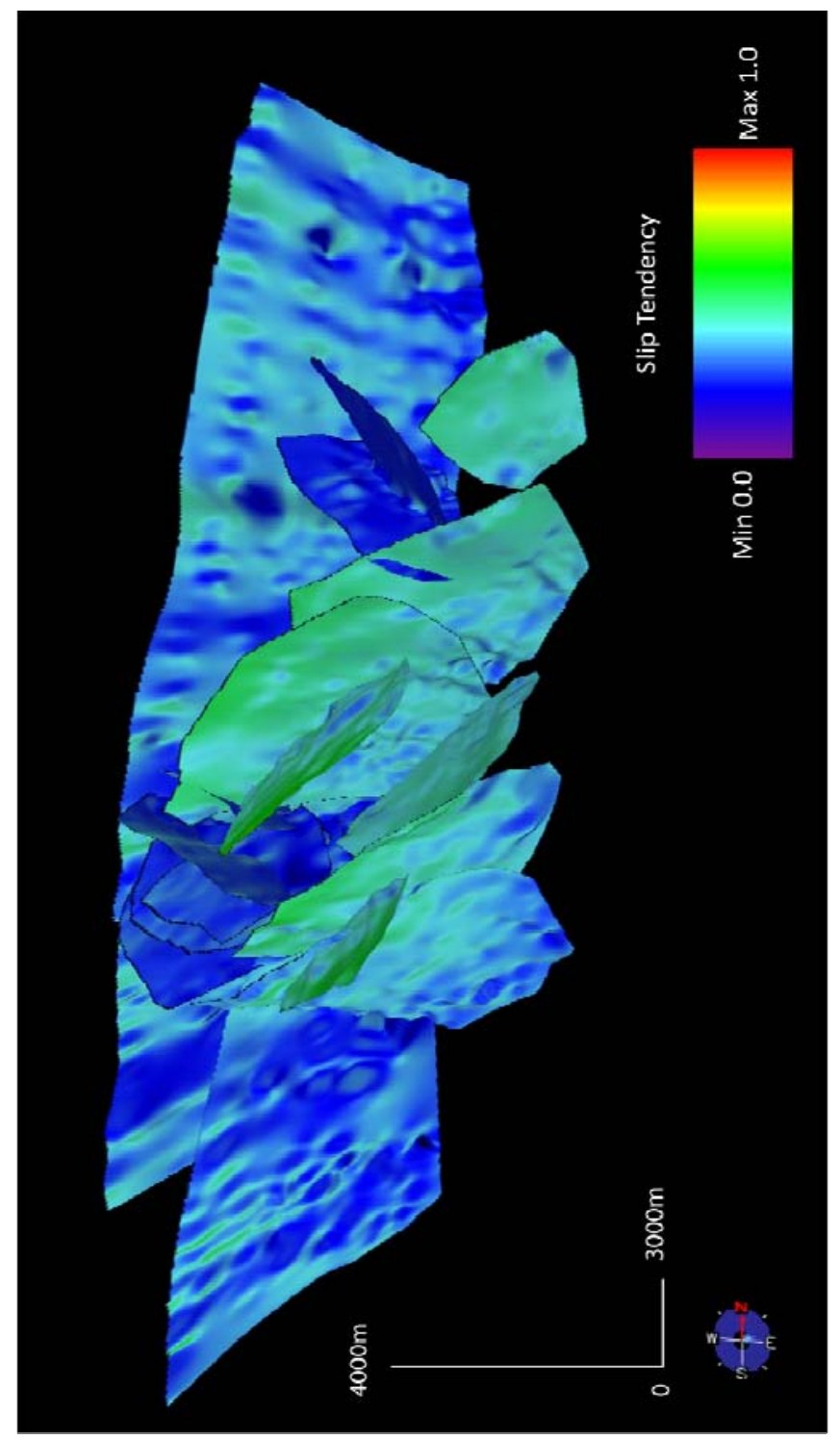

Figure 4.14 Oblique view west across the Kupe Area showing contours of Slip Tendency on reactivated fault surfaces that cut the Otaraoa top seal. Faults are truncated at the top of the Otaraoa seal for easier viewing. The top seal covers the top $\sim 100-200 \mathrm{~m}$ of the faults. Note that there is a slight increase in Slip Tendency on north-east striking faults. However, all values of Slip Tendencyare $<0.5$. 


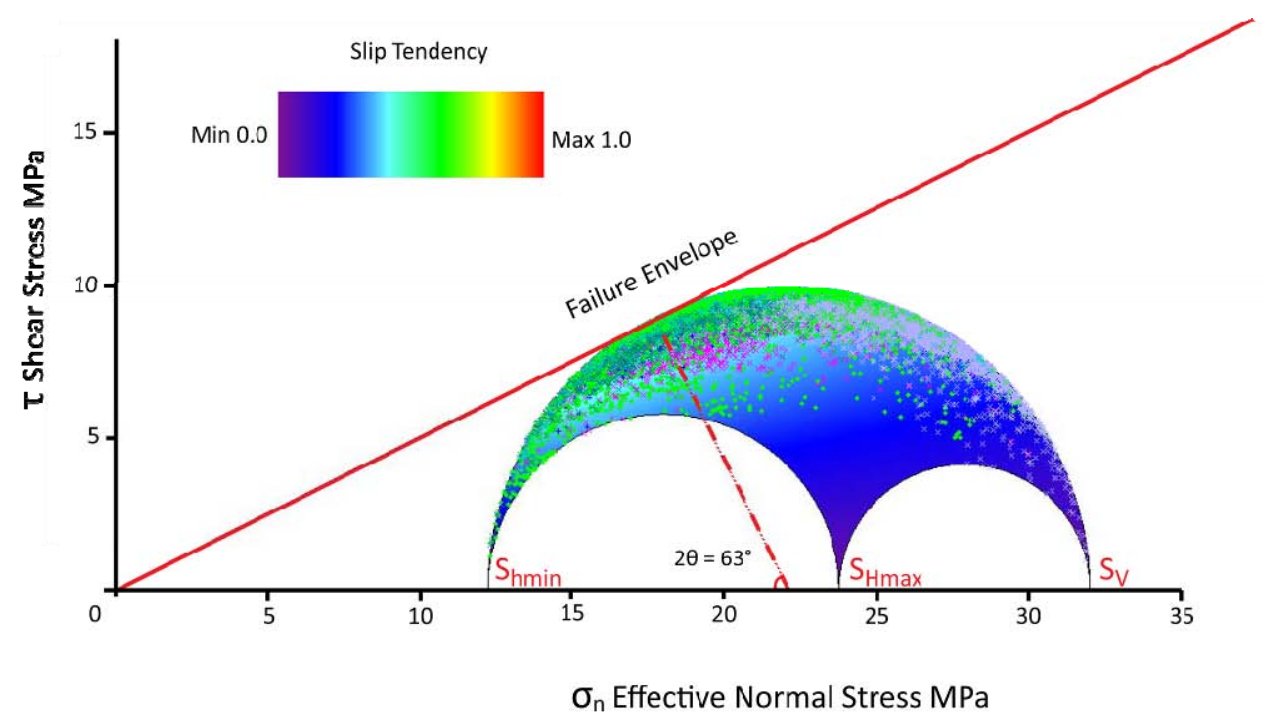

Figure 4.15 Mohr plot of Slip Tendency (hydrostatic pressure). Fault poles displayed for faults below top seal. Each fault has a set of poles that represent locations on individual fault surfaces. All poles to an individual fault surface are the same colour. A coefficient of friction of 0.5 results in no critically stressed faults.

The influence of $S_{\mathrm{Hmax}}$ on faults not optimally oriented for slip in extensional stress fields has been suggested to play and influential role on slip stability and has therefore been investigated. Morris and Ferrill, (2009) showed an increase of over 50\% in the number of faults with high Slip Tendency when intermediate stress $\left(S_{H \max }\right)$ was varied from halfway between minimum stress $\left(\mathrm{S}_{\mathrm{hmin}}\right)$ and maximum stress $\left(\mathrm{S}_{\mathrm{V}}\right)$ to approximately equal to minimum or maximum stress. They concluded that the magnitude of $\mathrm{S}_{\mathrm{Hmax}}$ influences rock mass strength and therefore "stress controlled fault transmissibility" (Morris and Ferrill, 2009). Results from this study indicate that there is an insignificant change in Slip Tendency values when $S_{H \max }$ is varied towards $S_{\mathrm{V}}$ and $\mathrm{S}_{\mathrm{hmin}}(\sim 0.1$ increase in Slip Tendency). The limited change seen may, in part, be due to the low differential stress in the Kupe Area. 


\subsubsection{Dilation Tendency}

Dilation Tendency for faults at hydrostatic pressure above the Otaraoa top seal (above 3300 $\mathrm{m}$ ) varies significantly across individual fault surfaces and can be high across many parts of fault surfaces. Dilation Tendency ranges from $\sim 0.005-1$, with fault orientation and depth within the stress field exerting a significant influence on Dilation Tendency values (variation of 0.995). There is an observable separation of average Dilation Tendency values based on fault strike (Fig. 4.16 and Fig. 4.17). The highest Dilation Tendency is on faults striking $020^{\circ}-070^{\circ}$ and $200^{\circ}-250^{\circ}$. The lowest Dilation Tendency is on faults striking $290-340^{\circ}$ and $210^{\circ}-260^{\circ}$. Modelling therefore indicates that there is a high risk of dilated fractures existing in many of the faults zones above the Otaraoa top seal. All faults with associated gas chimneys had high Dilation Tendency ( $>0.5)$ at a number of locations on their surfaces. High Dilation Tendency regions do not always correlate with locations on faults where gas chimneys are present and ranges from 0-1 at these chimney locations.

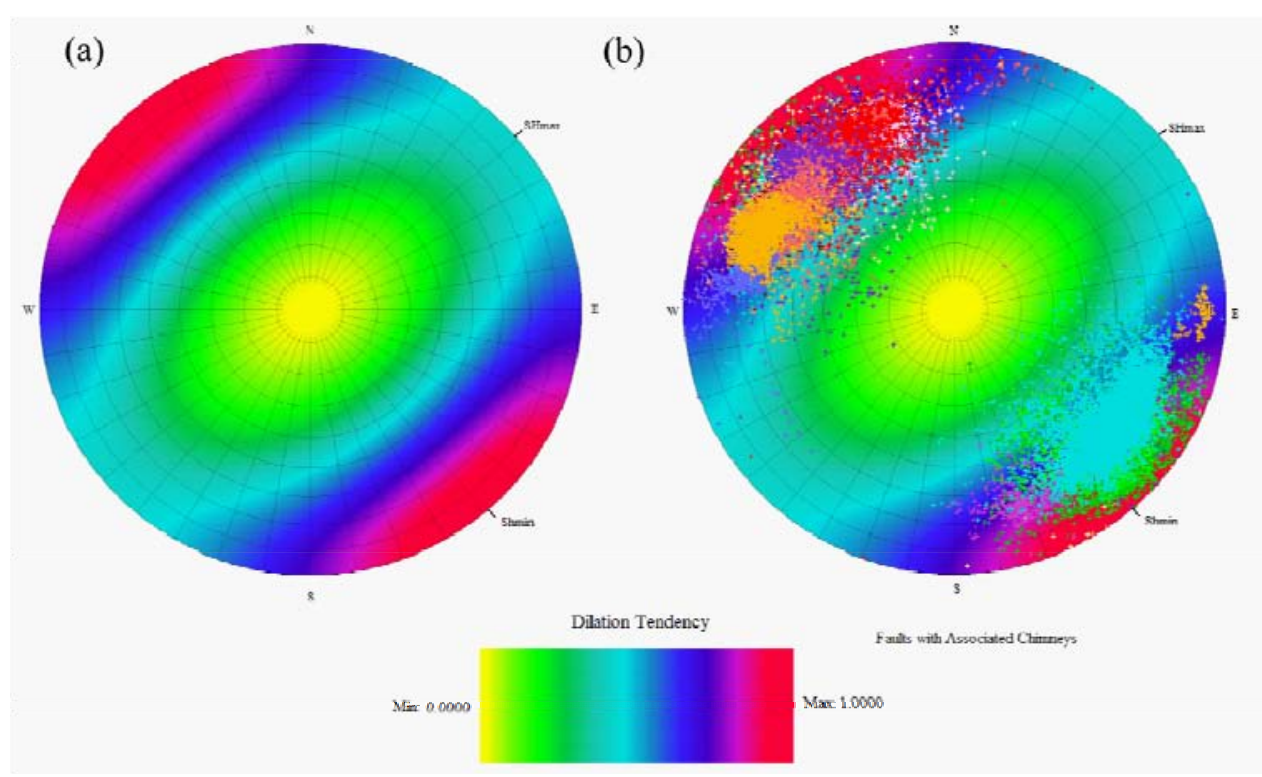

Figure 4.16 Equal area stereonet plots of Dilation Tendency at 2000m (TVDSS). (a) Dilation Tendency for all fault orientations in the Kupe Area. Dilation Tendencies are indicated by colours which correspond to values ranging from 0-1 (see colour bar). (b) Dilation Tendency with poles to all faults with visible gas chimneys plotted. Steeply dipping faults with strikes of $20-70^{\circ}$ are most at risk of dilational behaviour and therefore are most likely to have high structural permeability. Each fault has a set of poles that represent locations on individual fault surfaces. All poles to an individual fault surface are the same colour and the pole colours do not represent the Dilation Tendency. Note the change in colour scale from Slip Tendency. 
Faults below and cutting the Otaraoa top seal, in the overpressure zone (below $3300 \mathrm{~m}$ ), have a similar range of Dilation Tendency values to above the seal (0-1) (Fig 4.17). Again, fault orientation and depth within the stress field are the dominant influence and the effect of pore pressure is negligible. Faults with associated gas chimneys generally strike $020^{\circ}$ $070^{\circ}$ and $200^{\circ}-250^{\circ}$ and have the highest average Dilation Tendency (Fig. 4.18).

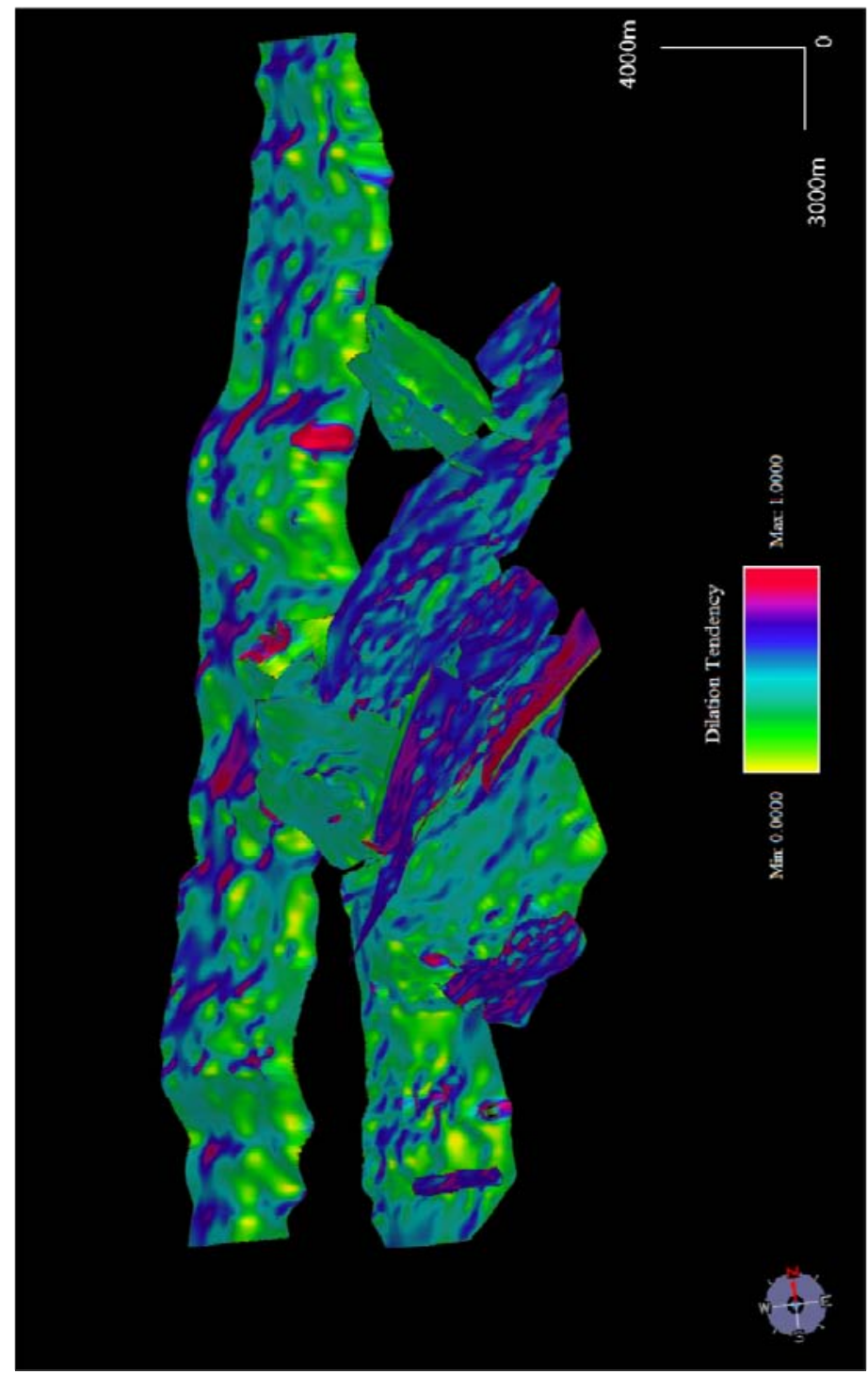

Figure 4.17 Map view of Dilation Tendency contours on reactivated fault surfaces that cut the Otaraoa top seal. Faults are truncated at the top of the Otaraoa seal for easier viewing. The top seal covers the top 100$200 \mathrm{~m}$ of the faults. Higher Dilation Tendency is observed on north-east striking faults. 

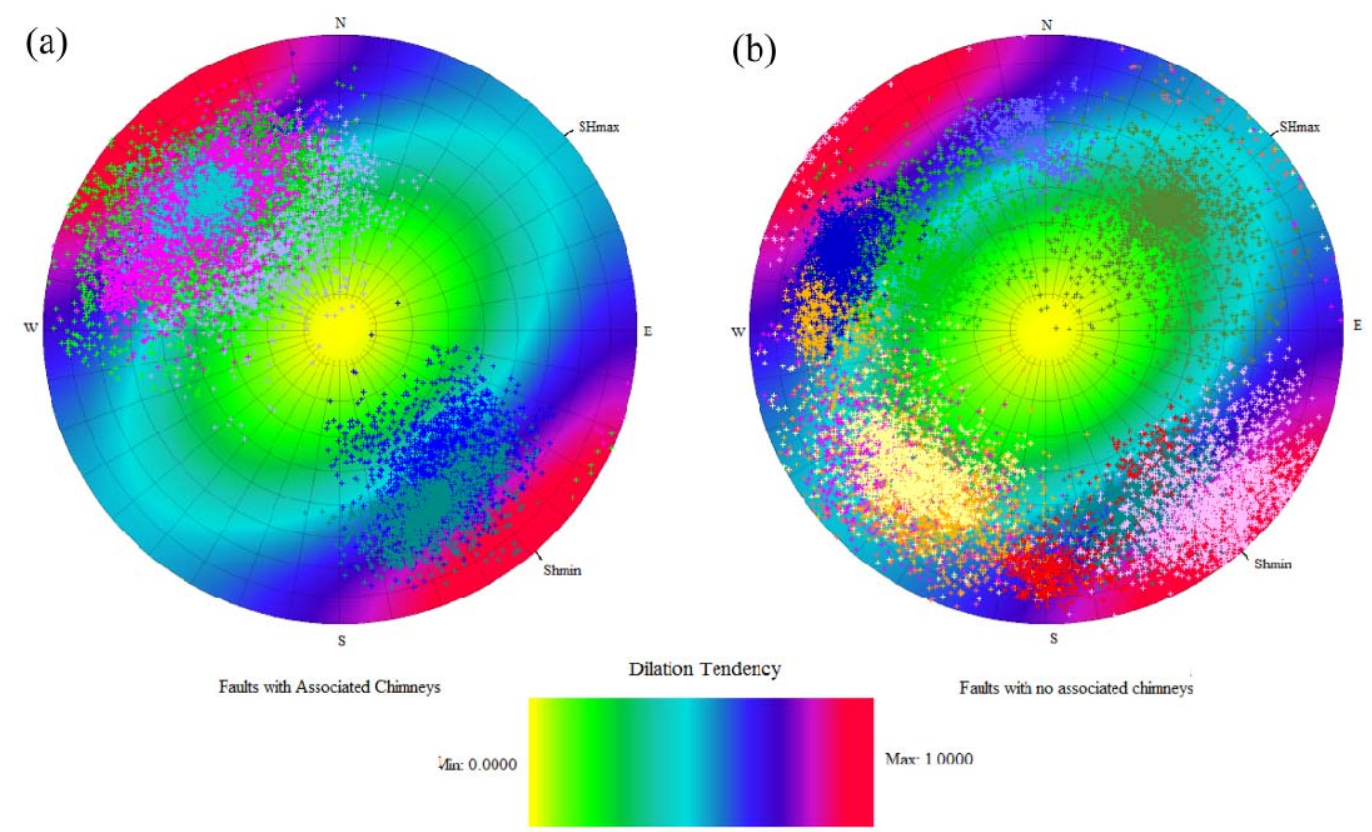

Figure 4.18 Equal area stereonet plots of Dilation Tendency at $\sim 3300 \mathrm{~m}$ (TVDSS). Dilation Tendencies are indicated by colours which correspond to values ranging from 0-1 (see colour bar). Poles to faults are plotted as points on the stereonets. Each fault has a set of poles that represent locations on individual fault surfaces. All poles to an individual fault surface are the same colour and the pole colours do not represent the Dilation Tendency values; (a) Shows Dilation Tendency and poles to faults that displace the Otaraoa top seal and have associated shallow gas chimneys. (b) Poles to all faults that displace the top seal and have no associated gas chimney.

\subsubsection{Fracture Stability}

Fracture Stability modelling for hydrostatic pressures indicates that faults above the Otaraoa seal (above 3300m) with observed gas chimneys require only a minor increase in pore pressure to induce failure (Fig. 4.19). Pore pressure values required to induce failure range from $\sim 0.8-26 \mathrm{MPa}$, indicating that some faults are close to failure. Variation in Fracture Stability along individual faults is associated primarily with variation in depth. Shallow sections of faults require the lowest pore pressure perturbation to induced failure, with values commonly between $\sim 2-5 \mathrm{MPa}$. There is no discernable variation in values of Fracture Stability between faults that have visible gas chimneys and those that do not.

Faults within and below the Otaraoa seal, in the overpressure region (below 3300m), have lower modelled risk of failure than above the seal. Critical pore pressures required to 
induce failure range from $\sim 6-85 \mathrm{MPa}$, with pressure required to induce failure increasing with depth. Pressure values required for failure at the top of the Otaraoa seal are at the lower bound of values observed on all faults below the seal and range from 6-24MPa (Fig. 4.20). Fault strike has an observable influence on Fracture Stability below 3300m. Faults striking between $020-070^{\circ}$ have the lowest Fracture Stability and those between $120-160^{\circ}$ have the highest Fracture Stability (Fig. 4.20). Modelling results suggest that faults below $3300 \mathrm{~m}$ have moderate to low probability of producing zones of enhanced structural permeability that could act as conduits for fluid and/or gas flow. The probability decreases with depth as the pore pressure required to induce failure increases.

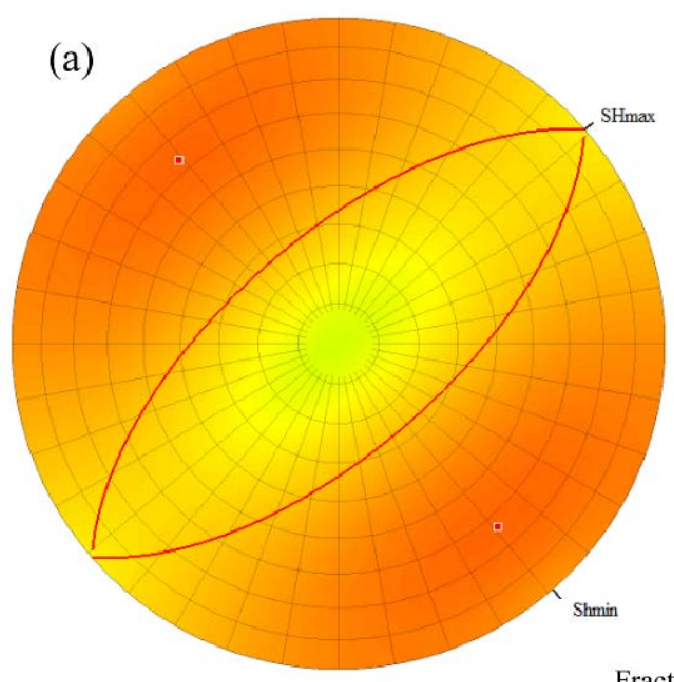

(b)

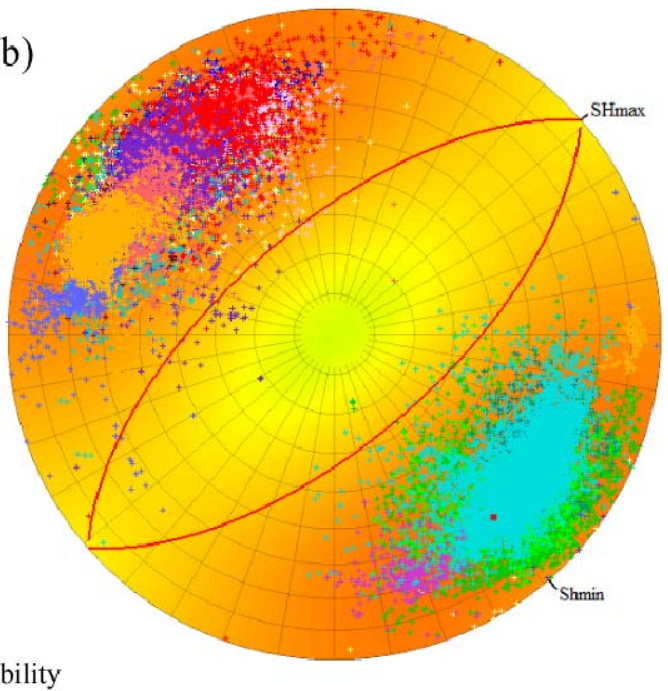

Max: $100 \mathrm{MPa}$

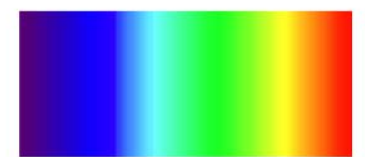

Min: $0 \mathrm{MPa}$

Figure 4.19 Equal area stereonet plots of Fracture Stability (pore pressure perturbation required to induce failure) at $\sim 2000 \mathrm{~m}$ hydrostatic pressure. (a) Shows Fracture Stability across the Kupe Area. Fracture Stability values are indicated by colours which correspond to values ranging from 0-1 (see colour bar). (b) Fracture Stability with poles to all faults with visible gas chimneys. Each fault has a set of poles that represent locations on individual fault surfaces. All poles to an individual fault surface are the same colour and the pole colours do not represent the Fracture Stability. The maximum pore pressure perturbation needed to induce failure is uniformly low across all strike orientations. Note change in colour bar from Dilation Tendency and Slip Tendency. 


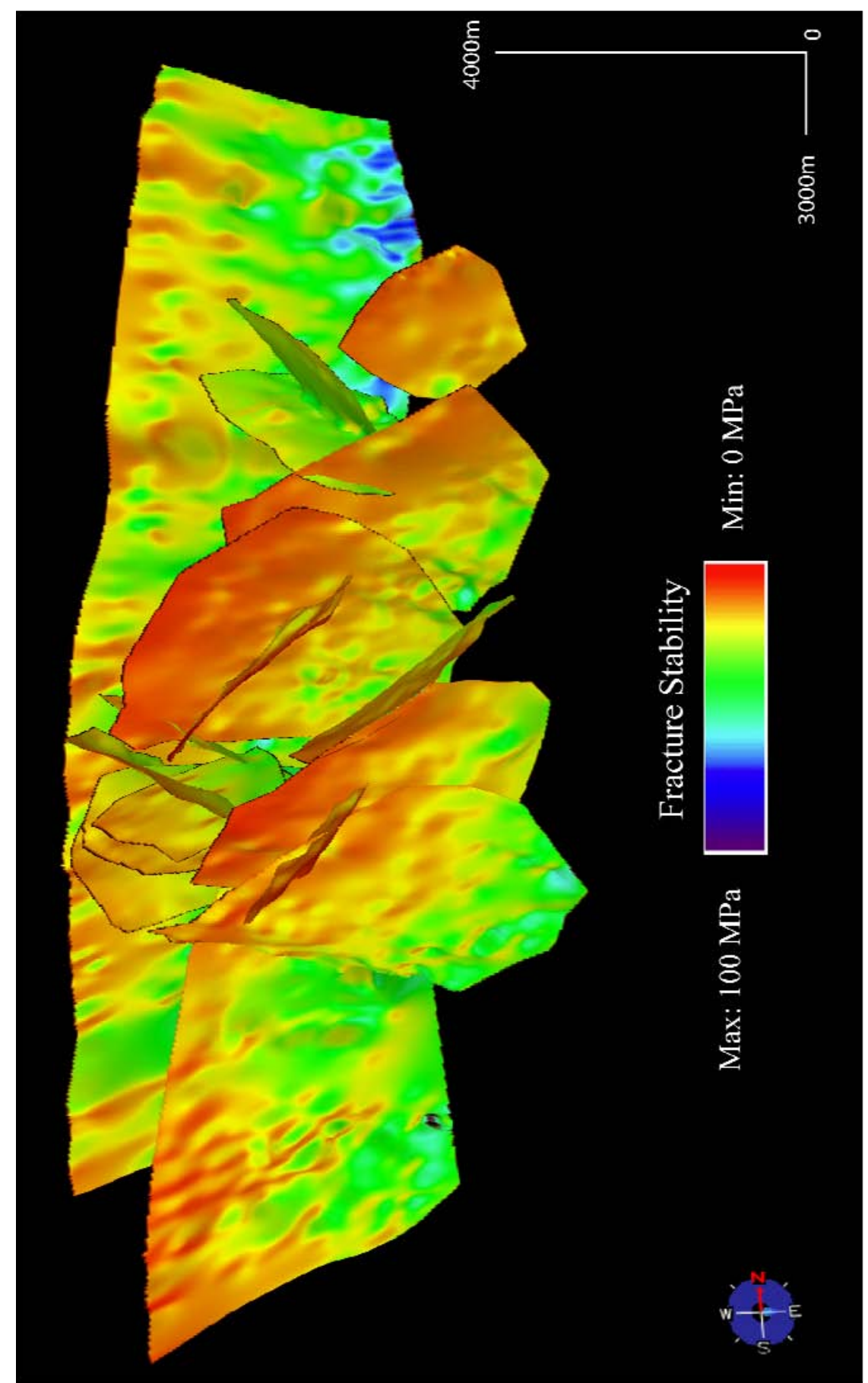

Figure 4.20 Oblique view west across the Kupe Area showing contours of Fracture Stability on reactivated fault surfaces that cut the Otaraoa top seal. Faults are truncated at the top of the Otaraoa seal for easier viewing. The top seal covers the top $\sim 100-200 \mathrm{~m}$ of the faults. North-east striking faults require a lower (5$15 \mathrm{MPa}$ ) pore pressure perturbation to induce failure. 


\subsection{Predicting Gas Chimney Locations on Individual Faults}

The ability of geomechanical methods to predict the precise locations of chimneys on faults can be tested by comparing the measured leakage risk parameter (i.e. Dilation Tendency, Slip Tendency and Fracture Stability) at parts of ten individual faults with observable chimneys. The ten faults with observed associated gas chimneys (i.e. chimneys within the fault zone or adjacent to the fault surface) were sampled at three metre vertical and horizontal spacing across their modelled fault surfaces. Leakage risk parameters on areas of the fault surface with an observed gas chimney and with no observed gas chimney have been discriminated and plotted separately. Results are presented as histograms of Slip Tendency, Dilation Tendency and Fracture Stability (pressure increased required to induce failure) (Figs. 4.22, 4.24 and 4.26) and are summarised in Table 4.5.

Table 4.5 Summary of statistical parameters for each of the geomechanical methods.

\begin{tabular}{|l|l|l|l|l|l|l|}
\hline & $\begin{array}{l}\text { Dilation } \\
\text { Tendency } \\
\text { Chimney }\end{array}$ & $\begin{array}{l}\text { Dilation } \\
\text { Tendency } \\
\text { Non- } \\
\text { Chimney }\end{array}$ & $\begin{array}{l}\text { Slip } \\
\text { Tendency } \\
\text { Chimney }\end{array}$ & $\begin{array}{l}\text { Slip } \\
\text { Tendency } \\
\text { Non- } \\
\text { Chimney }\end{array}$ & $\begin{array}{l}\text { Fracture } \\
\text { Stability } \\
\text { Chimney }\end{array}$ & $\begin{array}{l}\text { Fracture } \\
\text { Stability } \\
\text { Non- } \\
\text { Chimney }\end{array}$ \\
\hline Mean & 0.785 & 0.786 & 0.312 & 0.307 & 8.663 & 8.860 \\
\hline Median & 0.806 & 0.794 & 0.320 & 0.321 & 7.535 & 8.167 \\
\hline Min & 0 & 0 & 0 & 0 & 0 & 0 \\
\hline Max & 1 & 1 & 0.408 & 0.417 & 76.750 & 72.540 \\
\hline $\begin{array}{l}\text { Standard } \\
\text { Deviation }\end{array}$ & 0.135 & 0.122 & 0.041 & 0.050 & 6.022 & 5.572 \\
\hline
\end{tabular}




\subsubsection{Slip Tendency}

Slip Tendency values at locations on fault surfaces with observed gas chimneys does not vary significantly between chimney and non-chimney locations (Fig. 4.21). Frequency histograms show that sections of the faults sampled that are enclosed in chimneys and those distal to chimneys have a similar range of Slip Tendency values for all ten faults (Fig. 4.24). These histograms typically have a single mode at Slip Tendencies of $\sim 0.3-0.35$. For the entire data set Slip Tendency at chimney locations is only 0.001 higher than nonchimney locations. Comparisons on individual faults reveal a similar pattern with little discernable difference between Slip Tendency values at chimney and non-chimney locations and a similar range of values across all locations (Fig. 4.23). Based on these data from a sample of ten faults in the Kupe Area Slip Tendency appears to be an unreliable means of predicting which parts of fault surfaces are most likely to accommodate channelised gas flow.

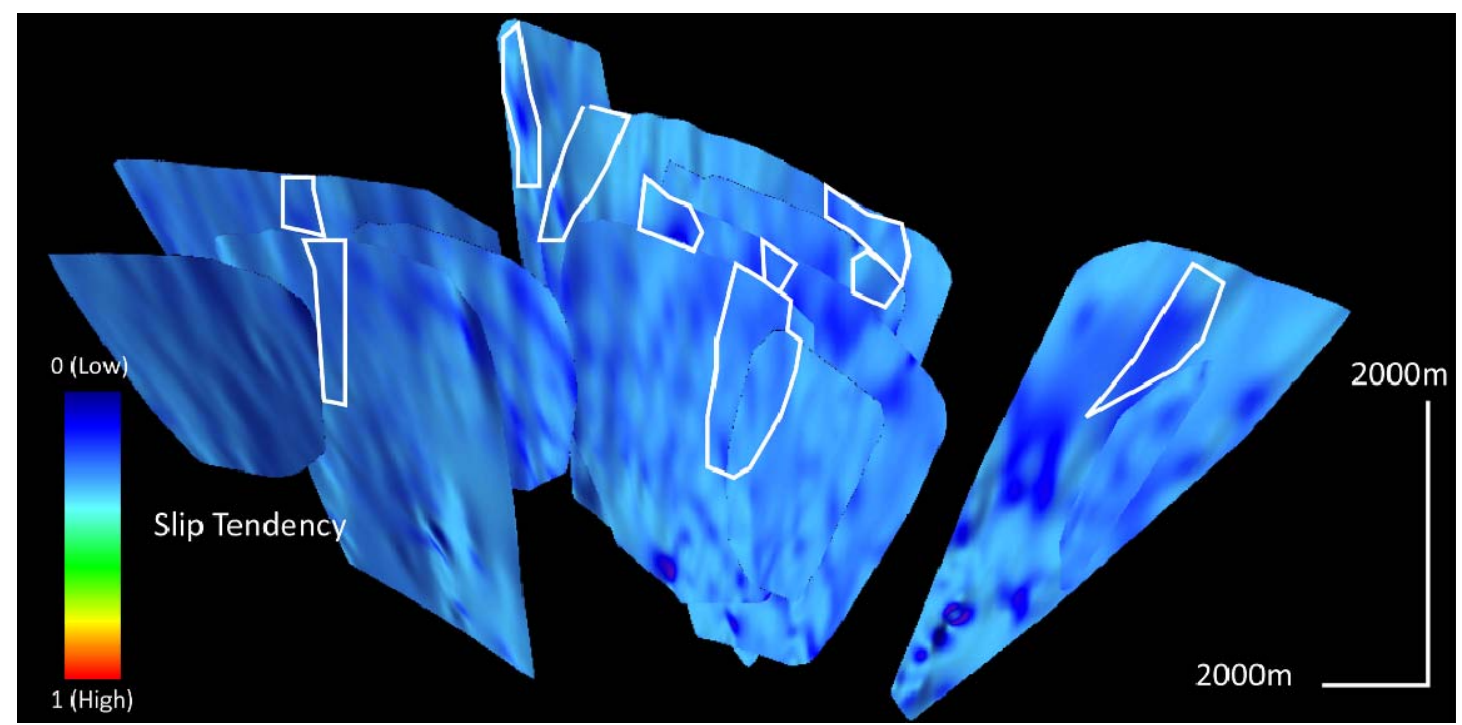

Figure 4.21 Slip Tendency mapped onto gas chimney bearing faults. White polygons outline locations of chimneys on fault surfaces. Slip Tendency values do not vary significantly between chimney and nonchimney locations. 

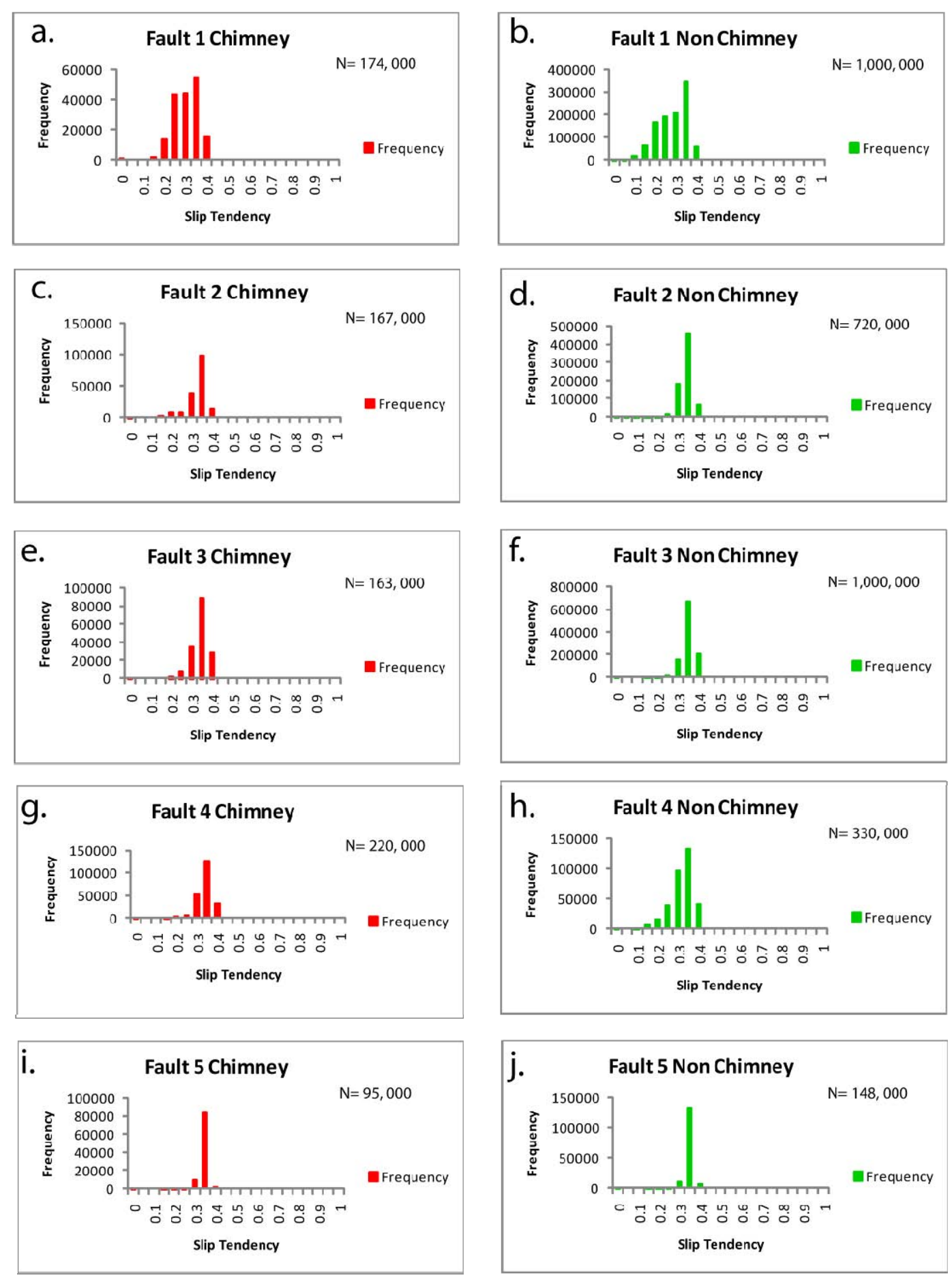

Figure 4.22 Histograms of Slip Tendency for 10 faults (fault numbers shown at the top centre of each graph). Red and green histograms on each row are for a single fault surface. Red histograms (left column of graphs) are Slip Tendencies calculated at chimney locations on fault surfaces, while green histograms (right column of graphs) are Slip Tendencies on fault surfaces at locations where no chimneys are observed. The number of sample points is shown on the top right of graphs $(\mathrm{N})$. 

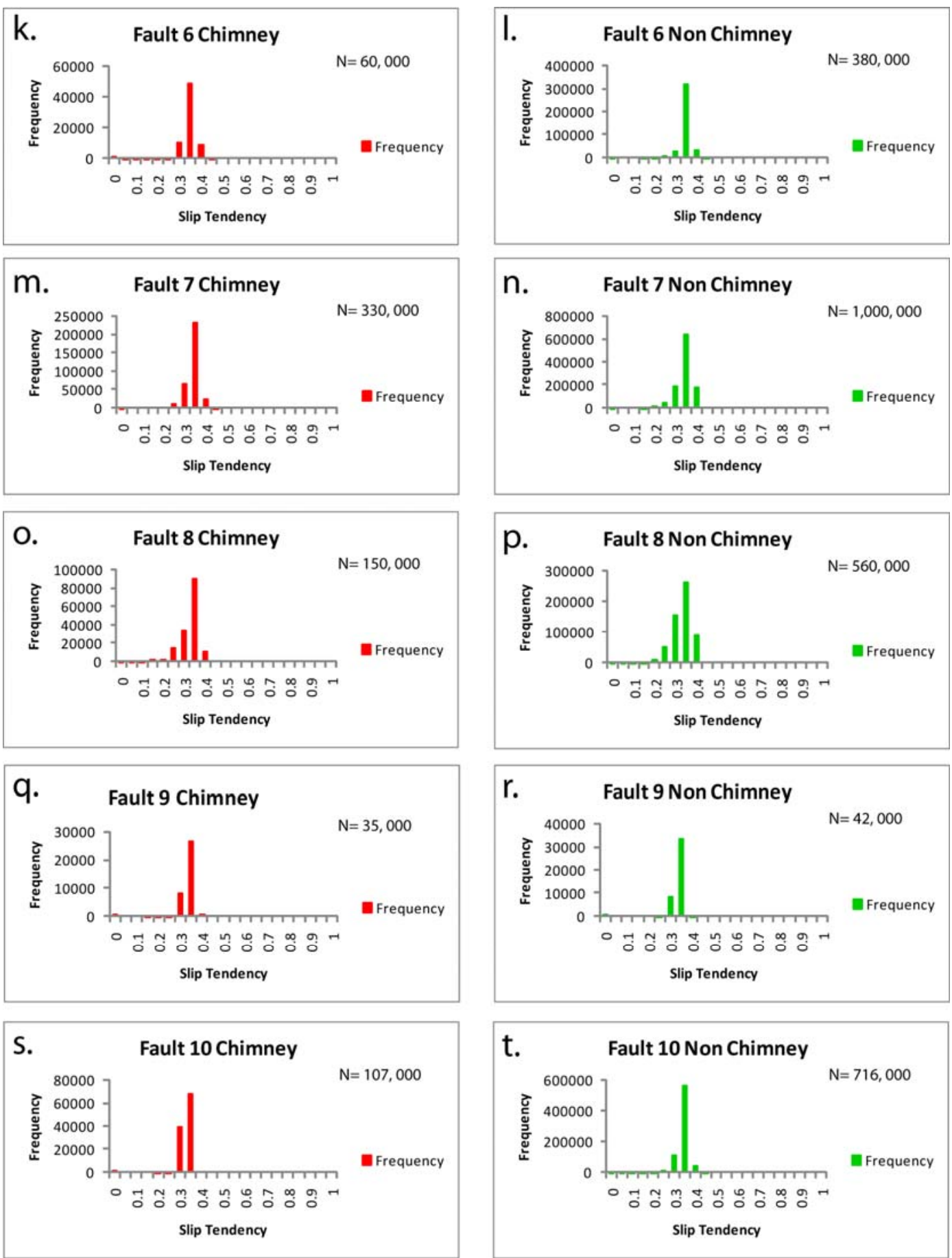

Figure 4.22 Continued 


\subsubsection{Dilation Tendency}

Dilation Tendency at locations on fault surfaces with observed gas chimneys does not vary significantly between chimney and non-chimney locations (Fig. 4.23). Frequency histograms show that sections of faults sampled that are enclosed in chimneys and those distal to chimneys have a similar range of Dilation Tendency values (Fig. 4.24). Dilation Tendency data for all of the faults analysed has comparable frequency histogram shapes on chimney and non-chimney parts of the individual fault surfaces. These histograms range from bimodal, with a primary mode at Dilation Tendencies of $\sim 0.85$ and a secondary mode at $\sim 0.05-0.10$ to single mode at $0.8-0.9$. Dilation Tendency is slightly lower at chimney locations than non-chimney locations, which is the inverse of what would be expected if gas locations on the fault were positively related to higher Dilation Tendency.

Comparisons on individual faults reveals a similar pattern, with average Dilation Tendency at chimney locations lower than non-chimney locations and a similar range of values across all locations (Fig. 4.24). Based on the data from a sample of ten faults in the Kupe region it again appears that Dilation Tendency is not a reliable means of predicting which parts of fault surfaces are most likely to accommodate channelised gas flow.

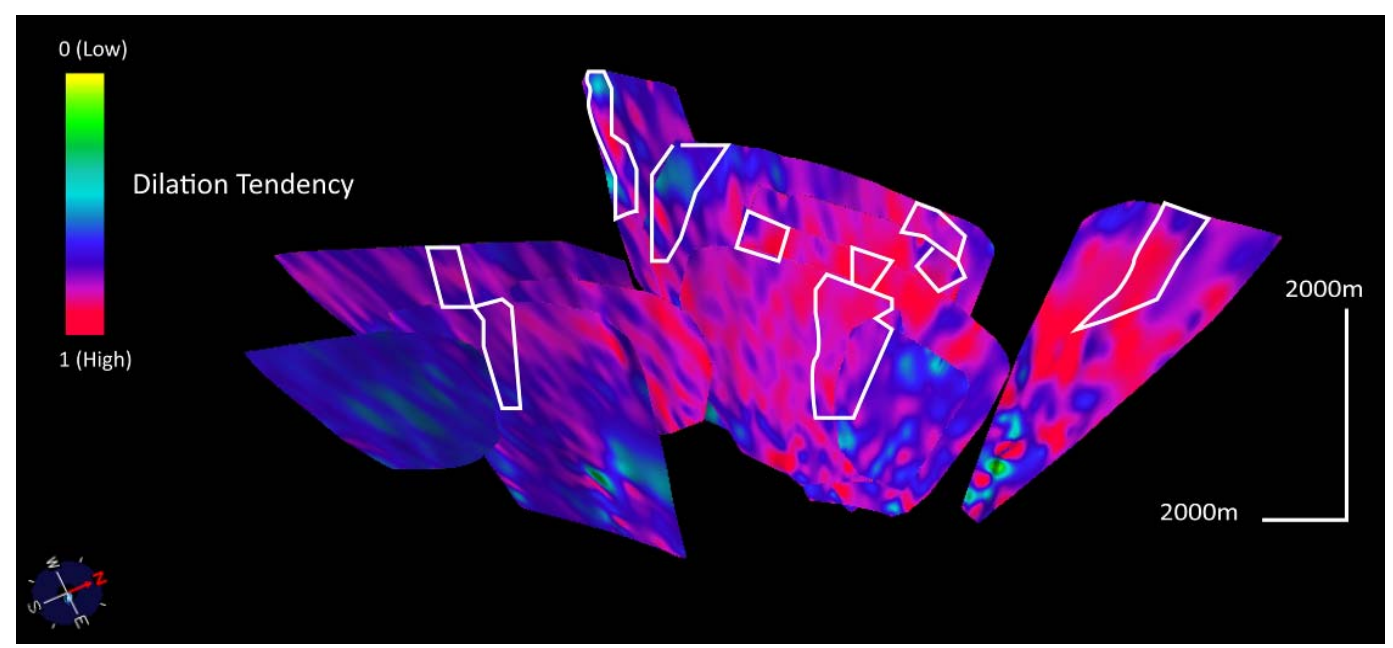

Figure 4.23 Dilation Tendency mapped onto gas chimney bearing faults. White polygons outline locations of chimneys on fault surfaces. Dilation Tendency values are not uniformly high across chimney locations, with some chimney locations showing low Dilation Tendency. 

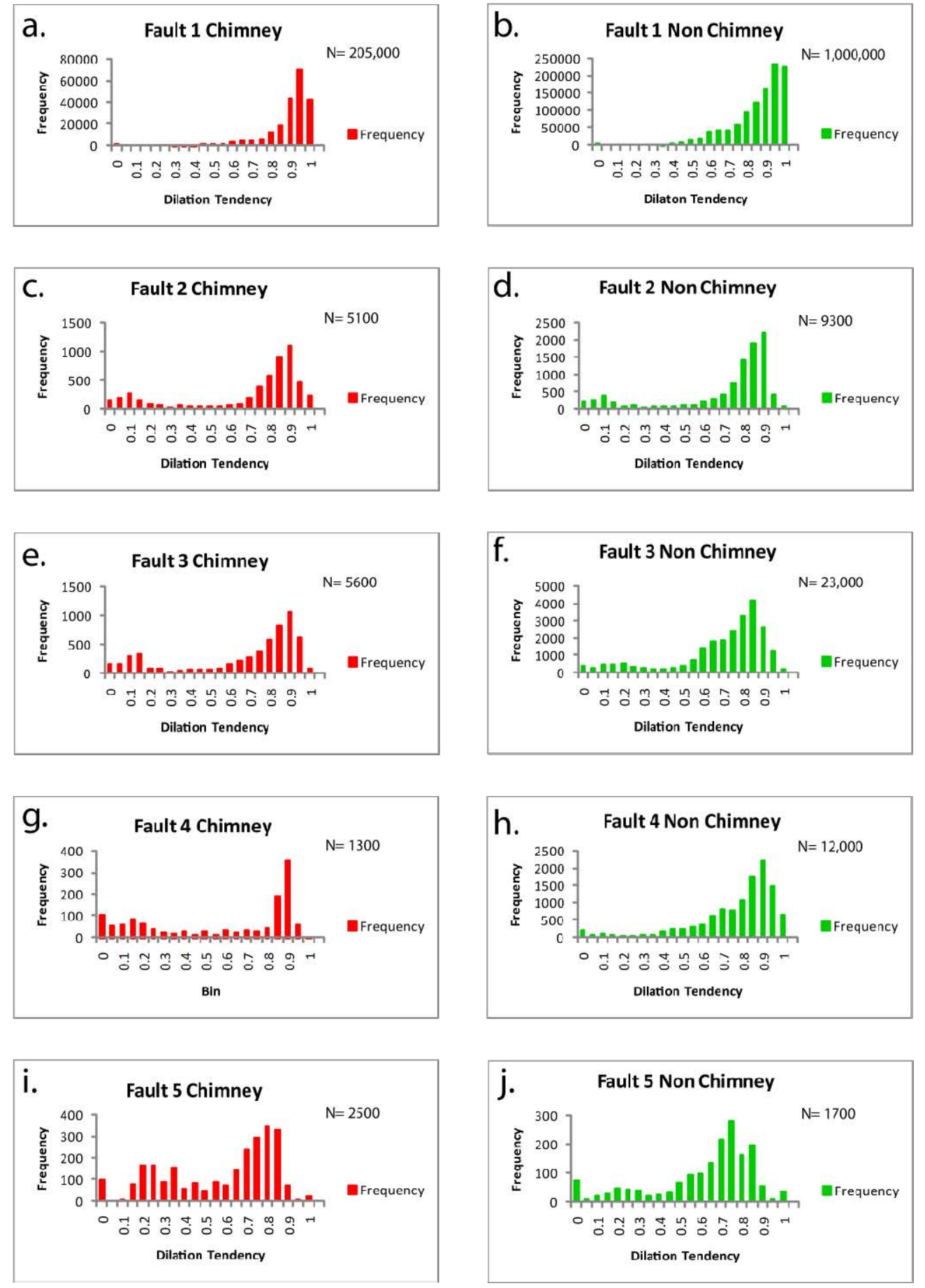

Figure 4.24 Histograms of Dilation Tendency for 10 faults (fault numbers shown at the top centre of each graph). Red and green histograms on each row are for a single fault surface. Red histograms (left column of graphs) are Dilation Tendency calculated at chimney locations on fault surfaces, while green histograms (right column of graphs) are Dilation Tendency on fault surfaces at locations where no chimneys are observed. The number of sample points is shown on the top right of graphs $(\mathrm{N})$. 

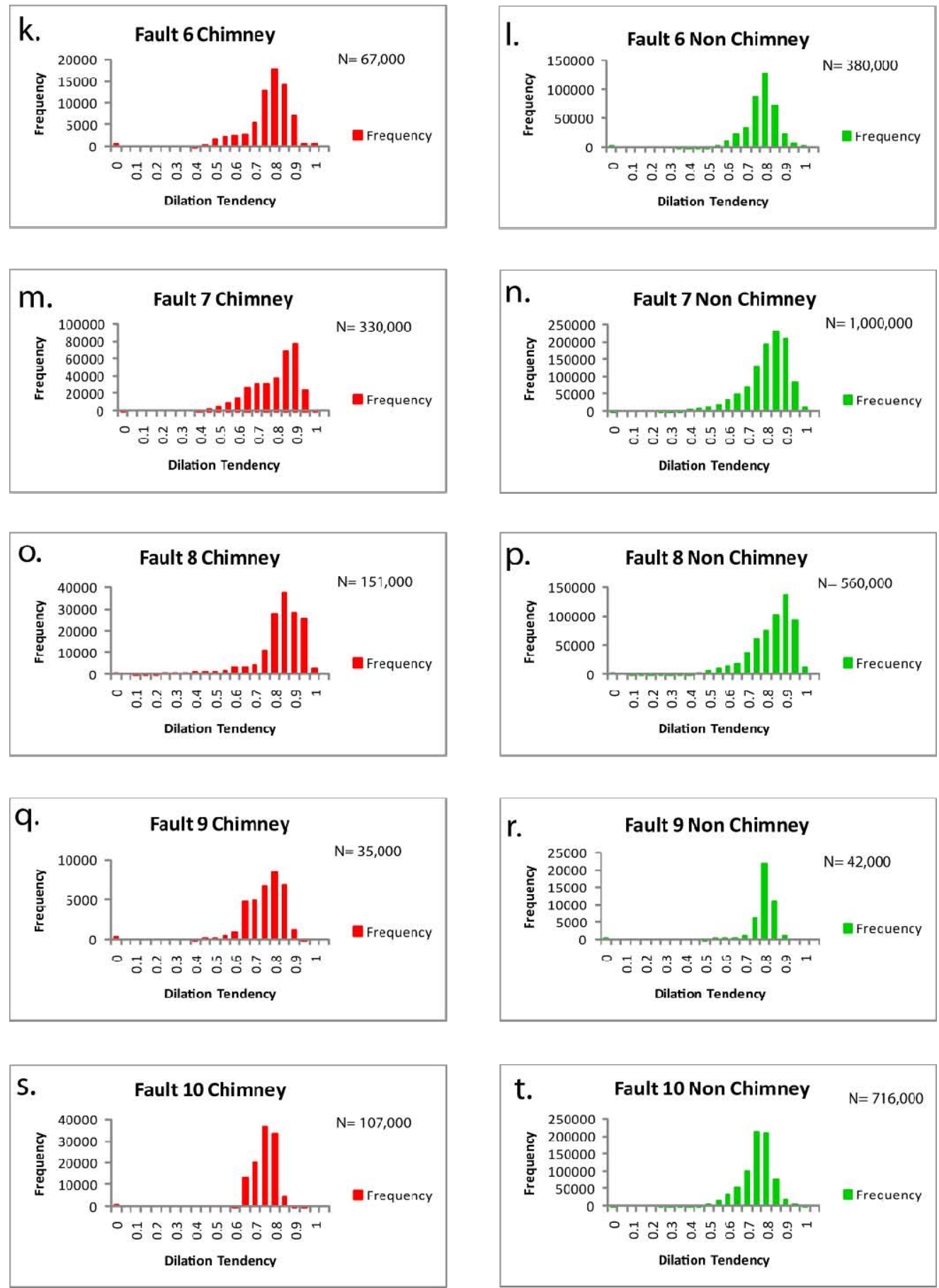

Figure 4.24 Continued. 


\subsubsection{Fracture Stability}

Fracture Stability at locations on fault surfaces with observed gas chimneys does not vary significantly between chimney and non-chimney locations (Fig. 4.25). Average Fracture Stability (pore pressure required to induce failure) across the entire fault population is slightly higher at chimney locations (8.663 MPa), compared to non-chimney fault locations (8.860 MPa) (see Table 4.5). Data for all of the faults analysed have comparable frequency histogram shapes for chimney and non-chimney parts of the fault surfaces (Fig. 4.26). Individually faults have similar Fracture Stabilities at chimney and non-chimney locations as shown in Figure 4.26. Histograms have a single mode distribution of pore pressure increase required to induce failure ranging from $\sim 10-50 \mathrm{MPa}$ (Fig. 4.26). Overall the relative difference in risk of up-fault gas flow between chimney and non-chimney locations based on Fracture Stability is statistically small given the range of values (Fig 4.26). The similarity of Fracture Stability at chimney and non-chimney locations would not be expected if it were positively correlated with gas locations on the faults. These data and analyses suggest that based on the ten faults in the Kupe Area Fracture Stability is not a reliable method for predicting locations of channelised gas flow on individual fault surfaces.

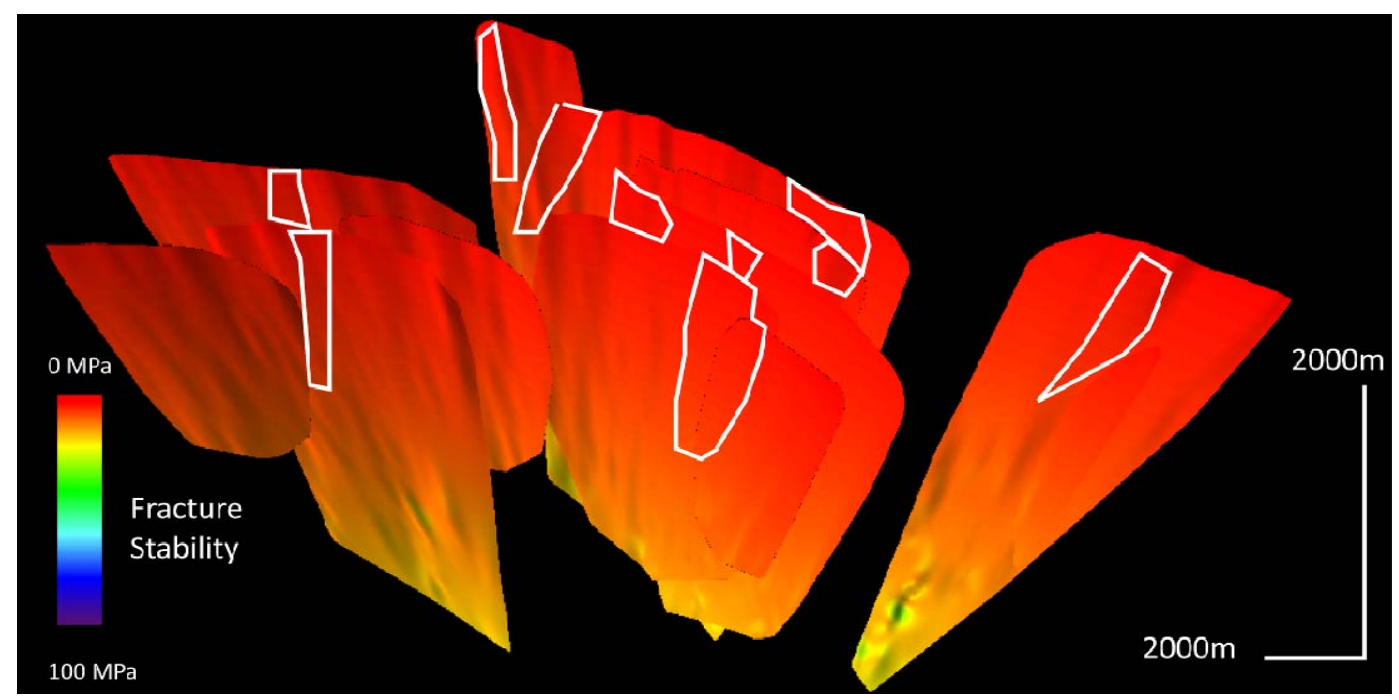

Figure 4.25 Fracture Stability mapped onto gas chimney bearing faults. White polygons outline the locations of chimneys on fault surfaces. Fracture Stability values do not vary significantly between chimney and nonchimney locations. 

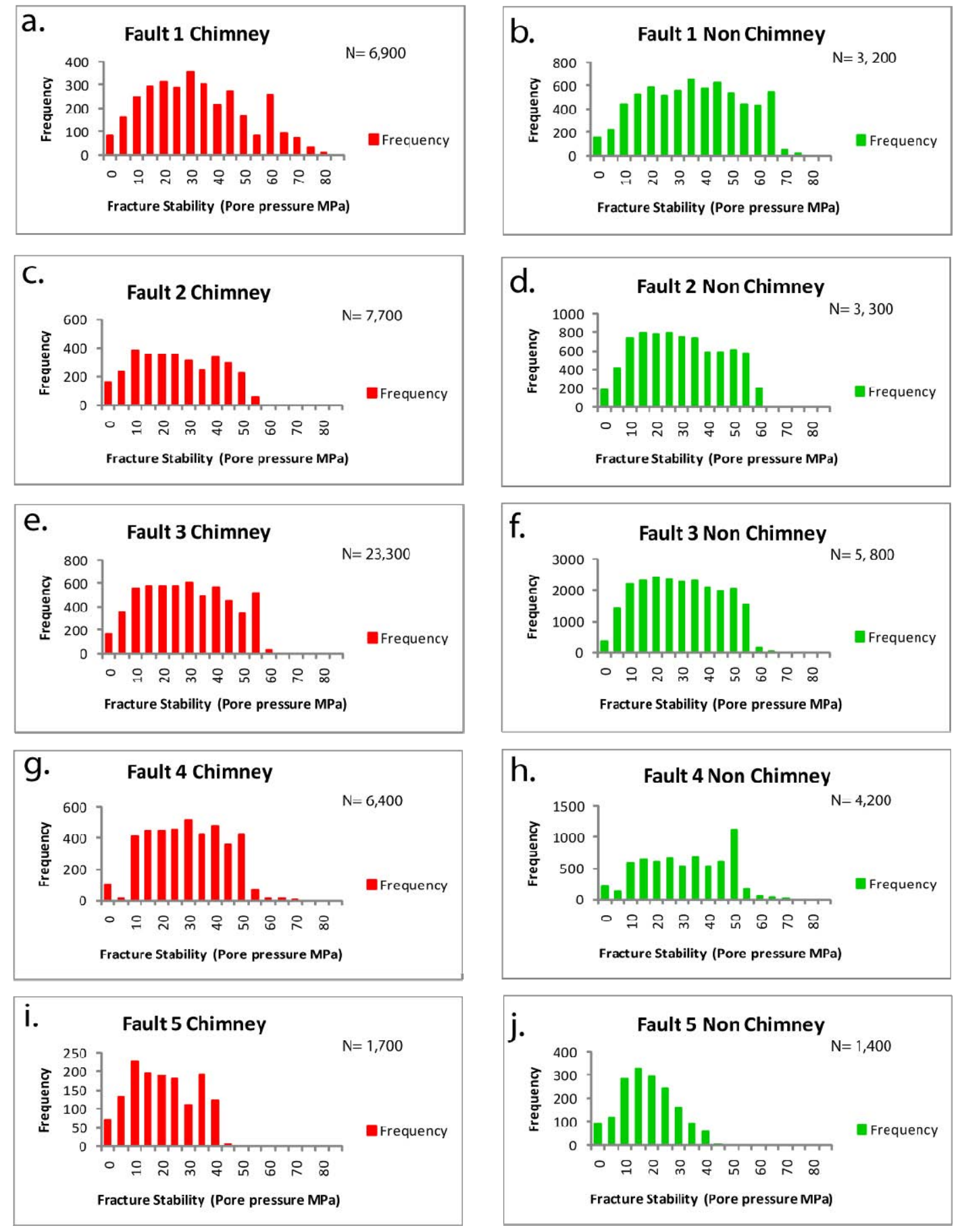

Figure 4.26 Histograms of Fracture Stability for 10 faults (fault numbers shown at the top centre of each graph). Red and green histograms on each row are for a single fault surface. Red histograms (left column of graphs) are Fracture Stability calculated at chimney locations on fault surfaces, while green histograms (right column of graphs) are Fracture Stability on fault surfaces at locations where no chimneys are observed. The number of sample points is shown on the top right of graphs $(\mathrm{N})$. 

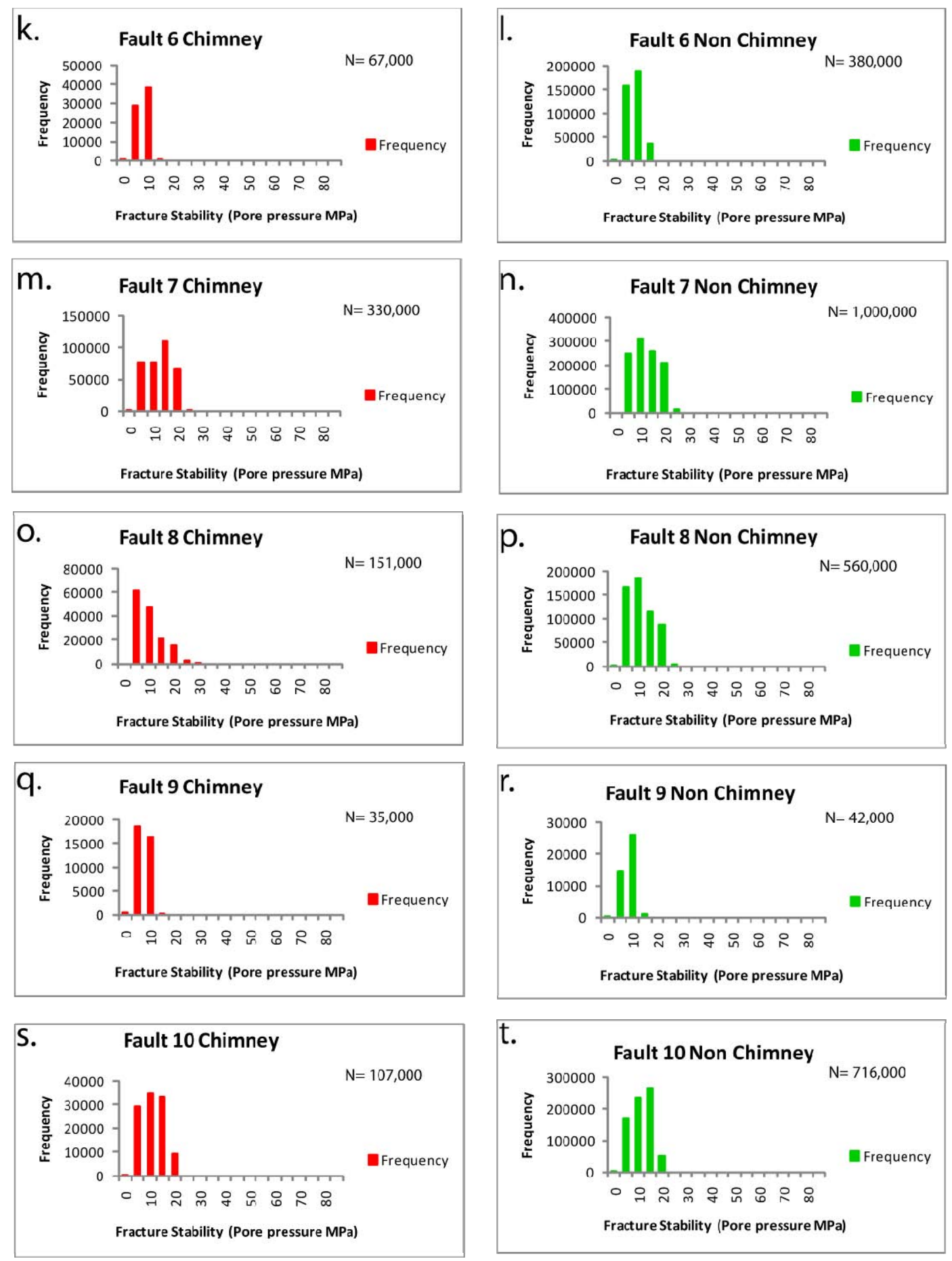

Figure 4.26 Continued. 


\subsection{Ability of Geomechanical Techniques for Predicting Gas Flow}

Geomechanical techniques for predicting the locations of enhanced up-fault fluid and/or gas flow are widely used and rarely tested with independent fluid and/or gas flow data. Here, gas chimneys mapped in a 3D seismic reflection volume provide a means of testing the ability of geomechanical modelling. Slip Tendency and Dilation Tendency Geomechanical modelling methods provide a first-order means of separating fault sets that have observed gas chimneys and those that have no chimneys. This separation is based primarily on fault strike within the current stress field and methods calculated highest leakage risks on faults that have a similar strike to $S_{\text {Hmax }}$. In absolute terms, Slip Tendency indicated low risk levels across all fault orientations but differentiated between relatively higher risk and lower risk faults sets. Faults with associated chimneys striking sub parallel to $\mathrm{S}_{\mathrm{Hmax}}$ have higher Slip Tendency (0.1 higher) than faults that have strikes that depart from the $\mathrm{S}_{\mathrm{Hmax}}$ orientation and have no observed chimneys. Dilation Tendency indicates a higher leakage risk on all faults compared to Slip Tendency. However, the leakage risk for those faults that are associated with chimneys and parallel to $\mathrm{S}_{\mathrm{Hmax}}$ is still not the highest possible risk (i.e. Dilation Tendency average is 0.8 out of possible maximum 1). Fracture Stability predicted uniformly low pore pressure perturbation required to induce failure on all faults above $\sim 3000 \mathrm{~m}$ (both those with and without observed gas chimneys), suggesting the ability of the method to differentiate higher leakage risk fault sets was limited. However, it did suggest faults are at risk of failure.

The ability of Slip Tendency and Dilation Tendency in making first-order predictions of faults sets most likely to enhance up-fault channelised flow can also be demonstrated by correlation of modelling results with drilling results from petroleum exploration wells in the Area. The Kupe Area contains a producing gas condensate field which is located across a series of fault blocks separated by northwest-southeast normal faults within the Manaia Anticline. The faults in the main producing field displace the Otaraoa top seal and likely developed prior to hydrocarbon charge. The Field Area faults offset the Otaraoa by 150 (m) and are likely sealing to lateral hydrocarbon migration through either juxtaposition of reservoir units against the Otaraoa top Seal or due to the development of low permeability fault-rock. These north-west to south-east reservoir faults are orientated approximately perpendicular to the $\mathrm{S}_{\mathrm{Hmax}}$ direction. They show no visible evidence in seismic reflection 
data of reactivation in the current stress field, nor are there any visible associated gas chimneys above the field or within the fault zones that penetrate the reservoir sections. Geomechanical modelling predicts a lower risk of leakage on these reservoir faults in comparison to surrounding north-east striking faults (Fig. 4.27). Due mainly to their northwest orientation, the reservoir bounding faults are considered likely to be sealing, resulting in no leakage through the top seal.

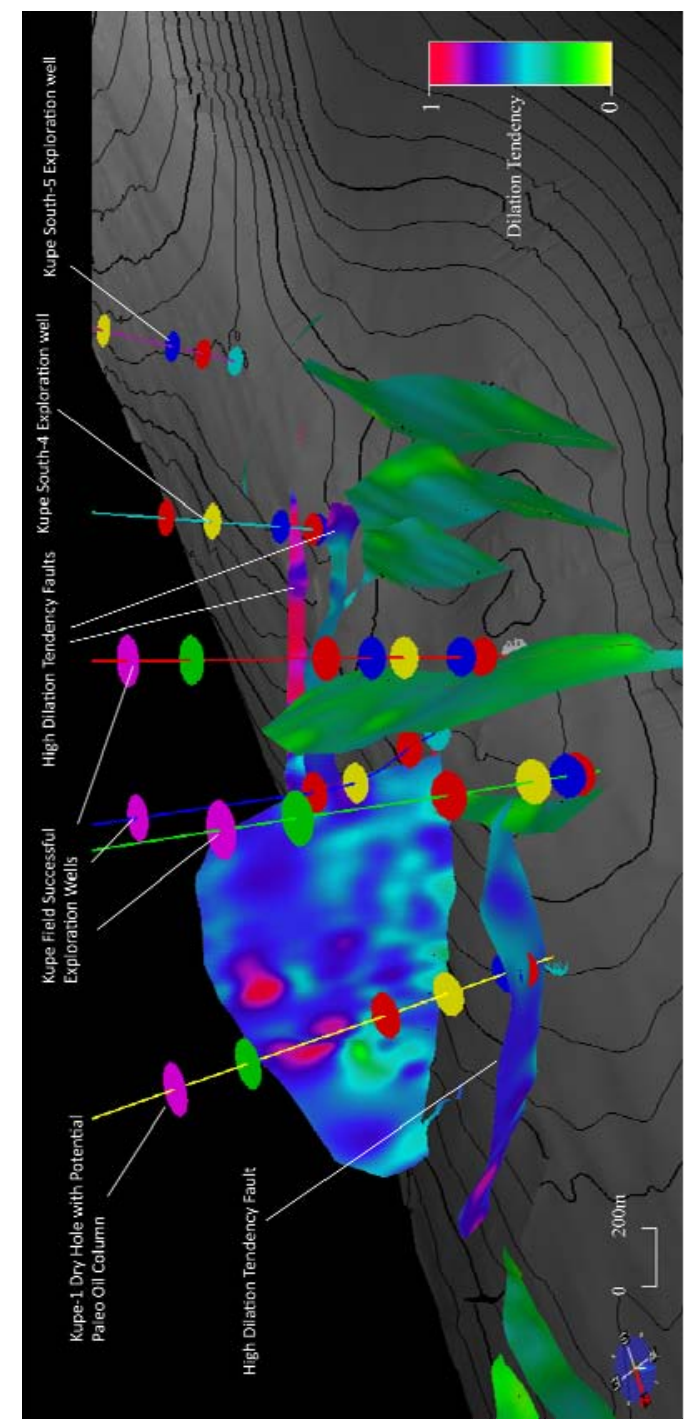

Figure 4.27 Oblique view across the Kupe Area showing exploration wells. Contoured horizon is the base of the Otaraoa top seal. Note low Dilation Tendencies on faults that bound successful exploration wells and higher Dilation Tendencies on the faults bounding the Kupe-1 dry hole and the Kupe South-4 well. 
Drilling results from the Kupe South-4 well, a minor oil and gas discovery, indicate that the Kupe South-4 hydrocarbon accumulation may have a restricted column height due to faultrelated leakage. The north-east striking-trap bounding faults at the Kupe South-4 discovery have a higher modelled risk of leakage than the main field faults when examined with all three methods (e.g., Dilation Tendency shown in Fig. 4.27). When the oil-water contact for the Kupe South-4 accumulation is plotted onto the base of the top seal, it coincided with locations where both trap-bounding faults offset the top seal. Both faults also have associated gas chimneys in the Plio-Pleistocene strata. Further to this, the Kupe-1well, a dry-hole with evidence of a Paleo-oil column, is bound by a geologically reactivated northeast striking fault that displaces the Otaraoa top seal (Fig. 4.27). The reactivated fault also has a higher modelled leakage risk than the Kupe reservoir faults based on Slip Tendency and Dilation Tendency.

Although the geomechanical modelling methods may provide an indication as to which fault sets are most likely to accommodate up-dip fluid and/or gas flow, they do not appear to represent a reliable means of predicting where on a fault surface channelised flow will occur. Histograms (Figs. 4.22, 4.24, and 4.26) have similar modes and distributions of Dilation Tendency, Slip Stability and Fracture Stability for parts of the fault surface with, and without, gas chimneys. There was no clear separation between the two populations that would allow the geomechanical methods to be applied with certainty at other localitions without independent gas and/or fluid flow data.

The inability of geomechanical modelling methods to predict local channelised flow on fault zones may be due to the geometrical complexities that exist in and around faults such as fault relays, fault intersections and lateral fault tips. These locations are generally associated with local increases in off-fault strain manifested as bed rotation and high densities of interconnected sub-seismic fractures (including small faults) (e.g., Childs et al., 1996; Davatzes and Aydin, 2003; Foldin and Aydin, 2004; Fossen, et al., 2005; Eichhubl et al., 2009). Sub-seismic faults and fractures are generally orientated semi-parallel to main faults (e.g., Davatzes and Aydin, 2003; Dockrill and Shipton, 2010), and as all faults with associated gas chimneys in the Kupe Area are orientated parallel to $S_{H m a x}$ fault-related fractures are likely to be parallel to $S_{H \max }$. Fractures that parallel $S_{H \max }$ are most likely to be dilated and open and are therefore capable of acting as conduits to gas flow (Jolley and 
Sanderson, 1997). This assumption, however, breaks down for pre-existing faults and fractures that were not formed in the current (or modelled stress field). In areas where faults cause large perturbations in the stress field orientation (e.g., Yale, 2003), pre-existing faults and fractures that are located in these perturbations could be incorrectly modelled as high or low leakage risks (relative to their orientation in the stress field) due to the stress field not being properly defined. Thus, applications of a generic stress field and the assumption that the strike of fault-related fractures parallels that of proximal larger faults may not be applicable in all situations.

The application of a regional stress field to all faults investigated also relies on the assumption is that stress is homogeneous across the fault network. Maerten et al. (1999) showed that there can be large variations in slip distributions and the manner in which stress is taken up at fault intersections and, as such, stress may not have the same impact on the development of structural permeability at all locations within a fault network. Gartrell et al. (2006) concluded that there was no apparent relationship between fault orientation, reactivation potential and the preservation of hydrocarbons in the Timor Sea. Structures that had been reactivated and were optimally orientated for reactivation in the current stress field contained significant hydrocarbon columns, while other structures that were not optimally orientated for reactivation when drilled showed paleocolumns and evidence of leakage. They concluded that faults with the greatest magnitude of geological reactivation had the greatest risk of fault seal breach and leakage. The conclusions of Gatrell et al. (2006) are consistent with results in this thesis from the Kupe Area where faults that strike parallel to $S_{H \max }$, but have insufficient dip dimensions to breach the regional seal, often do not carry gas chimneys.

This thesis suggests that the theory behind geomechanical modelling methods is sound but the application of such methods suffers due to insufficient data at the small scales needed to define high density interconnected zones of fractures and perturbations in the regional stress field. In addition, the technique takes little account of whether a given fault extends through the top seal into the region of the reservoir; for a fault to carry hydrocarbons it must have sufficiently high permeabilities and intersect a hydrocarbon reservoir or migration pathway. Methods must be applied appropriately in the context of whether a 
fault actually breaches a top seal and whether it is likely to come into contact with hydrocarbons.

\subsection{Conclusions}

Gas chimneys and normal faults imaged in a 3D seismic reflection volume provide a means of testing the ability of geomechanical models to predict locations of up-fault hydrocarbon leakage. This study suggests that the use of geomechanical methods for predicting leakage risk is only applicable as a first-order estimate of which fault sets present the highest risk of up-dip leakage. Slip Tendency and Dilation Tendency were able to differentiate fault orientations in the Kupe Area most at risk of leakage and both indicated higher risk of leakage for the fault set striking parallel to $\mathrm{S}_{\mathrm{Hmax}}$. This fault set displayed the most visible signs of up-dip gas leakage in seismic data. In contrast, Fracture Stability was not able to differentiate fault sets most at risk of leakage in the Kupe Area. The ability of geomechanical modelling methods to locate high leakage risk areas on individual fault surfaces appears to be limited. There was no statistical difference in leakage risk between chimney and non-chimney locations on fault surfaces when applying Slip Tendency, Dilation Tendency and Fracture Stability. This may arise because geomechanical analysis does not include small scale information on the local stress tensor and locations of open interconnected fractures. Additionally these geomechanical methods may fail because they do not take account of whether individual faults breach the seal and are likely to intersect a source of hydrocarbons. Results indicate that when no independent evidence of faultrelated leakage available to calibrate modelled risk it is difficult to establish how much weight should be placed on modelling results. Geomechanical modelling results should not be taken as a measure of real risk of up-dip leakage. Rather, they should be taken as a method to rank risk across various fault sets with widely varying strike. 


\section{Chapter V}

\subsection{Fault-Zone Structure and Gas Flux Rates}

\subsection{Introduction}

Detailed knowledge of fault zone structure is required to better understand the influence that faults have on host rock permeability. Faults are typically resolved in seismic reflection data when their throws exceed the seismic data resolution, which is generally 10$30 \mathrm{~m}$ (depending on quality of seismic data) (Brown, 2004). Fault structure below the limit of seismic reflection data resolution is often more complex than the single slip-surfaces imaged. The limited resolution of seismic data often precludes the identification of locations of structural complexity such as minor relay zones, fault splays, fault intersections and multiple slip-surfaces. Increased densities of interconnect minor sub-seismic scale faults and joints are commonly found at these sites of structural complexity (e.g., Childs et al., 1996; Davatzes and Aydin, 2003; Foldin and Aydin, 2004; Fossen, et al., 2005; Eichhubl et al., 2009), and it is likely that these locations of structural complexity enhance up-dip permeability (e.g., Caine et al. 1996; Childs et al. 1996, 2009; Gatrell et al. 2004; Eichhubl et al. 2009; Dockrill and Shipton, 2010).

Seismic reflection data in the Kupe Area has enabled a model to be established describing the influence of faults on the subsurface migration of hydrocarbons (Chapter III). Up-dip gas migration within fault zones has occurred in the past within the Kupe Area and may be continuing to the present day. However, available seismic reflection data only provides resolution of faults with throws $>12.5$ m preventing identification of the precise mechanisms which induce (and maintain) up-dip gas migration. Seismic reflection data also provides little evidence of potential gas flux rates through chimneys.

In this chapter, field-based observations of faults and up-dip gas migration within the onshore region of the Taranaki Basin are used to examine three primary questions. First, how fault-zone structure differs between faults imaged within seismic reflection data and faults in examined in outcrops is investigated. Secondly, how might sub-seismic fault-zone structure influence up-dip hydrocarbon migration within these fault zones is examined. Thirdly, based on field observations of fault-related gas flow what the possible bounds for gas flux rates through faults within the Kupe Area are considered. To address these 
questions of fault-zone structure, fault zones have been examined that are exposed in coastal cliff of northern Taranaki, and western Waikato. This chapter uses data from these cliffs because there are few coastal exposures close to the Kupe Area. These coastal cliffs offer near $100 \%$ exposure and the faults in the cliffs displace multiple formations, including the Oligocene siltstones of the Te Kuiti Group which are a local correlative of the Otaraoa top seal in the Kupe Area.

To examine gas flux rates associated with Plio-Pleistocene normal faulting gas concentration data have been collected from the floor of the Bristol Road Quarry, which is in the immediate hanging-wall of the Inglewood Fault. The Quarry floor is periodically flooded (i.e. every 1-2 days), and at these times gas escaping into the atmosphere can be readily located. Therefore, the Quarry is an excellent site for locating and quantifying gas flux. Collectively, the Quarry and outcrop data provide information on fault structure and gas flux that is directly applicable to the Kupe Area.

\subsection{Fault Zone Structure}

The ability of faults and joints to locally increase or decrease rock permeability is widely recognised (e.g., Yielding et al., 1997; Manzocchi et al., 1999; James et al., 2004; Meyers et. al., 2007; Manzocchi et al., 2008; Odling et al., 1999; Corona et al., 2010). Fault studies have predominantly focused on faults and fractures within reservoir intervals as these are often localities where the majority of high resolution borehole data (image logs, geophysical logs and core samples) is acquired. Within the reservoir, faults are important because they have the potential to act as barriers or baffles to hydrocarbon flow on production time scales (e.g., Manzocchi et al., 1999; Meyers et. al., 2007; Manzocchi et al., 2008). The impact of faults and joints on low permeability top seals (such as the Otaraoa formation in the Kupe Area) is less well known (e.g., Cartwright et al., 2007). The precise manner in which faults and fractures impact on up-sequence fluid and gas migration is dependent on a number of factors including host rock properties (lithology and permeability) (e.g., Hanks et al., 1997; Knipe et al., 1998 and references therein), fault-rock properties (permeability and relative permeability) (e.g., Yielding, et al., 1997), reservoir pressure and temperature conditions (e.g., Fisher and Knipe, 1998; Olson et al., 2007), 
fracture dimensions, spacing, aperture, connectivity and orientation in the current stress field (e.g., Rawnsley et al., 2007) and permeability of any material hosted within fractures (e.g., Antonellini and Mollema, 2000; Bar et al., 2007).

Faults are zones that at outcrop scale are typically complex and characterised by heterogeneous strain distributions. Fault-rock commonly consists of very low permeability (e.g., $<0.01 \mathrm{mD}$ ) clay rich material that has the potential to act as barriers to lateral fluid flow (e.g., Yielding et al., 1997). Fault-rock can vary spatially over the fault surface and generally increases in thickness with fault displacement (e.g., Hull, 1988; Blenkinsop, 1989; Childs et al., 2009). The surrounding fault zone can contain fractures and minor faults that often form anastomosing networks of interconnected slip-surfaces commonly aligned sub-parallel to the main slip-surface. The spatial distribution of fractures within a fault zones is also variable, with higher densities of fractures found at changes in fault geometry (e.g., steps or bends), fault intersections, relay zones and near fault tips (e.g., Childs et al. 2009; Dockrill and Shipton, 2010). Fractures are more likely to be interconnected at locations where their densities are high, and if open, have the potential to enhance up-dip permeability and migration of fluids and gas.

Faults generally comprise gouge, breccia and/or cataclasite, which are often referred to as 'fault-rock' or 'fault core’ (Fig. 5.1), adjacent to which a zone of small-scale faulting or fracturing may be referred to as 'fault zone' or 'damage zone; (Fig. 5.1). These terms, however, are not necessarily synonymous (see Childs et al., 2009). 


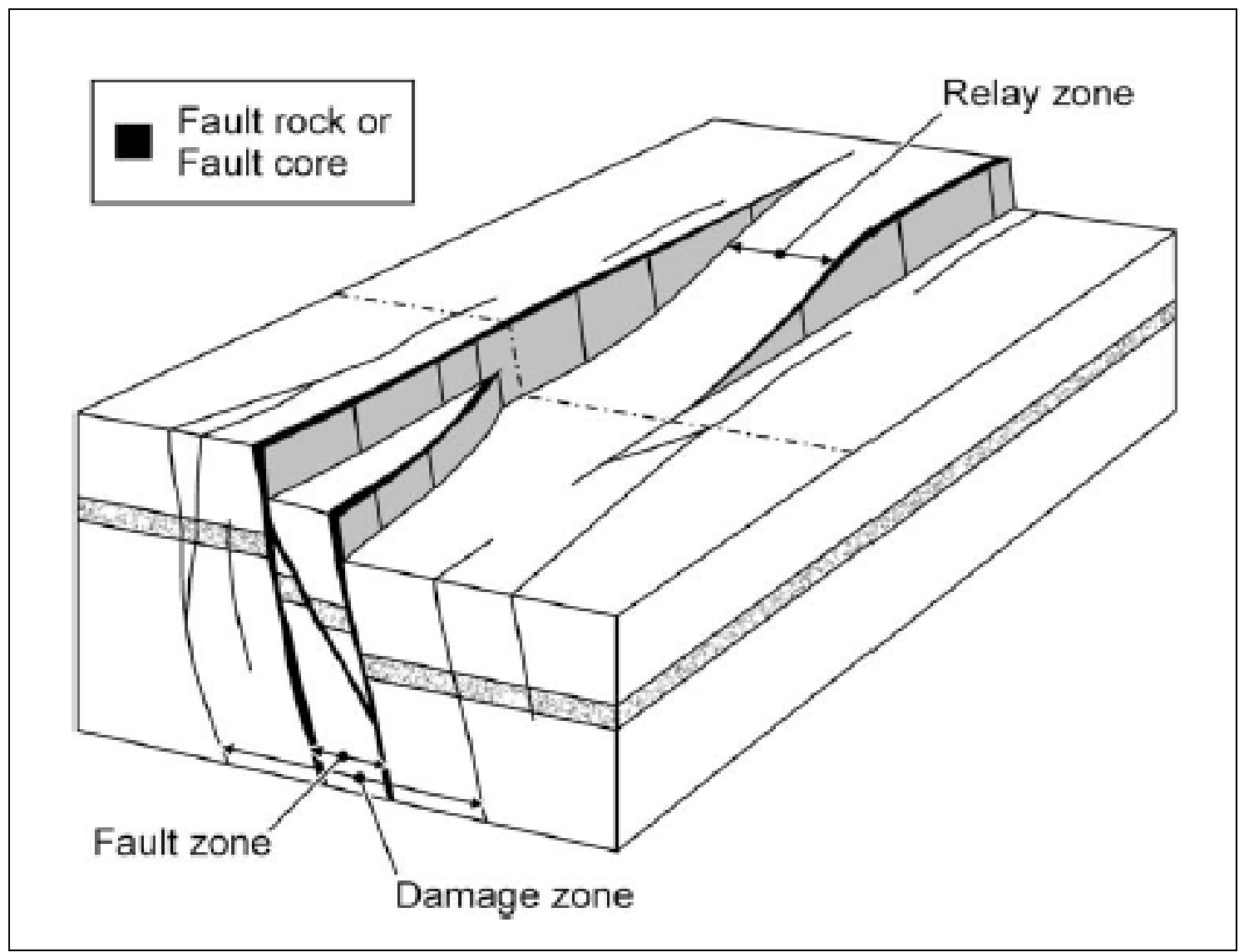

Figure 5.1 Model of fault structure showing terminology used to describe faults in this study (from Childs et al., 2009).

In this study, the outcrop expressions of faults were investigated at two locations within the onshore area of the Taranaki Basin. The first location, Tongaporutu, is located $60 \mathrm{~km}$ north-east of New Plymouth and contains outcrops of interbedded turbidite sequences of the Mt Messenger Formation (Fig. 5.2). The Mount Messenger rocks are cut by a series of north-east striking normal faults of $<8 \mathrm{Ma}$ age exposed along coastal cliff sections. The second location, Waikawau, at Port Waikato (70 km south of Auckland) contains Oligocene age calcareous siltstones of the Te Kuite Group (Fig. 5.2). The siltstones are cut by a series of north-west striking normal faults of $<12$ Ma age (Giba, 2010). The two locations were chosen as they provided comparison of fault structure in potential Late Miocene reservoir (Tongaporutu) and Late Oligocene top seal (Waikawau) sequences. 


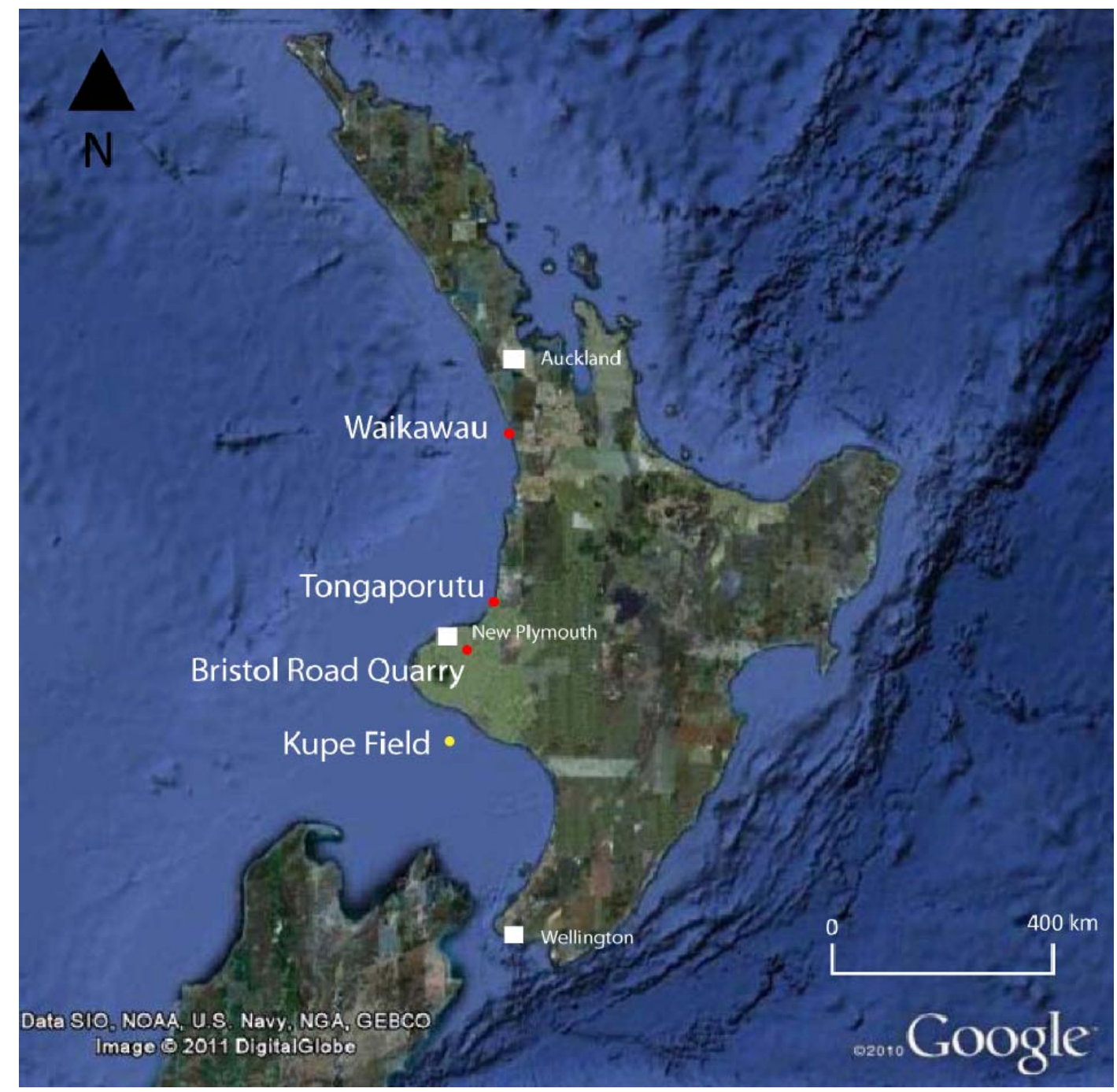

Figure 5.2 Map of the North Island, New Zealand. Field work locations are shown as red circles. The yellow circle marks the Kupe gas condensate field. White squares mark main urban centres. Image adapted from Google Maps (www.maps.google.com).

\subsubsection{Late Miocene Reservoir - Tongaporutu}

The Miocene age turbidite sequences of the Mt Messenger Formation host a number of faults with throws ranging from sub-millimetre to tens of metres. The structure of these fault zones is highly complex and heterogeneous, with the majority of faults likely to be sub-resolution in the Kerry 3D seismic volume (displacements $\leq 10$ metres). Figure 5.3 shows the locations of fault zones examined at Tongaporutu. 


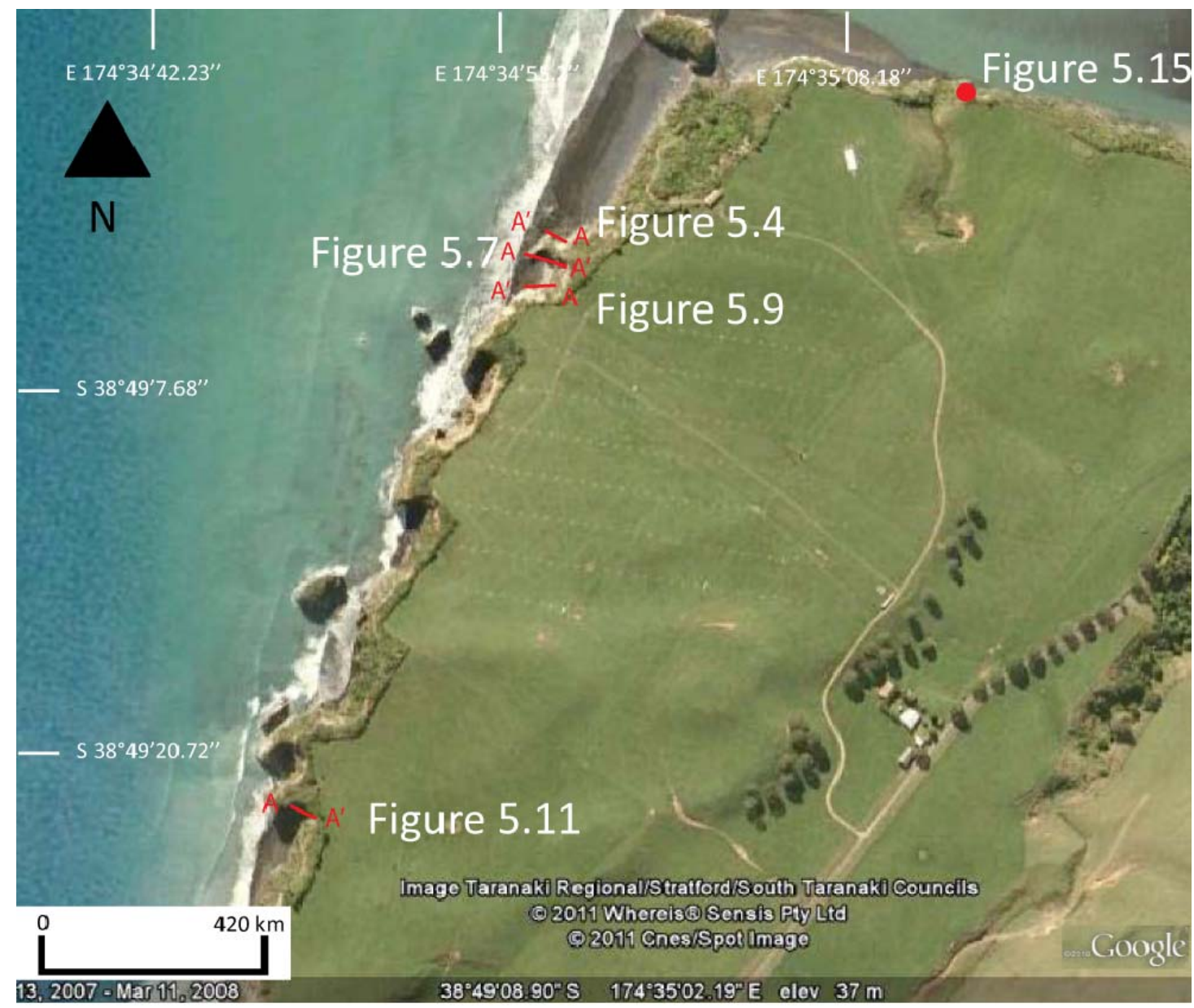

Figure 5.3 Aerial view of Tongaporutu Field Area showing locations and orientations of outcrop images. Image adapted from Google Maps (www.maps.google.com). Location of image is shown in Figure 5.2.

The first fault zone examined provides an excellent analogue for the heterogeneous nature fault zones and the difficulties associated with predicting varying fault structure along even small strike distances (20-50 metres). The fault zone outcrops in near vertical cliff faces three times over an approximate distance of $50 \mathrm{~m}$, and at each outcrop the fault-zone is different. At Locality One (Fault Zone 1, Outcrop A), the fault has an approximate throw of six metres on the main slip-surfaces and the hanging-wall contains a number of smaller throw (0.2-1.5 metres) antithetic and synthetic faults (Fig. 5.4). Fault-rock thickness between the main slip-surfaces is approximately $5-10 \mathrm{~cm}$ at the top of the outcrop, and thickens to 50-60 cm at the base of the outcrop. Fault-rock comprises predominantly 
cataclasite and both sandstone and siltstone beds that have been extensively sheared and brecciated as they were dragged along the fault. Deformation bands are common within the fault zone and in the hanging-wall of the main slip-surface (e.g., Fig. 5.5). The bands form due to strain localisation in porous granular media and are low displacement, narrow zones of rotated and translated grains which may be crushed (Antonellini et al., 1994; Fossen et al., 2007). The bands are commonly associated with a reduction in porosity (Fossen et al., 2007). The deformation bands at Tongaporutu have complex cross cutting relationships, suggesting a complex history of sequential (and non-synchronous) band development. A synthetic fault with approximately $80 \mathrm{~cm}$ of throw in the hanging-wall of the main slipsurface contains an approximately $50 \mathrm{~cm}$ long section of sandstone fault-rock, which appears to have been dragged and smeared along the fault (Fig. 5.6). Thin veins (2-5mm thick) are also present within several of the smaller fault zones in the hanging-wall of the main slip-surface. 


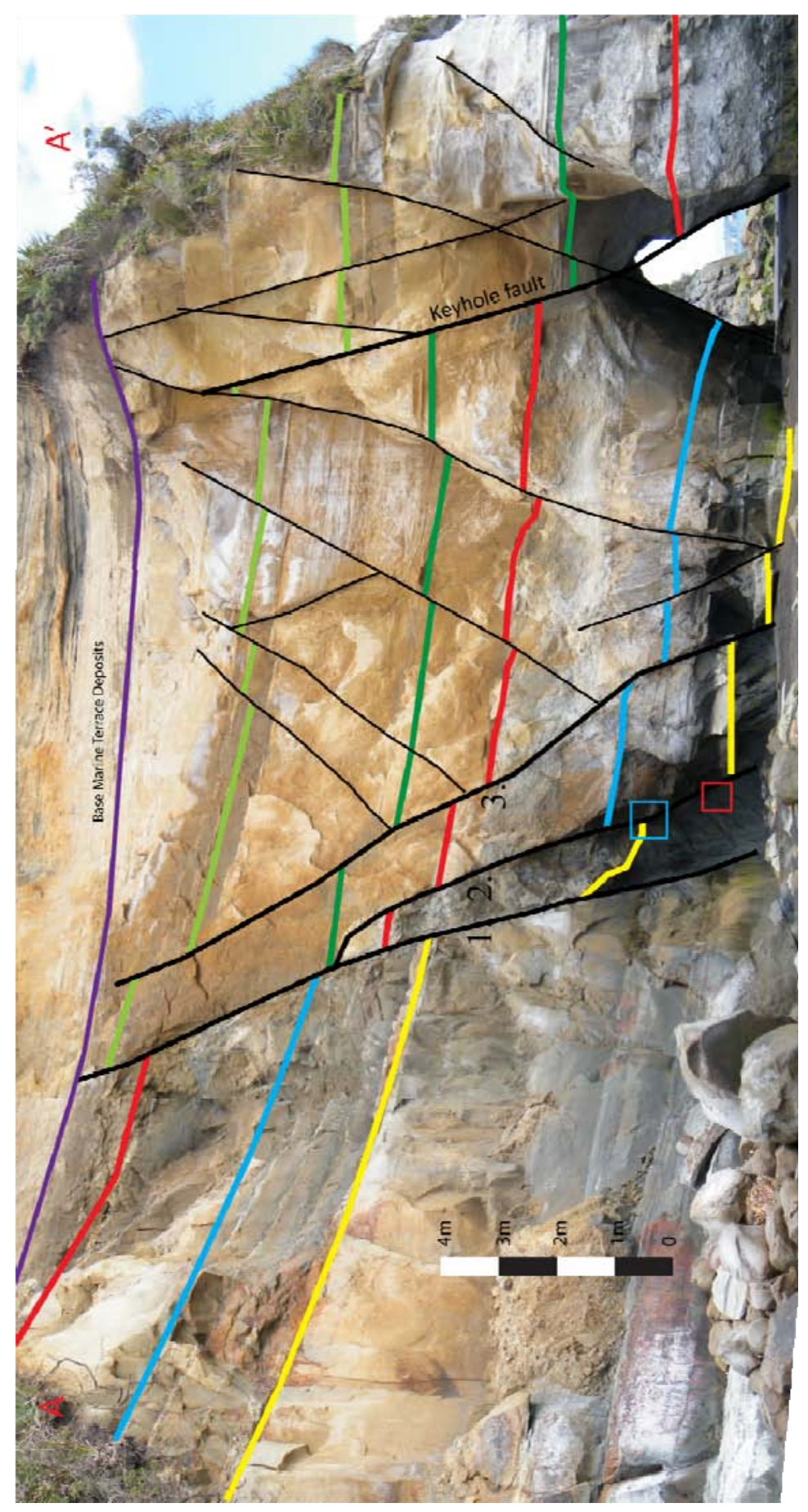

Figure 5.4 Fault Zone 1, Outcrop A, Tongaporutu. View is to the south. Note the two slips surfaces labelled 1 and 2 that bound a lens of deformed host rock in the main fault zone. The blue rectangle is the location of Figure 5.5 and red rectangle is the location of Figure 5.6. The keyhole fault is located on the right side of the photograph. Figure 5.7 is located $\sim 10 \mathrm{~m}$ through the cave and the figure's view is to the north in the opposite direction to this figure. The scale is approximate and the location of this section is shown on Figure 5.3. 


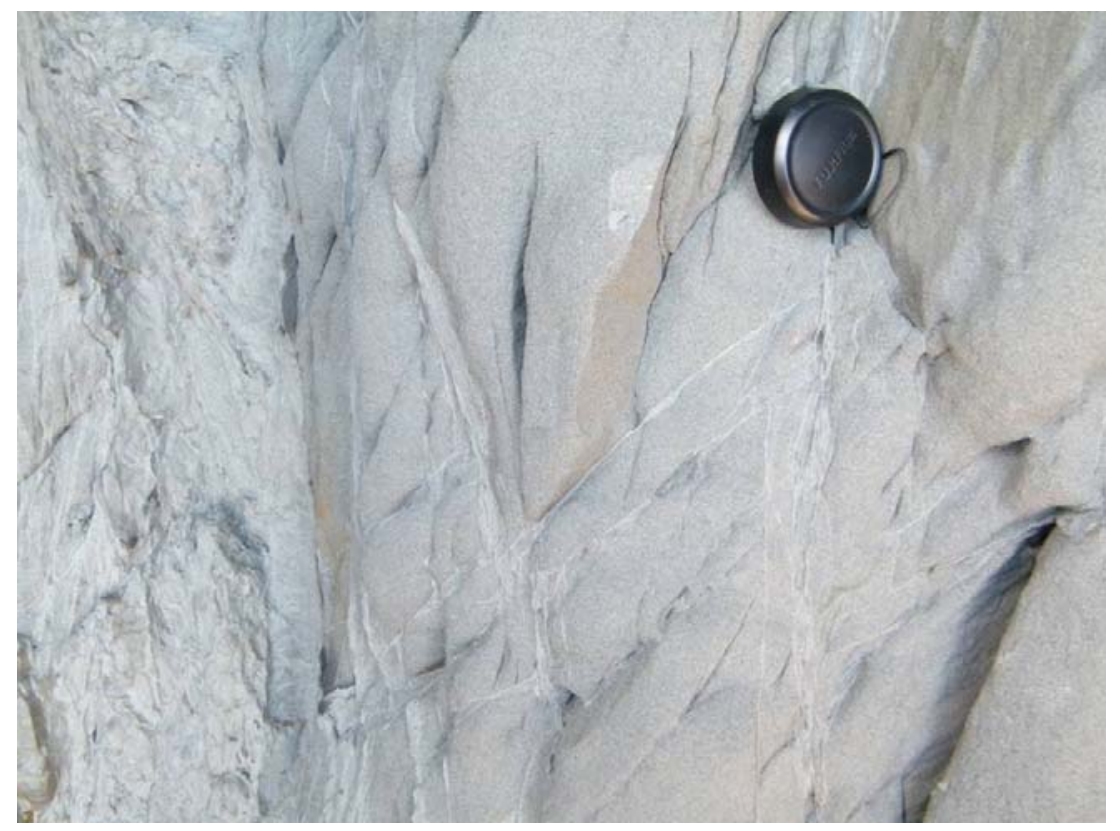

Figure 5.5 Deformation bands cutting through a relatively undeformed fine sandstone host rock in Outcrop 1 (see Fig. 5.4 for location). Note the change to deformed fault-rock on the left of the image and the mutually cross-cutting relationships of the deformation bands. Lens cap is $\sim 6 \mathrm{~cm}$ diameter.

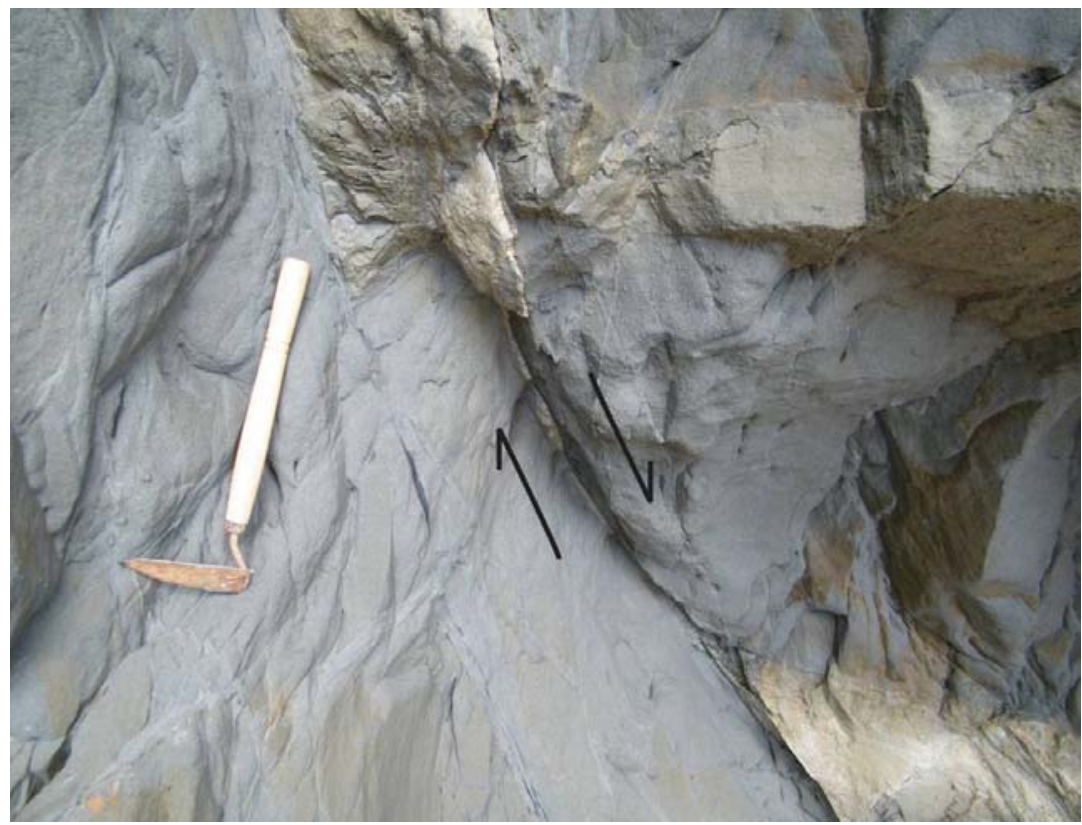

Figure 5.6 Normal fault (downthrown to the right) with approximately $0.5 \mathrm{~m}$ throw from Outcrop 1 at Tongaporutu (see Fig. 5.4) for location). White/light brown indurated sandstone bed (bottom right and top centre left) has been displaced by the fault. Between the two arrows the sandstone bed has been smeared along the slip-surface. Wooden tool handle is $\sim 25 \mathrm{~cm}$ long. 
Outcrop B (Fig. 5.7 and Fig. 5.8) is approximately 10 metres from Outcrop A on the opposite side of the cliff face. The general pattern of faulting is similar in both outcrops with the main fault zone and the Keystone Fault exposed in each (Compare Figs. 5.4 and 5.7). These two faults have developed in the same beds and have similar fault zone and faults rock dimensions. In the main fault zone of Outcrop B, a $40 \mathrm{~cm}$ thick sandstone bed has been incorporated into the fault zone (above and immediately right of the person's head in Figure 5.7). Given the approximate height and angle of dip on the bed in relation to Outcrop A, it is likely it is the same section of sandstone bed in the fault zone in Outcrop A (Fig. 5.5). However, in detail the spatial distribution, numbers and displacements of the faults have changed in Outcrop B. For example, the main fault zone in Outcrop B has two major slip-surfaces as opposed to the three slip-surfaces in Outcrop A. In addition, there are far fewer deformation bands contained within the fault-rock and hanging-wall of the main fault. Given the low permeability of deformation bands this could result in significant change in fault-rock and fault zone permeability between the two outcrops. 


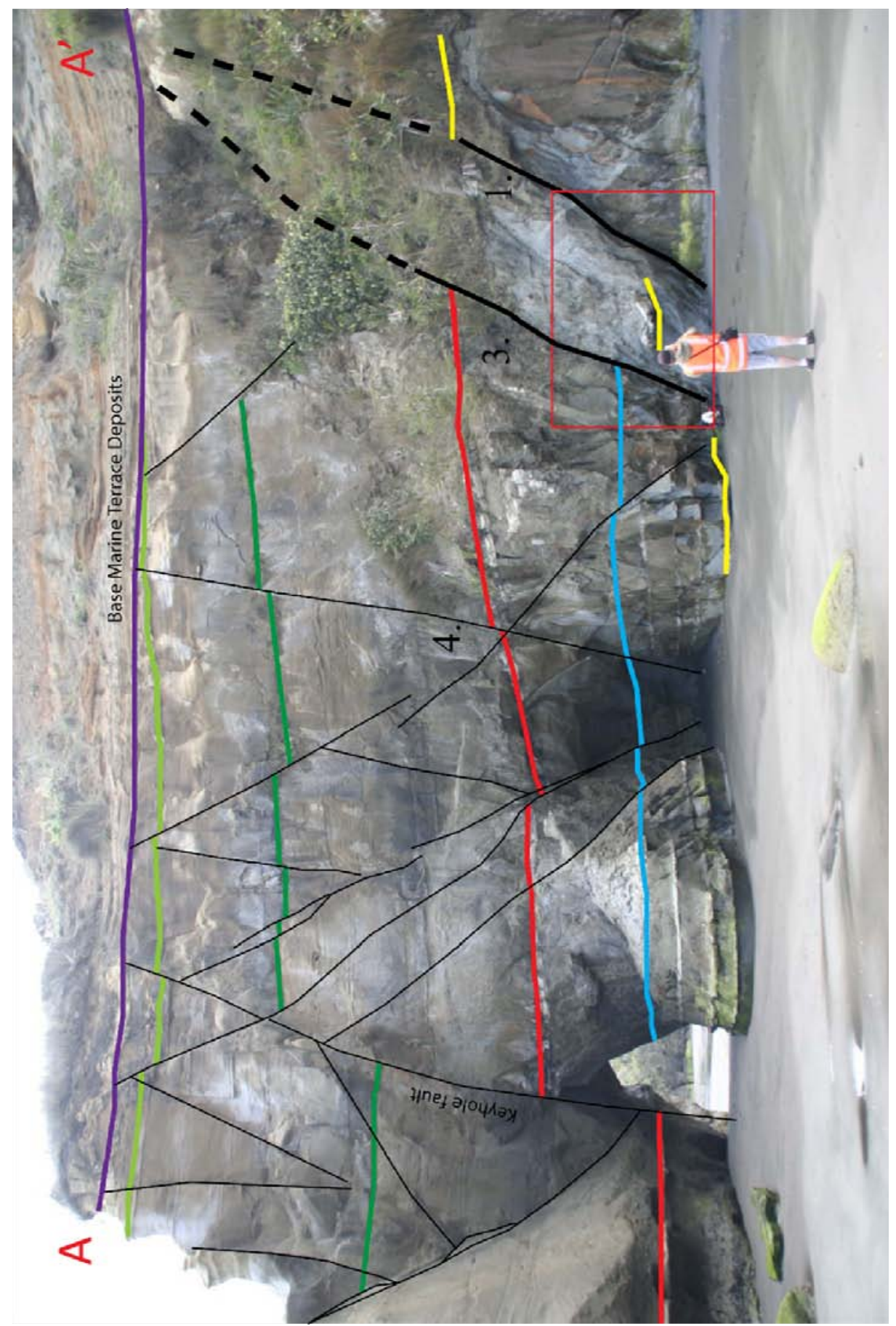

Figure 5.7 Fault Zone 1, Outcrop B, Tongaporutu. The figure's view is to the north, the opposite direction to Figure 5.4. Horizons correlate with the horizons in Figure 5.4 and have the same colours in each photo. Two slip-surfaces (labelled 1 and 3) correlate with slip-surfaces 1 and 3 in Figure 5.4 and bound a lens of deformed host rock in the main fault zone. Red rectangle is the location of Figure 5.8. Person in the photo is $\sim 1.8 \mathrm{~m}$ high. Location of section is shown on Figure 5.3. 


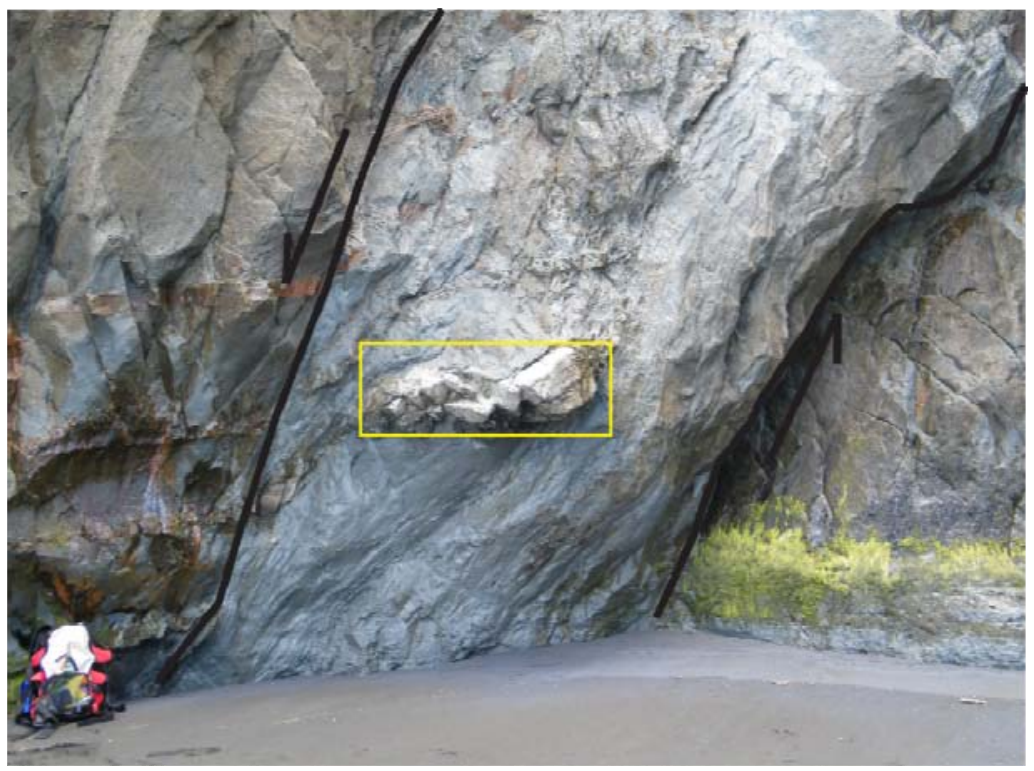

Figure 5.8 Close up of main Fault Zone 1, Outcrop B, Tongaporutu. Note the entrained sandstone bed (inside yellow rectangle) between the two primary slip-surfaces of the main fault (approximate locations and direction of slip indicated by black lines and arrows). Backpack is $\sim 60 \mathrm{~cm}$ tall.

The main fault zone in Outcrops A and B is exposed for a third time in Outcrop C, which is a further 15 m south of Outcrop B. The main fault zone has a different character in Outcrop C compared to Outcrops A and B. In Outcrop C, the main fault comprises a thin sliver of fault-rock $(\sim 20 \mathrm{~cm})$ along the top section which thickens to $\sim 2 \mathrm{~m}$ over $\sim 10 \mathrm{~m}$ vertical distance towards the base of the visible fault. This upward thinning of fault-rock reflects the fact that the two primary slip-surfaces that bound the fault-rock converge at the top of the outcrop (Fig. 5.9). The Keystone fault appears to project seaward of Outcrop C and is not well exposed in this cliff. Fault Four, from Outcrop B, is well exposed in Outcrop C and has two discrete sets of slip-surfaces at the top of the outcrop that bound a lens of relatively undeformed wall rock. There is a minor amount of fault-rock between the slip-surfaces $(10-20 \mathrm{~cm})$ at the top of the outcrop. At the base of the outcrop, the fault-rock thickness increases to approximately $80 \mathrm{~cm}$ and the lens of wall rock appears more deformed. This increase in deformation appears to coincide with a change in the lithology from sandstone to mudstone. Deformation bands are present throughout the bottom section of fault-rock and the hanging-wall. The fault-rock also contains segments of entrained sandstone host rock totalling $180 \mathrm{~cm}$ long (Fig. 5.10). The faults in Outcrop C 
predominantly dip seaward with few faults dipping landwards, as was observed in Outcrops A and B (Fig. 5.4 and Fig. 5.7).

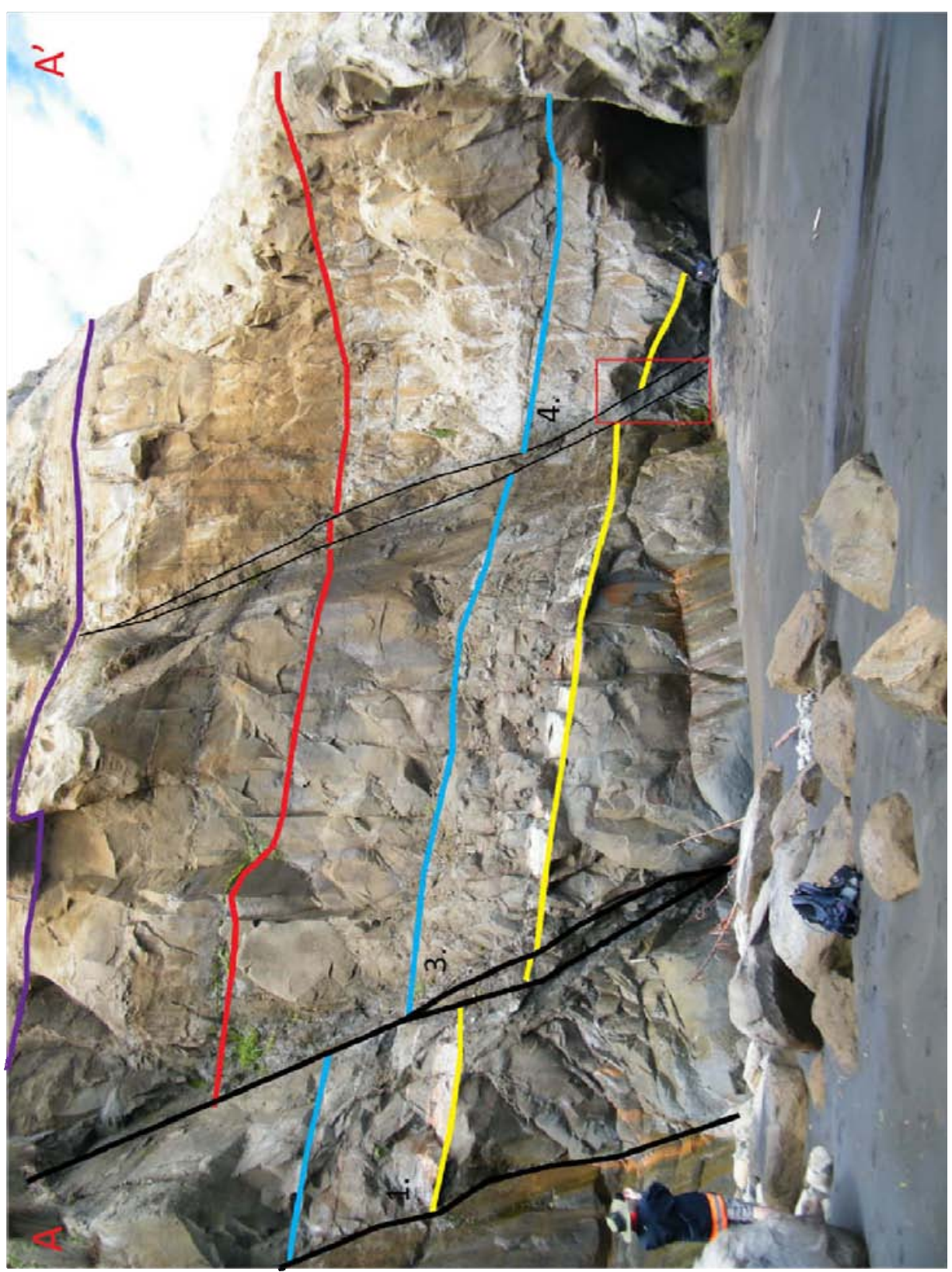

Figure 5.9 Fault Zone 1, Outcrop C, Tongaporutu. View to the south. Horizons correlate with the horizons in Figures 5.4 and 5.7 and have the same colours in each photo. The main fault zone located on the left of the photograph now has another minor lens of host rock bound by two slip-surfaces. The red rectangle indicates the location of Figure 5.10. Person in photograph is $\sim 1.8 \mathrm{~m}$ high. Location of section is shown on Figure 5.3 . 


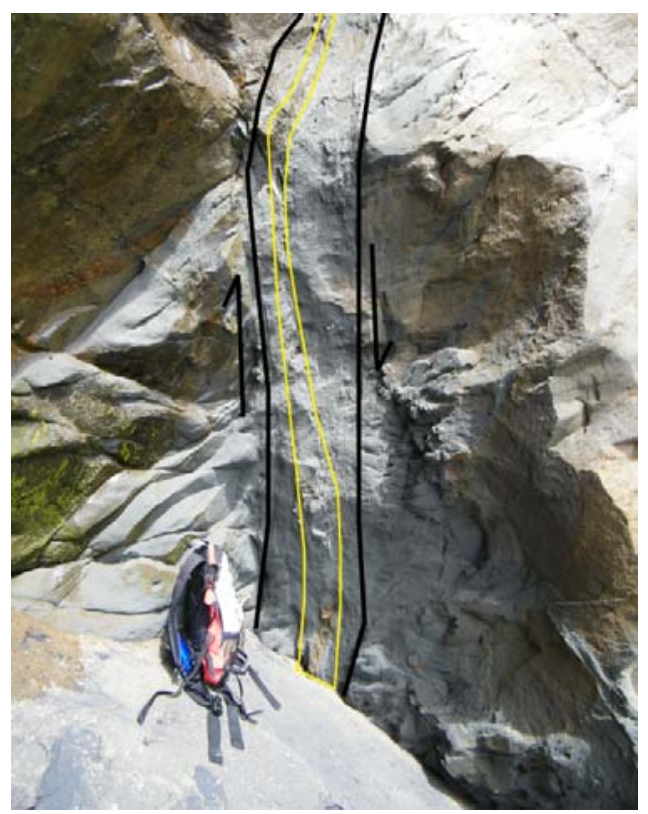

Figure 5.10 Close up of the bottom of Fault 4, in Outcrop C, Tongaporutu. The yellow polygon outlines the segments of sandstone incorporated within the fault-rock. The sand is most visible at the bottom of the polygon. The black lines and arrows mark the approximate locations of the main fault-rock bounding slipsurfaces and their displacement direction. The bag is $\sim 60 \mathrm{~cm}$ high.

Unlike all of the faults in Outcrops A, B and C at Tongaporutu, which would be subresolution in the Kerry 3D seismic dataset, the $\sim 30 \mathrm{~m}$ throw fault in Figure 5.11 would be observed in seismic reflection lines. This is the largest throw fault along the Tongaporutu cliffs and comprises a fault zone that is bound within two main slip-surfaces. Beds between these slip-surfaces have been rotated towards the dip-direction of the fault (i.e. to the left in Figure 5.11). The majority of the total throw (> $20 \mathrm{~m}$ ) is accommodated on the slipsurfaces bounding the right side of the fault zone (Fig. 5.12). Fault-rock on these slipsurfaces ranges from 5 to $50 \mathrm{~cm}$ in width along the fault trace and the foot-wall contains extensive minor faulting (Fig. 5.13). The fault-rock, hanging-wall and foot-wall all contain significant densities of deformation bands which also form minor faults within the fault-rock (Fig. 5.15). There are numerous locations where thin sand beds ( $<30 \mathrm{~cm}$ thick) appear to have been smeared into the fault-rock in a manner similar to clay smears (Fig. 5.14). The sand smears are lozenge in shape and approximately $1-2 \mathrm{~cm}$ wide and 2-30 cm long. Although this $\sim 30 \mathrm{~m}$ displacement fault would be routinely resolved in the Kerry 3D 
seismic dataset, it is unlikely that multiple slip-surfaces and the small scale structures visible in Figure 5.12 would be observed.

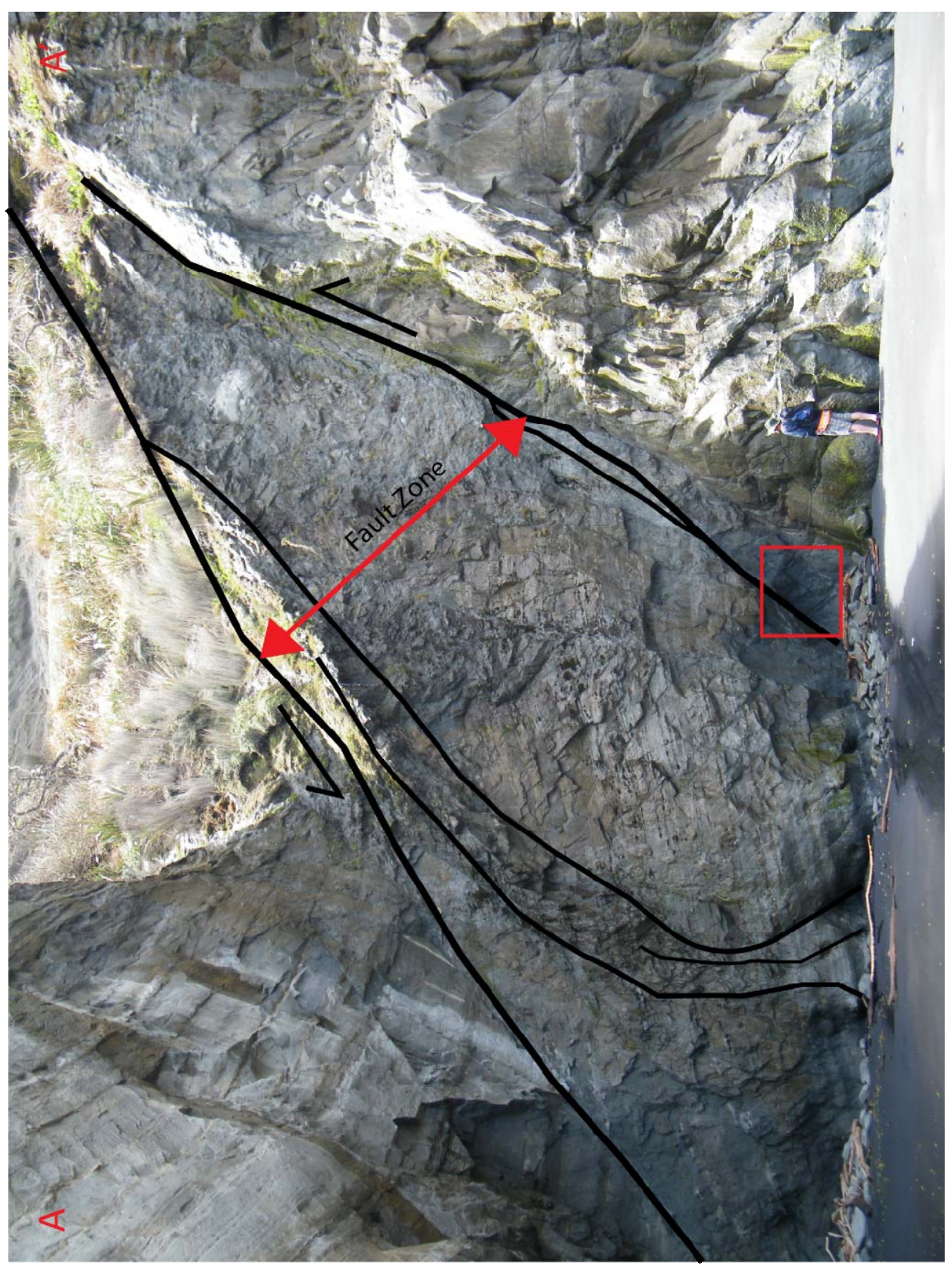

Figure 5.11 Fault Zone 2, Tongaporutu. Fault has a throw of $\sim 30 \mathrm{~m}$. Person in photograph is $\sim 1.8 \mathrm{~m}$ high. Red rectangle shows the location of Figure 5.12. Location of section is shown on Figure 5.3. 


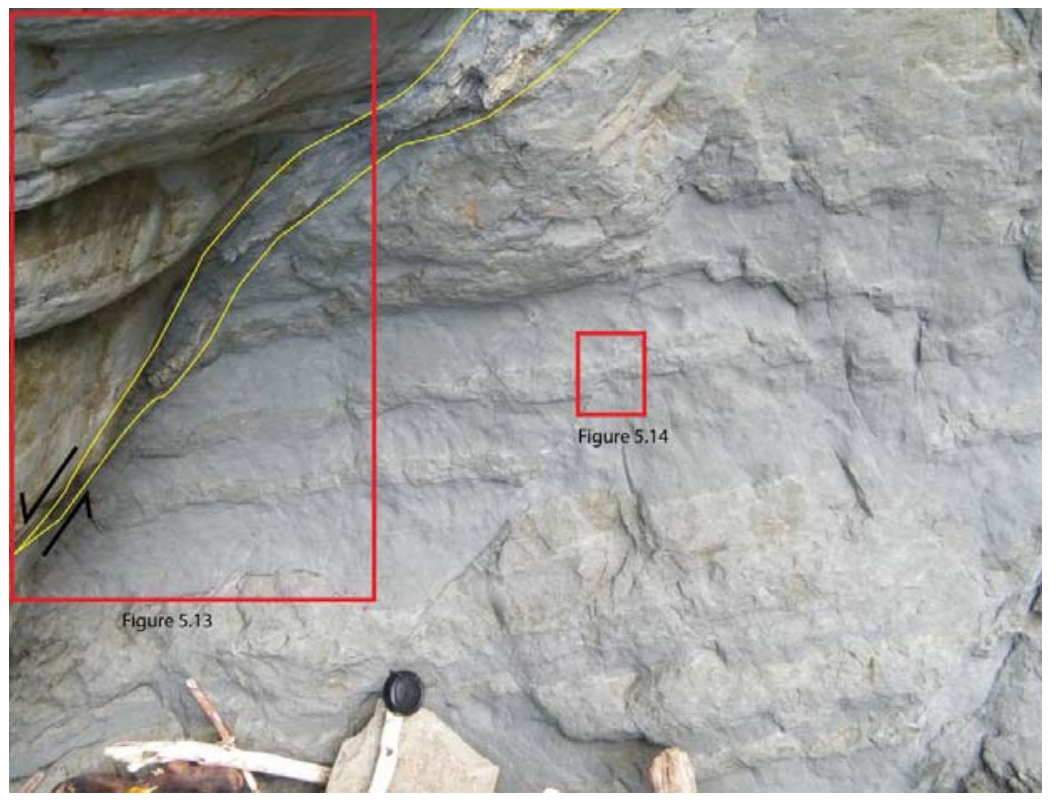

Figure 5.12 Close up of Fault Zone 2. Yellow lines are the edges of the fault-rock. Note the variability in fault-rock thickness vertically up the photograph. Sand lenses (light brown to white in colour) that have been incorporated into the fault-rock are visible in the yellow polygon (top centre). The foot-wall contains numerous minor faults and deformation bands. The red boxes indicate the locations of Figure 5.13 and Figure 5.14. Lens cap is $\sim 6 \mathrm{~cm}$ in diameter.

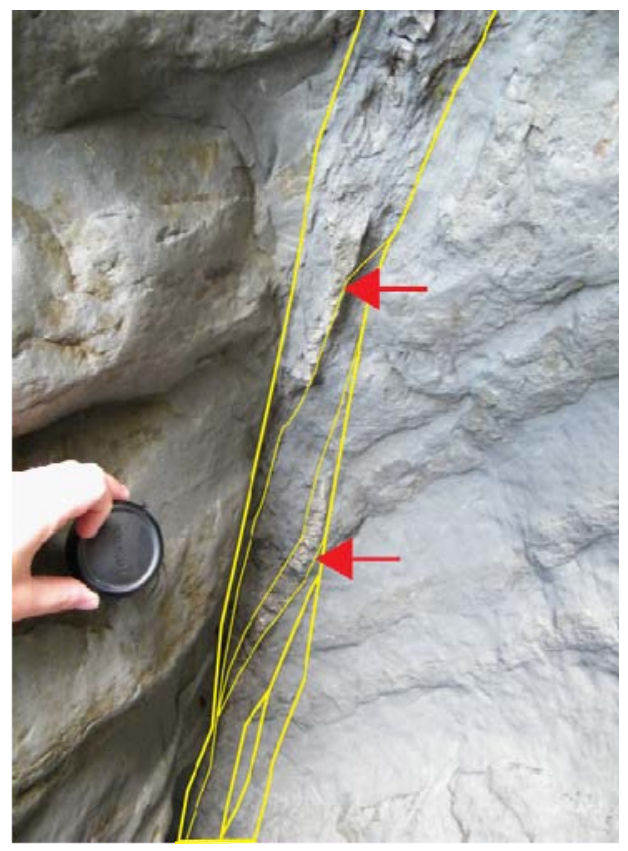

Figure 5.13 Lenses of sandstone (shown by red arrows) incorporated into the fault-rock along multiple slipsurfaces (yellow lines). Lens cap is $\sim 6 \mathrm{~cm}$ diameter. See Figure 5.12 for location. 


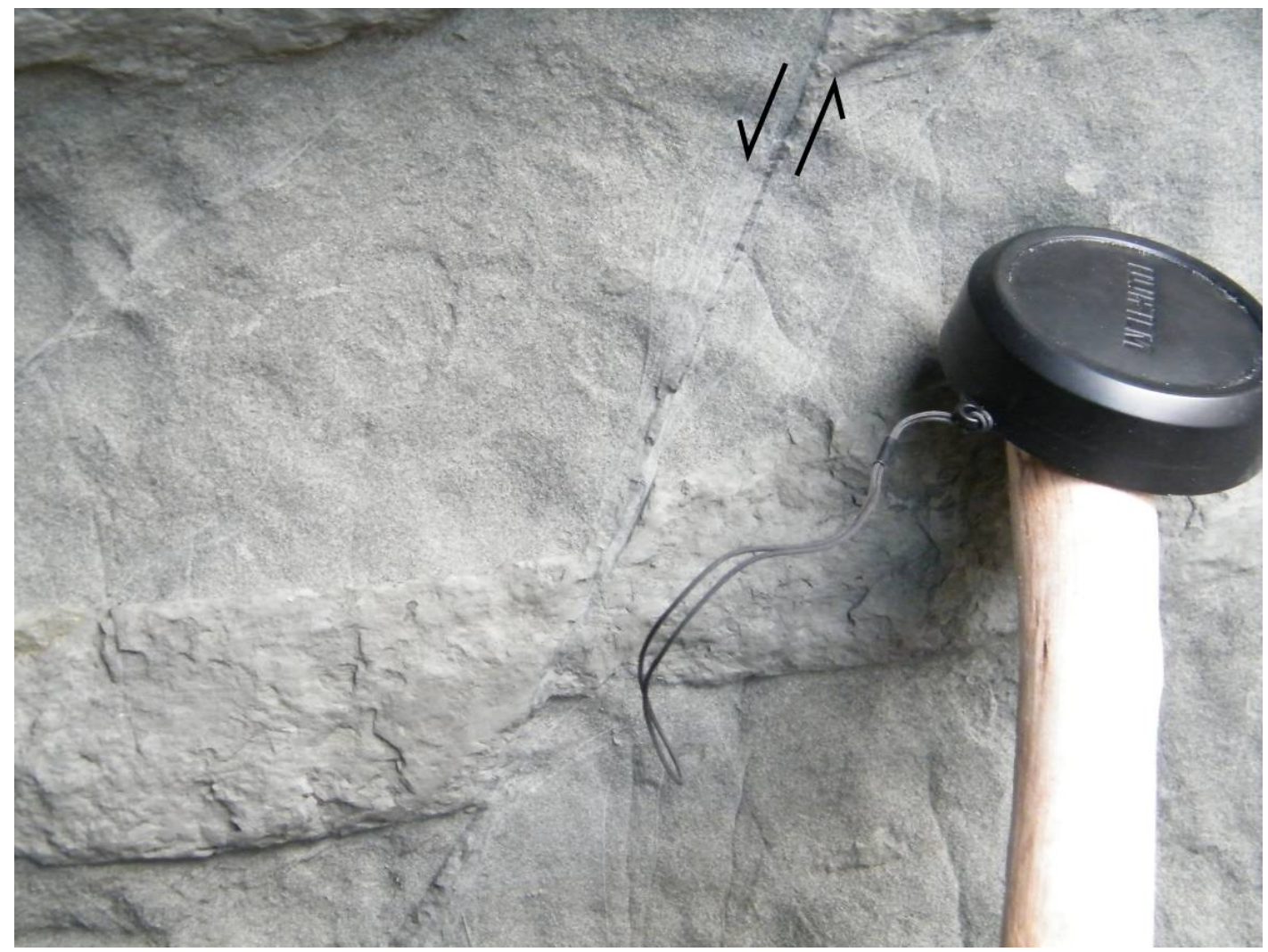

Figure 5.14 Minor fault in the foot-wall of Fault Zone 2. Deformation bands in the sandstone enclose the primary slip-surface which towards the top of the photo is defined by dark grey fault-rock. Arrows indicate slip sense along the fault. Lens cap is $\sim 6 \mathrm{~cm}$ diameter.

The dimensions, geometries and fault-rock content of the fault zones vary significantly along many of the faults shown in Figures 5.5-5.14. The complexity and heterogeneity of fault zones in these figures contrasts with Fault Zone 3 (Fig. 5.15). Fault Zone 3 comprises a single near-straight trace and displaces strata by $\sim 3$ metres. This fault zone is very narrow (2-4cm), with only minor deformation and no evidence of bed rotation in the wall-rock away from the slip-surface. There is a minor amount of fault-rock between the slip-surfaces $(<2 \mathrm{~cm})$. 


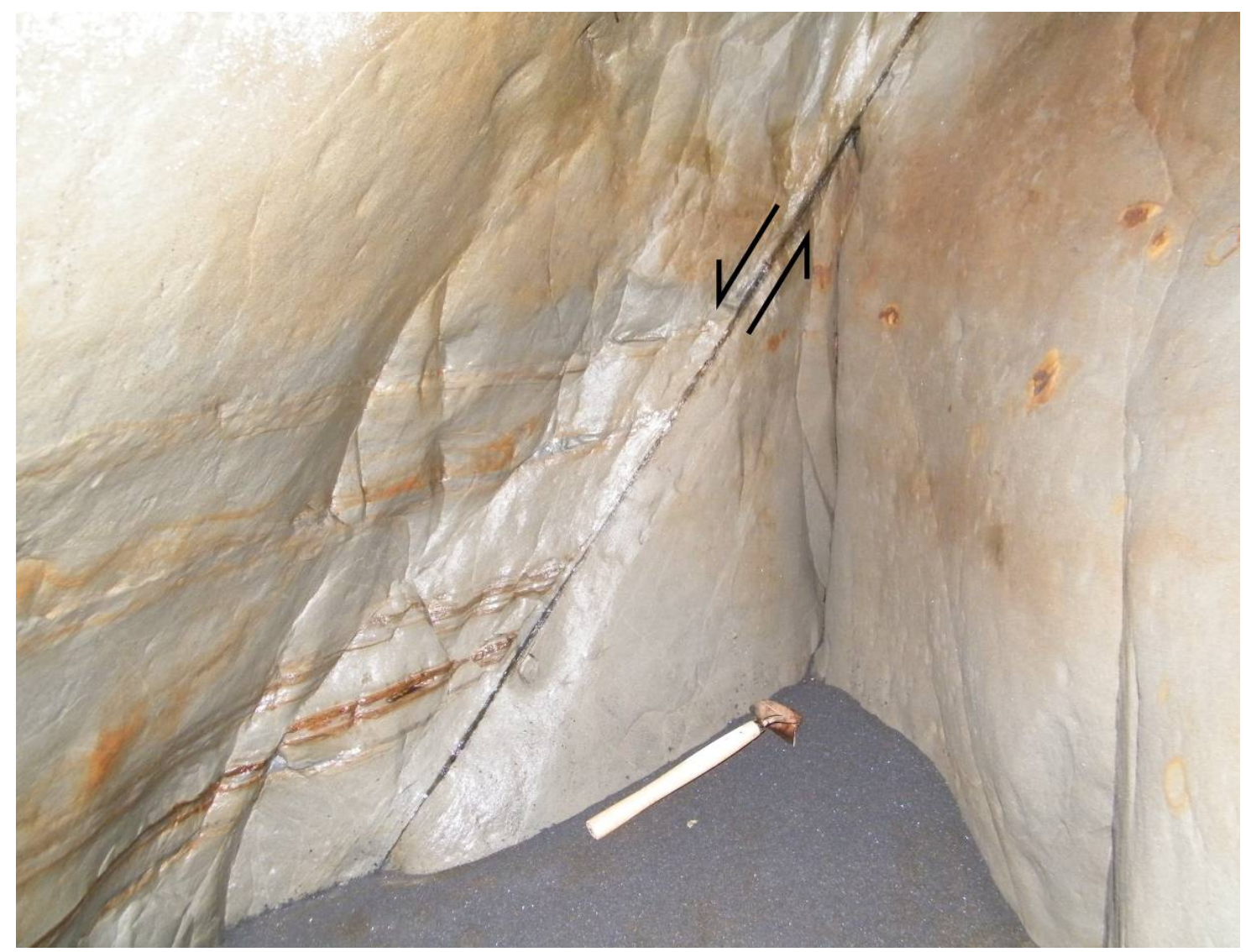

Figure 5.15 Fault Zone 3, Tongaporutu River. The fault has a single well defined slip-surface. Dark grey material defining the fault surface is fault-rock and comprises both silt and sand (some of which appears to have been smeared along the fault). Wooden tool handle is $\sim 25 \mathrm{~cm}$ long. Location of outcrop is shown on Figure 5.3. 


\subsubsection{Fault Heterogeneity}

Fault zones as simple as the fault illustrated in Figure 5.15 represent an extreme case rather than the norm. Faults at Tongaporutu more typically exhibit rapid spatial variation in structure and fault-rock properties over short distances within the same sedimentary sequences. Fault-rock thicknesses vary significantly and in places do not adhere to general trends of increasing thickness with increasing throw. Deformation bands are present at some localities but not others, and minor faulting is constrained to the hanging-wall on one fault and the foot-wall on another fault. Variation in fault structure and fault-rock composition are likely to be below seismic resolution resulting in difficulties when trying to predict fluid and gas flow in and around faults from seismic data. However, many faults interpreted from seismic reflection lines (including in the Kupe Area) are inferred to comprise simple fault zones similar to Fault 3 (Fig. 5.15), rather than the heterogeneous fault zones shown in Figures 5.5-5.14.

Current fault seal and leakage risk modelling methods are commonly applied at the resolution of seismic data, and subtleties in structure that could impact on fluid and gas migration are often missed or neglected from inclusion in risk assessments. Further to this, generic predictive methods for fault-rock composition currently do not address the possibility of deformation bands or sand gouge or smear in fault permeability assessments which could result in unrealistically high or low assumptions of fault zone permeability.

\subsubsection{Oligocene Seal - Waikawau Beach}

Cliff faces at Waikawau Beach host a number of 12 Ma age normal faults in Oligocene age siltstones and fine grained sandstones of the Te Kuiti Group (Edbrooke, 2001). Faults investigated in this Area range from throws of several centimetres up to 5 metres and provide clues to the sub-seismic structure of faults that deform the Otaraoa seal in the Kupe Area. Locations of outcrops investigated are shown in Figure 5.16. 


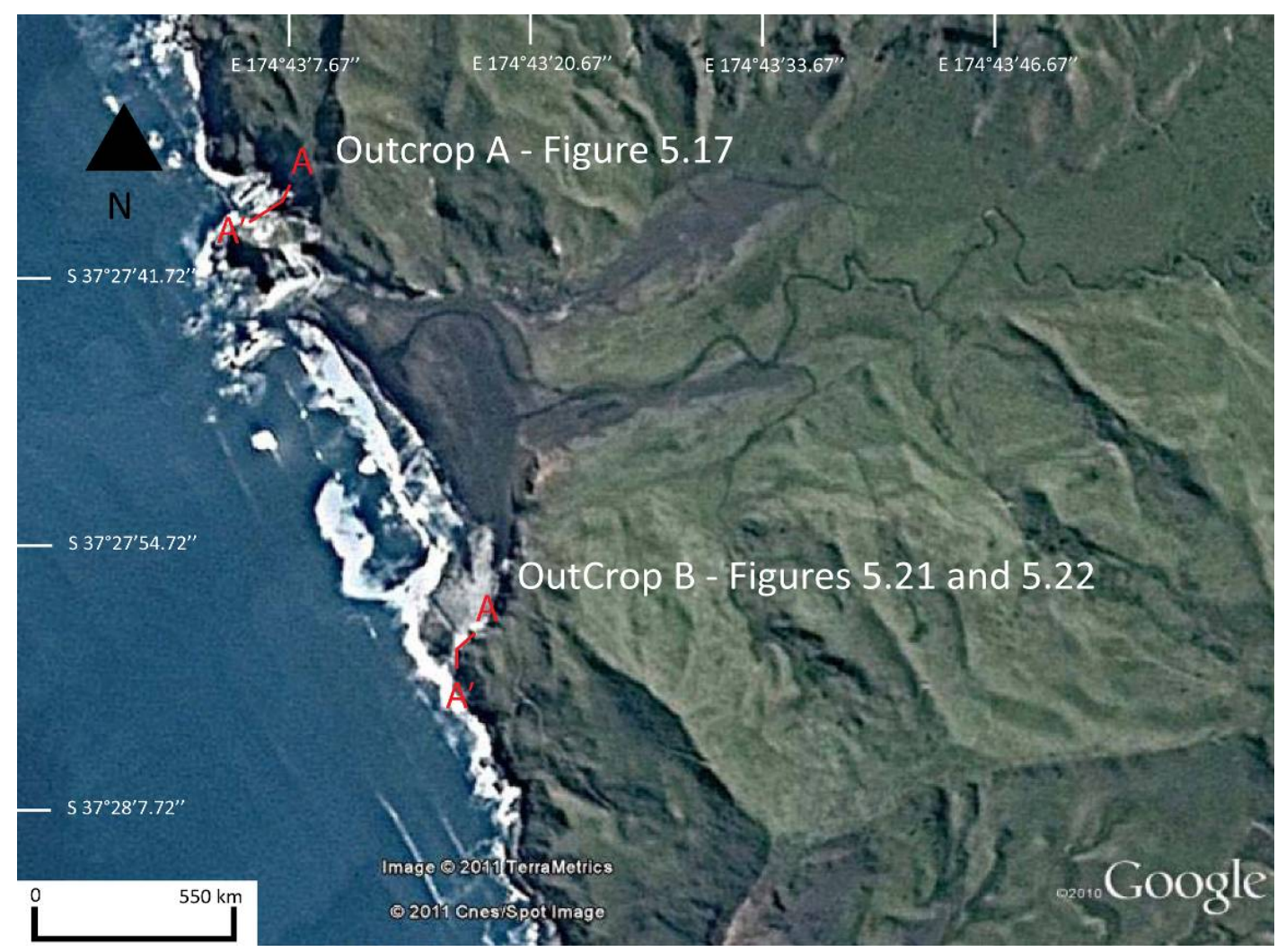

Figure 5.16 Aerial view of Waikawau Beach Field Area showing locations and orientations of outcrop images. Image adapted from Google Maps (www.maps.google.com). Location of image is shown in Figure 5.2.

Faults at Outcrop A, Waikawau Beach, have throws ranging between 50-200 cm. Fault zones vary from singular slip-surfaces to paired slip-surfaces that bound lenses of densely fractured wall rock (Fig. 5.17). High densities of fractures (compared to undeformed wall-rock) typically occur within fault zones. Fractures often appear to bifurcate from the main slip-surface and can be traced for up to 2 metres from the main fault before terminating. Localised higher density zones of fractures are observed at changes in slipsurface orientation or where there was vertical segmentation of slip-surfaces (i.e. bends, steps and intersections) (e.g., Fig. 5.18 and Fig. 5.19). These locations contain extensive calcite veining that ranges in thickness from a few millimetres to 10 centimetres thick and is confined to between slip-surfaces and/or filled open fractures (e.g., Fig. 5.19 and Fig. 5.20). The veins show no evidence of anisotropic crystal growth or fabrics relating to shearing within the fault zone and thus appear to post date fault slip. Veins are also found in the majority of fractures connected to main slip-surfaces and occur throughout the 
outcrop at locations where interconnected fractures were present. Faults generally contain minimal thicknesses of fault-rock $(\leq 5 \mathrm{~cm})$, which often comprised of lenses of brecciated wall rock bound by slip-surfaces.

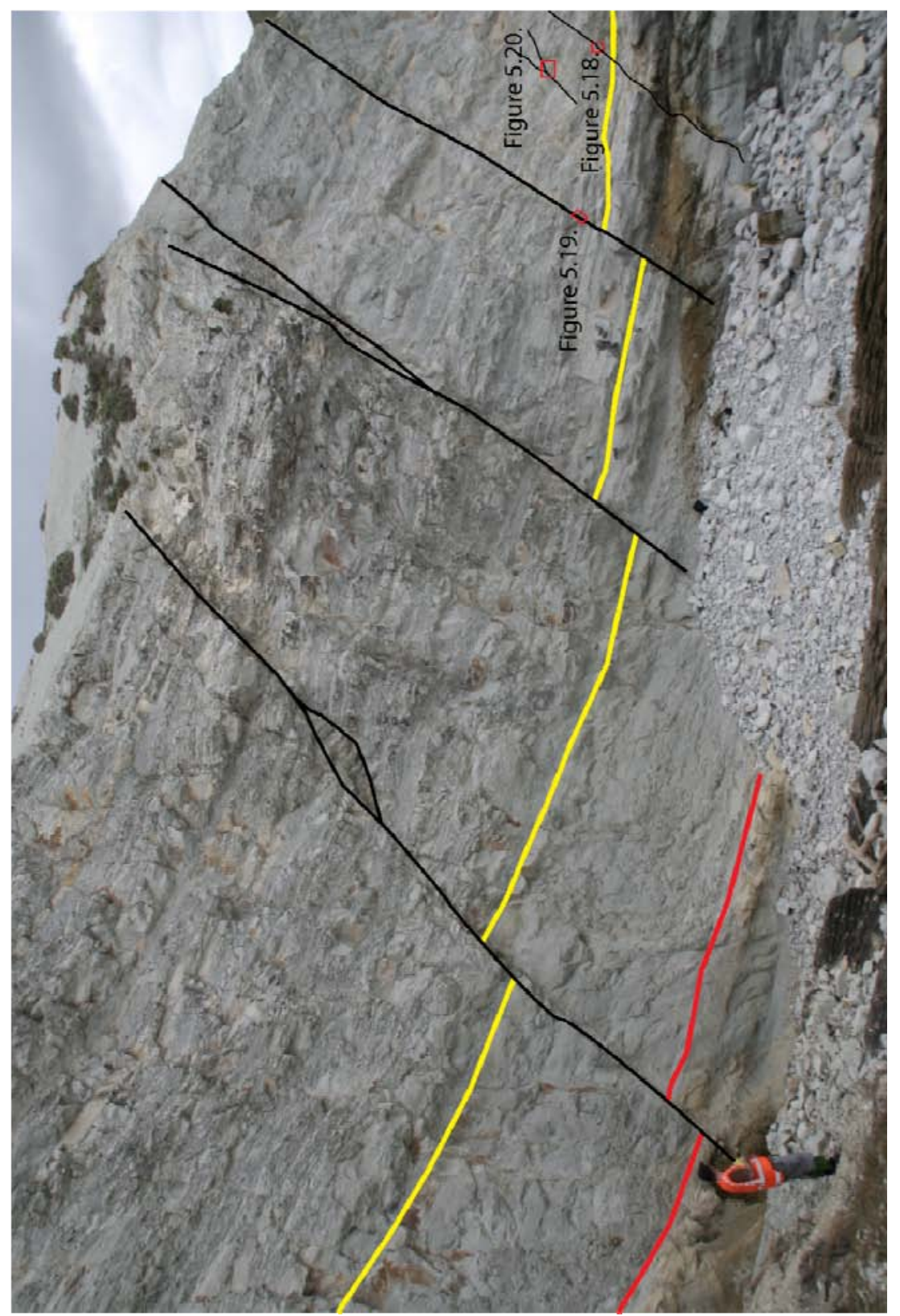

Figure 5.17 Location 1, Waikawau Beach. Normal faults ranging in displacement from $\sim 10-120 \mathrm{~cm}$ in the Te Kuiti Group siltstones. Red boxes show the locations of Figures 5.18-5.20. Person is $\sim 1.8 \mathrm{~m}$ high. Location of section is shown on Figure 5.16. 


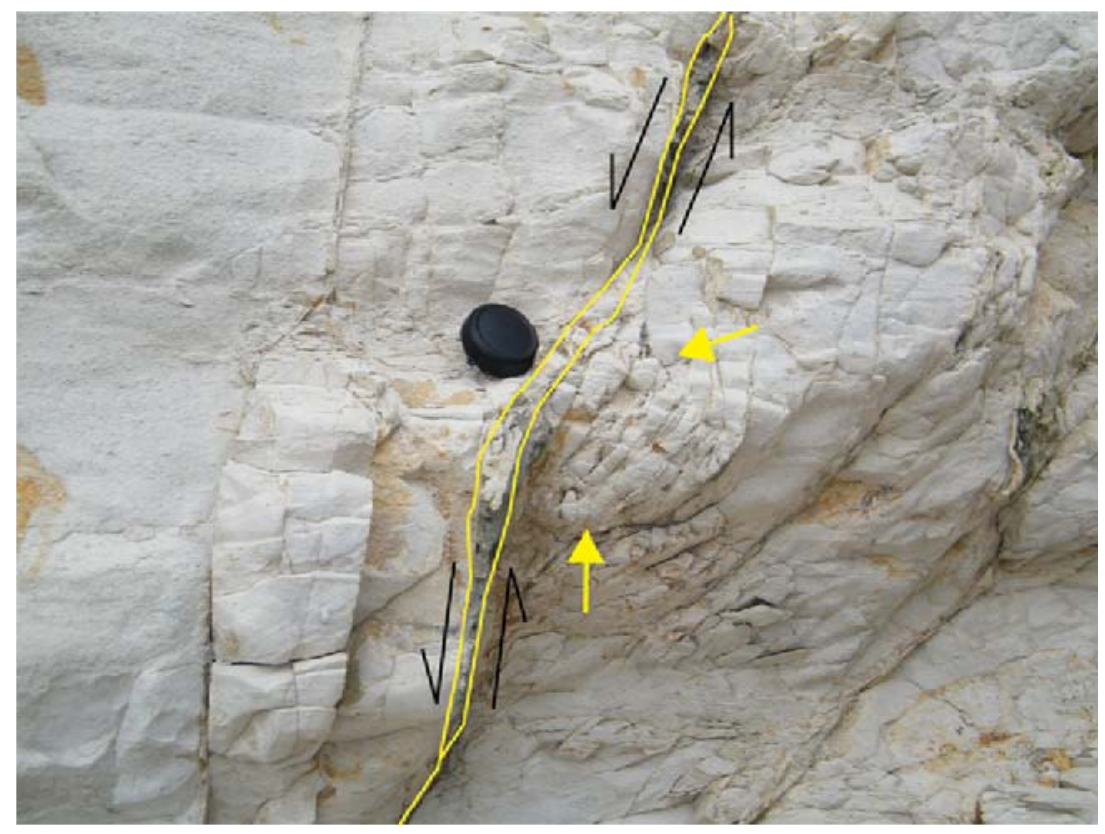

Figure 5.18 Higher density of fractures at bend in fault surface (the bend is at the approximate height of lens cap). Yellow lines are main fault slip-surfaces and the yellow arrows indicate the main area of high density fractures. Lens cap is $\sim 6 \mathrm{~cm}$ diameter.

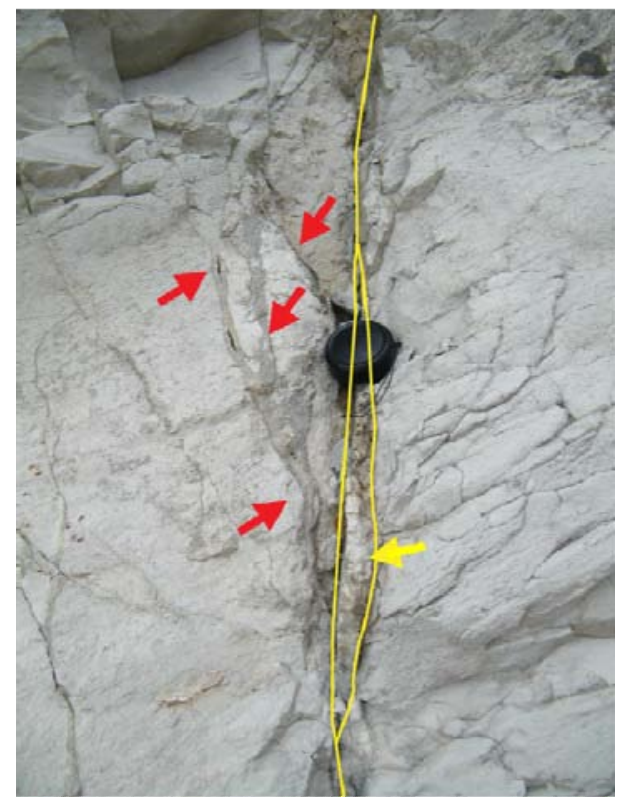

Figure 5.19 Calcite veining (yellow arrow) within fault zone (yellow lines mark main slip-surfaces). Note fractures trending away from the fault (red arrows) filled with calcite. Lens cap $\sim 6 \mathrm{~cm}$ Diameter. 


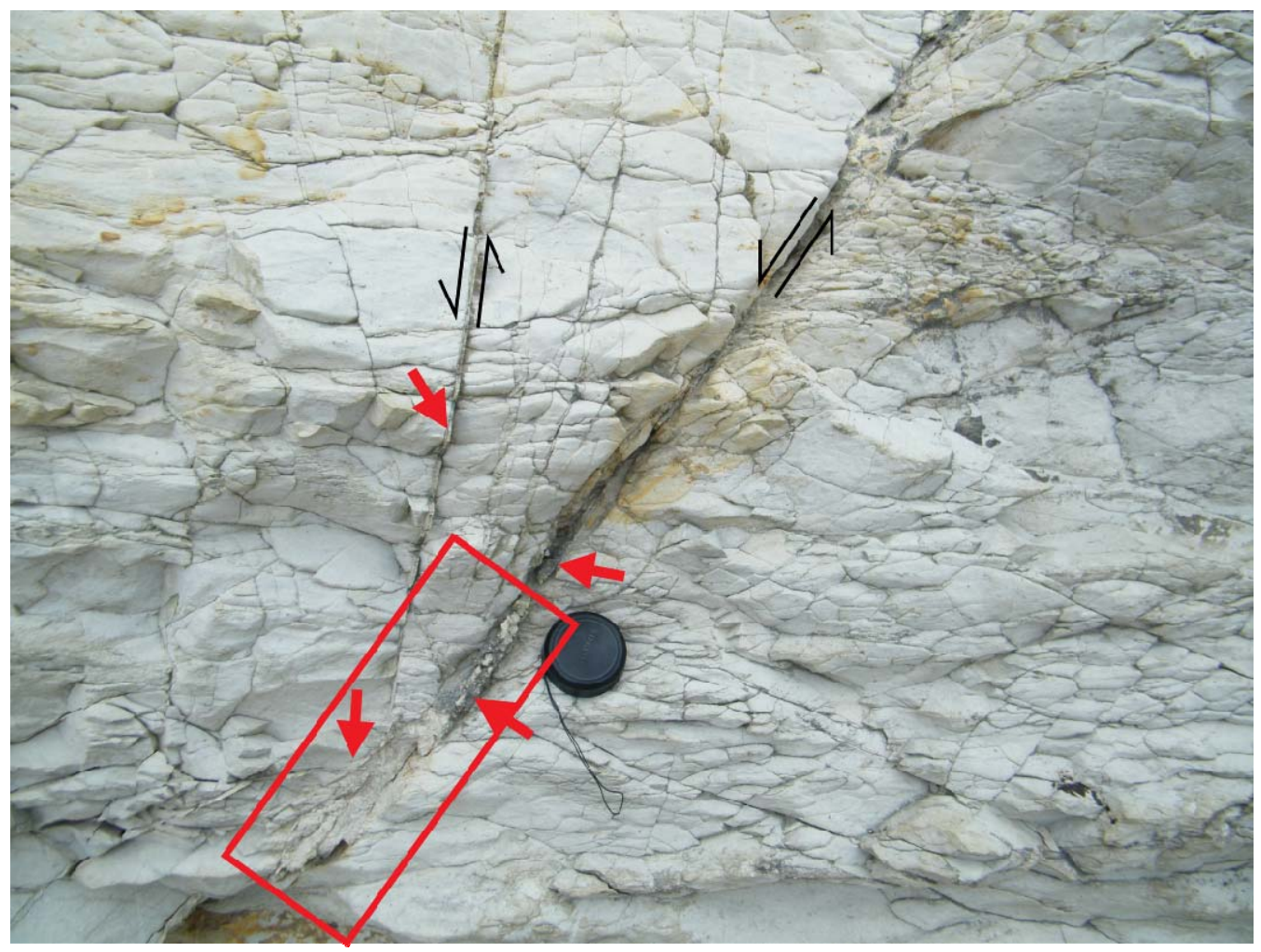

Figure 5.20 Fault intersection with increased thickness in calcite veining (within red rectangle). Red arrows show locations of calcite veins between fault slip-surfaces. Lens cap is $\sim 6 \mathrm{~cm}$ diameter.

Outcrop B at Waikawau Beach hosts a fault with $4 \mathrm{~m}$ throw again in the Te Kuiti group siltstones. The fault consists of two slips surfaces that join at the boundary between the siltstone and overlying strata. The slip-surfaces bound a lens of host rock cross cut by multiple minor faults and fractures that link the two slip-surfaces in many places. Changes in fault zone architecture along strike are highly visible across a wave-cut platform (Fig. 5.21 and Fig. 5.22.). The fault zone and surrounding fractures also host calcite mineralisation often 5-10 cm thick that appear to post date fault movement (Fig. 5.23). Fault-rock $\leq 5 \mathrm{~cm}$ thick is present in sections of the fault zone and there is some evidence of minor silt/clay smearing on an exposed section of the foot-wall (Fig. 5.24). The fault is visible in map-view for $\sim 20 \mathrm{~m}$ across a wave-cut platform, and exhibits minor corrugations along the fault trace that appear to be related to locations where minor faults and fractures intersect the main slip-surface (Fig. 5.21 and Fig. 5.25). 


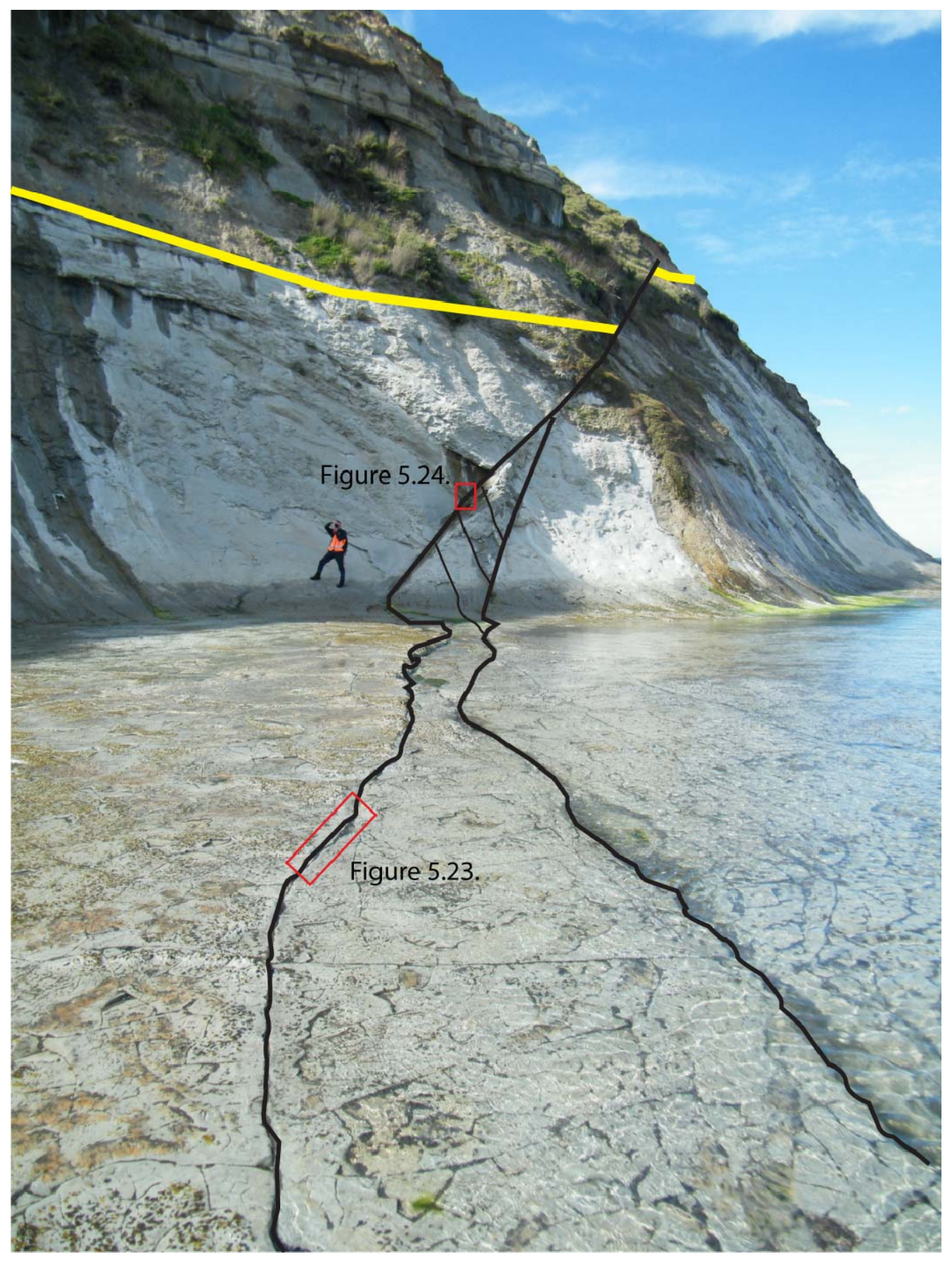

Figure 5.21 Locality 2, Waikawau. Normal fault with $\sim 4 \mathrm{~m}$ throw exposed in cliff and wave-cut platform. Black lines indicate slip-surfaces. Person is $\sim 1.8 \mathrm{~m}$ high. Red rectangles show locations of Figure 5.23 and Figure 5.24. Location of section is shown on Figure 5.16. 


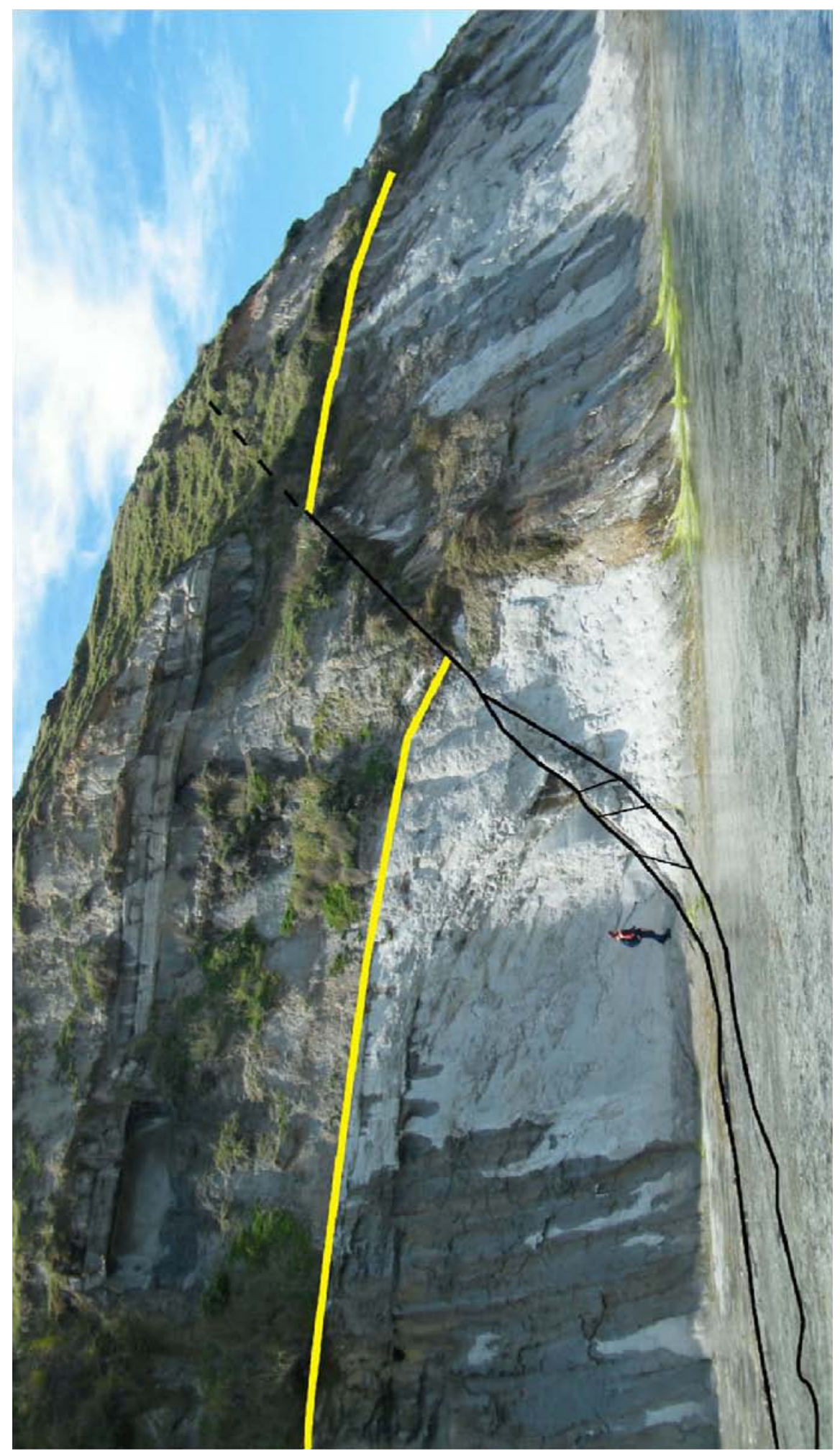

Figure 5.22 Locality 2, Waikawau Beach. Fault with $\sim 4 \mathrm{~m}$ throw exposed in cliff and wave-cut platform. Person in photograph is $~ 1.8 \mathrm{~m}$ high. Location of section is shown on Figure 5.16. 


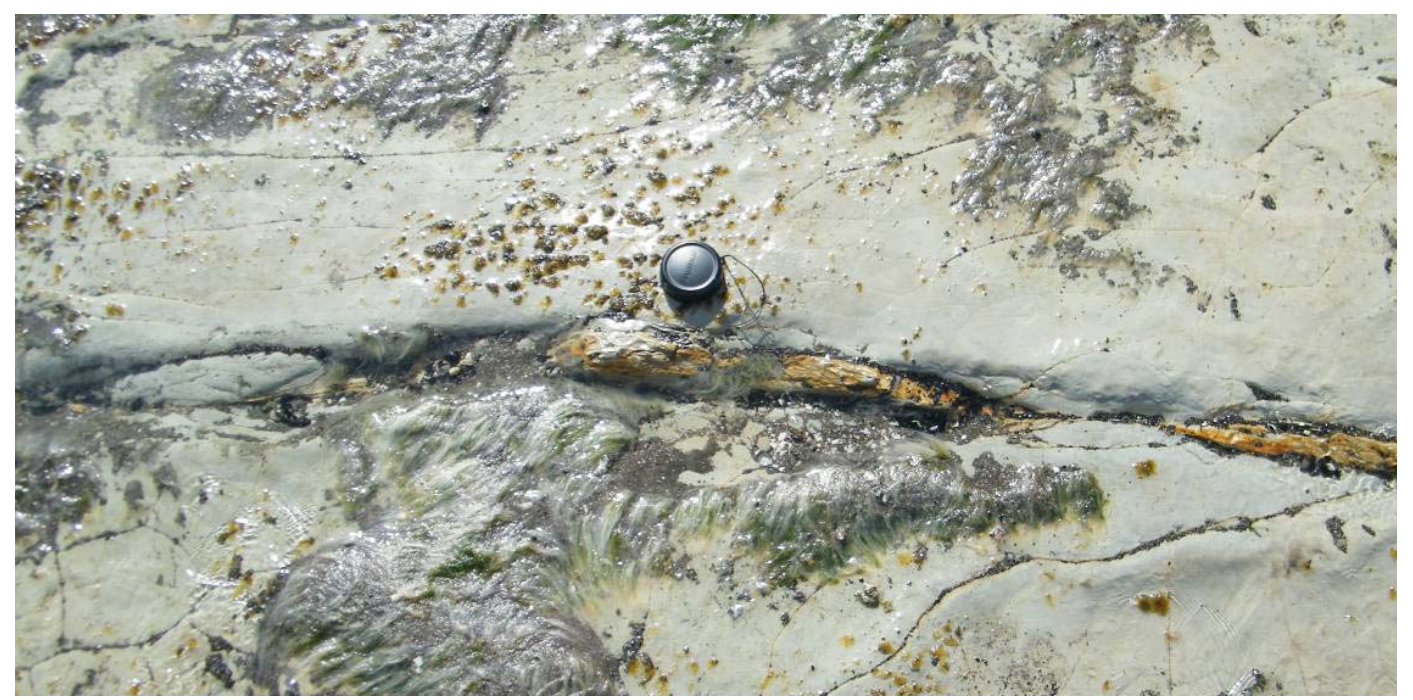

Figure 5.23 Calcite vein in fault zone exposed on the wave-cut platform. Lens cap is $\sim 6 \mathrm{~cm}$ diameter

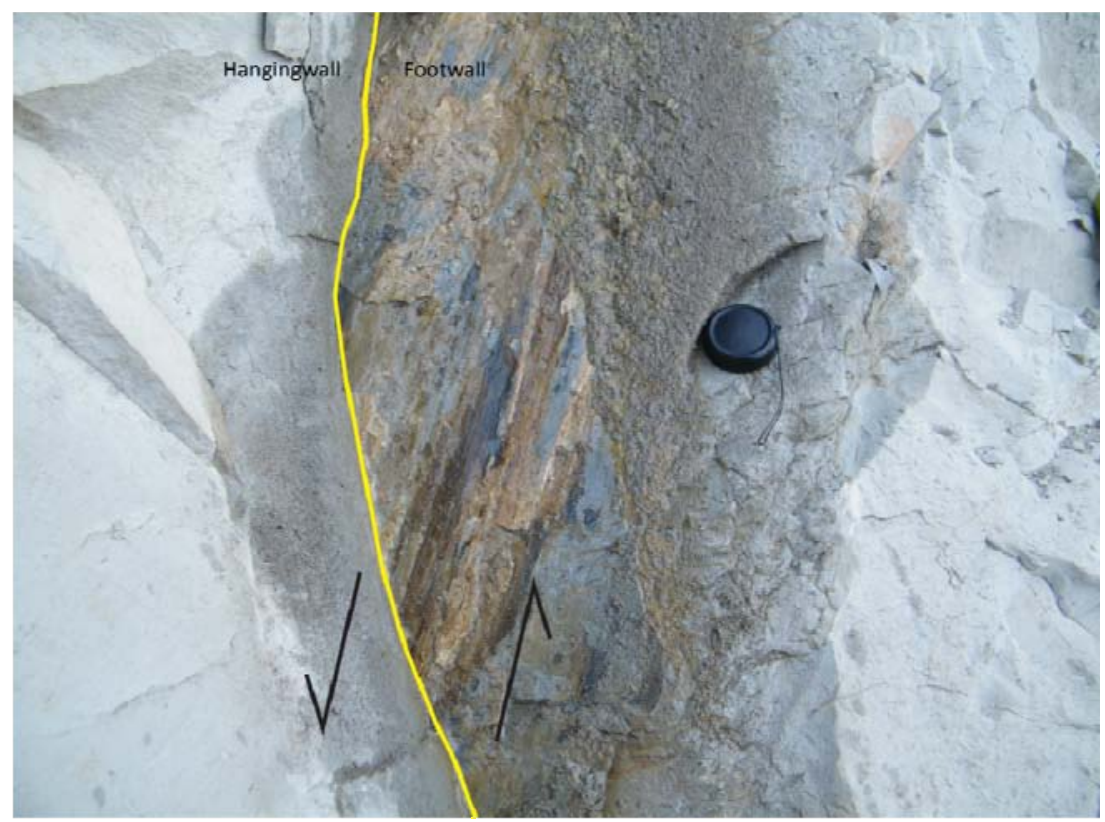

Figure 5.24 Striations on exposed fault surface. Minor amounts of silt smeared onto the foot-wall. Lens cap is $\sim 6 \mathrm{~cm}$ diameter. 


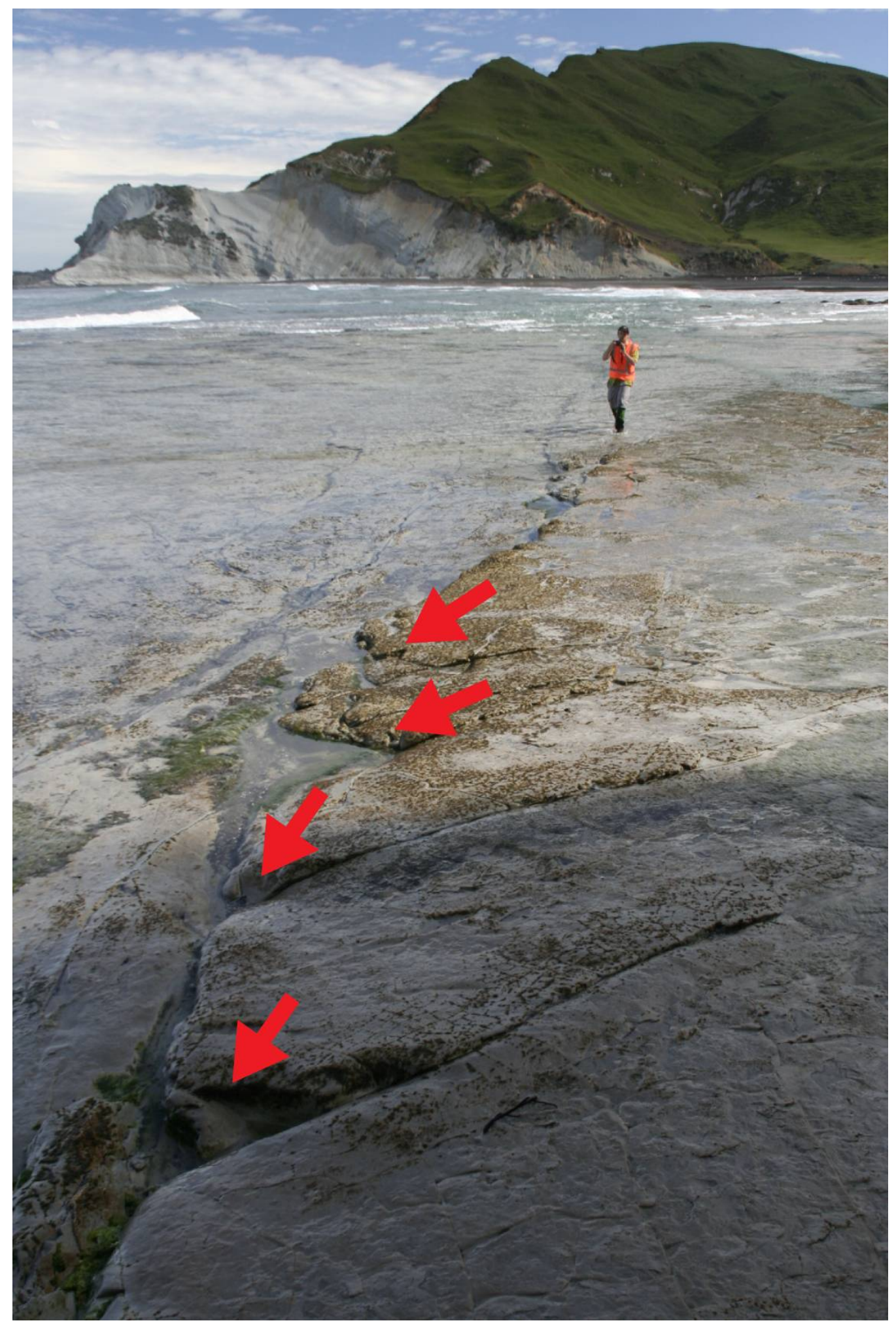

Figure 5.25 Fault trace across wave-cut platform. Corrugations appear to occur in main fault surface where it is intersected by minor faults and fractures (red arrows). View point is looking northwards (and away from the cliff face) from the person in Figure 5.21. Person in this figure is $\sim 1.8 \mathrm{~m}$ high. 


\subsubsection{Fractures As Migration Pathways}

Fault-related fracturing in the Te Kuiti Group siltstones suggests that in the laterally equivalent Otaraoa top seal fractures could impact on top seal integrity. Undeformed veins in the Te Kuiti Group fault zones suggest that after faulting ceased, fractures remained dilated and harboured sufficient fluid flow to result in calcite precipitation. Therefore, in areas where faulting penetrates top seals of similar lithology to the Te Kuiti Group silts, it is possible that fault-related dilated fractures are present even when the faults are no longer active. Fracture development and concentrated veining, coupled with a lack of significant thickness of low permeability fault-rock suggests that faults and fault zones in similar siltstones could provide localised high permeability pathways that have the ability to act as conduits for up-sequence fluid and gas leakage through top seals. Based on outcrop observations from Waikawau Beach, and the lithological similarity of the Te Kuiti Group and Otaraoa Formation calcareous siltstones, it is suggested that sub-seismic scale faults and fractures could provide the necessary pathways for hydrocarbon migration through the top seal in the Kupe Area. Fractures are most abundant at steps, bends and intersections supporting the model developed in Chapter III for up-dip gas migration at locations of geometrical complexity. These zones of fault-related fracturing are unlikely to be resolvable at the resolution of seismic reflection lines, thus creating difficulties when applying current geomechanical modelling techniques for predicting up-dip leakage risk.

\subsection{Rates of Gas Flux}

\subsubsection{Introduction}

Defining the rate of gas flux through chimneys in the Kupe Area is important for estimation of hydrocarbon leakage rates, risking fault-related top seal breach, for predictions of fault permeability. As chimneys are located offshore in approximately $30 \mathrm{~m}$ of water, direct sampling of gas is cost prohibitive. Instead, an onshore analogue for fault-related gas leakage is used to estimate gas flux rates. The Bristol Road Quarry, located 15 km southeast of New Plymouth, has been an active hydrocarbon seep for at least 50 years or more (Bristol Road Quarry Manager, pers com 2010). The Quarry is located proximal to the surface trace of the Inglewood Fault $(<100 \mathrm{~m})$, in the Fault's hanging-wall (Fig. 5.26). The 
Inglewood fault is a northeast striking normal fault that is considered currently active (GNS Active Faults Database). The close proximity of the hydrocarbon seep to the active fault trace suggests that the fault may be locally elevating permeabilities and thus control the locations of the gas seeps in the Quarry floor. A number of oil and gas seeps that occur along the length of the Inglewood Fault were chemically interrogated and appear to be thermogenic in origin. Tarry oil sampled for biomarkers in the 1990s from a seep near the junction of State Highway Three and Lepper Road (Grid reference Q19 1245 2735) suggested an Eocene source signature (McAlpine pers comm, 2004). At the Bristol Road Quarry, the gas was sampled for gas chromatography and gave a 'wet gas' signature, consistent with the gas being thermogenic and probably closely associated with oil (McAlpine pers comm, 2004).

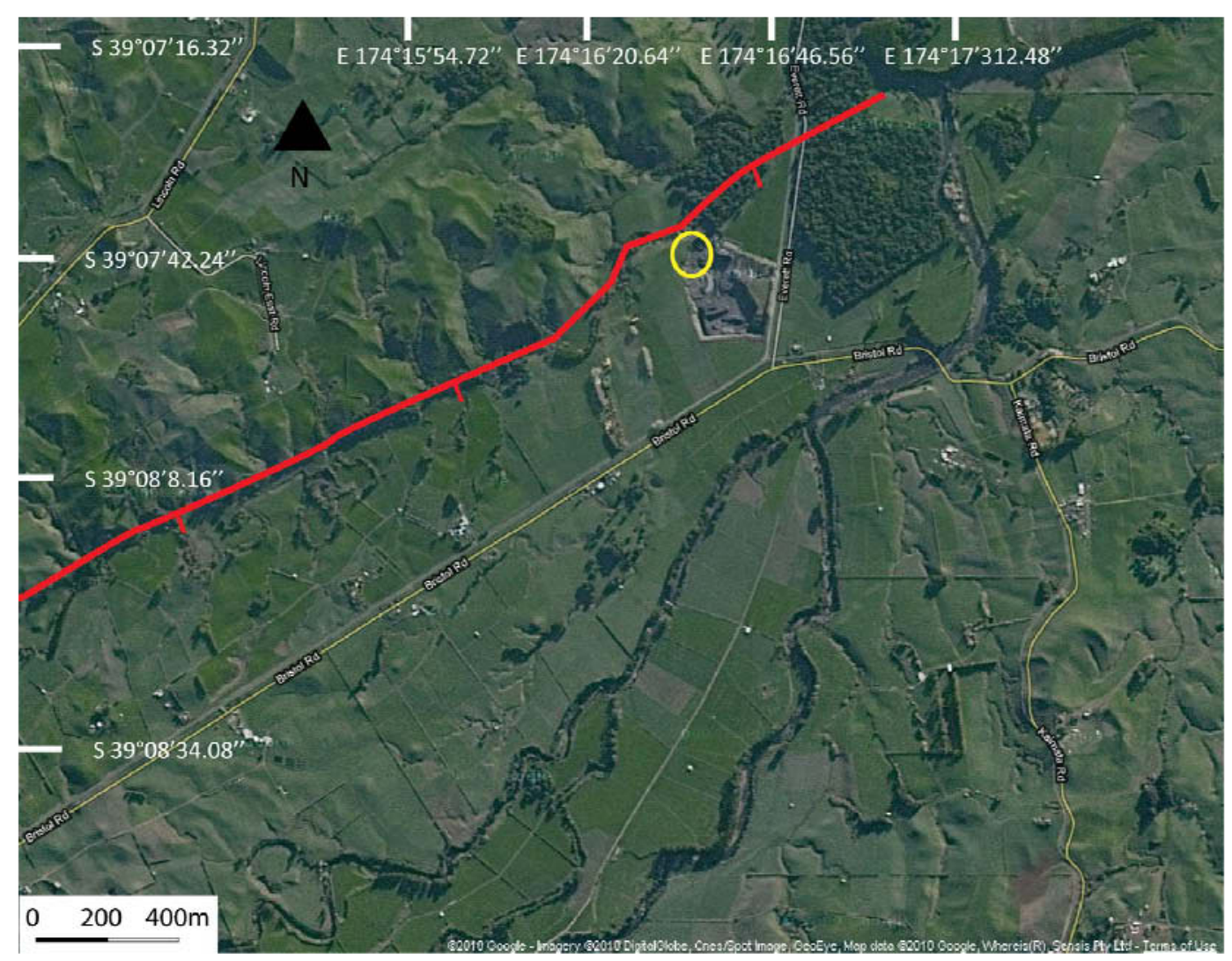

Figure 5.26 Inglewood Fault (ticks indicate down-throw and dip direction). Yellow circle highlights the location of oil and gas surface leak in Bristol Road Quarry. Image adapted from Google Maps (www.maps.google.com). Location of image is shown in Figure 5.2. 
Gas emanates from within sediments that are periodically (every 1-2 days) submerged by ground water at the floor of the Quarry. Gas bubbles carry a component of oil with them when they migrate out of the sediments into the water column, and a thin slick of oil often covers the edges of pooling water (e.g., Fig. 5.27a and Fig. 5.27b). Significant upwelling of water was witnessed in areas at the bottom of the Quarry and may indicate that gas and oil is carried upwards through artesian movement of water in association with the Inglewood Fault (Fig. 5.28). Gas bubbles flow in continuous streams from small volcano like cones for several seconds up to several minutes, with associated oil intermittently released over the period of bubbling. Water often flows through the cones for several minutes after bubbling has ceased. Gas bubbles frequently returned to the same spot and had an approximate density of one point source per square metre.

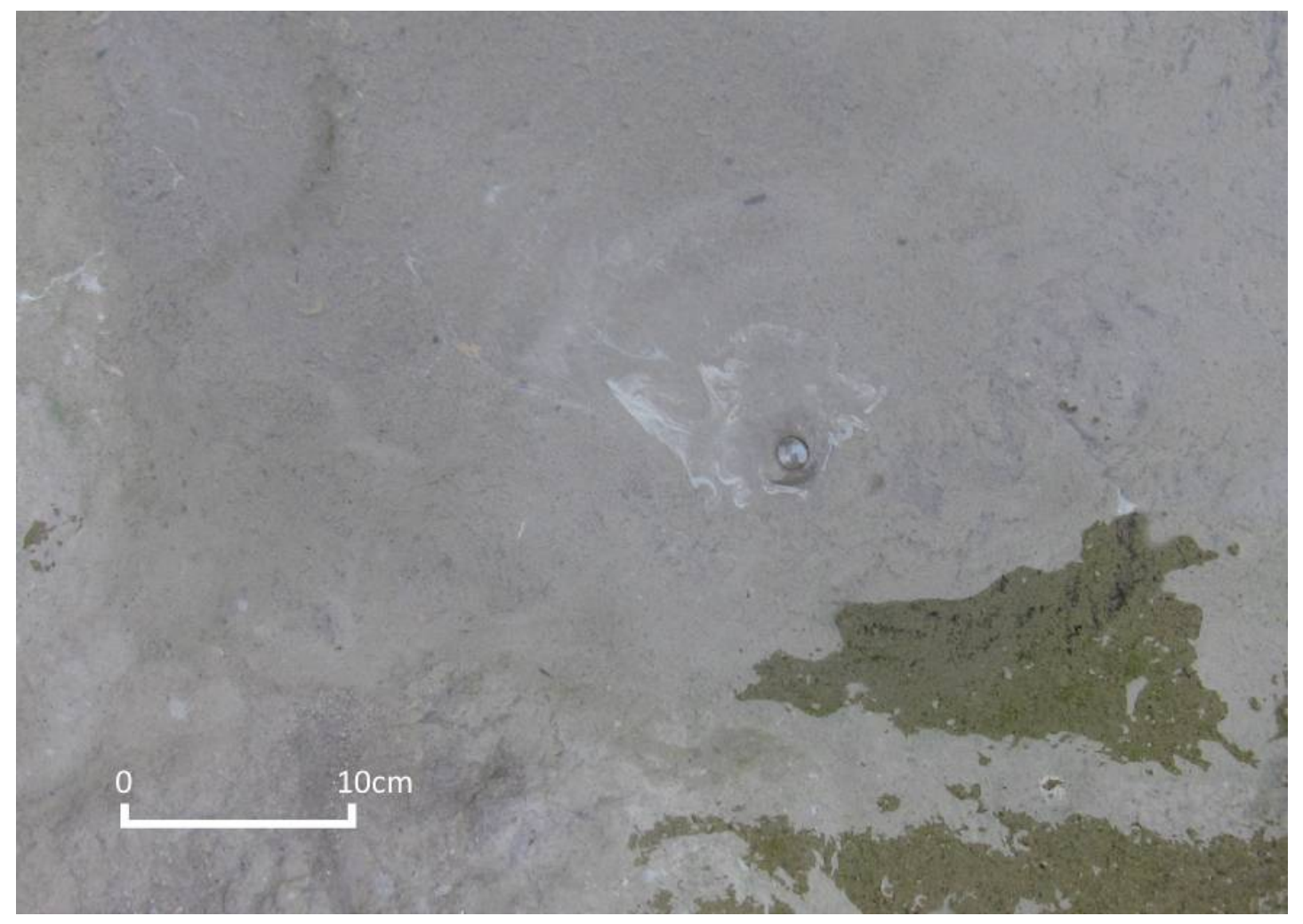

Figure 5.27 Gas and oil bubbling through sediments into the water column in the Quarry floor. 


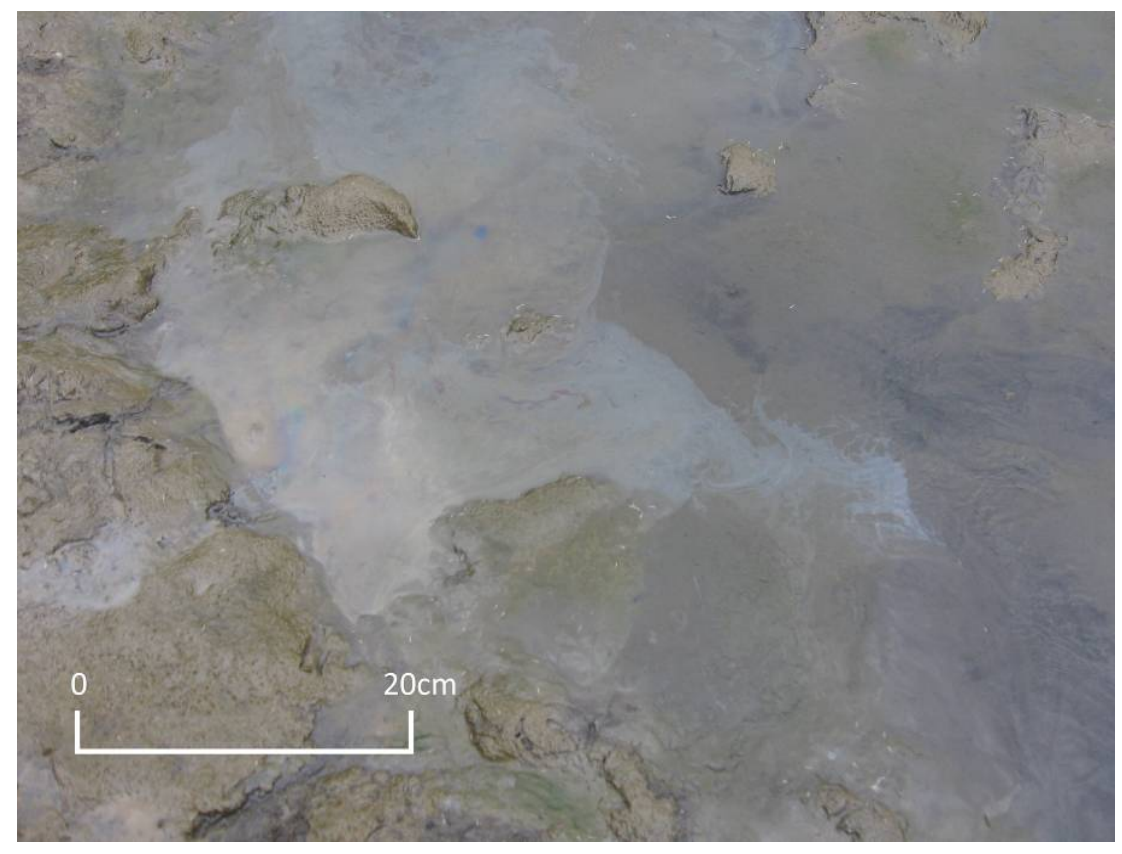

Figure 5.28(a) Oil slick in water in the Quarry floor.

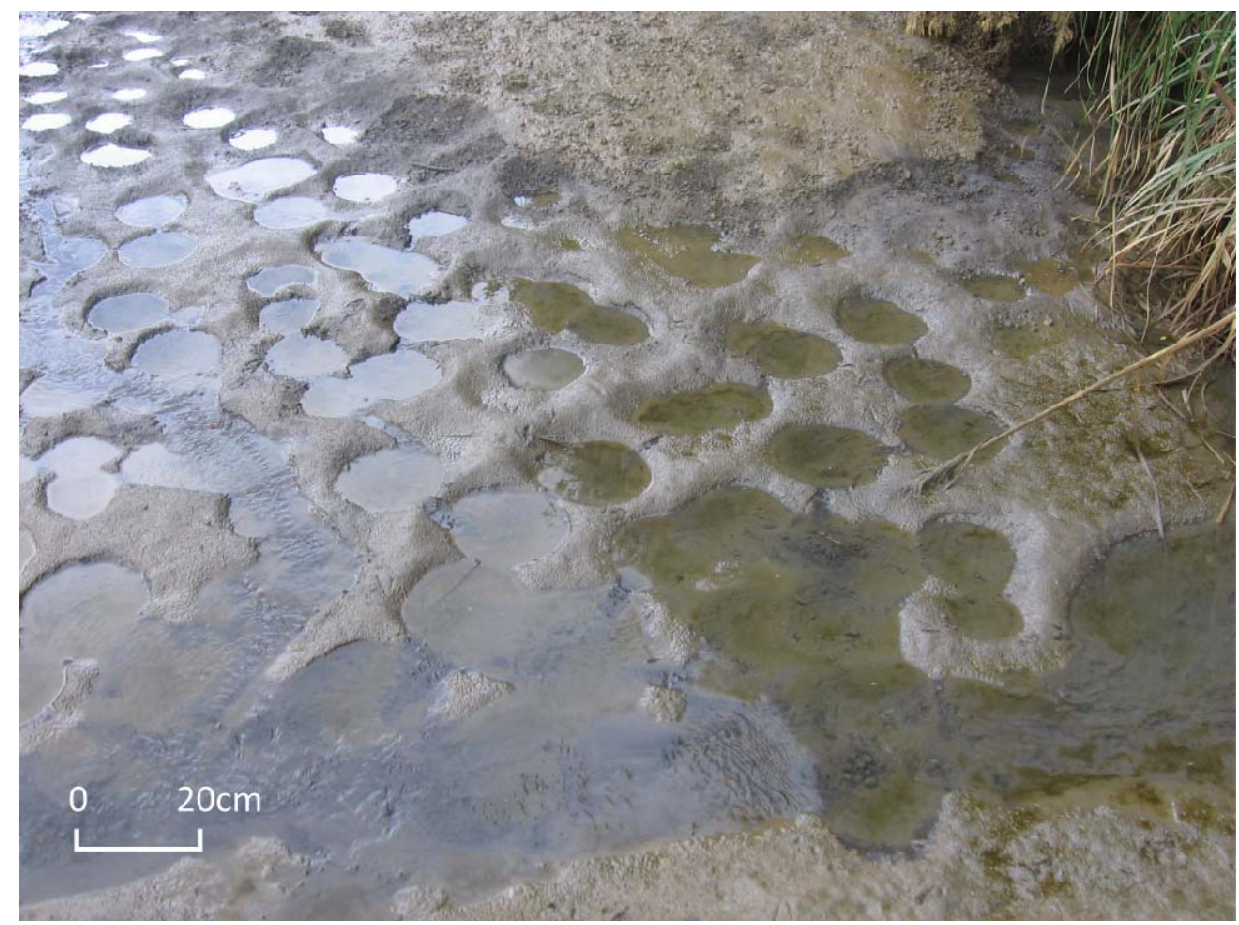

Figure 5.28(b) Pockmarks in the Quarry floor produced by the upwelling of water, oil and gas when the Quarry floor was submerged (note that the Quarry floor shown is below the water table, and is periodically exposed by pumping of water from the Quarry. 


\subsubsection{Methods}

Measurements of gas concentrations were taken in the floor of the Quarry using a MiniRAE 3000 PID portable gas sniffer. The unit measures parts per million concentrations of volatile organic compounds (CH4). A funnel was placed over an area of sediment under the water column and the measuring wand from the gas unit placed into the funnel just above the water column (see Fig. 5.29). This allowed measurements of gas concentrations to be made as gas bubbles were trapped in the funnel. Fresh air could flow back into the collector so that the concentration estimates taken were based on each flow of gas and not an accumulation of all previous flows. Measurements were taken every ten seconds over three separate streams of bubbles.

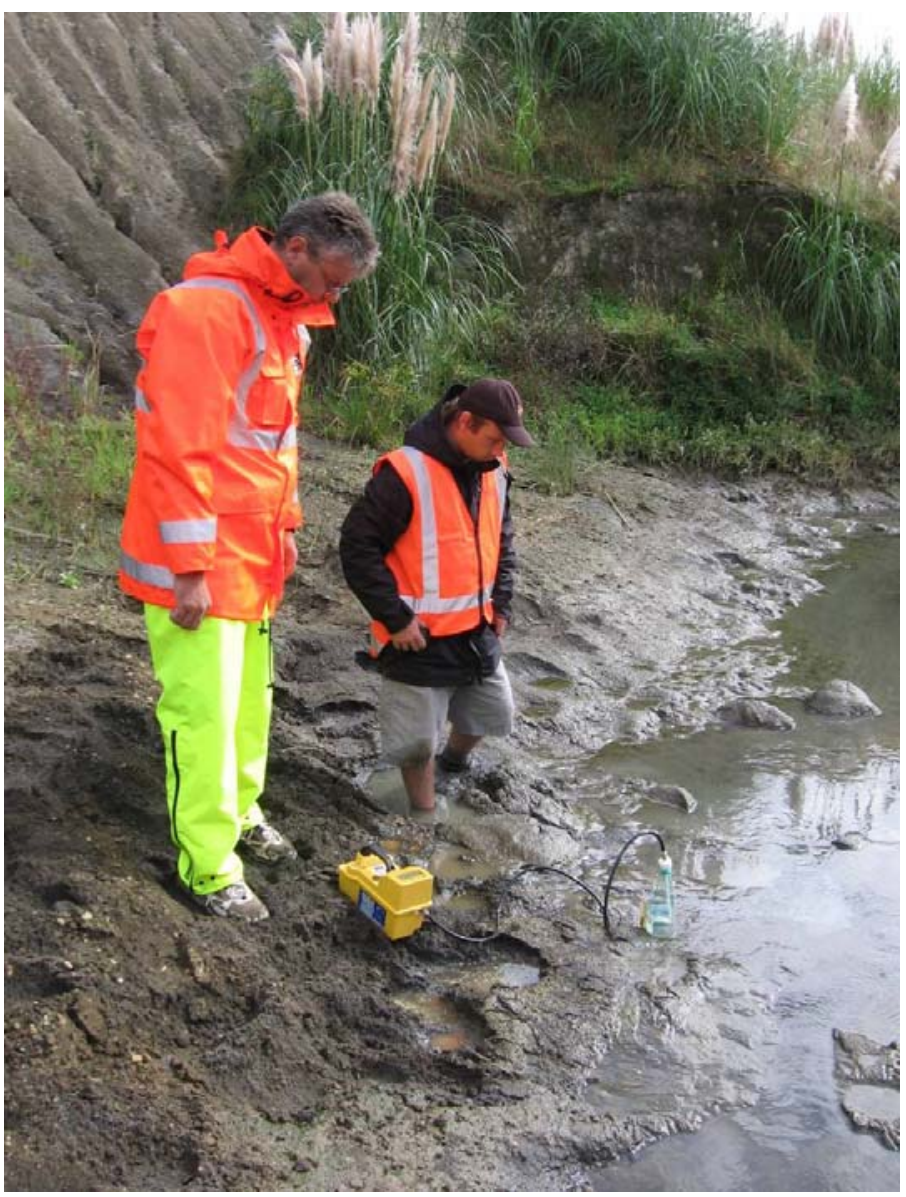

Figure 5.29 Operating the gas sniffer in the floor of the Bristol Road Quarry. 


\subsubsection{Gas Concentration Measurements}

Average CH4 concentration during bubble flows was 275 ppm, and the lower and upper bounds were $5 \mathrm{ppm}$ and 2200ppm. Figure 5.30 illustrates graphically the gas concentrations for the two minute durations of three gas bubble streams. The distribution of gas concentrations over time indicates discrete flux events over the measured time intervals. Elevated levels of $\mathrm{CH} 4$ often developed over approximately 60 seconds of bubbling and then decayed, gradually dropped to background values of 5-100 ppm as bubbling intensity reduced (Fig. 5.30). Observations were only made for a period of 1-2 hours over which a rough estimate of the return frequency of bubbling at each point source was about 15 minutes.
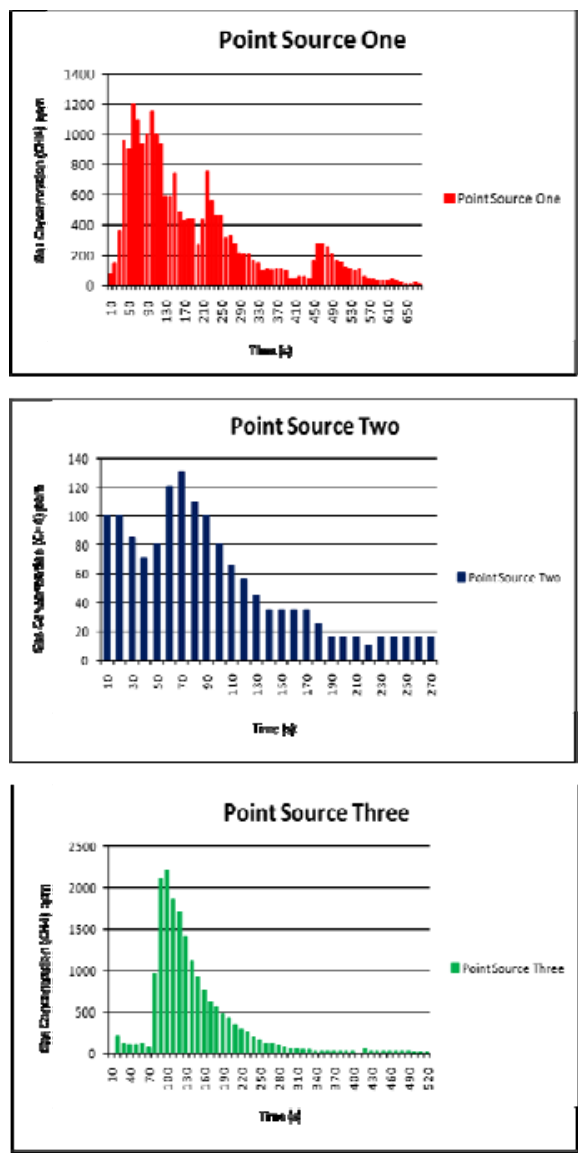

Figure 5.30 Gas concentration measurements over time for three point sources at Bristol Road Quarry. 
Based on the observation that variance in gas concentration measurements represents discrete flux events (as opposed to sampling variance), coupled with the field observations that gas flows occurred in discrete events, gas flux rates were calculated using the average, lower and upper measured concentrations of $\mathrm{CH}_{4}$. Calculations have been made based on the assumptions that these values are representative of continued flux rates over time, the average length of bubbling is 60 seconds and bubbling frequency is every 15 minutes.

\subsubsection{Estimated Flux Rates}

The average calculated gas flux rate from a point source is $240 \mathrm{~cm}^{3} /$ day or $0.8 \times 10^{-2}$ $\mathrm{ft}^{3} /$ day, with a lower bound of $1.75 \times 10^{-5} \mathrm{ft}^{3} /$ day and an upper bound of $0.9 \times 10^{-3} \mathrm{ft}^{3} /$ day. Extrapolated out to a year this equates to an average of $0.34 \mathrm{ft}^{3} / y e a r$, with a lower bound of $0.0062 \mathrm{ft}^{3} /$ year and an upper bound of $3.1 \mathrm{ft}^{3} /$ year. Table 6.1 shows further extrapolation to 10,000 years and 1 million years with $\mathrm{cm}^{3}$ equivalents.

Table 6.1 Gas flux calculations for single point source. Results have been rounded to 2sf.

\begin{tabular}{|l|r|r|r|}
\hline Flux Rates & \multicolumn{1}{|l|}{ Average } & \multicolumn{2}{l|}{ Upper } \\
\hline & 275ppm/min & 2500ppm/min & \multicolumn{2}{l|}{$5 \mathrm{ppm} / \mathrm{min}$} \\
\hline Flux $\mathrm{cm}^{3} /$ hour & 1.1 & 10 & 0.02 \\
\hline Flux $\mathrm{cm}^{3} /$ day & 26.4 & 240 & 0.48 \\
\hline Flux $\mathrm{ft}^{3} /$ day & 0.0009 & 0.0080 & $1.7 \times 10^{-05}$ \\
\hline Flux $\mathrm{m}^{3}$ /year & 9636 & 87600 & 0.00018 \\
\hline Flux $\mathrm{ft}^{3} /$ year & 0.34 & 3.1 & 0.0062 \\
\hline Flux $\mathrm{m}^{3} / 10,000$ yrs & 96000000 & 876000000 & 1.80 \\
\hline Flux $\mathrm{ft}^{3} / 10,000$ yrs & 3400 & 31000 & 62 \\
\hline Flux $\mathrm{m}^{3} / 1$ million yrs & 9600000000 & 87600000000 & 480000 \\
\hline Flux $\mathrm{ft}^{3} / 1$ million yrs & 340000 & 3100000 & 6200 \\
\hline
\end{tabular}


Gas migration pathways in the near surface are likely to be complicated with factors such as weathering profiles, water table height and rock and soil permeability possibly influencing both the locations and rates of gas flux (e.g., Dockrill and Shipton, 2010 and references therein). Combined with the inherent complexities of fault zone structure and fault permeability discussed previously in this chapter, upscaling flux rates from one point source to estimates of a fault zone or entire chimney are difficult and errors are likely to be large. Given these observations the following calculations of flux through a gas chimney in the Kupe Area should be considered preliminary. A much greater understanding of gas flux rates over time, internal chimney structure and the relationship between point source estimates and diffuse gas flow through chimneys are needed to reliably estimate potential gas flux through the Kupe chimney structures.

Using an average chimney size of $1 \mathrm{~km}^{2}$ as interpreted within the Kupe Area in Chapter III, an average observed density of one point source per metre squared, and the previously calculated gas flux rates, the average gas leakage for one chimney per day would be 930 $\mathrm{ft}^{3}$, with a lower bound of $17 \mathrm{ft}^{3}$ and an upper bound of $8500 \mathrm{ft}^{3}$. For a year, this would equate to an average of 0.34 million $\mathrm{ft}^{3}$, with a lower bound of 0.0062 million $\mathrm{ft}^{3}$ and an upper bound of 3.1 million $\mathrm{ft}^{3}$. The Kupe Area has five chimneys of this size and when leakage estimates for them are combined results an average gas flux over one million years of 700 billion $\mathrm{ft}^{3}$, with a lower bound of 31 billion $\mathrm{ft}^{3}$ and an upper bound of leakage of 16 trillion $\mathrm{ft}^{3}$. The Kupe gas condensate field holds gas reserves of $\sim 370 \mathrm{bcf}$. Assuming the five chimneys have continuous leakage with rates similar to those previously calculated, this gas reserve would be dissipated in 220,000 years based on the average flux rate, in 12 million years based on the lower bound flux rate and in 23,000 years based on the upper bound gas flux rate. Given gas charging of the Kupe structure is thought to have occurred over the last $\sim 3 \mathrm{Ma}$ (see Chapter III) it is unlikely gas flux through chimneys is continuous. The presence of $\leq 100 \mathrm{~m}$ hydrocarbon columns in the Kupe gas condensate Field suggests that either gas migration into the structure must be greater than 31 billion $\mathrm{ft}^{3}$ per million years for hydrocarbons to accumulate (assuming chimneys maintain a constant gas flow) or gas flux occurs in discrete events lasting from days to years. This study suggests that the later of the two scenarios is the most likely. 


\subsection{Conclusions}

Field-based investigations of fault structure and gas flux have been undertaken to understand better gas and fluid migration within faults in the Kupe Area. Outcrop investigations of faults zones in the Late Miocene Mt Messenger Formation suggest that at sub-seismic scales faults comprise spatially heterogeneous structure. Current seismic reflection based interpretations of faults are likely to over simplify fault zone heterogeneities. In the absence of a detailed understanding of fault zone structure (e.g., local fracture orientations and densities), geomechanical modelling may not accurately predict minor structures that influence hydrocarbon migration. Analysis of outcrop correlatives of the Otaraoa top seal in the Kupe Area suggested that at sub-seismic scales these seal rocks are likely to be faulted. The regions of most intense fracturing in the seal correlative are typically found to be where faults step, bend or intersect. Undeformed veins within these fractures confirm that some post-faulting fluid flow occurred along these faults. Faults observed in outcrops displayed much greater complexity than seismic reflection data can reveal, with many faults exhibiting multiple slip-surfaces, minor faults and high densities of associated fractures. A better understanding sub-seismic structure of faults, and, in particular where open interconnected fractures are most likely to occur, may help us to identify risk areas for up-fault hydrocarbon migration.

Measurements of fault-related gas flux rates at an onshore analogue for faults and related gas chimneys in the Kupe Area give some bounds on likely activity within chimney structures. Gas flux over one year could equate to an average of 0.34 million $\mathrm{ft}^{3}$, with a lower bound of 0.0062 million $\mathrm{ft}^{3}$ and an upper bound of 3.1 million $\mathrm{ft}^{3}$. Though the calculated flux rates are only preliminary, they provide an initial estimate and may help to calibrate better models for gas flux in and out of traps as a result of faulting. Gas flux through faults is unlikely to be continuous and may occur as discrete events lasting from days to years with possible gas flows of $\sim 930 \mathrm{ft}^{3}$ per chimney per day or 0.34 million $\mathrm{ft}^{3}$ per year. 


\section{Chapter VI}

\subsection{Conclusions}

\subsection{Introduction}

This thesis combines investigations of fault structure and gas leakage from seismic reflection lines with outcrop and field-based measurements of gas flux to understand better how up-sequence fluid and gas migration might occur within fault zones. Up-dip gas migration in the Kupe Area is structurally controlled. Spatial relations between gas chimneys and normal faults have been established, with zones of structural complexity along faults such as relays, lateral fault tips and fault intersections, which are likely to host the highest densities of interconnected fractures, coinciding with the locations of gas migration. Gas chimneys are hosted within Plio-Pleistocene normal fault zones which reactivate Late Cretaceous-Paleocene normal faults. The reactivation of faults likely creates interconnect fractures that act as seal bypass mechanisms through the Otaraoa top seal. The reactivation of faults in the Kupe Area is controlled by the orientation of Late Cretaceous-Paleocene normal faults within the current stress field and therefore up-dip gas migration is most prolific in places where the strike of Late Cretaceous-Paleocene normal faults is aligned with the current orientation of $S_{\text {Hmax }}$. Geomechanical modelling methods can be used to predict which fault sets are most likely to enhance up-sequence fluid and/or gas migration but cannot be used to predict locations along individual faults where migration is (or has been) focused. The inability of current geomechanical methods to predict these locations is most likely a data resolution issue. The high densities of fractures commonly observed at fault relays, intersections and are predominantly below seismic data resolution and would not be included in geomechanical analysis. Outcrop observations of faults support the view of structural complexity below the resolution commonly observed in seismic reflection data and gas flux measurements provide a first-pass estimate of potential flux rates through normal faults in the Taranaki Basin. 


\subsection{Conclusions}

Each chapter of this thesis has independent conclusions and therefore only the most important conclusions from each are outlined below.

Investigations of the structural evolution of the Kupe Area of the South Taranaki Basin have shown (Chapter II):

- Sedimentary strata record four main periods of deformation from pre-Late Cretaceous through to Recent.

- The locations and orientations of various periods of faulting have been influenced by the locations and orientations of pre-existing faults.

- Plio-Pleistocene faults in the Kupe Area appear to form a relatively immature fault system in which fault lengths were achieved rapidly, with subsequent growth due to displacement accumulation.

Studies of the relationship between normal faulting and gas chimneys in the Kupe Area reveal that (Chapter III):

- Gas chimneys within the Kupe Area are spatially coincident with the locations of Pliocene to Recent normal faults. Fifteen of 17 chimneys initiate directly within these post Miocene fault zones.

- Chimneys predominantly occur at locations of geometrical complexity within fault zones such as fault relays, lateral fault tips and fault intersections. These locations are likely to host open interconnected fracture networks that enhance up-dip gas migration.

- Gas migration is not necessarily synchronous with earthquakes on faults and is unlikely to be continuous for extended periods of time (i.e. > $1 \mathrm{Ma}$ ).

- In the south Taranaki Basin Pliocene to Recent normal faults, with estimated permeability ranging between $\sim 12$ and $380 \mathrm{mD}$, are likely to induce up-dip gas migration predominantly through fracture networks within the Otaraoa Formation top seal and overlying mudstone dominated Miocene strata. 
Testing the ability of geomechanical modelling to predict the faults, and locations on these faults, where up-dip migration of hydrocarbons in fault zones (leakage) is most likely to occur, has been undertaken for the Kupe Area (Chapter IV). The results indicate that:

- Slip Tendency and Dilation Tendency when tested against independent evidence of gas leakage within faults, have an ability to provide first-order approximation of high leakage risk fault sets.

- Slip Tendency and Dilation Tendency are able to differentiate fault orientations most at risk of leakage, and both methods indicate high risk of leakage for the fault set with visible leakage.

- None of the geomechanical techniques examined provided a robust basis for predicting which parts of individual are most likely to be sites of focused gas flow.

Field-based studies of fault zone structure and a gas leakage rates in exposed onshore sections of the Taranaki Basin reveal (Chapter V):

- Current seismic reflection based interpretations of fault structure are likely to be over simplified, and when coupled with geomechanical modelling may not accurately predict the locations of minor structures that influence hydrocarbon migration.

- High fracture densities are found at locations of geometrical complexities (e.g., relay zones, fault bends and fault intersections) within fault zones. Evidence for fluid flux post fault activity was found in these fracture networks supporting the model for locations of high vertical permeability presented in Chapter III of this thesis.

- Gas flux through faults is unlikely to be continuous and may occur as discrete events lasting from days to years with possible gas flows of $\sim 930 \mathrm{ft}^{3}$ per chimney per day or 0.34 million $\mathrm{ft}^{3}$ per year. 


\subsection{Further Research Areas}

During the course of this research, several interesting questions were raised and geological features noted within the Kupe Area that were beyond the scope of this study and warrant discussion as potential future lines of research. These include a more detailed analysis of inversion of Late Cretaceous rift faults, the implications of structural style in the Kupe Area on New Zealand plate boundary settings, further investigations of Plio-Pleistocene fault kinematics and growth history, and more detailed (and numerous) measurements of gas flux rates at gas and oil seeps onshore.

\subsubsection{Inversion of Late Cretaceous Rift Faults}

Though this study was able to establish a time frame for inversion of Late Cretaceous rift faults in the South Taranaki Basin, the manner in which inversion occurred on individual faults still remains unclear. The location where inversion first initiated on individual faults is important when trying to understand why some faults undergo inversion and others do not. The location where inversion initiates is also important when investigating how the inversion initiated and progressed during a fault's growth history. More detailed analysis of sediment thickness variations across the Manaia Fault further north and south of the study area may help to constrain the manner in which inversion progressed on the Manaia Fault and other faults in the South Taranaki Basin.

The shape of fault-related folds above inverted faults provides another interesting study point. At locations where inversion of Late Cretaceous rift faults, grabens and half grabens has occurred prominent fault-related folds are present in Cretaceous-Miocene strata (Fig. 1a). At locations where the inversion related faults have increased in strike-length beyond the Late Cretaceous rift fault, there are no fault-related folds (Fig. 1b). The development of fault-related folds may be due to a component of shortening during contraction being taken up by folding and layer parallel slip within Late Cretaceous graben strata during inversion. At locations with there is no Late Cretaceous strata and possibly granitic basement rock, layer parallel slip cannot occur, folds do not develop and shortening appears to be taken up solely on the developing fault. These observation need to be further tested 
across all inverted faults within the South Taranaki Basin and with a more detailed understanding of the distribution of basement rocks.

(a)

Cretaceous Half Graben
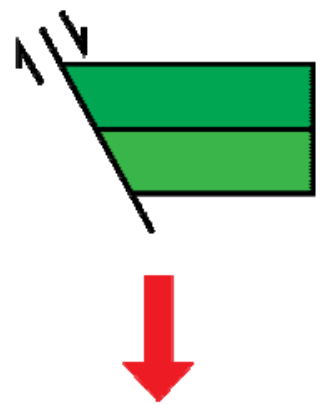

Inversion and Fault Related Fold Growth

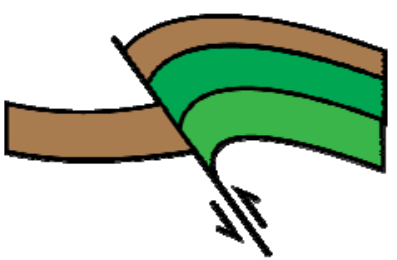

(b)

Basement With No Fault

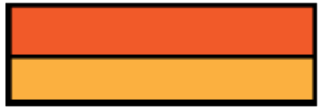

Contraction

New Fault With No Fault Related Fold Forms During Strike Length Increase

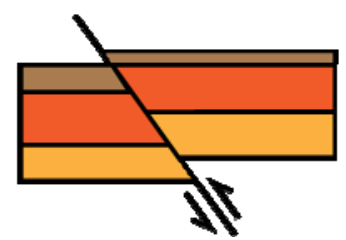

Figure 6.1 Varying structure of folds during contraction in the Kupe Area. (a) Inversion of Late Cretaceous half graben with fold-related fold developed. (b) No Late Cretaceous strata or fault present at the initiation of contraction. The fault develops during contraction due to strike length increase of an out of plane inverted Late Cretaceous fault. No fault-related fold develops.

\subsubsection{Implications of Structural Style in the Kupe Area on New Zealand}

\section{Plate Boundary Settings}

Temporal changes in the structural styles of deformation in the Kupe Area reflect largescale changes in plate boundary kinematics across New Zealand. Significant work still needs to be undertaken to establish the detailed relationships between plate boundary development and plate boundary deformation. For example, the Late Cretaceous (<85 Ma) extension direction in the South Taranaki Basin does not appear to have been parallel to the seafloor spreading directions in the Tasman Sea. Some possible explanations for this disparity include; a transform fault propagating northward through New Zealand with the 
Late Cretaceous rift forming as a pull-apart basin (King and Thrasher, 1996), Neogene deformation across the plate boundary between the Australian and Pacific plates resulting in rotation of the Taranaki Basin block, or possible minor variations in Late Cretaceous seafloor spreading speeds and/or orientations resulting in intra-plate extension occurring at a different orientation. Further work is required to elucidate the driver of Late Cretaceous extension in the Taranaki rift and why the rift's extension direction is different to that of Late Cretaceous plate boundaries proximal to the Basin.

\subsubsection{Plio-Pleistocene Fault Kinematics and Growth History}

Plio-Pleistocene faults in the Kupe Area form a relatively immature, low strain fault system that provides insight into fault initiation and growth processes. This study investigated some of the interesting features of the Kupe Area Pliocene to Recent fault system, such as low displacement to length ratios and limited fault tip-line propagation. Further detailed analysis of tip line propagation and fault death (end of growth on faults) in the Kupe Area could provide interesting insights into fault growth models and kinematic interaction between separate fault segments during fault growth and death. How faults die and whether their tip lines retreat during fault death is still relatively unexplored and warrants further investigation.

\subsubsection{Further Measurement of Gas Flux Rates at the Bristol Road Quarry}

The Bristol Road Quarry provides an onshore, easily accessible analogue for fault-related gas leakage in the offshore areas of the Taranaki Basin. This study was able to determine preliminary estimates of gas flux through the Quarry floor related to the Inglewood fault and extrapolate these to estimate gas flux through chimneys in the Kupe Area.

Measurements, however, were only taken over short time intervals and were only collected over single point sources. Extrapolating these measurements out to larger spatial and temporal scales introduced significant uncertainties. To be able to more accurately assess and extrapolate gas flux rates over space and time, measurements need to be taken over a larger area at the base of the Quarry and the measurement site needs to be occupied for an 
extended period of time. This will allow more certainty in measured flux rates and a more accurate assessment of variability in gas flow. These measurements could also be augmented by gas flux measures from other gas and oil seep sites in the onshore Taranaki Basin. Many such sites have been identified yet detailed measurements of gas compositions, concentrations and fluxes have not been completed. 


\section{References}

Anderson, A.L. and Hampton, L.D. (1980) Acoustics of gas bearing sediments 1.

Background. Journal of the Acoustical Society of America, Vol. 67, No. 6: 1865-1889

Antonellini, M., Aydin, A. and Pollard, D. (1994) Microstructure of deformation bands in porous sandstones in Arches National Park, Utah. Journal of Structural Geology, Vol. 16, No. 7. 941-959

Antonellini, M. and Mollema, P. (2000) A natural analog for a fractured and faulted reservoir in dolomite: Triassic Sella Group, Northern Italy. American Association of Petroleum Geologists Bulletin, Vol. 84, No. 3: 314-344

Armstrong, P. A. and Chapman, D.S. (1996) Thermal modelling and hydrocarbon generation in an active-margin Basin: Taranaki Basin, New Zealand. American Association of Petroleum Geologists Bulletin, Vol. 80, No. 8: 1216

Aydin. A. (2000) Fractures, faults and hydrocarbon entrapment, migration and flow. Marine and Petroleum Geology. Vol. 17: 797-814

Ballance, P. F. (1976) Evolution of the upper Cenozoic magmatic arc and plate boundary in northern New Zealand. Earth and Planetary Science Letters, Vol. 28: 356-370

Barr, D., Savory, K.E., Fowler, S.R., Arman, K. and McGarrity, J.P. (2007) Predevelopment fracture modelling in the Clair field, west of Shetland. In: Lonergan, L., Jolly, R.J.H., Rawnsley, K. and Sanderson, D.J. eds., Fractured Reservoirs. Geological Society, London, Special Publications, 270: 205-225 
Barton, C. A., Castillod, D. A., Moos, D., Peska, P. and Zoback, M. D. (1998) Characterising the full stress tensor based on observations of drilling-induced wellbore failures in vertical and inclined boreholes leading to improved wellbore stability and permeability prediction. APPEA Journal, Vol. 38: 466-487

Barton, C. A. and Zoback, M. D. (1994) Stress perturbations associated with active faults penetrated by Boreholes: Possible evidence for near-complete stress drop and a new technique for stress magnitude measurement. Journal of Geophysical Research, Vol. 99, No. B5: 9373-9390

Benchilla, L., Stagpoole, V.M. and Funnell, R.H. (2006) Integrated modelling approach and quantitative assessment of petroleum charge to the structurally complex Kupe Field, New Zealand. In: AAPG International Conference and Exhibition, November 5-8, 2006, Perth, WA: abstracts.

Berndt, C. (2005) Focused fluid flow in passive continental margins. Philosophical Transactions of the Royal Society, Vol. 363: 2855-2871

Best, D.D. and Parvar, H.L. (1989) Kupe South reservoir simulation study. Petroleum Report Series PR2241. Ministry of Economic Development.

Blenkinsop, T. G. (1989) Thickness-displacement relationships for deformation zones: Discussion. Journal of Structural Geology, Vol. 11: 1051-1053.

Bradshaw, J.D. (1989) Cretaceous Geotectonic patterns in the New Zealand region. Tectonics, Vol. 8, No. 4: 803-820

Branquet, Y., Cheilletz, A., Giuliani, G., Laumonier, B. and Blanco, O. (1999) Fluidized hydrothermal breccia in dilatant faults during thrusting: the Colombian emerald deposits. In. McCaffrey, K. J.W., Lonergan, L. and Wilkinson, J. J. eds., Fractures, Fluid Flow and Mineralization. Geological Society, London, Special Publications, 155: 183-195 
Brown, A.R. (2004) Interpretation of Three-Dimensional Seismic Data. AAPG Memoir 42. Tulsa Oklahoma, pp153

Brudy, M. and Kjorholth, H. (2001) Stress orientation on the Norwegian continental shelf derived from borehole failures observed in high-resolution borehole imaging logs. Tectonophysics, Vol. 337: 65- 84

Byerlee, J. (1978) Friction of Rocks. Pure and Applied Geophysics, Vol. 116, Nos. 4-5: 615-626

Byerlee, J. (1993) Model for episodic flow of high pressure water in fault zones before earthquakes. Geology, Vol. 2: 303-306

Camac, B., Hunt, S., Gilbert, C. and Anthony, D. (2005) Using 3D distinct element method to predict stress distribution - Kupe Field, Taranaki Basin, New Zealand. Petroleum Report Series PR3374. Ministry of Economic Development.

Cande, C. and Stock, J.M. (2004) Pacific-Antarctic-Australian motion and formation of the Macquarie Plate. Geophysical Journal International, Vol. 157: 399-414

Caine, J. S., Evans, J. P. and Forster, C. B. (1996) Fault zone architecture and permeability structure. Geology, Vol. 24: 1025-1028

Cartwright, J., Huuse, M. and Aplin, A. (2007) Seal bypass systems. American Association of Petroleum Geologists Bulletin, Vol. 91, No. 8: 1141-1166

CGG Australia Services Pty Ltd (2004) Reprocessing report for Kerry 3D survey. Petroleum Report Series PR4184. Ministry of Economic Development. 
Chanchani, S., Zoback, M.D. and Barton, C. (2003) A Case study of hydrocarbon transport along active faults and production-related stress changes in the Monterey Formation, California. In: Amen, M. ed., Fractures and in-situ stress characterisation of hydrocarbon reservoirs. Geological Society of London Special Publications, 209: 17-26

Chand, S. and Munshall, T. A. (2003) Seismic constraints on the effects of gas hydrate on sediment physical properties and fluid flow: a review. Geofluids, Vol. 3: 275-289

Childs, C., Easton, S.J., Vendeville, B.C., Jackson, M.P.A., Lin, S.T., Walsh, J.J. and Watterson, J. (1993) Kinematic analysis of faults in a physical model of growth faulting above a viscous salt analogue. Tectonophysics, Vol. 228: 313-329

Childs, C., Walsh, J.J., Manzocchi, T., Bonson, C., Nicol, A. and Schöpfer, M.P.J. (2009) A geometric model of fault zone and fault rock thickness variations. Journal of Structural Geology, Vol. 31: 117-12

Childs, C., Nicol, A., Walsh, J.J. and Watterson, J. (2003) The growth and propagation of synsedimentary faults. Journal of Structural Geology, Vol. 25: 633-648

Childs, C., Walsh, J.J. and Watterson, J. (1997) Complexity in fault zone structure and implications for fault seal prediction. Norwegian Petroleum Society Special Publications, Vol. 7: 61-72

Childs, C., Watterson, J. and Walsh, J.J. (1995) Fault overlap zones within developing normal fault systems. Journal of the Geological Society of London, Vol. 152: 535-549

Childs, C., Watterson, J. and Walsh, J.J. (1996) A model for the structure and development of fault zones. Journal of the Geological Society of London, Vol. 153: 337340 
Compagnie Generale de Geophsique. (1992) Final report of seismic data processing carried out by Compagnie Generale de Geophsique for Shell Todd Oil Services. Area Maui-B 3D Survey 1991. Petroleum Report Series PR2301. Ministry of Economic Development.

Corona, F.V., Davis, J.S., Hippler, S.J. and Vrolijk. P.J. (2010) Multi-fault analysis scorecard: testing the stochastic approach in fault seal prediction. In: Jolley, S. J., Bar, D., Walsh, J.J. and Knipe, R. J. eds., Structurally Complex Reservoirs. Geological Society, London, Special Publications, 292: 317-332

Cowley. R, and O’Brien, G. W. (2000) Identification and interpretation of leaking hydrocarbons using seismic data: A comparative montage of examples from the major fields in Australia's North West Shelf and Gippsland Basin. APPEA Journal, 2000: 121150

Crown Minerals. (2010) New Zealand's Petroleum Basins. Crown Minerals, Ministry of Economic Development, Wellington, New Zealand. Retrieved from http://www.nzpam.govt.nz/cms/petroleum/publications\#nz-petroleum-basins

Davatzes, N.C. and Aydin, A. (2003) Overprinting faulting mechanisms in high porosity sandstones of SE Utah. Journal of Structural Geology, Vol. 25:1795-1813

Dockrill, B. and Shipton, Z.K. (2010). Structural controls on leakage from a natural $\mathrm{CO}_{2}$ geologic storage site: Central Utah, U.S.A. Journal of Structural Geology. Vol. 32, No. 11: 1768-1782

Edbrooke, S. W. (2001) Geology of the Auckland area; scale 1:250,000. Institute of Geological and Nuclear Sciences Lower Hutt New Zealand (NZL)

Eichhubl, P., Davatzes, N.C. and Becker, S.P. (2009) Structural and Diagenetic control of fluid migration and cementation along the Moab fault, Utah. American Association of Petroleum Geologists Bulletin, Vol. 93, No. 5: 653-681 
Eichhubl, P. and Boles, J.R. (2000) Focused fluid flow along faults in the Monterey Formation, coastal California. Geological Society of America Bulletin, Vol. 112, No. 11: 1667-1679

Engbers, P., Dekker, S., Crookbain, R. and Jeaffreson, D. (2002) Mauri 3D Seismic Interpretation Report. Petroleum Report Series PR2754. Ministry of Economic Development.

Ferrill, D.A., Winterle, J., Wittmeyer, G., Sims, D., Colton, S. and Armstrong, A. (1999) Stressed rock strains groundwater and Yucca Mountain, Nevada. GSA Today, Vol. 9, No. 5: $1-7$

Fisher, Q.J. and Knipe, R.J. (1998) Fault sealing processes in siliclastic sediments. In: Knipe, R. J., Jones, G. and Fisher, Q. J. eds., Faulting, fault sealing and fluid flow in hydrocarbon reservoirs. Geological Society, London, Special Publications, 147: 117-134

Flodin, E., and Aydin, A. (2004) Evolution of a strike-slip fault network, Valley of Fire, southern Nevada. Geological Society of America Bulletin, Vol. 116, No. 1-2: 42-59

Fossen, H., Johansen, T.E.S., Hesthammer, J. and Rotevatn, A. (2007) Fault interaction in porous sandstone and implications for reservoir management; examples from southern Utah. American Association of Petroleum Geologists Bulletin, Vol. 89, No. 12: 15931606

Fossen, H., Schultz, R.A., Shipton, Z. K. and Mair, K. (2007) Deformation bands in sandstones: A review. Journal of the Geological Society of London. Vol. 164. 1-15

Gatrell, A., Bailey, W.R. and Brincat, M. (2006) A new model for assessing trap integrity and oil preservation risks associated with postrift fault reactivation in the Timor Sea. American Association of Petroleum Geologists Bulletin, Vol. 90, No. 12:1921-1944 
Gay, A., Lopez, M., Chochonat, P., Sultan, N., Cauqual, E. and Briguad, F. (2003) Sinuous pockmark belt as indicator of shallow buried turbiditic channel on the lower slope of the Congo Basin, West African Margin. In: Van Rensbergen, P., Hillis, R.R., Maltman, A.J. and Morley, C.K. eds., Subsurface sediment mobilization. Geological Society of London Special Publication, 216: 173-189

Giba, M. (2010) The evolution of Tertiary normal faults in the Taranaki Basin, New Zealand. Unpublished PhD Thesis, National University of Ireland

Giba, M., Nicol, A. and Walsh, J.J. (2010) Evolution of faulting and volcanism in a backarc basin and its implications for subduction processes. Tectonics, Vol. 29: TC4020

GNS Science. (2002-2006) New Zealand digital well summary sheets. Well data sheets Available from http://www.gns.cri.nz/Home/Our-Science/Energy-Resources/Oil-andGas/Products/New-Zealand-Digital-Well-Summary-Sheets.

Grain, S. (2008) Paleogeography of a Mid-Miocene turbidite complex, Moki Formation, Taranaki Basin, New Zealand. Unpublished MSc thesis, University of Victoria, Wellington, New Zealand

Grueschow, E., Kwon, O., Main, I.G and Rudnicki, J.W. (2003) Observation and modelling of the suction pump effect during rapid dilatant slip. Geophysical Research Letters, Vol. 30, 4 p. doi:10.1029/2002GL015905.

Halliday. E. J., Barrie, J. V., Chapman, N. R. and Rohr, K. M. M. (2008) Structurally controlled hydrocarbon seeps on a continental margin, Hectate Strait, offshore British Columbia. Marine Geology, Vol. 252: 193-206

Hanks, C.L., Lorenz, J., Teufel, L. and Krumhardt, A.P. (1997) Lithological and structural controls on natural fracture distribution and behaviour within the Lisburne Group, northeastern Brooks Range and North Slope subsurface, Alaska. American Association of Petroleum Geologists Bulletin, Vol. 81, No. 10: 1700-1720 
Heggland, R. (1998) Gas seepage as an indicator of deeper prospective reservoirs. A study based on exploration 3D seismic data. Marine and Petroleum Geology, Vol. 15: 1-9

Hill, M., Milner, M. and Kroeger, K. (in prep). 3D Static Modelling of the Kupe Region, Taranaki Basin - 4D Taranaki Project. GNS Science Report

Hippler, S.J. (1997) Microstructures and diagenesis in North Sea fault zones: Implications for fault-seal potential and fault-migration rates. In: Surdam, R.C. ed., Seals, traps and the petroleum system. American Association of Petroleum Geologists, Memoir 67. 101-113

Holt, W.E. and Stern, T.A. (1994) Subduction, platform subsidence, and foreland thrust loading: the late Tertiary development of Taranaki Basin, New Zealand. Tectonics, Vol. 13: 1068-1092

Homberg, C., Hu, J. C., Angelier, J., Bergerat, F. and Lacombe, F. (1997) Characterisation of stress perturbations near major fault zones: insights from 2-D distinctelement numerical modelling and field studies (Jura Mountains). Journal of Structural Geology, Vol. 19, No. 5: 703-718

Horan, S. (1997) Borehole stress study of the Kupe South and Toru fields. PML 38146. Petroleum Report Series PR2764. Ministry of Economic Development.

Homberg, C., Hu, J. C., Angelier, J., Bergerat, F. and Lacombe, F. (1997) Characterisation of stress perturbations near major fault zones: insights from 2-D distinctelement numerical modelling and field studies (Jura Mountains). Journal of Structural Geology, Vol. 19, No. 5: 703-718

Hull, J. (1988) Thickness-displacement relationships for deformation zones. Journal of Structural Geology, Vol. 10: 431-435 
Hunt, S. P. and Boult, P. J. (2005) Distinct-element stress modelling in the Penola Trough, Otway Basin, South Australia. In: Boult, P. and Kaldi, J. eds., Evaluating fault and cap rock seals: AAPG Hedberg Series, No. 2: 199-213

Ilg, B.R., Hemmings-Sykes, S., Baur, J., Nicol, A., Fohrmann, M., Funnell, R. and Milner, M. (in prep) Gas expulsion, migration and leakage at an active plate boundary, southern Taranaki Basin, offshore New Zealand. Manuscript accepted by AAPG. Available by emailing request to sam.hemmings.sykes@gmail.com

Ito, T., Evans, K., Kawai, K. and Hayashi, K. (1999) Hydraulic fracture reopening pressure and estimation of maximum horizontal stress. International Journal of Rock Mechanics and Mining Sciences, Vol. 36, No. 6: 811-826

Jaeger, J. C. and Cook, N. G. W. (1979) Fundamentals of Rock Mechanics. Chapman and Hall, London.

James, W.R., Fairchild, L.H., Nakayama, G.P., Hippler, S.J. and Vrolijk, P.J. (2004) Faultseal analysis using a stochastic multi-fault approach. American Association of Petroleum Geologists Bulletin, Vol. 88: 885-904

Jefferies, R. (1996) Kupe South Reservoir Simulation Study. PML 38146. Petroleum Report Series PR2763. Ministry of Economic Development.

Jolley, S. J., Bar, D., Walsh, J.J. and Knipe, R. J. (2007) Structurally complex reservoirs: an introduction. In: Jolley, S. J., Bar, D., Walsh, J.J. and Knipe, R. J. eds., Structurally Complex Reservoirs. Geological Society, London, Special Publications, 292: 1-24

Jolley, R.J.H. and Sanderson, D.J. (1997) A Mohr circle construction for the opening of a pre-existing fracture. Journal of Structural Geology, Vol. 19, No. 6: 887-892

Judd, A. G. and Hovland, M. (1992) The evidence for shallow gas in marine sediments. Continental Shelf Research, Vol. 12, No 10: 1081-1095 
Kachi, T., Yamada, H., Yasuhara, K., Fujimoto, M., Hasegawa, S., Iwanaga, S. and Sorkhabi, R. (2005) Fault-seal analysis applied to the Erawan gas-condensate field in the Gulf of Thailand. In: Sorkhabi, R. and Tsuji, Y. eds., Faults, fluid flow and petroleum traps. AAPG Memoir 85: 59-78

Killops, S. D. and Woolhouse, A.D., Weston, R.J. and Cook, R.A. (1994) A geochemical appraisal of oil generation in the Taranaki Basin, New Zealand. American Association of Petroleum Geologists Bulletin, Vol. 78, No. 10: 1560-1585

King, P.R. and Thrasher, G.P. (1992) Post-Eocene development of the Taranaki Basin, New Zealand: convergent overprint of a passive margin. In: Watkins, J.S., Zhiquang, F. and McMillan, K.J. eds., Geology and geophysics of continental margins. American Association of Petroleum Geologists Memoir 53: 93-118

King, P.R., Browne, G.H. and Slatt, R.M. (1994) Sequence architecture of exposed Late Miocene basin floor fan and channel-levee complexes (Mount Messenger Formation), Taranaki Basin, New Zealand. In: Weimer, P., Bouma, A.H. and Perkins, B.F. eds., Submarine fans and turbidite systems: Sequence stratigraphy, reservoir architecture and production characteristics, Gulf of Mexico and international. Houston, Texas: Gulf Coast Section. 117-192

King, P.R. and Thrasher, G.P. (1996) Cretaceous-Cenozoic geology and petroleum systems of the Taranaki Basin, New Zealand. Institute of Geological and Nuclear Sciences Monograph 13. 243 p.

Knipe, R. J., Jones, G. and Fisher, Q. J. (1998) Faulting, fault sealing and fluid flow in hydrocarbon reservoirs: an introduction. In: Knipe, R. J., Jones, G. and Fisher, Q. J. ed., Faulting, fault sealing and fluid flow in hydrocarbon reservoirs. Geological Society, London, Special Publications, 147, vii-xxi

Corne, K., Holt, W.E. and Haines, A.J. (2003) An integrated global model of present-day plate motions and plate boundary deformation. Geophysics Journal International, Vol. 154: 8-34 
Lamarche, G., Proust, J. and Nodder, S.D. (2005) Long-term slip rates and fault interactions under low contractional strain, Wanganui Basin, New Zealand. Tectonics, Vol. 24: TC4004

Ligtenberg, J. H. (2003) Chimney detection and interpretation, revealing sealing quality of faults, geohazards, charge of and leakage from reservoirs. Journal of Geochemical Exploration, Vols. 78-79: 385-387

Ligtenberg, J. H. (2005) Detection of fluid migration pathways in seismic data: implications for fault seal analysis. Basin Analysis, Vol. 17: 141-153

Loncke, L., Mascle, J. and Fanil Scientific Parties (2004) Mud volcanoes, gas chimneys, pockmarks and mounds in the Nile deep-sea fan (Eastern Mditerranean): geophysical evidences. Marine and Petroleum Geology, Vol. 21, No. 6: 669-689

Loseth, H., Gading, M. and Wensaas, L. (2009) Hydrocarbon leakage interpreted on seismic data. Marine and Petroleum Geology, Vol. 26: 1304-1319

Losh, S., Walter, L., Meulbroek, P., Martini, A., Cathles, L. and Whelan, J. (2002) Reservoir fluids and their migration into the South Eugene Island Block 330 reservoirs, offshore Louisiana. American Association of Petroleum Geologists Bulletin, Vol. 86, No. 8:1463-1488

Maerten, L., Gillespie, P. and Pollard, D. D. (2002) Effects of local stress perturbation on secondary fault development. Journal of Structural Geology, Vol. 24: 145-153

Maerten, L., Willemse, E.J.M., Pollard, D.D. and Rawnsley, K. (1999) Slip distributions on intersecting normal faults. Journal of Structural Geology, Vol. 21, No. 3: 259-272

MacDonald, I.R., Buthman, D. B., Sager, W. W., Peccini, M. B. and Guinasso Jr, N.L. (2000) Pulsed oil discharge from a mud volcano. Geology, Vol. 28, No. 10: 907-910 
Main, I. G., Kwon, O., Ngwenya, B.T. and Elphick, S.G (2000) Fault sealing deformationband growth in porous sandstone. Geology, Vol. 28: 1131-1134

Manzocchi, T., Walsh, J.J., Nell, P. and Yielding, G. (1999) Fault transmissibility multipliers for flow simulation models. Petroleum Geoscience, Vol. 5: 53-63

Manzocchi, T., Heath, A.E., Palananthakumar. B., Childs, C. and Walsh, J.J. (2008) Faults in conventional flow simulation models: a consideration of representational assumptions and geological uncertainties. Petroleum Geoscience, Vol. 14: 91-110

Martin, K.R., Baker, J.C., Hamilton, P.J. and Thrasher, G.P. (1994) Late meteoric flushing and timing of hydrocarbon entrapment in the Kupe South field. 1994 New Zealand Petroleum Conference Proceedings 1994

Medialdea,T., Somoza, L., Pinheiro, L.M., Fernández-Puga, M.C., Vázquez, J.T., León, R., Ivanov, M.K., Magalhaes, V., Díaz-del-Río, V. and Vegas, R. (2008) Tectonics and mud volcano development in the Gulf of Cádiz. Marine Geology, Vol. 261: 48-63

Matthai, S. K. and Fisher, G. (1996) Quantative modelling of fault fluid discharge and fault dilation induced fluid pressure variations in the seismogenic cycle. Geology, Vol. 24, No. 2: $183-186$

Marone, C., Raleigh, C. B. and Scholz, C. H. (1990) Frictional behavior and constitutive modelling of simulated fault gouge. Journal of Geophysical Research, Vol. 95: 70077025

Meyer, V., Nicol, A., Childs, C., Walsh, J.J. and Watterson, J. (2002) Progressive localisation of strain during the evolution of a normal fault population. Journal of Structural Geology, Vol. 24: 1215-1231 
Mildren, S. D., Hillis, R. R., Dewhurst, D.N., Lyon, P.J., Meyer, J.J. and Boult, P.J. (2005) FAST: A new technique for geomechanical assessment of the risk of reactivation-related breach of fault seals. In: Boult, P. and Kaldi, J. eds., Evaluating fault and cap rock seals. AAPG Hedberg Series, No. 2: 73 - 85

Mildren, S.D., Scott, D. and Meyer, J.J. (2005) Regional seal evaluation of North Taranaki Graben, PEP38485. Petroleum Report Series PR3344. Ministry of Economic Development.

Milner, M., Massey, M., Viskovic, P., and Jones, C., 2009 Taranaki phase-matched seismic database. Available from http://www.gns.cri.nz/Home/Our-Science/Energy-Resources/Oiland-Gas/Products/Taranaki-Basin\#seismic

Mitra, S. (1990) Fault-propagation folds: Geometry, kinematic evolution and hydrocarbon traps. American Association of Petroleum Geologists Bulletin, Vol. 74, No. 6. 921-945

Moos, D. and Zoback, M.D. (1990) Utilization of observations of well bore failure to constrain the orientation and magnitude of crustal stresses: application to continental, deep sea drilling project and ocean drilling program boreholes. Journal of Geophysical Research. Vol. 95, No. B6: 9305-9030

Morgan, J. K. (1999) Numerical simulations of granular shear zones using the distinct element method 2. Effects of particle size distribution and interparticle friction on mechanical behaviour, Journal of Geophysical Research, Vol. 104, No. B2: 2721-2732

Morris, A.P. and Ferrill, D.A. (2009) The importance of the effective intermediate principal stress $\left(\sigma_{2}\right)$ to fault slip patterns. Journal of Structural Geology, Vol. 31: 950-959

Morris, A.P., Ferrill, D.A. and Henderson, D.B. (1996) Slip tendency and fault reactivation. Geology, Vol. 24: 275-278

Mortimer, N. (2004) New Zealand's geologic foundations. Gondwana Research, Vol. 7, No.1: 261-272 
Muir-Wood, R. (1993) Hydrological signatures of earthquake strain, Journal of Geophysical Research. Vol. 98: 22035-22068

Myers, R.D., Allgood, A. Hjelbakk, A., Vrolijk, P. and Briedis, N. (2007) Testing fault transmissibility multipliers in a structurally dominated reservoir: Ringhorne field, Norway. In: Jolley, S. J., Bar, D., Walsh, J.J. and Knipe, R. J eds., Structurally Complex Reservoirs. Geological Society, London, Special Publications, 292, 271-294

Nelson, C. S., Kamp, P.J.J. and Young, H.R. (1994) Sedimentology and petrography of mass-emplaced limestone (Orahiri Limestone) on a late Oligocene shelf, western North Island, and tectonic implications for eastern margin development of Taranaki Basin, New Zealand Journal of Geology and Geophysics, Vol. 37, No.3: 269-285

Nelson, E.J. and Hillis, R.R. (2005) In-situ stresses of the West Tuna area, Gippsland Basin. Australian Journal of Earth Sciences, Vol. 52: 299-313

Nelson, E.J., Meyer, J.J., Hillis, R.R. and Mildren. S.D (2005) Transverse drilling induced tensile fractures in the West Tuna area, Gippsland Basin, Australia: implications for the insitu stress regime. International Journal of Rock Mechanics and Mining Sciences, Vol. 42: 361-371

Nguyen, P.T., Cox, S.F., Harris, L.B. and Powell, C.M. (1998) Fault valve behaviour in optimally oriented shear zones: an example at the Revenge gold mine, Kambalda, Western Australia. Journal of Structural Geology, Vol. 20, No. 12: 1625-1640

Nicol, A., Mazengarb, C., Chanier, F., Rait, G., Uruski, C. and Wallace, L. (2007) Tectonic evolution of the active Hikurangi subduction margin, New Zealand, since the Oligocene. Tectonics, Vol. 26, TC4002

Nicol, A., Walsh, J., Berryman, K. and Nodder, S. ( 2005) Growth of a normal fault by the accumulation of slip over millions of years. Journal of Structural Geology, Vol. 27: 327342 
Nicol, A., Watterson, J., Walsh, J.J., and Childs. C. (1996) The shapes, major axis orientations and displacement patterns of fault surfaces. Journal of Structural Geology, Vol. 18; 235-248

Nicol, A., Walsh, J.J., Watterson, W. and Bretan, P.G. (1995) Three-dimensional growth and geometry of normal faults. Journal of Structural Geology, Vol. 17: 847-862

Nicol, A., Walsh, J. J., Watterson, J. and Underhill, J. R. (1997) Displacement rates of normal faults. Nature, Vol. 390: 157-159

Nodder, S.D. (1993) Neotectonics of the offshore Cape Egmont fault zone, Taranaki Basin, New Zealand. New Zealand Journal of Geology and Geophysics, Vol. 36:167-184

Nodder, S. D. (1994) Characterizing potential offshore seismic sources using highresolution geophysical and seal floor sampling programs: An example from Cape Egmont fault zone, Taranaki shelf, New Zealand. Tectonics, Vol. 13, No. 2: 641-658

O’Brien, G. W. and Woods, E. P. (1995) Hydrocarbon related diagenic zones (HRDZ) in the Vulcan Sub Basin, Timor Sea: Recognition and exploration implications. APEA Journal 1995: 220-252

Odling, N.E., Gillespie, P., Bourgine, B., Castaing, C., Chilés, J-P., Christensen, N.P., Fillion, E., Genter, A., Olsen, C., Thrane, L., Trice, R., Aarseth, E., Walsh, J.J. and Watterson, J. (1999) Variations in fracture system geometry and their implications for fluid flow in fractured hydrocarbon reservoirs. Petroleum Geoscience, Vol. 5: 374-384

Olson, J.E., Laubach, S.E. and Lander, R.H. (2007) Combining diagenesis and mechanics to quantify fracture aperture distributions and fracture pattern permeability. In: Lonergan, L., Jolly, R.J.H., Rawnsley, K. and Sanderson, D.J. eds., Fractured Reservoirs. Geological Society, London, Special Publications, 270: 101-116

OpendTect Manual 4.0 (2010). Retrieved from http://www2.dgb-group.com/ 
Palmer, J. A. and Andrews, P.B. (1993) Cretaceous-Tertiary sedimentation and implied tectonic controls on the structural evolution of Taranaki Basin, New Zealand, In: Ballance. P.F. ed., South Pacific sedimentary basins, Sedimentary Basins of the world 2, Elsivier, Amsterdam: 309-328

Peterson, K., Clausen, O.R. and Korstgard, J.A. (1992) Evolution of a salt related listric growth fault near the D-1 well, block 5605, Danish North Sea; displacement history and salt kinematics. Journal of Structural Geology, Vol. 14: 565-577

Pilaar, W. F. H. and Wakefield, L. L. (1978) Structural and stratigraphic evolution of the Taranaki Basin, offshore North Island, New Zealand. The APEA Journal, Vol.18, Part 1: 93-101

Proust, J., Lamarche, G., Nodder, S. and Kamp, P.J.J. (2005) Sedimentary architecture of a Plio-Pleistocene proto-back-arc basin: Wanganui Basin, New Zealand. Sedimentary Geology, Vol. 181: 107-145

Rad, U.V., Berner, U., Delisle, G., Doose-Rolinski, H., Fechner, N., Linke, P., Luckge, A., Roeser, H.A., Schmaljohann, R., Wiedicke, M., and SONNE 122/130 Scientific Parties (2000) Gas and fluid venting at the Makran accretionary wedge off Pakistan. Geo-Marine Letters, Vol. 20: 10-19

Rawnsley, K., De Keijzer, M., Wei, L., Bettembourg, S., Asyee, W., Massaferro, J.L., Swaby, P., Drysdale, D. and Boettcher, D. (2007) Characterizing fracture and matrix heterogeneities in folded Devonian carbonate thrust sheets, Waterton tight gas fields, Western Canada. In: Lonergan, L., Jolly, R.J.H., Rawnsley, K. and Sanderson, D.J. eds., Fractured Reservoirs. Geological Society, London, Special Publications, 270: 265-279

Rogers, S.F. (2003) Critical stress-related permeability in fractured rocks. In: Ameen, M. ed., Fracture and In-Situ Stress Characterization of Hydrocarbon Reservoirs. Geological Society of London Special Publication, 209: 7-16 
Roncaglia, L., Morgans, H.E.G., Arnot, M.J., Baur, J., Bushe, H., Jones, C., King, P.R., Milner, M. and Zhu, H. (2008) Stratigraphy, well correlation and seismic-to-well tie in the Upper Cretaceous to Pliocene interval in the Kupe region, Taranaki Basin, New Zealand. Introduction to the Stratigraphic database in PETREL. GNS Science Report, 2008/07, 24p

Roncaglia, L., Arnot, M.J., Baur, J., Forhmann, M., King, P.R., Kroeger, K. F., Hill, M., Strogen, D. and Zhu, H. (2010) From seismic facies to basin evolution visualisation: An integrated workflow for modelling offshore Taranaki Basin. Technical Poster, New Zealand Petroleum Conference Proceedings 2010. Retrieved from http://www.nzpam.govt.nz/cms/petroleum/conferences/2010-nzpc/2010-new-zealandpetroleum-conference-posters

Santarellie, F. J., Brown, E.T. and Maury, V. (1986) Analysis of borehole stresses using pressure-dependent, linear elasticity. International Journal of Rock Mechanics and Mineral Sciences. Geomechanical Abstracts, Vol. 6: 445-449

Schlagenhauf, A., Manighetti, I., Malavieille, J. and Dominguez, S. (2008) Incremental growth of normal faults: Insights from a laser-equipped analog experiment. Earth and Planetary Science Letters, Vol. 273: 299-311

Schmidt, D.S. and Robinson, P.H. (1989) The structural setting and depositional history for the Kupe field, Taranaki Basin. New Zealand Petroleum Conference Proceedings 1989

Scholz, C. H. (1990) The mechanics of earthquakes and faulting. Cambridge University Press. New York

Schroot, B. M., Klaver, G. V. and Schuttenhelm, R.T.E. (2005) Surface and subsurface expressions of gas seepage to the seabed - examples from the southern North Sea. Marine and Petroleum Geology, Vol. 22: 499-515

Sibson, R. H. (1974) Frictional constraints on thrust, wrench and normal faults. Nature, Vol. 249: $542-544$ 
Sibson, R.H. (1985) A note on fault reactivation. Journal of Structural Geology, Vol. 7, No. 6: $751-754$

Sibson, R. H. (1989) Earthquake faulting as a structural process. Journal of Structural Geology, Vol. 11: 1-14

Sibson, R. A. (1994) Crustal stress, faulting and fluid flow. In: Parnell, J. ed., Geofluids: Origin, migration and evolution of fluids in sedimentary basins. Geological Society, London, Special Publications, 78: 69-84

Sibson, R.H. (1996) Structural permeability of fluid-driven fault-fracture meshes. Journal of Structural Geology, Vol. 18, No. 8: 1031-1042

SIPM. (1989) Kapuni 3D 1989 Seismic survey conducted in PML38839. Petroleum Report Series PR1667. Ministry of Economic Development.

Stagpoole, V. and Nicol, A. (2008) Regional structure and kinematic history of a large subduction back thrust; Taranaki Fault, New Zealand. Journal of Geophysical Research (Earth Surface), Vol. 113: B01403

Steed, H., de Bock, F and Brewster, T. (1998) Exploration of PML 38146 Kupe Mining License Area. Petroleum Report Series PR2859. Ministry of Economic Development.

Stern, T.A. and Davey, F.J. (1990) Deep seismic expression of a foreland basin: Taranaki Basin, New Zealand. Geology, Vol. 18: 972-982.

Stern, T. A., Quinlan, G.M. and Holt, W.E. (1993) Crustal dynamics associated with the formation of Wanganui Basin, New Zealand. In: Ballance, P.F. ed., South Pacific sedimentary basins, Sedimentary Basins of the world 2, 213-223 
Stern, T., Stratford, W. R. and Salmon, M.L. (2006) Subduction evolution and mantle dynamics at a continental margin. Reviews of Geophysics, Vol. 4: RG4002

Streit, J.E. and Hillis, R.R. (2004) Estimating fault stability and sustainable fluid pressures for underground storage of CO2 in porous rock. Energy, Vol. 29: 1445-1456

Sultan, N., Voisset, N., Marsset, T., Vernan, A.M., Cauquil, E., Colliat, J. L. and Curinier, V. (2007) Detection of free gas and gas hydrate based on 3D seismic data and cone penetration testing: An example from the Nigerian Continental Slope. Marine Geology, Vol. 240: 235-255

Suppe. J. (1983) Geometry and kinematics of fault-bend folding. American Journal of Science, Vol. 283. 684-721

Sutherland, R. (1995) The Australia-Pacific boundary and Cenozoic plate motions in the SW Pacific: some constraints from Geosat data. Tectonics, Vol. 14, No.4: 819-831

Sutherland, R. and Hollis, C. (2001) Cretaceous demise of the Moa plate and strike-slip motion at the Gondwana margin. Geology, Vol. 29, No. 3: 279-282

Sutherland. R., King, P. and Wood, R. (2001b) Tectonic evolution of Cretaceous rift basins in south-eastern Australia and New Zealand: Implications for Exploration Risk Assessment. In: Hill, K.C. and Bernecker, T. eds., Eastern Australian Basins symposium. A refocused Energy perspective for the Future. Petroleum Exploration Society of Australia, Special Publication. 49-60

Takatoshi, I. and Kazuo, H. (2003) Role of stress-controlled flow pathways in HDR geothermal reservoirs. Pure and Applied Geophysics, Vol. 160: 1103-1124.

Thrasher, G.P. (1992) Late Cretaceous geology of Taranaki Basin, New Zealand. Unpublished PhD thesis, Victoria University of Wellington, New Zealand 
Thrasher, G. (1990) The Maui field and the exploration potential of southern Taranaki; a few unanswered questions. Petroleum exploration in New Zealand News 25, Ministry of Commerce: 26-30

Townsend, D., Nicol, A., Mouslopoulou, V., Begg, J.G., Beetham, R.J., Clark, D., Giba, M., Heron, D., Lukovic, B., Macpherson, A., Seeback, H. and Walsh, J.J. (2010) Paleoearthquakes histories across a normal fault system in the southwestern Taranaki Peninsula, New Zealand. New Zealand Journal of Geology and Geophysics, Volume 53, No. 4: $375-394$

Townend, J. and Zoback, M.D. (2000) How faulting keeps the crust strong. Geology, Vol. 28, No. 5: 399-402

Van Rensbergen, P., Rabaute, A., Colpaert, A., St. Ghislain, T., Mathijs, M. and Bruggenman. A. (2007) Fluid migration and fluid seepage in the Connemara Field, Porcupine Basin interpreted from industrial 3D seismic and well data combined with high resolution site survey data. International Journal of Earth Sciences, Vol. 96: 185-197

Vernik, L. and Zoback, M.D. (1992) Estimation of maximum horizontal stress magnitude from stress-induced well bore breakouts in the Cajon Pass scientific research borehole. Journal of Geophysical Research, Vol. 97, No. B4: 5109-5119

Voggenreiter, W. R. (1991) Kapuni 3D interpretation - Imaging Eocene Paleogeography. New Zealand Petroleum Conference Proceedings 1991

Walsh, J.J., Nicol, A. and Childs, C. (2002) An alternate model for the growth of faults. Journal of Structural Geology, Vol. 24:1669-1675

Walsh, J.J., Bailey, W.R., Childs, C., Nicol, A. and Bonson, C.G. (2003) Formation of segmented normal faults; a 3-D perspective. Journal of Structural Geology, Vol. 25:12511262 
Walsh, J.J. and Watterson, J., (1989) Displacement gradients on fault surfaces. Journal of Structural Geology, Vol. 11: 307-316

Walsh, J.J., Watterson, J., Bailey, W.R. and Childs, C. (1999) Fault relays, bends and branch lines. Journal of Structural Geology, Vol. 21: 1019-1026

White, J. E., 1975, Computed seismic speeds and attenuation in rocks with partial saturation. Geophysics, Vol. 40, 224-232

Wilkins, S.J. and Naruk. S.J. (2007) Quantitative analysis of slip-induced dilation with application to fault seal. American Association of Petroleum Geologist Bulletin, Vol. 9, No. 1. $97-113$

Wiprut, D. and Zoback, M.D. (2002) Fault reactivation and fluid flow along a previously dormant normal fault in the northern North Sea. Geology, Vol. 28, No. 7: 595-598

Wiprut, D., Zoback, M.D., Hanssen, T. and Peska, P. (1997a) Compressive and tensile failure of inclined well bores and determination of in-situ stress and rock strength. Journal of Geophysical Research, Vol. 100: 1279 - 1281.

Wiprut, D., Zoback, M.D., Hanssen. T and Peska, P. (1997b) Constraining the full stress tensor from observations of drilling-induced tensile fractures and leak-off tests: Application to borehole stability and sand production on the Norwegian Margin. International Journal of Rock Mechanics and Mineral Science, Vol. 34, No. 3: 3-4

Yaghoubi, A.A. and Zeinali, M. (2009) Determination of magnitude and orientation of the in-situ stress from borehole breakout and effect of pore pressure on borehole stability Case study in Cheshmeh Khush oil field of Iran. Journal of Petroleum Science and Engineering, Vol. 67: 116-126 
Yale, D.P. (2003) Fault and stress magnitude controls on variations in the orientation of insitu stress. In: Ameen, M. ed., Fracture and in-situ stress characterisation of hydrocarbon reservoirs. Geological Society, London, Special Publications, 209: 55-64

Yielding, G., Freeman, B., Needham, D.T. (1997). Quantitative fault seal prediction. American Association of Petroleum Geologists Bulletin, 81: 897-917

Zhang, X. and Sanderson, D. J. (1996) Numerical modelling of the effects of fault slip on fluid flow around extensional faults. Journal of Structural Geology, Vol. 18: 109-119

Zhang, X. and Sanderson, D. J. (2002) Numerical study of fluid flow of deforming fractured rocks using dual permeability model. Geophysical Journal International, Vol. 151: $452-468$

Zhang,Y., Schaubs, P.M., Zhao, C., Ord, A., Hobb, B.E. and Barnicoat, A.C. (2008) Fault related dilation, permeability enhancement, fluid flow and mineral precipitation patterns: numerical models. In: Wibberley, C.A.J., Kurtz, W., Imber, J., Holdsworth, R.E. and Collettini, C. eds., The Internal Structure of Fault Zones: Implications for Mechanical and Fluid-Flow Properties. Geological Society London, Special Publications, Vol. 299: 239_ 255

Zoback, M., Barton, C., Finkbeiner, T. and Dholakia, S. (1996) Evidence for fluid flow along critically-stressed faults in crystalline and sedimentary rock. In: Jones, G., Fisher, Q., Knipe, R. eds., Faulting, Faults Sealing and Fluid Flow in Hydrocarbon Reservoirs. Geological Society of London Special Publications, 147: 47-48.

Zoback, M. D. (2007) Reservoir Geomechanics. Cambridge University Press, Cambridge. 


\section{Appendix I}

\section{Fault Displacement to Length Ratio Data Sources}

Bailey, W.R., Walsh, J.J. and Manzocchi, T. (2005) Fault populations, strain distribution and basement fault reactivation in the East Pennines coalfield, UK. Journal of Structural Geology, Vol. 27: 913-928

Bergen, K.J. and Shaw, J.H. (2010) Displacement profiles and displacement-length scaling relationships of thrust faults constrained by seismic-reflection data. GSA Bulletin, Vol. 122, No. 7/8: 1209-1219

Bohnenstiehl, D.R. and Kleinrock, M.C. (2000) Evidence for spreading-rate dependence in the displacement-length ratios of abyssal hill faults at mid-ocean ridges. Geology, Vol. 28, No. 5: 395-398

Fault Analysis Group Dublin, Unpublished Data Sets

Geological and Nuclear Sciences Internal Unpublished Data Set

Kim, Y.S., Andrews, J.R., and Sanderson, D.J. (2000) Damage zones around strike-slip fault systems and strike-slip fault evolution, Crackington Haven, southwest England. Geoscience Journal, Vol. 4: 53- 72

Lamarche, G. J., Proust, N. and Nodder, S.D. (2005) Long-term slip rates and fault interactions under low contractional strain, Wanganui Basin, New Zealand. Tectonics, Vol. 24: TC4004

Nicol, A. (2000-2010) Unpublished Data 
Olson, J.E. (2003) Sublinear scaling of fracture aperture versus length: an exception or the rule? Journal of Geophysical Research, Vol. 108, No. 2413, doi:10.1029/ 2001JB000419

Walsh, J.J., Nicol, A., and Childs, C. (2002) An alternative model for the growth of faults. Journal of Structural Geology, Vol. 24: 1669- 1675

Wilkins, S.J. and Gross, M.R. (2002) Normal fault growth in layered rocks at Split Mountain, Utah: influence of mechanical stratigraphy on dip linkage, fault restriction and fault scaling. Journal of Structural Geology, Vol. 24: 1413- 1429. 


\section{Appendix II}

\section{Seismic Reflection Lines}

All seismic data used in this study was obtained from GNS Science PEGI Project Seismic Reflection Legacy Database (Milner et al. 2007)

\section{D Seismic Reflection Data}

Survey

$86 M a$

G

HZT-82a

K89

$\boldsymbol{M}$

Or003

P95
101, 109, 118

1-5

\section{Line Name}

27-58

102-105

2

100-152

1007-1037

500, 504, 506, 508, 510 
Sk

$13 e$

ST

306, 309

TNZ-82

414, 428, 510, 618, 630a

3D Seismic Reflection Volumes

Volume Name

Kapuni 3D

Kerry 3D

Maui 3D

\section{Area $\left(\mathrm{km}^{2}\right)$}

$100 \mathrm{~km}^{2}$

$384 \mathrm{~km}^{2}$

$1000 \mathrm{~km}^{2}$ 


\title{
Appendix III
}

\author{
Well Log Data
}

$\begin{array}{lllllllll}\text { Well Name } & \begin{array}{l}\text { Density } \\ \text { Curve }\end{array} & \begin{array}{l}\text { Gamma } \\ \text { Curve }\end{array} & \begin{array}{l}\text { Velocity } \\ \text { Curve }\end{array} & \text { DST } & \begin{array}{l}\text { Mud } \\ \text { Weight }\end{array} & \text { RFT } & \text { LOT } & \text { FIT }\end{array}$

\begin{tabular}{|l|l|l|l|l|l|l|l|l|}
\hline Kea-1 & & Y & Y & & & & & \\
\hline Kupe-1 & Y & Y & Y & Y & Y & Y & Y & \\
\hline Kupe South-1 & & Y & Y & Y & Y & Y & Y & Y \\
\hline Kupe South-2 & & Y & Y & Y & Y & Y & & Y \\
\hline Kupe South-3 & & Y & Y & & Y & Y & & Y \\
\hline Kupe South-4 & & Y & Y & Y & Y & Y & & Y \\
\hline Kupe South-5 & & Y & Y & & Y & Y & & Y \\
\hline Kapuni-13 & & Y & Y & & & & & \\
\hline Tahi-1 & & Y & Y & Y & Y & Y & Y & \\
\hline Toru-1 & & Y & Y & & Y & Y & & Y \\
\hline Maui-1 & & Y & Y & & & & & \\
\hline Maui-2 & & Y & Y & & & & & \\
\hline Maui-3 & & Y & Y & & & & & \\
\hline Maui-7 & & Y & Y & & & & & \\
\hline Maui B Production-8 & & Y & Y & & & & & \\
\hline
\end{tabular}

DST $=$ Drill String Test

RFT $=$ Repeat Formation Test

LOT $=$ Leak Off Test

FIT $=$ Formation Integrity Test 


\section{Appendix IV}

\section{Petroleum Reports}

Best, D.D. and Parvar, H.L. (1989) Kupe South reservoir simulation study. PPL38116 Petroleum Report Series PR1484. Ministry of Economic Development.

Best, D.D. and Parvar, H.L. (1989) Kupe South reservoir simulation study. Petroleum Report Series PR2241. Ministry of Economic Development.

Crocker, S. (1991) Toru-1 Well Completion Report. PPL38116 Petroleum Report Series PR1668. Ministry of Economic Development.

Donaldson, I.F., Way, C.J. and Wellensiek, J.A. (1987) Kupe South-2 Well completion report. PML 38116. Petroleum Report Series PR1285. Ministry of Economic Development.

Donaldson, I.F., Way, C.J. and Everret, T. (1988) Kupe South-3, 3a and 3b Well completion report. PML 38116. Petroleum Report Series PR1368. Ministry of Economic Development.

Duff, S., Elliot, C., Morgans, H.G. and Pocknall, E.T. (1991) Kupe South-5 Well completion report. PML 38116. Petroleum Report Series PR1678. Ministry of Economic Development

Fekete Australia Pty Ltd, (1998) Kupe South drill stem test review. Petroleum Report Series PR2858. Ministry of Economic Development. 
Flopetrol Laboratory/Schlumberger (1987) Final PVT Study Report. Kupe South-2, DST 3,4,5. PML 38116. Petroleum Report Series PR1322. Ministry of Economic Development.

Geoservices. (1989) Final well report, Kupe South-4. PML38116. Petroleum Report Series PR1482. Ministry of Economic Development.

Jefferies, R. (1996) Kupe South Reservoir Simulation Study. PML 38146. Petroleum Report Series PR2763. Ministry of Economic Development.

Matthews, E.R. and Bennett, D.J. (1987) Kupe South-1 Well completion report. PML 38116. Petroleum Report Series PR1284. Ministry of Economic Development.

Palmer, J. (1984) Tahi-1 Well completion report. PML 38116. Petroleum Report Series PR1030. Ministry of Economic Development.

Sloan, M. (1997) Kupe South Central Field Area. Geologic and Geophysical interpretation report. PML 38146. Offshore Taranaki Basin, New Zealand. Petroleum Report Series PR2746. Ministry of Economic Development.

Shell BP Todd Oil Services Ltd (1976) Well Resume Kupe-1. Petroleum Report Series PR662. Ministry of Economic Development.

Steed, H., de Bock, F and Brewster, T. (1998) Exploration of PML 38146 Kupe Mining License Area. Petroleum Report Series PR2859. Ministry of Economic Development.

Wadsley, A.W. (1998) Reservoir simulation of the Kupe South reservoir. PML 38146. Petroleum Report Series PR2862. Ministry of Economic Development. 